\title{
AMOSTRAGEM E ANÁLISE DE DADOS EDAFO-BIO- CLIMÁTICOS DE UM REMANESCENTE FLORESTAL NO MUNICÍPIO DE PINDORAMA (SP)
}

\author{
GERD SPAROVEK
}

Engenheiro Agrônomo

Orientador: Dr. OTAVIO ANTONIO DE CAMARGO

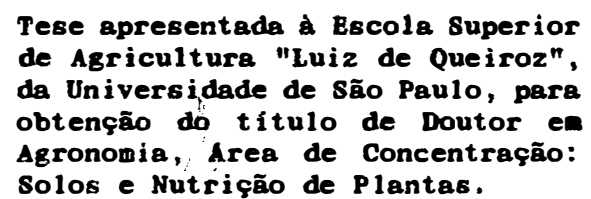

Piracicaba

Estado de São Paulo - Brasil

novembro - 1993 
Ficha catalugrafica preparada pela Seçâ de Livros da Divisao de fidiliateca e Documentacáo - FCLQ/USF

\section{$5736 a$}

Sparovek, Gerd

Amostragem e arialise de dados edafo-bia-climáticos de un remanescente florestal no Municipio de findorama (SF). Firacicaba, 1993. $132 p$.

TESE - Esalg

Bibliografia.

1. Delineamento do experimento 2. Floresta - Delineamento de experimento I. Escola Superior de Agricul tura Luiz de Queiraz, Firacicaba 


\title{
AMOSTRAGEM E ANÁLISE DE DADOS EDAFO-BIO- CLIMÁTICOS DE UM REMANESCENTE FLORESTAL NO MUNICÍPIO DE PINDORAMA (SP)
}

\author{
GERD SPAROVEK
}

Aprovada em 14 de dezembro de 1993

Comissão julgadora:

Dr. Otavio Antonio de Camargo IAC

Prof. Dr. Fabio Poggiani ESALQ

Dr. Igo Fernando Lepsch IAC

Prof. Dr. Harold Gordon Fowler UNESP

Dr. Luiz Antonio Ferraz Matthes IAC

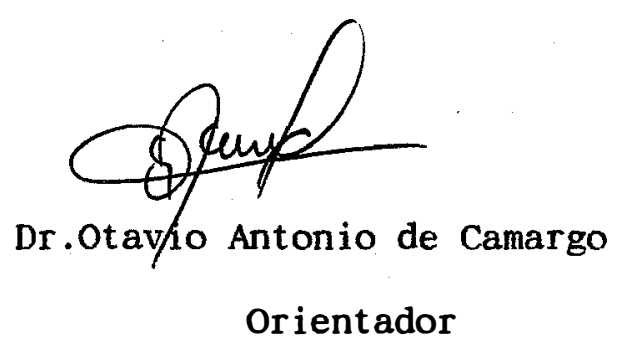


Aos meus pais, Ingo e Herta, ofereço.

A Beta, que já cansou de perguntar, e a TESE ?, dedico. 
Agradecimentos

Ao Dr. Otávio Antonio de Camargo, pela amizade, or ientação e apoio.

Ao Conselho Nacional de Pesquisa e Desenvolvimento Científico, pelo financiamento do Projeto

A Escola Superior de Agricultura "Luiz de Queiroz" pela oportunidade.

Ao Instituto Agronômico, espacialmente à turma da Estação Experimental de Pindorama, pela acolhida calorosa e pela grande colaboração na execução dos trabalhos. Agradecimento especial ao Pirassoles, figura chave na coleta de dados.

Ao Ricardo Ribeiro Rodrigues pela caracterização florística da área.

Ao Sidney Rosa Vieira pelo auxílio na interpretação dos dados.

Aos acadêmicos Alexandre, Tereza Cristina, Ivan, Eric, Edson.... 
Página

LISTA DE FIGURAS . . . . . . . . . . . . . . . . . . . . v v

LISTA DE TABELAS . . . . . . . . . . . . . . . . . . . vi vi

RESUMO . . . . . . . . . . . . . . . . . . . . vi vi

SUMMAY . . . . . . . . . . . . . . . . . . . . xi

1 INTRODUÇÃO . . . . . . . . . . . . . . . . . . . . 1

1.1 Histórico do trabalho . . . . . . . . . . . . . . . . 1

1.2 Objet ivo e hipbtese . . . . . . . . . . . . . . . . . . . 3

2 REVISÃO BIBLIOGRAFICA . . . . . . . . . . . . . . . . 5

2.1 Variabilidade espacial . . . . . . . . . . . . . . 5

2.2 Estudos de variabilidade en florestas de regiões tropicais . 7

2.3 Estudos de variabilidade em florestas de regiões temperadas 11

2.4 Outros estudos de variabilidade . . . . . . . . . . . . . 19

2.5 outros estudos em florestas brasileiras . . . . . . . . . 22

3 MATERIAL E METODOS . . . . . . . . . . . . . . . . 27

3.1 Descrição do local . . . . . . . . . . . . . . . . . 27

3.2 Amostragem e metodologia analítica . . . . . . . . . . 29

3.2.1 Definição dos locais de coleta de anostras . . . . . 29

3.2.2 Parâmetros amostrados e épocas de amostragem . . . . 33

3.2.3 Metodologia analítica . . . . . . . . . . . 34

3.3 Estatística . . . . . . . . . . . . . . . . . 36

3.3.1 Valores centrais . . . . . . . . . . . . . 36

3.3.3 Ajuste à distribuição normal e lognormal . . . . . . 38

3.3.4 Análise de variância entre parcelas . . . . . . . . 39

3.3.5 Análise hierárquica de variância . . . . . . . . . 40

3.3.6 Observação dos valores en função da sua posição. . . 41

3.3.7 Semivariância . . . . . . . . . . . . . . 4 41

4 RESUltadoS E DISCUSSÃO . . . . . . . . . . . . . . . . 43

4.1 Serapi lheira produzida . . . . . . . . . . . . . . . 43

4.1.1 Estatístic̈a descritiva. . . . . . . . . . . . . . 43

4.1.2 Valores médios das parcelas . . . . . . . . . . . . . 44

4.1.3 Representação dos valores nos eixos direcionais . . . 45 
4.1.4 Senivariograma e análise hierárquica de variância . . 49

4.1.5 Análise global e delineamento recomendado . . . . . . 49

4.2 Precipitação interna . . . . . . . . . . . . . . . 50

4.2.1 Estatística descritiva . . . . . . . . . . . 50

4.2.2 Valores médios das parcelas. . . . . . . . . . 51

4.2.3 Representação dos valores nos eixos direcionais . . . 51

4.2.4 Semivariograma e análise hierárquica de variância . . 53

4.2.5 Análise global e delineamento recomendado . . . . . . 53

4.3 Serapi heira acurulada sobre o solo . . . . . . . . . . . 60

4.3.1 Estatística descritiva . . . . . . . . . . . . 60

4.3.2 Valores médios das parcelas. . . . . . . . . . 61

4.3.3 Representação dos valores nos eixos direcionais. . . 63

4.3.4 Semivariograma e análise hierárquica de variância. . 76

4.3.5 Análise global e delineamento recomendado . . . . . . 77

4.4 Atributos químicos do solo mineral . . . . . . . . . . . 78

4.4.1 Estatística descritiva . . . . . . . . . . . 78

4.4.2 Valores médios das parcelas . . . . . . . . . . . 81

4.4.3 Representação dos valores nos eixos direcionais . . . 85

4.4.4 Semivariograma e análise hierárquica de variância . . 104

4.4.5 Análise global e delineamento recomendado . . . . . . 107

4.5 Granulonetria do solo . . . . . . . . . . . . . . . 109

4.5.1 Estatística descritiva . . . . . . . . . . . 109

4.5.2 Valores médios das parcelas . . . . . . . . . . . 110

4.5.3 Representação dos valores nos eixos direcionais . . . 112

4.5.4 Semivariograma e análise hierárquica de variância . . 112

4.5.5 Análise global e delineamento recomendado . . . . . . 112

5 CONCLUSÕES . . . . . . . . . . . . . . . . . . . 120

6 REFERENCIAS BIBLIOGRAFICAS . . . . . . . . . . . . . 122 


\section{LISTA DE FIGURAS}

Página

Figura 1 - Localização da área de estudo e das unidades de solo (LEPSCH \& VALADARES, 1976). . . . . . . . . . . . . . . . 27

Figura 2 - Perfil topográfico esquemático da área de estudo. . . 29

Figura 3 - Subdivisão da área central da mata de Pindorama em dezesseis parcelas ident ificadas numericamente com a localização dos pontos de amost ragem (pontos). . . . . . . . . . . . . . 30

Figura 4 - Localização dos pontos de amostragem das parcelas 7 e 8 e as distâncias entre eles . . . . . . . . . . . . . 31

Figura 5 - Esquema do coletor de produção de serapilheira e de precipitação interna instalado nos pontos de amostragem. . . . 33 Figura 6 - Valores médios de serapilheira produzida das parcelas (barras) e diferenças significativas (Tukey 5\%) indicadas por letras distintas. . . . . . . . . . . . . . . . . . 46

Figura 7 - Representação dos valores de serapilheira produzida (ponto) e da média (linha cheia) em relação aos eixos direcionais. . . 47

Figura 8 - Semivariância normalizada (pontos) e variância acumulada (linhas verticais) em função da distância da serapilheira produzida. . . . . . . . . . . . . . . . . 48

Figura 9 - Valores médios de precipitação interna (barras) e diferenças significativas (Tukey 5\%) indicadas por letras distintas. . . . 54

Figura 10 - Representação dos valores de precipitação interna (pontos) e da média (linha cheia) em relação aos eixos. . . . . . . . 56

Figura 11 - Semivariância normalizada (pontos) e variância acumulada (1inhas verticais) em função da distância da precipitação interna. 58 Figura 12 - Valores médios da quantidade de sẹrapilheira acumulada, nutrientes contidos: nela e seus teores (barras) e diferenças significativas (Tukey 5\%) indicadas pór. Hetras distintas. . . . 64 
Figura 13 - Representação da quantidade de serapilheira acumulada, nutrientes contidos nela e seus teores (ponto) e da média (linha cheia) em relação aos eixos direcionais. . . . . . . . . . 68

Figura 14 - Semivariância normalizada (pontos) e variância acumulada (linhas verticais) em função da distância da quantidade de serapilheira acumulada, nutrientes contidos nela e seus teores

Figura 15 - Valores médios dos atributos químicos do solo nas três profundidades (barras) e diferenças significativas (Tukey 5\%) indicadas por letras distintas. . . . . . . . . . . . . 86

Figura 16 - Representação dos atributos químicos do solo nas três profundidades (ponto) e da média (linha cheia) em relação aos eixos direcionais. . . . . . . . . . . . . . . . . 91

Figura 17 - Semivariância normalizada (pontos) e variância acumulada (linhas verticais) em função da distância dos atributos químicos do solo nas três profundidades . . . . . . . . . . . . . . 96

Figura 18 - Valores médios dos atributos granulométricos do solo nas três profundidades (barras) e diferenças significativas (Tukey 5\%) indicadas por letras distintas. . . . . . . . . . . . . . . 114

Figura 19 - Representação dos atributos granulométricos do solo nas três profundidades (ponto) e da média (linha cheia) em relação aos eixos direcionais. . . . . . . . . . . . . . . . 116

Figura 20 - Semivariância normalizada (pontos) e variância acumulada (linhas verticais) em função da distância dos atributos granulométricos do solo nas três profundidades . . . . . . . . 118 
vi i

\section{LISTA DE TABETAS}

Página

Tabela 1 - Período de coleta das amostras utilizadas para as análises ou registro de dados . . . . . . . . . . . . . . . . 34

Tabela 2 - Parâmetros utilizados na análise de variância entre parcelas para a comparação dos valores das amostragens (GILBERT, 1976). 40 Tabela 4 - Valores médios e intervalos de confiança, coeficiente de variação, ajuste à distribuição normal e lognormal e número de amostras necessárias para se obter uma variação na média de 10 e $5 \%$ dos seis períodos de registro de serapilheira produzida. . . . 44

Tabela 5 - Valores médios e intervalos de confiança, coeficiente de variação, ajuste à distribuição da normal e lognormal e número de amostras necessárias para se obter uma variação na média de 10 e $5 \%$ para os dez eventos de precipitação interna registrados. . . . 52 Tabela 6 - Valores médios e intervalos de confiança, coeficiente de variação, ajuste à distribuição normal e lognormal e número de amostras necessárias para se obter uma variação na média de 10 e $5 \%$ da quantidade de serapilheira fina e grossa e dos teores e quantidades totais de Ca, Mg, K, N, P e S nessas duas frações. . . . . . . 62 Tabela 7 - Valores médios e intervalos de confiança, coeficiente de variação, ajuste à distribuição da normal e lognormal e número de amostras necessárias para se obter uma variação na média de 10 e 5\% dos atributos químicos das amostras de terra nas profundidades de 0 a $5 \mathrm{~cm}, 5$ a $25 \mathrm{~cm}$ e 60 a $80 \mathrm{~cm}$. . . . . . . . . . . . . . . . 82

Tabela 8 - Valores médios e intervalos de confiança, coeficiente de variação, ajuste à distribuição normal e lognormal e número de amostras necessárias para se obter uma variação na média de 10 e 5 \& da granulometria das amostras de terra coletadas nas profundidades de $0-5,5-25$ e 60-80cm. . . . . . . . . . . . . . . . . 111 
viii

\section{AMOSTRAGEM E ANÁLISE DE DADOS EDAFO-BIO- CLIMÁTICOS DE UM REMANESCENTE FLORESTAL DO MUNICÍPIO DE PINDORAMA (SP)}

Autor: GERD SPAROVEK

Orientador: Dr. OTAVIO ANTONIO DE CAMARGO

\section{RESUINO}

A amostragem e análise de dados de atributos edáficos, biológicos ou microclimáticos em florestas tropicais, marcadamente de elevada diversidade de espécies, é uma tarefa, no mínimo, difícil. A elevada variabilidade, característica de cada atributo e sua distribuição espacial muitas vezes complexa na área, não seguindo tendências facilmente identificáveis justificam esta dificuldade. Além disto encontramos pouca disponibilidade de estudos básicos desenvolvidos para orientar a amostragem e a análise de dados para estas situaçōes.

Este estudo foi conduzido com o objetivo de definir a melhor estratégia de amostragem e análise de dados para alguns parâmetros que são utilizados em estudos de ciclagem de nutrientes num remanescente de vegetação natural situado no oeste do Estado de São Paulo. Para isto foi selecionada uma área de 500 por 200m (10ha) na parte central de un remanescente de uma floresta mesófila semidecídua de área total de 30ha, localizada no Município de Pindorama (SP) nas coordenadas $48^{\circ} 55^{\prime} \mathrm{W}$ e $21^{\circ} 13^{\prime} \mathrm{S}$. $\%$ atributos estudados foram: produção de serapilheira, precipitação interna, quantidade e composição da serapilheira acumulada sobre o solo e atributos químicos e granulométricos do solo em três profundidades.

Os valores de produção de serapilheira apresentaram elevado coeficiente de variação, sem tendência definida de distribuição no espaço. Entretanto, houve evidências de dependência espacial em escala menor do que a escala 
mínima considerada neste estudo $(7 \mathrm{~m})$, provavelmente de poucos metros, comparável à distância entre árvores. Para a sua determinação não é necessário considerar a posição das observaçōes e os coletores podem ser distribuídos, casualmente, no maior número possível e sua redistribuição periodica, ao acaso e a curta distancia, pode reduzir o efeito da dependência espacial.

o coeficiente de variação da precipitação interna foi pequeno. A dependência espacial entre os valores não ocorreu ou foi pouco evidente e a correlação entre os eventos foi pouco significativa. Para a sua quantificação quarenta coletores distribuídos casualmente na área, sem necessidade de redistribuição peribdica, são suficientes.

A quantidade total de serapilheira acumulada sobre o solo e dos elementos contidos nela apresentaram coeficientes de variação elevados e os valores se distribuíram ao acaso no espaço. Os teores dos elementos na serapilheira acumulada apresentaram coeficientes de variação mais baixos e a dependência espacial foi peculiar para cada elemento. A amostragem para a determinação da quantidade de serapilheira deve ser distinta da amostragem para a avaliação dos teores dos elementos contidos nela sendo que, no primeiro caso não há necessidade de localização dos pontos e é necessário um grande número de amostras e no segundo um menor número de amostras de localização conhecida deve ser considerado.

A amostragem para a análise de atributos químicos não pode ser a mesma para as diferentes profundidades do solo. As amostras superficiais apresentaram dependência espacial a pequenas distâncias, relacionada, provavelmente, à presença de determinadas árvores ou grupamentos de árvores. 0 coeficiente de variação da camada superficial foi maior do que em' subsuperfície, com exceção da saturação por bases e pH, que se apresentaram valores menores na superfície, fato atribuído ao processo de biociclagem de elementos. As amostras das camadas mais profundas, apresentaram dependência espacial a distâncias maiores, indicando que hoțve um controle do material de origem, posição no relevo ou dos processos pedogenéticos sobre a variabilidade. Na coleta de amostras superficiais é importante verificar a localização dos pontos de amostragem 
em relação às mudanças da cobertura vegetal da área devendo a coleta de amostras ser feita em várias transeçōes curtas com intervalos amostrais de poucos metros. A coleta de amostras das camadas subsuperficiais também deve ser espacialmente referenciada, mas tomada em transeçōes ou malhas com distâncias maiores cobrindo toda a área. A coleta de amostras compostas não possibilita o estudo da relação dos atributos químicos do solo com a dinâmica superficial ou posição no relevo e material de origem. A análise de um número maior de amostras dos elementos de maior coeficiente de variação é recomendável. o fósforo foi o elemento de maior dificuldade de estudo. A estratégia de amostragem para determinações granulométricas pode ser semelhante a dos atributos químicos. 
xi

\section{SOIL, BIOLOGIC AND CLIMATIC DATA SAMPLING AND}

\section{ANALYSIS IN A REMANENT FOREST IN PINDORAMA}

\section{CITY, SÃO PAULO STATE.}

Author: GERD SPAROVEK

Adviser: Dr. OTAVIO ANTONIO DE CAMARGO

SUMARY

Sampling of soil, biological or micro climatic attributes in tropical forests, which are characterized by a high diversity of species is, at least, a difficult affair. The high spatial variability usually different for each single attribute and its usual complex distribution in the area not following easily identifiable tendencies can explain these difficulties. Despite of this fact, there are few basic studies developed to guide sampling and data analysis for these situations.

This study has the objective to define the best sampling strategy and data analysis for some parameters frequently used in nutrient cycling studies in a natural vegetation remanent in the West of São Paulo State (Brazil). Therefore an area of 500 to $200 \mathrm{~m}$ (10ha) in the center of the remanent forest of total area of 30ha located in Pindorama, São Paulo State $\left(48^{\circ} 55^{\prime} \mathrm{W}\right.$ e $\left.21^{\circ} 13^{\prime} \mathrm{S}\right)$ was selected. The attributes selected were: litter fall, throughfall, amount and litter composition and chemical and texture soil attributes at three depths.

Litter fall values had a high variation coefficient, with no defined tendency of spatial variation. Although, there are evidences of spatial dependency of variability in a scale below the minimum considered in this study $(7 \mathrm{~m})$, probably of a few meters, comparable to the distance between trees. For litter fall determination it is not necessary to consider the position of sampling. The collectors can be randomly distributed in greatest number as much as possible, and its periodic, random and short distance redistribution can reduce spatial variability.

Throughfall variation coefficients were small. Spatial dependency was: not observed and correlation between events was not significant. In order to quantify throughfall forty collectors distributed randomly in the area 
with no need of periodic redistribution are sufficient.

The total amount of litter and its element content had very high variance and no spatial dependency. The rate of elements in the litter had lower variance. Spatial dependency of element rates was peculiar to each one. Sampling for litter amount estimation is different as for litter element rate estimation. Anount estimation do not need to be spatially referenced and a big number of determinations are needed, and, element rate estimation can consider a smaller amount of spatially referenced samples.

Sampling of soil attributes can not be the same for all depths. Surface samples had spatial dependency within short distances, related probably to specific trees or group of trees. Variance was higher at the surface, with exception of base saturation and $\mathrm{pH}$, which were more homogeneous at surface, probably due to biocycling of elements. Sub surface samples had spatial dependency in longer distances, indicating a variability controlled by parent material, landscape position or pedogenic processes. The position of the sample in relation to vegetation cover was important for surface sampling. Short transects with sampling interval of a few meters are recommended. Subsurface samples must also be spatially referenced, but with transects or grids of longer distance covering the whole area. Composed samples do not allow the understanding of the relation of chemical properties with surface dynamic processes or landscape and parent material. The analysis of a greater number of samples from the elements with higher variance is recommended. Phosphorus was the element most difficult of studying. Sampling for soil texture analysis can be the same as for chemical analysis. 


\section{INTRODUÇÃO}

\subsection{Histórico do trabalho}

A idéia inicial do trabalho foi formar um banco de dados a respeito da ciclagem de nutrientes num remanescente de vegetação natural da região Oeste do Estado de São Paulo. Esta região foi escolhida por ser muito representativa do Estado, abrangendo, aproximadamente, um terço de sua área e onde ocorrem solos derivados dos sedimentos do Grupo Bauru. A atividade agrícola intensiva é relativamente recente. 0 ecossistema agrícola, principalmente as lavouras, apresentam certa fragilidade relacionada à elevada suscetibilidade à erosão das terras. 0 empobrecimento dos solos devido à erosão é bastante conhecido levando ao decréscimo do rendimento das culturas, à não sustentabilidade do sistema de produção e, principalmente à sérios problemas ambientais. As referências sobre este problema são antigas. GROHMANN \& CATANI (1949) descreveram 0 empobrecimento dos solos causado pela cultura algodoeira avaliado na Estação Experimental do Instituto Agronômico em Pindorama (SP). 0 efeito a médio e longo prazos da erosão e outras açōes antrópicas poderia ser melhor compreendido se comparado ao comportamento de um sistema pouco ou não perturbado. A comparação da dinamica de nutrientes, água e fluxo energético do sistema não perturbado, com os diversos sistemas agrícolas poderia contribuir para a sua compreensão, principalmente no que se refere a impactos e alterações ocorridos ou que irão ocorrer. Nesse contexto, a primeira idéia sobre um plano de trabalho foî estudar a ciclagem de nutrientes numa mata da Estação Experimental de Pindorama do Instituto Agronômico.

Entretanto, uma floresta com alta diversidade de espécies, apresenta uma 
variabilidade de seus atributos muito maior do que os sistemas agrícolas (GOLDIN \& LAVKULICH, 1988; LLOYD \& MARQUES, 1988; BöTCHER \& STREBEL, 1988b e BöTCHER \& STREBEL 1988c), O que pôde ser constatado pela simples observação da área. Este fato levou a uma certa insegurança no que diz respeito ao melhor delineamento experimental visando a amostragem dos parâmetros normalmente analisados nos estudos de ciclagem de nutrientes, como, teor de nutrientes no solo e na serapilheira acumulada, produção de serapilheirà e precipitação interna. Em consulta à bibliografia especializada e a alguns pesquisadores do assunto, as dúvidas quanto à melhor maneira de amostrar a área foram apenas parcialmente esclarecidas. Isto deveu-se principalmente ao fato de: 1) as florestas do hemisfério norte, intensamente estudadas e com vários trabalhos especificos sobre amostragem, apresentarem menor diversidade de espécies do que as florestas tropicais e subtropicais do hemisfério sul, dificultando assim, a aplicação das técnicas de trabalho e amostragem desenvolvidas para aquelas condições; e 2) a quantidade de estudos básicos sobre variabilidade espacial e técnicas de amostragem em florestas tropicais ser muito pequena.

Frente a esse novo quadro decidiu-se alterar o objetivo inicial do trabalho, desenvolveu-se uma primeira fase, na qual alguns parâmetros simples que são utilizados em estudos de ciclagem de nutrientes como precipitação interna, produção de serapilheira, quantidade e composição da serapilheira acumulada sobre o solo e atributos do solo, seriam avaliados quanto a sua variabilidade e melhor estratégia de amostragem. Com isso, o delineamento experimental ideal para parametros de determinação mais difícil como composição química da precipitação interna, composição da solução do solo, perdas por lixiviação, perdas por escorrimento superficial poderia ser melhor definido. Os dados coletados nesta primeira fase já formam parte do inventário de registros que caracterizarão o sistema não perturbado. 


\subsection{Objetivo e hipotese}

o objetivo do trabalho é quantificar a variabilidade de diversos atributos do solo, biomassa e quantidade de precipitação interna do remanescente florestal da Estação Experimental de Pindorama (SP), do Instituto Agronômico do Estado de São Paulo (IAC). Com isso pretende-se contribuir para a definição do delineamento experimental para a amostragem e análise de dados capazes de avaliar de forma segura, precisa e econômica ambientes semelhantes de estrutura de variação complexa.

0 ambiente agrícola e as florestas apresentam diferenças marcantes em muitos aspectos:

\section{Amiente agricola}

Solo: o solo sofre diversas formas de homogeneizaçăo durante a sua utilizaça agricola, cono o preparo do solo, a adiçáo do grande guantidade de mutrientes a materia organica en area total a a renoça da canada superficial de maior variabilidade pela erosto. Como consegülencia, tem-se us perfil do solo mais howogeneo, principalmente, na carada superficial.

\section{Floresta tropical}

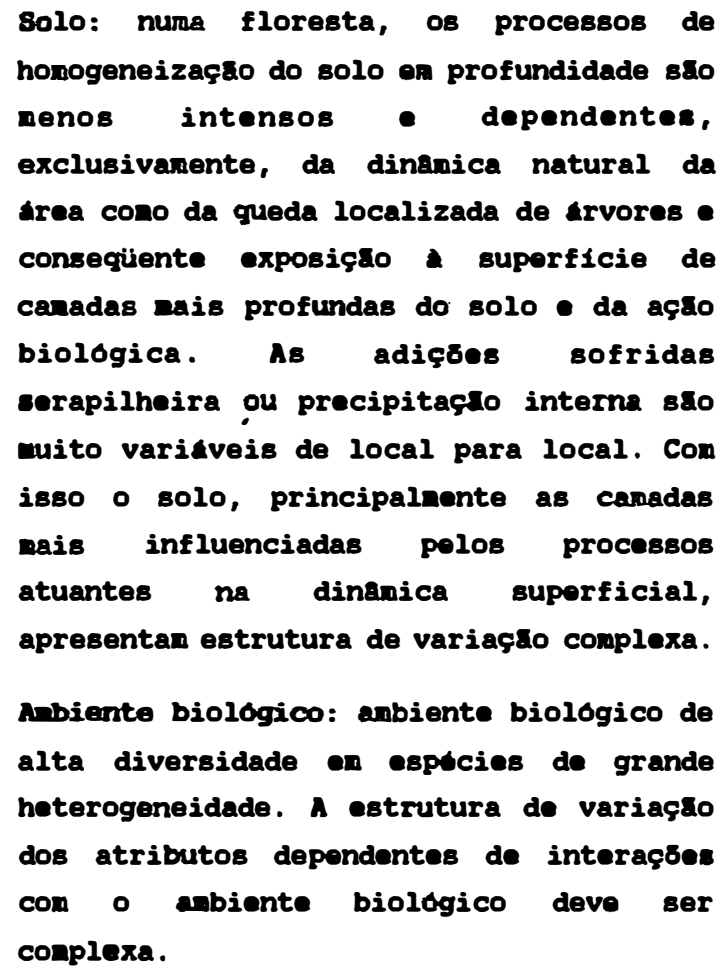

\begin{abstract}
Aniente biologico: ambiente biologico de baixs especies muito homogeneas. Con isso 08 atributos relacionados ao ambiente biotico ou fortemente relacionados a ele, devem apresentar estrutura de variaçăo pouco conplexa.
\end{abstract}


Ambiente agricola: Comparação de Floresta tropical: A caracterização tratamentos e estudos de causa e precisa da área de estudo, na sua efeito são frequilentes. Normalmente há condição natural, nomalmente é necessidade de resultado numérico importante. Os estudos de causa e preciso. Quando o trabalho for efeito são menos usuais. A necessidade descritivo, como por exemplo no de obtenção de um valor exato, uma mapeamento de solos, a quantificação faixa de variação ou uma estimativa da de parâmetros pode não ser feita em ordem de grandeza é dependente do tipo toda a área, sendo a mancha de solos de estudo. A dependência espacial e a caracterizada por un perfil modal. A distribuição normal das variáveis deve análise estatística normalmente é ser confirmada. Existem poucos clássica, supondo a distribuição trabalhos especificos sobre normal das variáveis e sua delineamento experimental. independência espacial. A análise de variância e estudos de correlação são muito utilizados. As técnicas de amostragem e investigação já foram muito estudadas.

Nesse contexto, as técnicas de amostragem e análise de dados empregadas em áreas agrícolas ou em florestas de menor variabilidade do hemisfério norte, que são, na maior parte, implantadas de forma regular e apresentam baixa diversidade de espécies, não se aplicam diretamente para a caracterização de florestas tropicais de alta diversidade e grande variabilidade. Neste caso devem ser empregados métodos de amostragem e análise de dados especificos para cada parâmetro a ser determinado e que sejam sensiveis aos componentes espacial e temporal de sua variabilidade.

A metodologia adotada permitiu grande flexibilidade na análise de dados. Na discussão dos resultados foi apresentada a estratégia que seria adotada caso a amostragem fosse repetida, considerando que o remanescente em questão seria caracterizado com a finalidade de conparacão com outra área. 


\section{REVISÃO BIBLIOGRAPICA}

\subsection{Variabilidade espacial}

0 pesquisador britânico R.A. Fisher publicou pela primeira vez em 1925 o livro "Statistical Methods for Research Workers", que foi reeditado onze vezes (FISHER, 1950). O americano G.W. Snedecor também publicou um livro clássico, pela primeira vez em 1937 e pela quarta em 1946 (SNEDECOR, 1946) com o título de "Statistical methods". Estas duas obras e outras anteriores estabeleceram os princípios e fundamentos da estatística experimental que são seguidos até hoje e que são largamente utilizados nas pesquisas agronômicas e ambientais. A independência espacial das amostras e a distribuição normal dos valores são condições básicas para sua aplicação. As variações naturais dos solos ou outros condicionantes do comportamento de alguma variável em estudo o rendimento de uma cultura, como exemplo, podem ser minimizados ou controlados por casualização e repetiçōes. As análises de variância, chi-quadrado, regressão e correlação são muito utilizadas. A teoria assim desenvolvida passou a ser chamada de estatística clássica.

No entanto, a independência espacial e distribuição casual da variância no espaço nem sempre é esperada intuitivamente. Espera-se, por exemplo, que os atributos do solo apresentem valores mais próximos se amostrados numa distância pequena do que amostras coletadas a grande distância uma da outra. Com essa preocupação, KRIGE (1951) elaborou a base da teoria das variáveis regionalizadas ou geoestatística. Posteriormente MATHERON (1963) estendeu e desenvolveu matematicamente esta teoria. Os trabalhos de Krige foram aplicados inicialmente para a estimativa do teor de minério aurifero na Africa do Sul una vez que os métodos da estatística clássica não previam bem esses teores por não considerarem a dependência espacial entre 
valores. Essa teoria posteriormente foi aplicada em outras ciências, particularmente na pedologia. Em muitos casos, essa ferramenta se mostrou valiosa, principalmente na previsão de valores.

Com relação ao tipo de variabilidade que pode ocorrer em solo ARNOLD \& WILDING (1991) afirmam que a variabilidade espacial ou temporal sistemática dos atributos do solo pode ser mapeada. Por outro lado, a variabilidade casual pode ser apenas descrita porque, neste caso, apenas a sua ocorrência pode ser prevista e não a sua localização.

A maneira de avaliar a variabilidade é descrita de forma geral por UPCHURCH \& EDMONDS (1991) que estabelecem que o campo da estatística é dedicado à compreensão da variabilidade em populações e a utilização dessa compreensão para a sua comparação. A variabilidade pode ser dividida em duas grandes classes, casual e sistemática, sendo essa divisão baseada no tipo de erro que produz a variação. A variabilidade sistemática é aquela que pode ser atribuída a uma causa conhecida, entendida e prevista. Por exemplo, as propriedades do solo variam sistematicamente em função da topografia, vegetação, clima e material de origem. Na estatística clássica a variabilidade casual tem recebido maior atenção. Presume-se que a variabilidade sistemática pode ser controlada pelo delineamento correto, ou que ela seja constante em toda a área. Assim, a estatística clássica presume normalidade, distribuição casual, variância uniforme e independência das observações, sendo que desvios dessas condições resultam em estimativas aproxinadas. Complementando esta afirmação MEAD \& CURNoW (1983) estabelecem que o pré-requisito básico para a utilização da estatística clássica é a distribuição normal dos dados da população e a independência entre observações e que distribuições diferentes da normal devem ser ajustadas por transformações.

Dessa forma, os estudos que lidam com variáveis que podem ser espacialmente dependentes e obedecer a uma distribuição de frequiências diferente da normal devem considerar não só a estatística clássica, una vez que a compreensão precisa de seu comportamento no espaço só pode ser obtida com uso de metodologias que consideram a posição espacial dos dados. 


\subsection{Rstudos de variabilidade em florestas de regiōes tropicais}

Como introdução a um trabalho descritivo, BONELL et al. (1987) afirmam que existem poucos estudos sobre as propriedades hidrológicas dos solos em florestas tropicais. 0 estudo da variação de propriedades hidrologicas como condutividade hidráulica e fluxo superficial da água foi feito em 26 pontos numa microbacia de 25,7 ha na Austrália com solos classificados como podzólicos vermelhos. A distribuição de frequiências foi na maior parte lognormal. 0 estudo da variação dos dados foi feito agrupando-se os pontos de amostragem quanto à intensidade de infiltração e descrevendo as regiōes onde ocorrem intensidades maiores ou menores.

Realizando estudo bastante detalhado sobre a interceptação da chuva em florestas tropicais utilizando a estatística clássica, LLOYD \& MARQUES Filho (1988) afirmam que parte da grande variação observada na porcentagem de interceptação de chuva ( 3 a 638 ) não se deve a diferenças climaticas e de estrutura das florestas mas sim à variabilidade espacial relacionada a outros condicionantes, não considerada normalmente nos estudos. Os autores concluem que a experiência dos inúmeros trabalhos realizados nas florestas temperadas que, normalmente, são plantações de uma ou poucas espécies, não pode ser diretamente aplicada d̀s florestas tropicais. Em seu trabalho eles estudaram métodos de amostragem de precipitação interna e escorrimento pelos troncos numa floresta de terra firme próxima à Manaus (AM), na qual foram definidas 505 posições de amostragem numa área de 100 por $4 \mathrm{~m}$, nas quais foram distribuídos 36 pluviômetros sorteando-se novas posiçōes a cada semana. O escorrimento pelos troncos foi medido em 19 árvores de diversos tamanhos. Os valores de precipitação interna apresentaram forte assimetria positiva, tendo sido transformados para os cálculos utilizando a raiz quadrada. 0 melhor delineamento experimental para a anostragem da precipitação interna foi a redistribuição de poucos pluviômetros sobre uma grande malha amostral. O escorrimento pelos troncos, representado em milímetros por milímetro total de chuva, apresentou um erro padrão entre as medidas de 50\%. Os autores apresentam a seguinte equação para calcular $\circ$ erro da estimativa de precipitação interna $\left(\sigma_{\tau}\right)$ : 


$$
\sigma_{\tau}-2,2\left[1+\left(\frac{494}{n m}\right)^{0,5}\right]
$$

onde:

n=número de pluviômetros

$\mathrm{m}=$ número de vezes que eles são reposicionados

Aproveitando-se de uma situação em que a variabilidade natural era muito evidente e utilizando os métodos da estatística clássica, SCHAIK van \& MIRMANTO (1985) estudaram durante três anos a variação de estrutura e produção de serapilheira numa área florestal de 200ha na Sumatra. Nessa área havia sido verificada uma grande variação na idade e fertilidade dos solos. Ao longo dos oito níveis de terraço identificados na paisagem, foram distribuídos 106 coletores serapilheira produzida agnupados em oito parcelas. O material coletado foi separado em material foliar e não foliar. Os autores encontraram diferenças significativas entre os valores médios das parcelas para a queda de folhas e não significativo para o material não foliar, além de correlação significativa entre o valor do $\mathrm{pH}$ do solo e a serapilheira produzida.

Como resultado de uma reunião técnica para discussão de metodologia de pesquisa, BREEMEN (1987) apresentou um modelo, para o estudo da ciclagem de nutrientes e água em florestas tropicais e áreas perturbadas. Para a coleta de dados, necessários para o modelo o autor sugere que em cada área de estudo devem ser feitas, durante quatro anos, as seguintes amostragens: precipitação interna com dez repetições e periodicidade semanal; umidade da serapilheira acumulada com dez repetições e periodicidade mensal; umidade do solo com quatro repetições em quatro profundidades, diariamente; textura do solo com dez repetiçōes uma vez, teor de nutrientes e pH do solo com dez repetiçōes, uma vez, e produção de serapilheira com quinze repetições e periodicidade semanal. Com objetivo semelhante, ANDERSON \& INGRAN (1989), editaram um manual de métodos em fertilidade e bịologia de solos tropicais no qual sugerem que a produção de serapilheira de árvores ou arbusțos seja medida a cada duas semanas e que dez coletores devem ser posicionados ao acaso em cada parcela homogênea. 
Ainda preocupados com metodologia para amostragem de florestas tropicais, HASE et al. (1985), estudaram diversas técnicas de determinação da biomassa total numa floresta de terra firme próxima à Manaus (AM) em comparação com a coleta total da biomassa. A determinação do diâmetro de 108 das árvores foi a estratégia que melhor estimou a biomassa total, associada ao menor custo de amostragem.

Num trabalho clássico sobre precipitação interna em florestas tropicais JACKSON (1971), afirma que a maior parte dos estudos sobre interceptação e precipitação interna foram feitos em latitudes temperadas e que poucos foram conduzidos em condições tropicais. 0 autor discute dados obtidos numa floresta tropical úmida na Tanzânia. A precipitação interna foi medida com vinte pluviômetros distribuídos casualmente sobre uma malha de 24 por $24 \mathrm{~m}$ com registros de aproximadamente meio ano. A maioria dos registros referiu-se a apenas um evento de precipitação. A distribuição de frequiência não foi normal em 25\% dos casos. 0 erro padrão da média foi usado para quantificar a variabilidade, sendo 15,38 maior em termos relativos para eventos de menor intensidade. 0 erro padrão da média, em valores absolutos, foi maior para as precipitaçōes intensas. 0 número de pluviômetros necessários para reduzir o erro padrão da média para 5\%, considerando uma precipitação média de $39,5 \mathrm{~mm}$, foi de 50 , valor que aumenta muito no caso de eventos de maior intensidade. A estimativa de interceptação de eventos de intensidade extrema foi considerada como sem sentido devido ao erro padrão dessa medida ser muito elevado. 0 uso da mediana como valor central foi útil em muitos casos. 0 efeito de eventos isolados quando se considera dados médios de períodos maiores foi marcante. 0 autor afirma que, devido a grande variabilidade e complexidade dos valores de interceptação, o modo de análise dos dados pode afetar significativamente os resultados obtidos.

Utilizando interessante metodologia, HARVEY et al. (1985) estudaram a variabilidade espacial dos teores de $\mathrm{C}, \mathrm{N}$ e $\mathrm{P}$ no solo de uma floresta tropical na Nigéria 22 meses após a sua derrubada. As ámostras de solo foram coletadas em 32 locais em cinco períodos de forma hierarquizada, com distância de 2 e 10m e repetição no menor nível de distância. A análise 
de variância hierarquizada foi utilizada para determinar a variabilidade espacial na área. A variância das repetições foi de 3 a 13 da variância total. A maior parte da variância encontrada foi no primeiro nível de distância para $0 \mathrm{C}, \mathrm{N}$ e S. $O$ teor de $\mathrm{P}$ apresentou a maior variância entre o nível de distância de 2 e $10 \mathrm{~m}$. Os autores explicaram esse comportamento diferenciado do $\mathrm{P}$ pela associação que esse elemento tem com $\circ$ teor de argila, que varia de forma semelhante na área. 0 carbono apresentou a maior variância no primeiro nível de distância, atribuida à deposição localizada de matéria orgânica.

Preocupados com a grande influência que a variabilidade espacial de atributos do solo poderia ter sobre o rendimento das culturas numa área experimental, TRAGMAR et al. (1987), estudaram seus atributos químicos e o rendimento da cultura do arroz cultivado sobre uma floresta recentemente desmatada num Haplortox na Indonésia. Para isto, foram coletadas 137 amostras, com diversas distâncias em várias direções na profundidade de 0-20 cm numa parcela de $784 \mathrm{~m}^{2}$. Os valores do $\mathrm{pH}$, Mg e Al trocáveis e saturação por Al apresentaram distribuição lognormal. 0 coeficiente de variação variou de $8 \%$ para 0 teor de argila até 1478 para o Ca trocável, tendo sido quase sempre superior a 30\%. A variância associada d̀s diferentes feições encontradas como áreas raspadas, com deposição de cinzas, antigas leiras e outras foi relativamente pequena, atingindo no máximo $28 \%$ da variância total, indicando que a variância dentro das feições foi bastante elevada. A dependência espacial encontrada para os parâmetros analisados em semivariogramas isotrópicos variou de 3,0 a 7,4m sendo que o semivariograma do Ca não apresentou estrutura definida. Os semivariogramas do rendimento do arroz apresentaram estrutura bem diversa daqueles dos atributos do solo. Este trabalho deixou bastante claro que a grande variabilidade dos atributos do solo sob floresta é um fator que necessariamente deve ser considerado e especificamente analisados nos estudos tanto de áreas sob floresta bem como de áreas recentemente desmatadas.

Trabalhando em condições de clima semi-árido TIESSEN \& SANTOS (1989) afirmam que estudos de ciclagem de nutrientes em condições tropicais 
necessariamente devem considerar a variabilidade espacial. Eles estudaram a variabilidade espacial de área com vegetação de caatinga em Terra Nova (PE) logo após e um ano após a derrubada da vegetação. A amostragem foi feita em quatro transeções num total de 42 amostras além de algumas amostragens separadas determinando-se a CTC, Fe-ditionito, C, N e P; quantidade de cascalho e granulometria. A variabilidade do teor total de P foi pequena, indicada por um coeficiente de variação baixo, enquanto que o teor extraído por resina apresentou valores de coeficiente de variação bem mais altos. 0 teor de $\mathrm{C}$ e $\mathrm{N}$ também apresentaram elevado coeficiente de variação, devido à sua forte associação com o microambiente do solo, já os teores de $\mathrm{C}, \mathrm{N}$ e $\mathrm{P}$ resina mostraram-se distribuidos casualmente na área. Os teores de $\mathrm{P}$ total e argila apresentaram dependência espacial. Interessante notar que após um ano do desmatamento o coeficiente de variação foi reduzido para muitos parâmetros.

Num estudo bastante detalhado sobre ciclagem de nutrientes em várias formações florestais do Panamá, GOLLEY et al. (1978) tiveram bastante dificuldade em definir o tamanho das parcelas e o número de amostras necessárias para caracterizar a área. Com relação à determinação da quantidade dos nutrientes no solo, os autores atribuíram esta dificuldade à complexa variação dos atributos tanto entre áreas diferentes bem como dentro de cada área, admitindo até, que a amostragem adotada pode estar estimando de forma errada alguns elementos.

\subsection{Estudos de variabilidade em florestas de regiōes temperadas}

A primeira conclusão de LIKENS et al. (1977) de um trabalho muito detalhado e de longa duração sobre ciclagem de nutrientes numa microbacia hidrográfica com cobertura florestal nativa no nordeste dos EUA foi que, para estudos deste tipo, considerável atenção deva ser dispensada para a seleção do ecossistema a ser estudado bem como para a metodologia de amostragem relacionada à localização e freqüência de coleta de amostras. Erros nesses critérios podem levar a desperdícios enormes de recuriốs e a conclusões errôneas motivadas pela multiplicação das imprecisões das estimativas. 
En trabalho no qual a preocupação com o delineamento experimental e a análise de dados foi muito grande, COURTIN et al. (1983) determinaram a média e variância de propriedades físicas e químicas do solo de florestas recém plantadas em zonas biogeoclimáticas distintas em áreas próximas à Vancouver, além de determinar o número de amostras necessárias para estimar a média com diversos graus de confiabilidade. Para isto, foram coletadas 35 amostras ao acaso na profundidade de $0-30 \mathrm{~cm}$ sorteando-se as coordenadas dos pontos de amostragem. Foram analisadas amostras simples e compostas das áreas a fim de determinar a variabilidade dentro e entre florestas. 0 valor do $\mathrm{pH}$ e dos teores de $\mathrm{N}$ e C mostraram a menor variância e os teores de P e Ca apresentaram a maior, sendo que, de maneira geral, a variância diminuiu com a profundidade de amostragem. 0 número de amostras para estimar a média com 10\% de variação e $95 \%$ de probabilidade foi maior do que 100 na maioria dos casos, valor superior ao que normalmente é coletado. Os autores sugerem coletar um grande número de amostras e analisar apenas uma parte para aqueles atributos de menor variância ou trabalhar com amostras compostas. Além disso recomendam que estudos de variabilidade devem preceder estudos de correlação ou caracterização mais detalhada das áreas. Este trabalho evidencia claramente a importância do estudo da variabilidade dos atributos do solo em florestas, mesmo em condiçōes de maior homogeneidade como são as florestas implantadas.

Aplicando os métodos da estatística clássica e procurando relacionar a variabilidade espacial e temporal de atributos do solo em relação à posição no relevo, HAMMER et al. (1987) estudaram formações de Quercus alba, Liriodendron tulipifera e Vaccinium spp. em Crossville (TN/EUA). Na área predominavam ultissolos e inceptissolos e, em cada formação, foram analisadas doze parcelas de 2,5m por 2,5m colocadas lado a lado sendo cada parcela subdividida em 25 subparcelas de $0,5 \times 0,5 \mathrm{~m}$. As subparcelas de variabilidade temporal foram amostradas mensalmente de forma casual e as de variabilidade espacial foram amostradas todas num único período. Amosträ̀. indeformadas foram coletadas nos três primeiros horizontes do solo e analisadas quanto a diversos atributos químicos. A análise de 
variância dos dados transformados determinou a magnitude da variabilidade. A posição no relevo representada pelo topo, meia encosta ou baixada foi o fator mais importante que influenciou a variabilidade espacial. 0 topo foi a posição de menor variância e a baixada a de maior. Nenhuma variável apresentou variação expressiva nas subparcela e apenas três entre parcelas ou no tempo. O horizonte $A$ apresentou a maior variabilidade temporal sendo que $\circ \mathrm{pH}$ foi $\mathrm{o}$ atributo do solo que apresentou a maior variabilidade temporal e espacial. A origem dos solos e suas características morfológicas foram utilizadas para explicar as variações nos dados, sugerindo una divisão geomorfológica como base para a subdivisão de áreas de experimentação. 0 conhecimento da morfologia e gênese dos solos e de sua dinâmica de água foram importantes para explicar as interações entre os fatores analisados. Os autores sugerem que os métodos estatísticos devem ser utilizados em conjunto com a caracterização dos solos. Interessante notar que foi observado um comportamento semelhante da variabilidade espacial para os três horizontes morfológicos estudados, indicando que a quantificação de atributós químicos do solo sob florestas deva subdividir os horizontes pedológicos superficiais, não obedecendo necessariamente critérios morfogenéticos.

Ainda utilizando a estatística clássica, DUIJSINGS et al. (1986) avaliaram a variabilidade espacial em pequena escala, representada pelo coeficiente de variação, da quantidade e composição da precipitação interna numa floresta de coníferas na Holanda próximo à fronteira com a Alemanha. A precipitação interna foi medida em onze locais e o escorrimento de troncos em oito durante 26 períodos de duas semanas. A precipitação interna representou em média 768 da total e o escorrimento pelos troncos $2,5 \%$ sendo o coeficiente de variação médio para a precipitação interna de 15\%. o coeficiente de variação da precipitação interna foi proporcional ao volume total de precipitação sendo que no verão seu valor foi maior do que no inverno. Os autores recomendaram pelo menos nove coletores para se obter una média anual confiável a um nível de 958 para o total de precipitação mas para a avaliação dos teores de $\mathrm{P}$, $\mathrm{H}, \mathrm{Mn}$ e $\mathrm{K}$ maior número de amostras seriam necessárias. 
Com a preocupação de determinar o número mínimo de amostras necessárias para estimar a média de atributos do solo e usando os métodos da estatística clássica, MCNABB et al. (1986) estudaram a variabilidade do teor de $\mathbf{N}$ e $\mathrm{C}$ do solo, sua densidade e teor de cascalho em seis florestas de coníferas em Oregon sob diferentes regimes térmicos e hídricos. Em cada uma foram coletadas vinte amostras ao acaso de $0-15 \mathrm{~cm}$ de profundidade. Em quase todos os casos, vinte amostras foram insuficientes para estimar a média com erro padrão de $10 \%$ e probabilidade de 95\%. Para estimar o C seriam necessárias em média 23 amostras, variando de 16 a 47 . A densidade do solo foi o atributo de menor variabilidade, e o mais variável foi o $\mathrm{N}$ mineralizável.

Em trabalho semelhante, ARP \& KRAUSE (1984) estudaram os teores e quantidades absolutas de diversos elementos na serapilheira acumulada e sua umidade numa floresta mista no Canadá coletando amostras numa área de 30 por $30 \mathrm{~m}$ em cem parcelas de 3 por $3 \mathrm{~m}$. A serapilheira acumulada foi amostrada num quadrado de 25 por $25 \mathrm{~cm}$ dentro de cada parcela. Os autores determinaram a média, desvio padrão, coeficiente de variação, número de amostras necessárias para estimar a média com erro de 10\%, assimetria, curtose, histogramas de distribuição de frequiências e matriz de correlação entre os atributos determinados. O desvio padrão foi maior e o coeficiente de variação menor com o aumento do teor do elemento ou com sua quantidade absoluta sendo que o valor do $\mathrm{pH}$ apresentou os menores coeficientes de variação. A quantidade absoluta dos elementos mostrou maior variação do que seu teor, sugerindo dessa forma que, a amostragem para determinar a quantidade total de um elemento deve ser mais intensa do que para determinar seu teor. Nenhuma das variáveis apresentou distribuição normal sendo a distribuição de frequiências em geral positivamente assimétrica com coeficiente a assimetria maior do que zero e curtose acima de três. A maior parte das variáveis ajustou-se à distribuição gamma e os teores de C e $\mathbf{N}$ ajustaran-se melhor à distribuição beta.

No intuito de comparar áreas cultivadas com floresta, GOLDIN \& LAVKULICH (1988) estudaram a variabilidade das propriedades químicas e da matéria orgânica de solos com diferentes materiais de origem, com períodos de 
cultivo distintos e sob florestas implantadas. Os solos sob floresta apresentaram coeficientes de variação maiores do que os cultivados para todas as propriedades sendo o $\mathrm{P}$ o elemento de maior variabilidade.

Preocupados em isolar diferentes fontes de variação, BAATH \& SöDERSTRÖM (1982) estudaram a variação sazonal e espacial da biomassa de fungos numa floresta de coniferas na região central da suécia. Foram comparadas durante três anos, áreas com derrubada e retirada da floresta, derrubada e permanência dos resíduos e sem derrubada, tendo sido o coeficiente de variação utilizado para estimar a variabilidade. o seu valor médio nas três áreas foi de 38\%, não diferindo muito de uma para outra. Este valor foi considerado alto o suficiente para mascarar possíveis variações sazonais dos valores de biomassa de fungos.

HOCKMAN et al. (1989), estudaram a variação dos nutrientes nas folhas de Abies fraseri [Pursh] Poir. numa floresta implantada na Carolina do Norte (EUA) e verificaram que para representar a média com $10 \%$ de erro e 958 de probabilidade eram necessárias sete amostras para $\mathrm{N}$, onze para $\mathrm{P}$, catorze para $\mathrm{K}$, quinze para Ca e quarenta para o Mg.

Afirmando que os padrōes de variação espacial em solos sob floresta são muito complexos e preocupados principalmente com a influência da vegetação sobre as propriedades do solo, RIHA et al. (1986), utilizando os recursos da teoria das variáveis regionalizadas, concentraram un estudo em três florestas plantadas no início dos anos 40 em Dryden (NY/EUA). Nessa área predominavam os inceptissolos rasos de aproximadamente $1 \mathrm{~m}$ de profundidade que anteriormente foram cultivados. Cada sitio florestal representou uma espécie homogênea plantada no espaçamento de aproximadamente 1,5 por 1,5m. Foram usadas transeçōes de vinte pontos distantes $4 \mathrm{~m}$ com amostras indeformadas de três tamanhos para avaliação de variáveis associadas à estrutura do solo. Para a determinação de variáveis associadas à presença de árvores foi feita uma amostragem radial saindo do centro das árvores em intervalos de $30 \mathrm{~cm}$ até $120 \mathrm{~cm}$ de distância nas quatro direções çardeais num total de vinte amostras por parcela. Com o objetivo de detectar a variabilidade associada à presença de populações, foi amostrada uma transeção de $6 \mathrm{~m}$ em intervalos de $5 \mathrm{~m}$ passando por todos os sítios. Segundo 
os autores, a variabilidade espacial de propriedades químicas do solo pode ocorrer em níveis ou escalas distintos. O primeiro nível ocorre devido às diferenças na estrutura mesoscópica ou macroscópica do solo. 0 pH não apresentou diferença com o tamanho da amostra coletada e apresentou baixo coeficiente de variação enquanto o C e o Al apresentaram mudanças de valores em relação ao tamanho das amostras, indicando que a estrutura do solo afeta estas propriedades sendo que os semivariogramas não mostraram dependência espacial de 20 a $360 \mathrm{~cm}$. A proximidade de árvores, em alguns casos, apresentou correlação significativa com as propriedades do solo apesar das amostras muito próximas das árvores tenderem a ser distintas das demais. 0 estudo de um semivariograma composto dos dados das três florestas foi eficiente para verificar a associação das propriedades com a presença de um ou outro tipo de vegetação tendo o pH e o C mostrado dependência da vegetação enquanto o Al não.

Num estudo bastante detalhado e no qual houve a preocupação de comparar áreas cultivadas com áreas com vegetação florestal BöTCHER \& STREBEL (1988a) demonstraram que a geoestatística pode ser uma ferramenta muito importante na determinação da concentração de solutos no lençol freático em áreas cultivadas. Em seu estudo analisaram uma transeção de 61 pontos distantes de $0,5 \mathrm{~m}$ tendo sido possível identificar dependência espacial entre as amostragens até $6 \mathrm{~m}$ para o teor de Ca e condutividade elétrica. BöTCHER \& STREBEL (1988 b) e BöTCHER \& STREBEL (1988 c), compararam a variabilidade do teor de solutos no lençol freático em áreas cultivadas e sob floresta de coniferas numa área de podzol em Fuhrberg na Alemanha. Na área cultivada com milho, a amostragem foi feita numa transeção de 61 pontos distanciados de $0,5 \mathrm{~m}$ e foram analisados os teores de vários elementos na água do lençol freático. Os dados apresentaram distribuição normal ou as vezes lognormal tendo o alcance dos semivariogramas sido de 6 a $6,5 \mathrm{~m}$ apresentando periodicidade de $12 \mathrm{~m}$ para os teores de nitrato e sulfato. A dependência espacial interferiu nas análises feitas pela estatística clássica e usando a krigagem, que considera a dependência ešpacial entre amostras, foram necessárias 61 amostras para estimar a média com a mesma variação do que 136 amostras pelos métodos da 
estatística clássica. Dessa forma, ficou evidenciado que pode-se reduzir a necessidade de amostras ou aumentar a confiabilidade dos dados usando a teoria das variáveis regionalizadas. A interpretação da dependência espacial e periodicidade foi baseada na forma de aplicação dos adubos, portanto devido a fatores extrínsecos à área. Na floresta a amostragem foi feita da mesma forma como na área arada e cultivada com milho tendo sido encontrada variância dos dados alta e a distribuição sempre normal. Os semivariogramas para sulfato, alumínio e pH foram muito semelhantes entre si tendo o alcance sido de 1,7 a $3 \mathrm{~m}$, sempre menor do que na área arada, e a periodicidade peculiar para cada caso. Para o nitrato 0 efeito pepita foi alto e a variancia aumentou linearmente sem alcançar um patamar, indicando uma tendência de variação numa escala maior do que a amostragem tendo a análise espectral mostrado várias periodicidades nos dados em diversas amplitudes de distância. A variação espacial dos dados pôde ser explicada por fatores intrínsecos, sendo a forma da copa o principal fator relacionado às diferenças encontradas. A análise geoestatística mostrou grande poder em avaliar a relação entre as variáveis e comparar padrōes de variação no espaço. Estas informações não puderam ser obtidas pela estatística clássica, que não foi sensivel para estabelecer correlação significativa entre variáveis que mostraram ser espacialmente correlacionadas.

Ainda avaliando propriedades hidrológicas do solo usando a teoria das variáveis regionalizadas, WILSON \& LUXMOORE (1988) trabalharam no oeste do Tenessee (EUA) onde florestas vêm sendo usadas para o enterrio de lixo doméstico e industrial sem considerar, muitas vezes, a sua aptidão hidrológica. O estudo da distribuição da taxa de infiltração, macro e mesoporosidade foi feito em duas áreas de 0,47 e 0,6ha sendo a primeira de udults profundos e a segunda de inceptissolos rasos. No solo profundo houve maior variabilidade na taxa de infiltração sendo que boa parte dos dados não tenha apresentado distribuição normal. Para o solo raso foi observada dependência espacial entre os pontos corn alcance de $15 \mathrm{~m}$, enquanto que no solo profundo o alcance foi de $4 \mathrm{~m}$, demonstrando ainda que existiu forte dependência do tipo de solo na variabilidade espacial. 
Procurando definir a relação do teor de fons na serapilheira acumulada e na camada superficial do solo, BUNZL \& SCHIMMACK (1989), estudaram o coeficiente de distribuição, $k_{j}$ que representa a relação entre o teor do elemento adsorvido no material seco e na solução de equilíbrio de nove Ions inorgânicos ao longo de uma transeção de cinquienta pontos distantes 3m numa floresta de pinus silvestris de cerca de cinqüenta anos de idade no sul da Alemanha, sobre spodosol (FAO). A distribuição do valor $k_{\gamma}$ de muitos Ions não foi normal e o valor do pH, perda por combustão da serapilheira e teor de césio no horizonte superficial do solo, também não apresentaram ajuste significativo à distribuição lognormal. Não foi encontrada correlação entre a distribuição dos valores $k_{y}$ dos íons no horizonte superficial do solo e na serapilheira. Nesta mesma área, SCHIMMACK et al. (1979) identificaram valores anômalos de $k_{j}$ ao longo de transeções que não foram considerados para o cálculo dos semivariogramas, a partir dos quais os autores classificaram a variação em peribdica para Cd, Co, Zn, Ce e Sr; aumento e posterior diminuição da semivariância para Tc; aumento e estabilização da semivariância para Ru; e sem estrutura de variação para I, Cs e pH. A variação peribdica de algums elementos foi associada à organização da floresta na forma de plantio regular com espaçamento de 4 a $5 \mathrm{~m}$.

A dependência espacial dos atributos do solo no entanto nem sempre é encontrada. WOPEREIS et al. (1988), estudaram a variabilidade espacial do teor de elementos pesados num sistema de amostragem hierárquica numa floresta de confferas no oeste da França considerando uma área de um hectare. Os autores não encontraram estrutura de variação nos semivariogramas para nenhum dos elementos estudados. 0 número de amostras necessárias para determinar a média com erro de 108 com 58 de probabilidade foi de quatro para o $\mathrm{Cu}$, sete para $\mathrm{Zn}$ e $\mathrm{Ni}$, dezesseis para - $\mathrm{Pb}$ e 121 para o $\mathrm{Cd}$.

Adotando métodos da estatística clássica, mas de forma bastante eficiente para detectar variaçōes no espaço, BRINGMARK (1989) determinou o valor do $\mathrm{pH}$ do solo em várias profundidades em 31 florestas de coniferas no sul da Suécia. A autora adotou un sistema de amostragem em quadrantes 
com níveis de distância variando de 0,05 a 4,0m calculando a distribuição de freqüências das diferenças entre valores do $\mathrm{pH}$ em diversos níveis de distância. Houve um aumento praticamente constante da variação dos valores do $\mathrm{pH}$ de 0,05 a 4,0m, com dois patamares de menor variação entre 0,1 e $0,7 \mathrm{~m}$ e entre 1,5 e $2,5 \mathrm{~m}$. Até a profundidade de $1,0 \mathrm{~m}$ as variações de $\mathrm{pH}$ foram igual às da superfície. A partir desta profundidade a camada subsuperficial variou mais, provavelmente devido à dinâmica do lençol freático.

\subsection{Outros estudos de variabilidade}

Num estudo bastante detalhado e elaborado especificamente para este fim, PERRIER \& WILDING (1986) compararam diversos métodos para estimar a variabilidade de atributos do solo e da produtividade numa área experimental cultivada com algodão, dividida em 1.280 parcelas de $1,4 \times 1,4 \mathrm{~m}$. Foram feitas análises de distribuição de frequiências, auto correlação e outras de correlação espacial como análise espectral, semivariograma e krigagem. Comparando todos os métodos na sua eficiência em quantificar a variabilidade da área, os autores concluem que cada método contribui de uma maneira para identificar a variabilidade existente. A correlação espacial contribuiu com 108 das informações sobre a variabilidade, a análise espectral 108, análise de probabilidades 108 , os semivariogramas 15\%, a análise do tamanho mínimo de parcelas em função do coeficiente de variação $15 \%$ e a krigagem 30\&. Com base nisto, os autores recomendaram que as características de cada conjunto de dados devem ser sempre consideradas, isto é, deve-se fazer un grande número de análises para identificar qual traz mais informações. Complementando, os autores afirmaram que a distância ideal entre cada amostra pode ser diferente para cada atributo da planta ou do solo e que o delineamento experimental deve constituir-se do mínimo de amostras necessárias para ter-se $Q$ melhor banco de dados para a análise estatística.

Num trabalho voltado para o estudo das propriedades físicas do solo e

utilizando simultaneamente técnicas de estatística clássica e geoestatística SILVA (1988) avaliou a variabilidade da granulometria, 
densidade das partículas e do solo, porosidade calculada e curva de retenção de água num Latossolo Roxo intensamente cultivado do Centro Experimental do Instituto Agronômico de Campinas (SP). Foram coletadas amostras em uma área de 160×120m numa malha de $20 \times 20 \mathrm{~m}$ e a variabilidade foi determinada pela estatística clássica através da média, desvio padrão, coeficiente de variação, número de amostras necessário para estimar a média dos dados, simetria e curtose e por geoestatística utilizando neste caso o semivariograma. A maior parte dos valores de coeficiente de variação foi abaixo de 10 e a distribuição foi normal em quase todos os casos. O número de amostras para estimar a média foi geralmente pequeno de uma a três amostras, apenas o silte apresentando valor de catorze amostras, levando a conclusão de que os atributos analisados apresentaram pouca variância na área. Não foi encontrada estrutura de variação nos semivariogramas acima de $20 \mathrm{~m}$ de distância entre pontos, indicando a independência espacial dos valores.

Preocupados com métodos de determinação de nuclídeos no solo, BACHRUBER et al. (1987), estudaram a variabilidade da concentração ativa do ${ }^{137} \mathrm{Cs}$ numa área de 150x100m no oeste da Alemanha num alfissolo cultivado com trigo. As amostras foram coletadas em duas transeçōes nas diagonais da área, sendo a distância média entre os pontos de amostragem de $3,6 \mathrm{~m}$. Os autores representaram os valores numéricos da concentração ativa do ${ }^{137} \mathrm{Cs}$ ao longo das diagonais e observaram a ocorrência de valores distintos ou anômalos. Os valores foram ordenados ao longo das transeções de forma casual centenas de vezes e foi calculada para cada ordenação a diferença média entre os vizinhos. As diferenças médias ordenadas geraram uma função de probabilidade que foi comparada à distribuição normal. 0 resultado indicou que a diferença média entre vizinhos, observada nas duas transeçōes foi essencialmente casual, apesar dos valores não serem normalmente distribuídos. Artifícios como este podem ser extremamente úteis para a compreensão do comportamento da variabilidade. Nessa mesma área no entanto, BUNZL \& SCHIMMACK, (1988) e BACHHUBER et al. (1985) observaram, utilizando diversos métodos de análise estatística, grande variabilidade espacial e dependência espacial entre os coeficientes de 
distribuição de outros elementos radiativos.

Preocupados em definir um delineamento experimental eficiente, DAHIYA et al. (1984), estudaram a variabilidade espacial de propriedades químicas de um solo derivado de depósito de loess numa área agrícola de 10ha situada ao norte da Alemanha. 0 objetivo foi determinar a variação lateral e vertical, bem como a maneira mais econômica de amostragem e, para isto, foram coletadas cinquienta amostras de terra, nas profundidades de 0-30, 30-60 e 60-90cm, divididas em duas parcelas de 30 por $30 \mathrm{~m}$ nas quais foram determinados os teores de $\mathrm{NO}_{3}, \mathrm{~K}, \mathrm{Mg}$ e $\mathrm{C}$. Os autores calcularam a média, variância, desvio padrão, coeficiente de variação, número de amostras necessárias para estimar a média e ajuste à distribuição normal. Os parânetros avaliados, na sua quase totalidade, apresentaram distribuição normal, tendo apenas o teor de $K$ apresentado distribuição lognormal em profundidade. A variabilidade do $\mathrm{K}$ foi maior do que a do $\mathrm{N}$, tanto laterl como verticalmente e o teor de $\mathrm{C}$ foi o que apresentou a menor variação de todos os parâmetros estudados. 0 menor número de amostras necessárias para representar a média variou bastante com o elemento considerado e com a precisão desejada. Os autores recomendaram coletar um número diferente de amostras conforme a profundidade. Posteriormente, DAHIYA et al. (1985), apresentaram um estudo sobre a dependência espacial dos dados discutidos por DAHIYA et al. (1984), no qual, eles calcularam o semivariograma das variáveis e fizeram interpolaçōes por krigagem. Os semivariogramas calculados para o $\mathrm{NO}_{3}$ não apresentaram dependência espacial tendo o efeito pepita sido de 100 \& indicando que a distribuição dos valores de $\mathrm{NO}_{3}$ foi casual em toda a área. Os semivariogramas de $\mathrm{K}$, Mg e C apresentaram dependência espacial tendo o ajuste sido linear para $\circ \mathrm{K}$ e Mg. A variância dos valores estimados pela krigagem foi menor do que a variância calculada pela estatística clássica, indicando que devido à dependência espacial esse valor foi superestimado. Como consequiência, o número de amostras necessárias para estimar a média pela krigagem foi menor do que pela estatística clássica.

Concluindo, podemos afirmar que a variabilidade espacial dos atributos do solo e da biomassa em áreas com florestas, principalmente se forem de 
grande diversidade de espécies, é elevada, complexa e distinta para cada atributo especifico ou conjunto de atributos. Por outro lado, existem diversas técnicas de amostragem e análise de dados que permitem conhecer esta variabilidade com maior ou menor grau de precisão. Dessa forma, a utilização de um ou outro delineamento experimental ou estratégia de amostragem e análise de dados, sem previamente se ter o conhecimento do comportamento do atributo de interesse, ou mesmo una amostragem sistemática igual para todos os atributos, pode levar a imperfeições na sua caracterização e a erros de interpretação posterior. Para resolver questões desse tipo e elaborar estratégias de amostragem eficientes e exequírveis, são necessários estudos básicos, preocupados principalmente com este objetivo, sendo que estes são muito raros para as condições tropicais.

\section{5 artros estudios en florestas brasileiras}

Trabalhando em matas de galeria próximo a Cuiabá (MT), OLIVEIRA-FILHO, et al. (1990), procuraram associar a composição florística a atributos químicos e físicos do solo. Os autores dividiram duas áreas de $30 \mathrm{~m}^{2}$ una em vinte e a outra em doze parcelas e coletaram una amostra de terra no centro de cada parcela na profundidade de $0-20 \mathrm{~cm}$. As diferenças florísticas das áreas foram atribuídas a diferentes condições de drenagem e fertilidade dos solos.

MATTHES, et al. (1988) estudaram uma área de recreação em Campinas (SP) de aproximadamente 10 ha chamada de Bosque dos Jequitibás. A coleta de amostras de terra foi feita nas profundidades de 10-20, 20-40 e 40-60cm. A amostragem foi feita ao acaso, coletando 17 amostras simples que formaram una única amostra composta. Os autores concluíram que a floresta contribuiu para a matéria orgânica e os nutrientes do solo, não atribuindo estas adições a ações antrópicas na área. 0 fato interessante na metodologia adotada pelos autores é a não inclusão da camada de $0-10 \mathrm{~cm}$ de profundidade na coleta de amostras de solo, sendo esta a camada mais influenciada pela vegetação.

Com o objetivo de realizar un estudo fitossociológico de uma área com 
vegetação nativa na reserva estadual de Bauru (SP) e verificar a sua relação com atributos do solo, CAVASSAN et al. (1984) coletaram seis amostras ao longo das picadas abertas na área compostas de cinco subamostras na profundidade de $0-40 \mathrm{~cm}$. Os autores concluíram que a fertilidade do solo depende quase exclusivamente da matéria orgânica incorporada ao solo pela floresta. A espessura da camada coletada, maior do que a normalmente utilizada em solos cultivados, chama a atenção neste trabalho.

BERTONI, (1984) estudou a composição florística e a estrutura fitossociológica de uma floresta em Porto Ferreira (SP). A floresta foi dividida em cinco áreas distintas com base em fotografias aéreas. Na parte central de cada área foram retiradas cinco amostras de solo ao acaso nas profundidades de $0-20,20-40$ e 80 a $100 \mathrm{~cm}$. O autor compara os valores médios dos atributos químicos e granulométricos e conclui que existem diferenças entre áreas.

MEGURO et al. (1979) estudaram a variação da produção de serapilheira e da quantidade de serapilheira acumulada numa mata secundária de 10ha no Campus da "Cidade Universitária Armando de Salles Oliveira" em São Paulo (SP). Para a determinação da produção de serapilheira 24 coletores foram distribuídos ao acaso na área e as determinações foram feitas mensalmente durante um ano. A quantidade de serapilheira acumulada sobre o solo foi determinada em vinte pontos distribuídos casualmente na área em duas épocas do ano. Em parcelas mais homogêneas GARRIDO \& POGGIANI (1982) estudaram a variação de produção de serapilheira e seu teor de nutrientes em parcelas de várias espécies florestais. Para a coleta, feita em parcelas de $192 \mathrm{~m}^{2}$ plantadas com espaçamento de 2 por $2 \mathrm{~m}$ em Assis (SP), foram utilizados catorze coletores distribuídos ao acaso.

Preocupada com a relação entre o teor de nutrientes nos solos e nas folhas de espécies arbóreas em duas matas mesófilas semidecíduas em Uberlândia no triângulo Mineiro, ARAÚJÓ (1992) delimitou uma área de 1ha dentro de cada mata, na qual foram localizadas cinquienta parcelas de $10 \times 10 \mathrm{~m}$ ao acaso. Nestas parcelas, foram coletadas amostras nas profundidades correspondentes ao horizonte $A_{1}$ e $A_{3}$ descrito anteriormente 
numa trincheira nas profundidades de 0 a 8 e 8 a $65 \mathrm{~cm}$ mum caso e 0 a 7 e 7 a $24 \mathrm{~cm}$ no outro. o levantamento fitossocilógico foi feito e o teor de nutrientes nas folhas foi determinado para várias espécies. A autora concluiu que as diferenças florísticas e estruturais observadas nas duas matas deveram-se a diferenças na composição granulométrica e química dos solos. Apesar desta conclusão geral, não foi possível estabelecer de forma clara e precisa a relação entre o teor dos nutrientes no solo e nas folhas. Interessante notar que a serapilheira acumulada não foi considerada nos estudos e que partiu-se da suposição de que os horizontes do solo apresentavam espessura uniforme na área.

PAGANO (1985) estudou a ciclagem de nutrientes, a composição florística e fitossociologia de uma mata natural de $230 \mathrm{ha}$ em Rio Claro (SP). Nesta área foram coletadas três amostras ao acaso, compostas de quinze subamostras nas profundidades de 0-20 e 0-50 cm abaixo da camada de serapilheira acumulada. Nestas amostras foram feitas determinações químicas. A produção de serapilheira foi determinada em 36 coletores de $100 \times 100 \times 15 \mathrm{~cm}$ distantes $15 \mathrm{~cm}$ da superfície do solo dispostos ao longo de picadas com distância aproximada de $170 \mathrm{~m}$ entre coletores. 0 autor chega a conclusão que há equilíbrio entre mineralização e consumo de matéria orgânica do solo e que a mineralogia predominante da fração argila do Latossolo Vermelho-Amarelo fase rasa e Latossolo Vermelho-Escuro orto, que, segundo o autor, provavelmente ocorrem na área é esmectítica. Tal conclusão evidentemente só pode ser fruto de um grave erro metodológico, provavelmente de interpretação dos resultados da análise de terra. 0 teor de vários elementos no solo foi considerado como variando desde valores muito baixos até muito elevados sendo que o P disponivel sempre apresentou valores baixos. A produção de serapilheira média observada foi de $8.643 \pm 134 \mathrm{~kg} / \mathrm{ha}$, constituida principalmente por folhas. A serapilheira acumulada foi determinada pela coleta de seis a vinte amostras ao acaso numa área de 50 por $50 \mathrm{~cm}$, encontrando-se valores médios de $5.713 \pm 980 \mathrm{~kg} / \mathrm{ha}$.

Com o objetivo de caräcterizar os solos num estudo da fitossociologia do estrato arboreo da floresta da reserva biológica do Instituto de Botânica em São Paulo (SP), vuoNo (1985) sorteou dez pontos por área de 
estudo coletando amostras nas profundidades de 0-20, 40-60 e 80-100cm e procedendo análises químicas e granulométricas. Em praticamente todos os atributos analisados, ocorreram pontos com valores anômalos, muito distantes da média. Foram observadas também grandes diferenças em relação às profundidades amostradas.

Apesar de ter observado diferenças entre os solos de una mata de galeria na estação ecológica do Panga em Uberlândia (MG) e ter associado a essas mudanças à ocorrência de certas espécies vegetais, SCHIAVINI (1992) não dispunha de levantamento de solos detalhado da área. Assim, com a finalidade de caracterizar os solos na área de estudo, dividida em sessenta parcelas de 10 por 10m, o autor coletou, em cada parcela, uma amostra composta de três amostras simples na profundidade de $0-20 \mathrm{~cm}$, procedendo-se análises granulométricas e químicas. Os dados coletados foram utilizados para descrever as áreas denominadas pelo autor de dique, meio e borda, sem contudo conseguir relacionar as diferenças observadas com a vegetação.

BERNACCI (1992) procedeu estudo florístico e fitossociológico numa floresta de Campinas e com a finalidade de caracterizar os solos das cinco áreas de interesse foram coletadas amostras compostas de 3 amostras simples nas profundidades de 0-20, 40-60 e 80-100 cm, que foram analisadas quanto aos atributos granulométricos e químicos de rotina. 0 laboratório que procedeu as análises forneceu também a classificação taxonômica detalhada dos solos segundo EMBRAPA (1988) sendo este procedimento no mínimo curioso, uma vez que esta classificação foi feita sem una descrição de campo. O autor não conseguiu relacionar os dados de solos com os dados fitossociológicos.

MARTINS (1979) estudou una mata de 322ha localizada no município de Santa Rita do Passa Quatro (SP), propondo una nova metodologia para descrição da vegetação. Para a caracterização dos solos foram coletadas quinze amostras distribuidas de forma casual nas profundidades de 0-20, 40-60 e 80-100cm procedendo-se análises químicas e granulométricas. Os resultados das análises foram utilizados para descrever a área quanto aos teores dos elementos. 
RODRIGUES (1991) analisou detalhadamente um remanescente de vegetação natural às margens do Rio Passa Cinco em Ipeúna (SP). Neste trabalho foi feita uma amostragem de solos sistemática, na forma de una grade com pontos de amostragem distantes $2,10,20,30$ e $40 \mathrm{~m}$ do rio tendo sido coletadas amostras simples nas profundidades de 0-5, 5-25 e 60-80 cm bem como a serapilheira acumulada. Além da amostragem sistemática na forma de grade, foi realizado um levantamento detalhado de solos na área, seguindo os métodos tradicionais (EMBRAPA, 1979). 0 autor selecionou pontos de amostragem e profundidades para a realização das análises químicas e granulométricas, obtendo una redução de 408 no custo das análises se comparado ao custo da análise de todas as amostras coletadas. No trabalho são apresentados mapas de isovalor dos parâmetros químicos e granulometricos do solo e a sua relação com a vegetação. 0 autor concluiu que a avaliação das características edáficas de forma sistemática e o levantamento de solos foram imprescindíveis para a compreensão do gradiente vegetacional identificado na formação florestal estudada. A profundidade de amostragem foi considerada importante, uma vez que foi observado um gradiente elevado entre as amostras coletadas de 0-5cm e 0$25 \mathrm{~cm}$.

Percebe-se na maioria dos trabalhos realizados em florestas uma preocupação para a caracterização dos solos. Entretanto, devido a uma estratégia de coleta de amostras muitas vezes inadequada, as informações obtidas sobre os solos, em grande parte dos casos apenas aparecem citadas sem relacionamento com a composição florística ou mesmo com outros atributos da paisagem como a posição no relevo.

Nos casos em que a descrição dos solos foi feita de maneira mais precisa e adequada a uma condição de floresta, como em RODRIGUES (1991), TRAGMAR et al. (1897), RIHA et al. (1986) e COURTIN et al. (1983) e acima de tudo, no mesmo nível de sofisticação do inventário florístico, ela se tornou extremamente útil e valiosa para a compreensão geral das relaçōes existentes entre o meio biológico e físico. 


\section{MATERTIAL B METODOS}

\subsection{Descriçảo do local}

A área em estudo localiza-se dentro de uma mata de aproximadamente 30ha da Estação Experimental de Pindorama, do Instituto Agronômico de Campinas a qual tem área de 533ha e situa-se na região sul do município de Pindorama (SP) nas coordenadas $48^{\circ} 55^{\prime} \mathrm{W}$ e $21^{\circ} 13^{\prime} \mathrm{S}$. 0 limite na extremidade oeste é, em parte, o divisor de águas das bacia dos rios Turvo e Tietê, as altitudes variam de 498 a $594 \mathrm{~m}$ e a litologia predominante são os arenitos do Grupo Bauru, do Cretáceo. Conforme a classificação de Köppen (CRITCHFIELD, 1960) o clima enquadra-se no tipo Aw, definido como tropical úmido com estação chuvosa no verão e seca no inverno sendo a precipitação média anual de $1.259 \mathrm{~mm}$, a temperatura média dos três meses

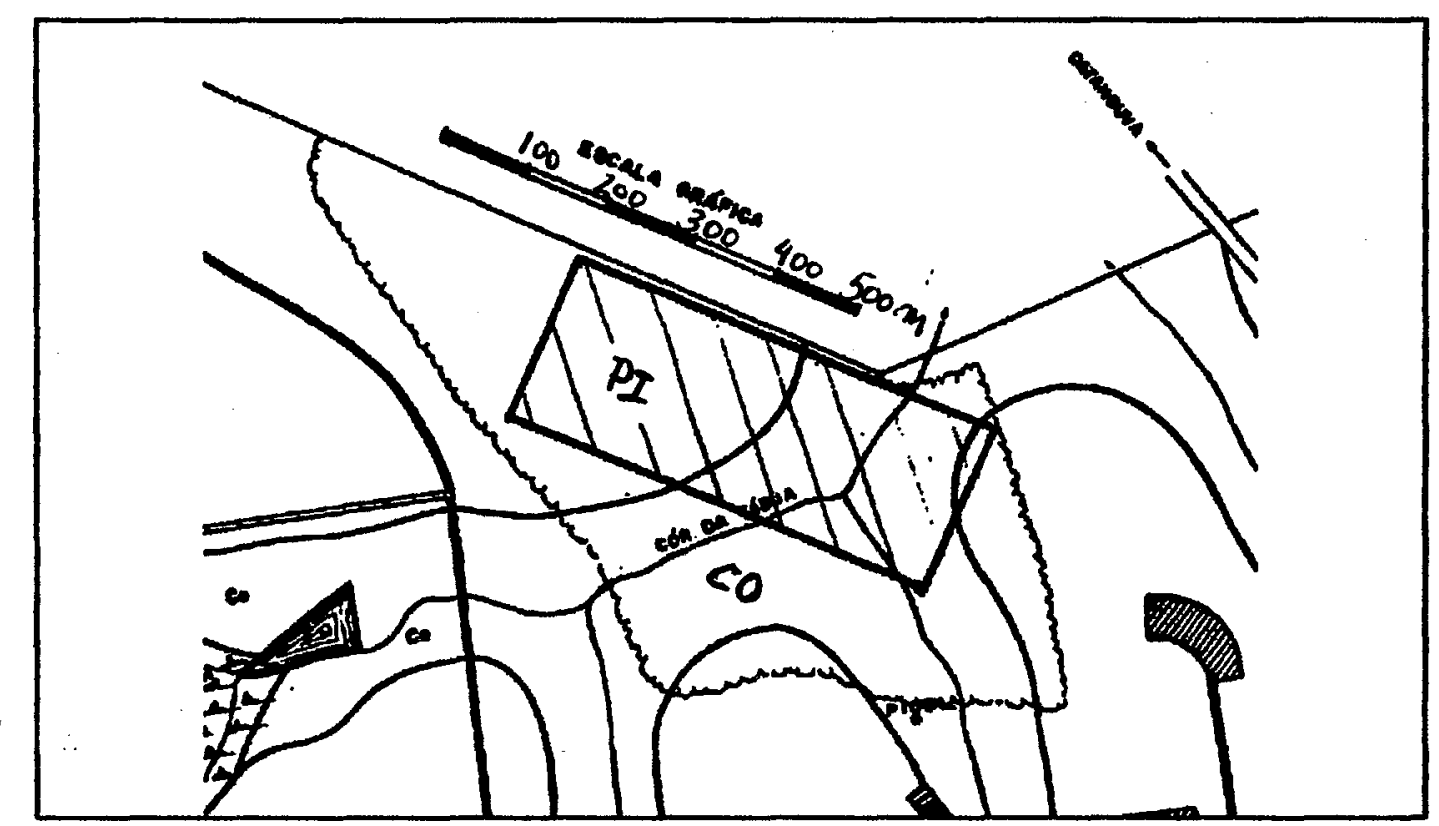

Figura 1 - Localização da área de estudo e das unidades de solo (LEPSCH \& VALADARES, 1976). 
de verão (dezembro, janeiro e fevereiro) de $23,8^{\circ} \mathrm{C}$ e a média dos três meses de inverno (junho, julho e agosto) de $19,3^{\circ} \mathrm{C}$. Na área de estudo, os solos da parte alta pertencem à unidade Pindorama (podzólico vermelho amarelo, Tb, eutrófico, abrupto, A moderado, textura arenosa/média, fase relevo ondulado) e próximo à rede de drenagem, à unidade Concreção (podzólico vermelho amarelo, Ta, distrófico, abrupto, A moderado, textura arenosa/média, fase relevo ondulado) segundo LEPSCH \& VALADARES (1976). o mapa de solos da área de estudo e a sua localização na estação experimental é apresentado na figura 1.

A mata não sofreu ação antrópica recente, uma vez que pelo menos desde a criação da Estação Experimental há 50 anos não há registros de perturbações. O remanescente florestal recebe a designação de Floresta Mesófila Semidecidua adaptada de RIZZINI (1976), que expressa melhor as características climáticas dominantes na região. Essa formação florestal se caractériza por apresentar un dossel irregular não perfeitamente contínuo entre 15-20m de altura, com presença de árvores emergentes de até 25-30m de altura, observando-se ainda a deciduidade concentrada na estação seca em aproximadamente $20 \%$ das espécies. Na falta de un inventário publicado mais detalhado sobre a composição florística da área apresentamos uma listagem das espécies que se destacam na área conforme estudos preliminares e cormunicação pessoal de RODRIGUES, 1993.

As espécies que se destacam nos estratos de dossel e emergentes foram: Astronium craveolens Jacq. (gravatá), Croton piptocalyx M. Arg. (cambraia), Cariniana estrellensis (Raddi) Kuntze (jequitibá branco), Hymenaea courbaril L (jatobá), Cedrela fissilis Vell. (cedro), Diatenopteryx sorbifolia Radlk (maria preta), Casearia gossypiosperma Briq. (pau de espeto), Croton floribundus Spreng. (capixingui), Aspidosperma polyneuron Muell. Arg. (peroba), Miconia cimamomifolia (D.C.) Naud (jacatirão), entre outras.

$\mathrm{Na}$ condição de subdossel, as espécies de destaque são: Trichilia claussenii C.DC. (catigua vermelho), Zanthoxyllum riedelianum Engl. (mamica de porca), Trichilia catiqua Adr. Juss. (catigua), Nectandra megapotamica (Spreng.) Ness (canelinha), Machaerium stipitatum (DC.) Vog. 
(sapuvinha), Machaerium nyctitans (Vell.) Benth. (bico de pato), Metrodorea nigra St. Hil (chupa ferro), Jacaratia spinosa (Aubl.) DC. (jaracatia), entre outras.

No subosque, as espécies de maior destaque são: Galipia multiflora Scult. (mamominha lisa), Esenbeckia febrifuga (St. Hil.) Juss. ex Mart. (mamominha), Blepharocalyx salicifolius (Humb. Bonpl et Kunth) Bug. (cambur), piper amalago (Jacq.) Yuncker (capeba), Coutarea hexandra (Jacq.) K. Schum (murta), Guetarada vibunoides Cham. et Schlecht, Randia armata (SN.) DC. (limão bravo), Rudgea jasminoides (Cham.) Muell. Arg. (café do mato), Solanum swartzianum Roem. et. Schult. (folha prata), Piper aduncum L. (erva de jaboti) entre outras.

o perfil topográfico da área de estudo, onde foram localizadas as parcelas está representado esquematicamente na figura 2.

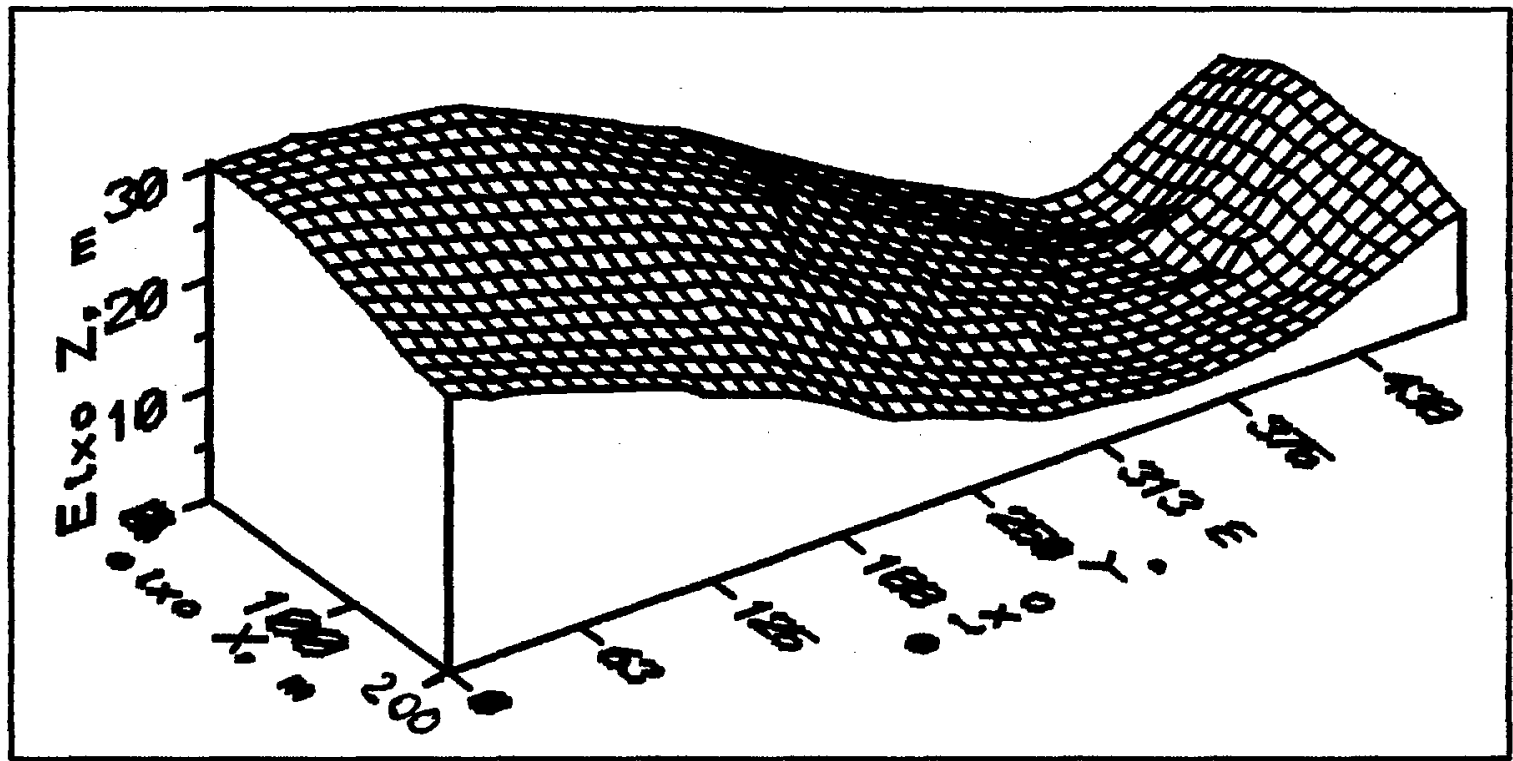

Figura 2 - Perfil topográfico esquemático da área de estudo.

\subsection{Amostragem e metodologia analítica}

\subsubsection{Defïiç̧ão dos locais de coleta de amostras}

Ao todo foram distribuidos, de forma sistemática, 64 pontos para coleta de amostras na área procedendo-se, inicialmente, a subdivisão da área central da mata em 16 parcelas a cada $62,5 \mathrm{~m}$ no eixo y e $100 \mathrm{~m}$ no eixo $\mathrm{x}$, 
numeradas da parte alta para a parte baixa e da direita para a esquerda de 1 a 16 (Figura 3). Os valores numéricos representados nos eixos $x$ e $y$ das figuras 2 e 3 delimitam as parcelas.

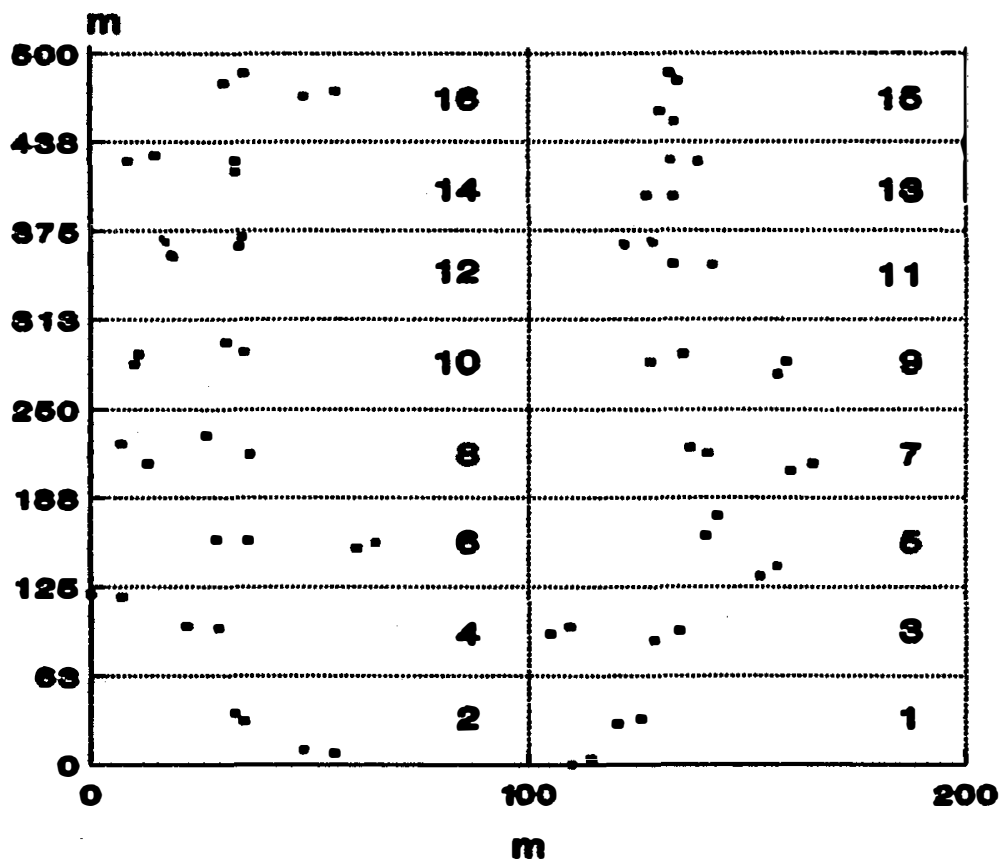

Figura 3. - Subdivisão da área central da mata de Pindorama em dezesseis parcelas identificadas numericamente com a localização dos pontos de amostragem (pontos).

Dentro de cada parcela foram localizados quatro pontos de amostragem dispostos de forma a que os pontos 1-2 e 3-4 tivessem distância de $7 \mathrm{~m}$ e que os conjuntos de pontos 1, 2 e 3, 4 tivessem entre si distáncia média de $25 \mathrm{~m}$, conforme representado na figura 4 para as parcelas 7 e 8 . Ainda, a distância média entre as parcelas vizinhas foi de $80 \mathrm{~m}$.

o procedimento adotado para a localização dos pontos seguiu a seguinte sequiência:

a) a partir do ponto central de cada parcela, identificado como ponto 1, sorteou-se uma das direções N, NE, E, SE, S, SW, W ou NW através de um programa de geração de caracteres aleatórios. Na primeira direção sorteada foi marcado o segundo ponto, ponto 2 , distante $7 \mathrm{~m}$ do ponto 1 . A seguir, 


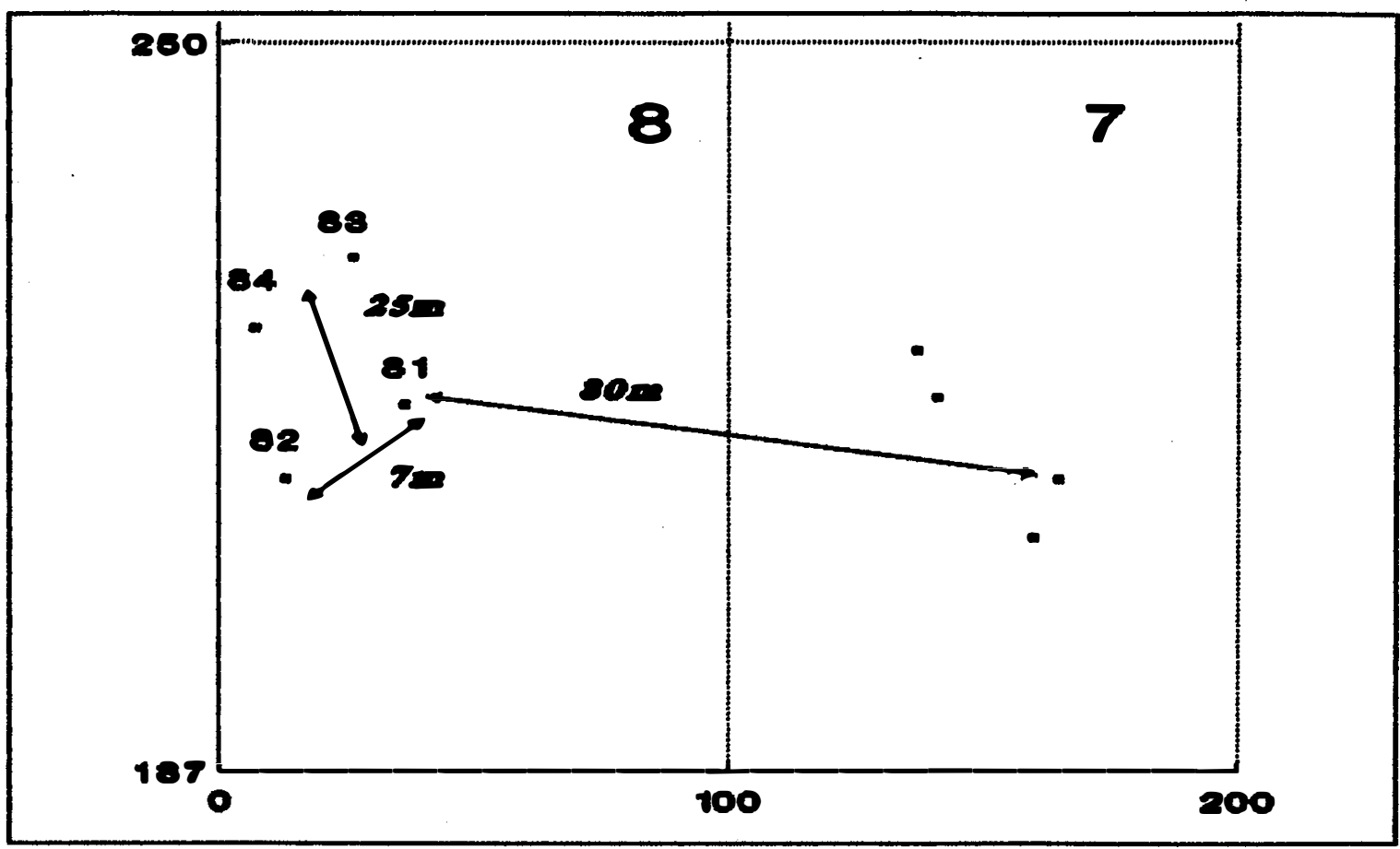

Figura 4 - Localização dos pontos de amostragem das parcelas 7 e 8 e as distâncias entre eles

nova direção foi sorteada a partir do ponto 2 e marcado novo ponto de amostragem a $25 \mathrm{~m}$ do ponto 2 , chamado de ponto 3 . A partir do ponto 3 foi localizado o ponto 4 distante deste $7 \mathrm{~m}$. Com isto, procurou-se espalhar sobre a área pontos de amostragem de forma a não concentrá-1os, simulando un delineamento em blocos com coleta casualizada, e, ao mesmo tempo permitir uma análise de variância hierarquizada e o cálculo dos semivariogramas.

Como não se dispunha de informaçōes prévias sobre a variabilidade dos atributos de interesse na área, o número de amostras coletadas bem como a distância entre os pontos foram determinados por dados de literatura e pelos recursos financeiros e pessoais disponíveis.

os pontos de amostragem, a localização das parcelas e a saída do córrego da mata, que constituiu o ponto externo identificável ná paisagem, foi feita num papel milimetrado na escala 1:1.000. A partir do ponto externo e seguindo as direçōes e distâncias já definidas e marcadas no papel milimetrado, procedeu-se caminhamento na área localizando os 64 pontos de 
amostragem. As direções foram medidas com uma bússola e as distâncias com trena seguindo o procedimento normal de um levantamento topográfico, isto é, a partir de uma linha poligonal básica foram localizados os pontos de amostragem. 0 erro angular, estimado no local visando-se do último ponto da poligonal o primeiro e subtraindo-se a leitura feita da leitura esperada determinada no mapa, foi de 30' e o erro linear 8,4m. Este erro, se distribuído entre os 64 pontos de amostragem pode ser considerado aceitável para a precisão exigida nas análises geo-referenciadas que foram feitas, indicando que o uso de equipamentos simples, desde que usados com cuidado (o tempo despendido para localizar os 64 pontos com bússola e trena contando com uma equipe de seis pessoas foi de cinco dias), pode ser bastante útil. A localização mais exata dos pontos de amostragem foi feita posteriormente com uso de teodolito, sendo que as coordenadas utilizadas como referência espacial dos pontos nas análises foram as determinadas por este método.

Procedendo-se desta forma para todas as parcelas assegurou-se una amostragem sem nenhuma influência de decisão local e contando com três níveis hierárquicos de distância, estando os pontos 1-2 e 3-4 com distância média de $7 \mathrm{~m}$, os conjuntos de pontos 1,2 e 3,4 com distância média de 25 e entre parcelas de $80 \mathrm{~m}$. As estacas marcadas foram interligadas com fita plástica para facilitar a orientação nas diversas amostragens.

Cabe una observação a respeito da amostragem. Como as coordenadas dos pontos haviam sido definidas previamente, o que não é comum neste tipo de amostragem, não houve tendência na sua localização no campo. A tarefa na área foi apenas achar o ponto e identificá-lo com una estaca. A grande maioria dos pontos ficou em locais onde, provavelmente, não se coletariam amostras no caso de uma amostragem com tomada de decisão da localização dos pontos diretamente no campo. Invariavelmente, havia um arbusto com espinhos, um ninho de marimbondos ou um tronco que dificultava a tradagem e, sempre, um local muito próximo muito mais aberto onde a coleta de amostras seria mais fácil. Não sabemos que influência a amostragem poderia ter nos resultados se fossem escolhidos apenas os locais próximos e mais 
abertos, entretanto, acreditamos que isto poderia levar a uma subestimação da variabilidade espacial pela introdução de uma tendência de escolha desses locais.

\subsubsection{Parâmetros amostrados e épocas de amostrager}

$\mathrm{Em}$ cada ponto de amostragem foi instalado um coletor de produção de serapilheira e precipitação interna, conforme esquematizado na Figura 5.

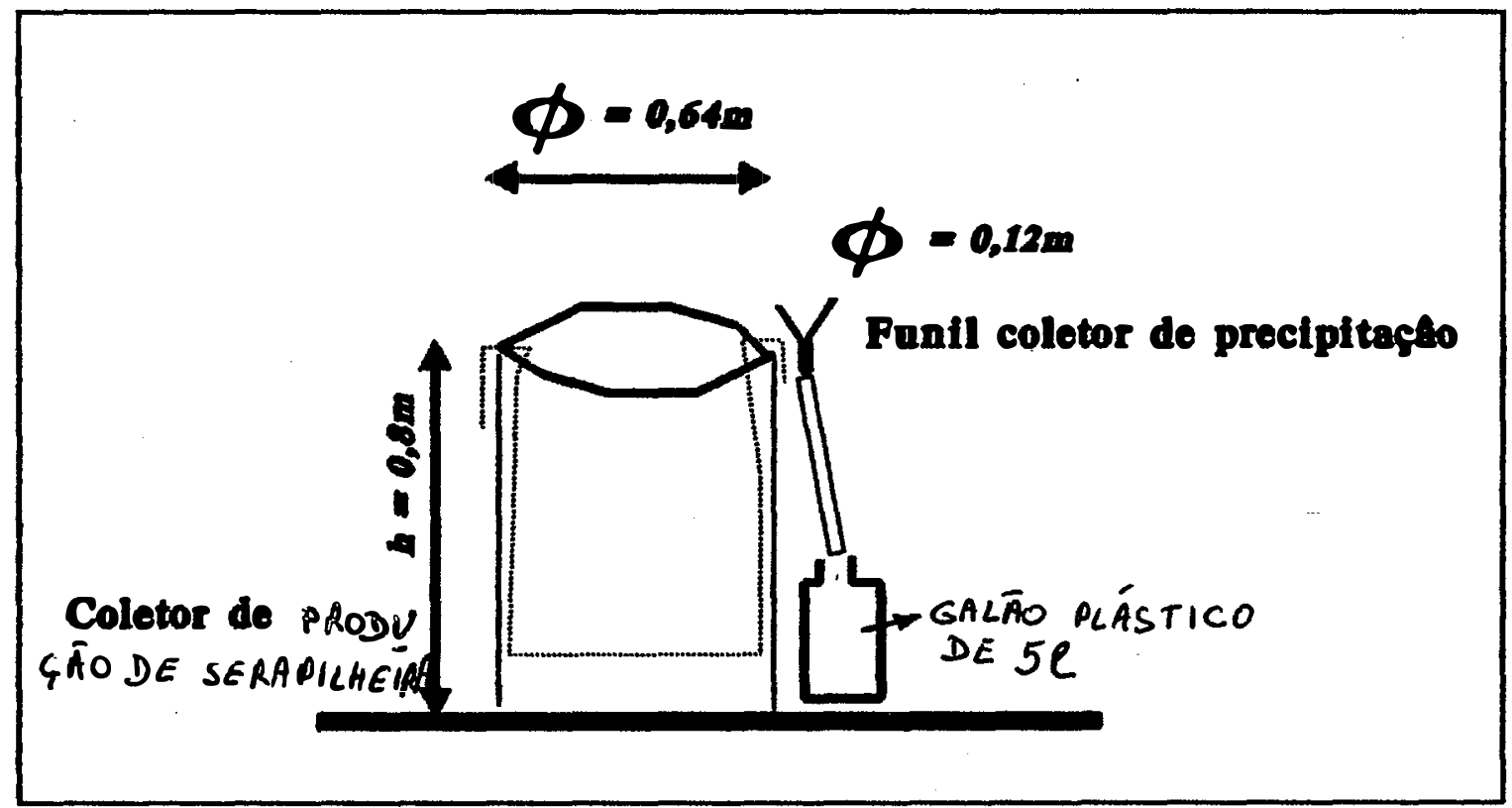

Figura 5 - Esquema do coletor de prođução de serapilheira e de precipitação interna instalado nos pontos de amostragem.

Uma tela plástica foi utilizada para a construção da armação externa e na parte superior foi fixado um arame grosso para manter o diâmetro constante. Toda a estrutura foi sustentada por estacas de madeira. Dentro dos coletores foi fixado um saco plástico furado no fundo com a finalidade de reter a serapilheira produzida. Lateralmente ao coletor, aproximadamente $3 \mathrm{~cm}$ acima deste, foi fixado um funil plástico que foi ligado a um reservatório plástico de 51 por uma mangueira, servindo de pluviômetro. o coletor foi montado no local o que facilitou sobremaneira - transporte do material para dentro da área. Os 64 coletores foram montados em dois dias por uma equipe de cinco pessoas. 
As datas em que foram registrados os dados ou coletadas as amostras aparecem na Tabela 1.

Tabela 1 - Período de coleta das amostras utilizadas para as análises ou registro de dados na mata da Estação Experimental de Pindorama (SP)

\begin{tabular}{llll}
\hline Serapilheira produzida & $\begin{array}{l}\text { Precipitação } \\
\text { interna }\end{array}$ & Solo & $\begin{array}{l}\text { Serapilheira } \\
\text { acumulada }\end{array}$ \\
\hline $7 / 7 / 89$ a $3 / 8 / 89$ (julho) & $28 / 8 / 89$ & $7 / 7 / 89$ & $7 / 7 / 89$ \\
$4 / 8 / 89$ a $4 / 9 / 89$ (agosto) & $4 / 9 / 89$ & & \\
$5 / 9 / 89$ a $7 / 10 / 89$ (setembro) & $18 / 9 / 89$ & & \\
$8 / 10 / 89$ a $7 / 11 / 89$ (outubro) & $4 / 10 / 89$ & & \\
$8 / 11 / 89$ a $7 / 12 / 89$ (novembro) & $6 / 11 / 89$ & & \\
$8 / 12 / 89$ a $5 / 1 / 90$ (dezembro) & $13 / 11 / 89$ & \\
& $22 / 11 / 89$ & \\
& $28 / 11 / 89$ & \\
& $15 / 12 / 89$ & \\
& $3 / 1 / 90$ & \\
\hline
\end{tabular}

A serapilheira acumulada sobre o solo foi coletada num quadrado de 0,5 por $0,5 \mathrm{~m}\left(0,25 \mathrm{~m}^{2}\right)$ localizado a $2,0 \mathrm{~m}$ na direção norte dos coletores. Neste mesmo quadrado, após a coleta da serapilheira, foram coletadas as amostras de solo nas profundidades de 0-5, 5-25 e 60-80 cm. Para a coleta da amostra de $0-5 \mathrm{~cm}$ toda a terra do interior do quadrado foi raspada com uma faca, homogeneizada e retirada uma amostra. Este procedimento foi necessário para obter a terra necessária para as análises devido à baixa densidade do solo nesta camada e à grande presença de raízes. Nas demais profundidades, foi utilizado um trado holandês procedendo-se a tradagem na parte central do quadro, coletando-se assim uma amostra simples num único ponto.

\subsubsection{Metodologia analítica}

As amostras de serapilheira produzida foram secas em estufa a $60^{\circ} \mathrm{C}$ no local, logo após a sua coleta e pesadas posteriormente sem separação 
de folhas, frutos ou galhos tendo sido os dados expressos em megagrama de matéria seca por hectare.

A serapilheira acumulada sobre 0 solo foi seca em estufa a $60^{\circ} \mathrm{C}$ e separada em duas frações por peneiramento: fração fina < 2,0mm e fração grossa > 2,0mm. As duas frações foram pesadas separadamente e os dados expressos em megagrama de matéria seca por hectare. Cada una das fraçōes foi submetida a análises químicas para determinação dos teores totais de N, P, K, Ca, Mg, S, e Zn. O extrato para determinação do nitrogênio foi obtido por digestão sulfúrica e para os outros elementos analisados por digestão nitro-perclórica. O N foi determinado em semi-micro-Kjeldahl, 으 $P$ por colorimetria do metavanadato, $S$ por turbidimetria do sulfato de bário, K por fotometria de chama de emissão e Ca, Mg e $\mathrm{Zn}$ por espectrofotometria de absorção atômica. A descrição detalhada dos procedimentos analíticos pode ser vista em MALAVOLTA et al. (1989).

As amostras de terra foram secas ao ar e passadas em peneira de $2,0 \mathrm{~mm}$. A terra fina resultante foi submetida a análises químicas e granulométricas. Foram determinados pH H $\mathrm{H}_{2}(1: 2,5)$; teor de matéria orgânica (MO) por oxidação pelo $\mathrm{H}_{2} \mathrm{SO}_{4}$ e quantificação por colorimetria; fósforo disponivel (P) e teores de $\mathrm{K}^{+}, \mathrm{Ca}^{++}, \mathrm{Mg}^{++}$, extraídos pela resina de troca iônica, sendo o P quantificado por colorimetria e o K, Ca e Mg por espectrofotometria de absorção atômica; teor de $\mathrm{Al}^{\text {t+t }}$ (Al) extraído pelo KCl $1 \mathrm{~N}$ e determinado por titulação ácido $\rightarrow$ base; teor de $\mathrm{SO}_{4}^{2-}$ por turbidimetria, teor de argila pelo método do densímetro de Boyoucus e calculados os parâmetros $\mathrm{T}=$ capacidade de troca de cátions, V=saturação por bases e m=saturação por aluminio na CTC efetiva. Uma descrição detalhada dos métodos analíticos empregados pode ser vista para o $\mathrm{SO}_{\text {, em VITTI }}$ (1989) e para as demais determinações em CAMARGO et al. (1986).

A precipitação interna foi registrada procurando-se isolar eventos, ou pequenos períodos de chuva. Após o evento ou pequeno período de chuva, a quantidade de áqua contida nos reservatórios foi medidá com uma proveta graduada. 


\subsection{Rstatística}

Para a análise dos dados foram determinados valores centrais, medidas de variabilidade, o ajuste à distribuição normal, análise de variância entre parcelas e hierárquica, valores em função da posição e a semivariância. Os procedimentos adotados são apresentados a seguir.

\subsubsection{Valores centrais}

Como valores centrais dos dados foram calculados os valores da média e da mediana. A mediana, designada pelas letras Md, é o valor central ou a média dos valores centrais após os dados terem sido arranjados em ordem crescente ou decrescente. A média foi calculada pela equação:

$$
\bar{X}=\frac{\sum x}{n}
$$

onde :

$\mathrm{X}=$ média das amostras $\mathrm{X}$

$\mathrm{n}=$ número de registros de $\mathrm{X}$

0 intervalo de confiança da média foi determinado pela equação:

$$
\pm Z=\frac{\bar{X}-\mu}{\sigma_{2}}
$$

onde:

$$
\sigma_{\bar{x}}=\frac{S}{\sqrt{n}}
$$

onde :

$z$ = variável independente da equação de distribuição normal. No caso dos cálculos utilizou-se o valor $\mathrm{Z}=1,96$ representando conseqüentemente un nível de significância de 958 para a estimativa do intervalo de confiança da média

$\mathrm{x}=$ média dos valores das amostras

$\mu=$ média da distribuição de frequiência das médias

$\sigma_{\mathrm{z}}=$ erro padrão da média 
$S$ = desvio padrão dos valores de $X$, equação (4)

$\mathrm{n}=$ número de registros de $\mathrm{X}$

A equação (2) resolvida para $\mu$ calcula o intervalo de confiança da média dos valores amostrados com 95\% de probabilidade (GILBERT, 1976).

o número de amostras necessárias para estimar a média com certo intervalo de confiança foi determinado pela equação:

$$
n-\frac{z^{2} s^{2}}{E^{2}}
$$

onde:

$\mathrm{n}=$ número de amostras necessárias para estimar a média

$z$ = mesmo significado equação (2)

$E$ = erro máximo a ser aceito na média da distribuição de frequiência das médias. Para os cálculos utilizou-se 5 e 108 do valor da média das amostras (GILBERT, 1976).

Os valores centrais foram calculados em planilha eletrônica programada para esta finalidade.

\subsubsection{Medidas de variabilidade}

Como medidas da dispersão dos valores amostrados foram determinadas a variancia, o desvio padrão.

\subsubsection{Variancia}

A variância foi determinada pela equação:

$$
S^{2}-\frac{\sum(X-\bar{X})^{2}}{n-1}
$$

onde:

$\mathrm{S}^{2}=$ variância das amostras $\mathrm{X}$

$X$ = média das amostras $X$

$\mathrm{n}=$ número de registros de $\mathrm{X}$

\subsubsection{Desvio Padrāo}

o desvio padrão foi determinado pela equação:

onde: 


$$
s-\sqrt{S^{2}}-\sqrt{\frac{\sum(X-\bar{X})^{2}}{n-1}}
$$

$\mathrm{S}=$ desvio padrão das amostras $\mathrm{X}$

$\mathbf{s}^{2}=$ variância das amostras $\mathrm{X}$

$\mathrm{X}=$ média das amostras $\mathrm{X}$

$\mathrm{n}$ = número de registros de $\mathrm{x}$

\subsubsection{Ajuste à distribuição normal e lognonnal}

A avaliação do ajuste dos valores amostrados à distribuição normal foi feita pelo método dos momentos utilizando os coeficientes de simetria e curtose e pelo teste $x^{2}$ e o ajuste à distribuição lognormal foi verificado apenas pelo teste $x^{2}$.

0 coeficiente de simetria foi calculado pela equação:

$$
C_{s}=\frac{3(\bar{X}-M d)}{S}
$$

onde:

$\mathrm{C}_{\mathrm{S}}=$ Coeficiente de simetria

$X=$ média das amostras $X$

Md = mediana das amostras $\mathrm{X}$

$S$ = desvio padrão das amostras $X$

o coeficiente de simetria tem valor zero quando a distribuição dos valores $X$ é perfeitamente normal. Valores maiores do que zero indicam assimetria para a direita e valores menores do que zero indicam assimetria para a esquerda. Como valor crítico do coeficiente de simetria foram utilizados $-0,565<\mathrm{C}_{\mathrm{s}}<0,565$, consequientemente com nivel de probabilidade de 58 (LANDIM, 1988).

A curtose reflete o grau de achatamento de una distribuição de frequiências. o coeficiente de curtose foi determinado pela equação:

$$
c_{c}-\frac{\mu^{4}}{\sigma^{2}}
$$


onde:

$\mu^{4}=$ momento central de quarta ordem

$\sigma=$ variância

o valor do coeficiente de curtose é igual a 3 para a distribuição normal. Valores inferiores a 3 indicam um achatamento da curva de distribuição e maiores una concentração dos valores em torno dos valores centrais. Como valores críticos para o coeficiente de curtose foram utilizados $2,14<C_{c}<4,25$, consequientemente com nível de probabilidade de 5우 (LANDIM, 1988). o coeficiente de simetria e curtose foi calculado em planilha eletrônica programada para esta finalidade.

0 teste $x^{2}$ foi determinado mediante a equação:

$$
\chi^{2}=\sum \frac{(O-E)^{2}}{E}
$$

onde:

0 = frequiência observada da variável $x$

$\mathrm{E}$ = frequiência estimada pela equação de distribuição normal na mesma faixa de probabilidade de 0

A população de 64 amostras foi dividida em oito classes conforme sugerido por LANDIM (1988). A comparação dos valores da solução da equação (7) com os valores de distribuição de probabilidade de $x^{2}$ permite estabelecer o nível de significância do ajuste à distribuição normal. Foram aceitos como significativos valores de probabilidade maiores do que $20 \%$ (DAVIS, 1973). 0 teste $x^{2}$ foi feito no programa statgraphics v. 2.6.

\subsubsection{Análise de variância entre parcelas}

As quatro repetições de cada parcela foram comparadas por análise de variância (teste $F$ ), seguindo a Tabela 2 , e a comparação das médias foi feita pelo teste de Tukey a 958 de probabilidade. 
Tabela 2 - Parâmetros utilizados na análise de variância entre parcelas para a comparação dos valores das amostragens (GILBERT, 1976).

\begin{tabular}{lcccc}
\hline Causas de variação & $\begin{array}{l}\text { Soma de } \\
\text { quadrados }\end{array}$ & $\begin{array}{l}\text { Graus de } \\
\text { liberdade }\end{array}$ & $\begin{array}{l}\text { Quadrado } \\
\text { médio }\end{array}$ & Teste F \\
\hline entre parcelas & $\mathrm{SQ}_{\mathrm{P}}$ & $\mathrm{m}-1$ & $\mathrm{QM}_{\mathrm{P}}$ & $\mathrm{QM}_{\mathrm{p}} / \mathrm{QM}_{\mathrm{P}}$ \\
entre repetições & $\mathrm{SQ}_{\mathrm{P}}$ & $\mathrm{N}-1$ & $\mathrm{QM}_{\mathrm{P}}$ & \\
variação total & $\mathrm{S} \mathrm{Q}_{\mathrm{P}}$ & $\mathrm{N}-1$ & & \\
\hline
\end{tabular}

onde:

$S_{Q, R, I}=$ Soma dos quadrados das parcelas, repetições e total respectivamente.

$Q M_{p, \mathbb{R}}=$ Quadrado médio das parcelas e das repetições, respectivamente.

$\mathbf{N}=$ número total de observações.

$\mathrm{m}=$ número total de parcelas.

\subsubsection{Análise hierárquica de variância}

A análise de variância considerando os niveis de distância médios de 7, 25 e $80 \mathrm{~m}$ descritos no item 3.2 .1 foi feita seguindo o esquema de cálculo apresentado na Tabela 3 conforme WEBSTER (1985).

Tabela 3 - Parâmetros utilizados na análise de variância em níveis hierárquicos para a comparação dos valores amostrados nos níveis médios de distância de 7, 25 e 80m, conforme WEBSTER (1985).

\begin{tabular}{lll}
\hline $\begin{array}{l}\text { Causa de } \\
\text { variação }\end{array}$ & Graus de liberdade & Componentes do quadrado médio \\
\hline $80 \mathrm{~m}$ & $n_{1}-1$ & $\mathrm{~s}_{3}^{2}+n_{3} s_{2}^{2}+n_{2} n_{3} s_{1}^{2}$ \\
$25 m$ & $n_{1}\left(n_{2}-1\right)$ & $s_{3}^{2}+n_{3} s_{2}^{2}$ \\
$7 m$ & $n_{1} n_{2}\left(n_{3}-1\right)$ & $s_{3}^{2}$ \\
total & $n_{1} n_{2} n_{3}$ & \\
\hline onde: & \\
$n_{1,2 \text { e } 3}=$ número de subdivisões dos níveis hierárquicos de 80,25 e $7 m$
\end{tabular}


respectivamente.

$\mathrm{s}_{1,2 \text { e } 3}^{2}=$ componente da variância dos níveis hierárquicos de 80,25 e $7 \mathrm{~m}$, respectivamente.

Os resultados da análise foram apresentados graficamente em porcentagem acumulada da variância total em cada nível hierárquico. As análises de variância foram calculadas pelo programa statgraphics v. 2.6.

\subsubsection{Observação dos valores em função da sua posição.}

Com o objetivo de observar, de forma simples, os valores das variáveis amostradas em função de sua localização na área, foram construídos gráficos, tendo como variável independente as coordenadas $X$, Y ou Z expressas em metros e como variáveis dependentes os valores numéricos dos atributos determinados. Nestes gráficos também aparecem representados como linhas contínuas os valores medios.

\subsubsection{Senivariância}

A semivariância foi estimada pela equação (VIEIRA, 1983):

$$
\dot{\gamma}_{(b)}=\frac{1}{2 N(h)} \sum_{i=1}^{N(h)}\left[z\left(x_{1}\right)-z\left(x_{i+h}\right)\right]^{2}
$$

onde:

$N(h)$ é o número de pares de pontos $\left[z\left(x_{i}\right), z\left(x_{i+h}\right)\right]$ separados pelo vetor de distância $h$. Os cálculos foram feitos no programa PC-GEOSTAT.

Com a finalidade de comparar mais facilmente variáveis de diferentes magnitudes, a semivariância foi dividida pela variância total dos valores das amostras, resultando a semivariância normalizada, conforme equação:

$$
\gamma_{(h)}^{*}-\frac{\gamma_{(h)}}{\boldsymbol{s}^{2}}
$$


Um gráfico da semivariância $\tau_{(h)}$ em função do vetor $h$, é chamado de semivariograma. Nos semivariogramas calculados foi considerado o valor médio do vetor $\mathrm{h}$ em todas as direções, mostrando una série de valores discretos correspondentes aos valores de $h$ aos quais, em alguns casos, foi ajustada uma função contínua $z^{*}(h)$ que é chamada de função da semivariância sendo que utilizaram-se equaçōes exponenciais ou esféricos. 0 ajuste a estas equações foi feito minimizando o quadrado médio dos residuos utilizando o programa PC-GEOSTAT.

Assumindo que exista uma dependência espacial entre os valores determinados de uma variável qualquer dentro dos limites de distância considerados no estudo, as observações feitas próximas unas das outras provavelmente terão valores mais próximos do que observações distantes. Desta forma, a diferença $\left[z\left(x_{i}\right), z\left(x_{i+h}\right)\right]$, isto $e ́$, a magnitude do vetor que as separa, decresce. o valor de $\tau$ quando $h$ é igual a zero é chamado de efeito pepita ou $\mathrm{C}_{0}$ e representa a variância casual, abaixo do menor nível de distância considerado ou ainda reflete erros de medida.

Com o aumento de $h$, o semivariograma normalmente atinge um patamar de valor máximo e o valor $\mathrm{h}$ correspondente ao inicio do patamar é chamado de alcance do semivariograma. Uma discussão detalhada sobre as equações apresentadas pode ser vista em VIEIRA (1983). 


\section{RRSULTADOS E DISCUSST̃O}

\subsection{Serapilheira produzida}

\subsubsection{Estatística descritiva.}

Na Tabela 4 estão representados os valores médios e intervalos de confiança, o coeficiente de variação, o ajuste à distribuição da função normal e lognormal e o número de amostras necessárias para se obter una variação na média de 10 e 58 dos seis períodos de registro da produção de serapilheira.

O primeiro período apresentou uma produção média bastante inferior aos demais, o segundo o maior valor e os últimos quatro períodos apresentaram valores semelhantes. Os valores médios observados foram muito próximos dos encontrados por SCHAIK \& MIRMANTO (1985) numa floresta na Sumatra. PAGANO (1985) encontrou valores muito mais elevados com menor coeficiente de variação numa mata mesófila semidecídua de Rio Claro (SP). Os valores observados em povoamentos puros de várias espécies por GARRIDO \& POGGIANI (1982) foram bem menores. O coeficiente de variação foi superior a $60 \%$ em todos os períodos, atingindo 1578 no quarto período com um valor médio de 88\%. SCHAIK \& MIRMANTO (1985) encontraram variações bem menores numa floresta na Sumatra, com erro padrão da média em torno de 78 em comparação com 208 observado neste estudo. Com exceção do primeiro período, não foi verificado ajuste dos valores à distribuição normal. No primeiro período e no quinto houve ajuste à função lognormal.

0 número de amostras necessárias para estimar a média com 10ษ de variação variou de 108 para o período 1 até 685 para o período 4 . 
Tabela 4 - Valores médios e intervalos de confiança, coeficiente de variação, ajuste à distribuição normal e lognormal e número de amostras necessárias para se obter una variação na média de 10 e $5 \%$ dos seis períodos de registro de serapilheira produzida.

\begin{tabular}{|c|c|c|c|c|c|c|c|c|c|}
\hline \multirow[t]{2}{*}{ Per íodo } & \multirow[t]{2}{*}{ média } & \multirow{2}{*}{$\begin{array}{c}\text { lim.inf. } \\
\mathrm{Mg} / \mathrm{ha}\end{array}$} & \multirow[t]{2}{*}{$1 \mathrm{im.sup.}$} & \multirow{2}{*}{$\begin{array}{r}\mathrm{cV} \\
\%\end{array}$} & \multirow{2}{*}{$\begin{array}{l}\mathrm{x}^{2} \\
\mathrm{~N}\end{array}$} & \multirow{2}{*}{$\begin{array}{l}\mathrm{x}^{2} \\
\mathrm{LN}\end{array}$} & \multirow{2}{*}{$\begin{array}{l}\text { Mo } \\
a / c\end{array}$} & \multirow{2}{*}{$\begin{array}{l}\mathrm{n}^{\circ} \\
0,1\end{array}$} & \multirow{2}{*}{$\begin{array}{l}\mathrm{n}^{\circ} \\
0,05\end{array}$} \\
\hline & & & & & & & & & \\
\hline 1 julho & 0,49 & 0,41 & 0,56 & 62 & * & * & ns & 108 & 155 \\
\hline 2 agosto & 1,46 & 1,23 & 1,69 & 65 & ns & ns & ns & 118 & 169 \\
\hline 3 setembro & 1,03 & 0,85 & 1,20 & 68 & ns & ns & $\mathrm{ns}$ & 130 & 187 \\
\hline 4 outubro & 1,00 & 0,62 & 1,38 & 157 & ns & ns & ns & 685 & 983 \\
\hline 5. novembro & 0,91 & 0,71 & 1,10 & 88 & $\mathrm{~ns}$ & $*$ & $\mathrm{~ns}$ & 216 & 309 \\
\hline 6dezembro & 0,93 & 0,74 & 1,13 & 87 & ns & ns & ns & 212 & 304 \\
\hline
\end{tabular}

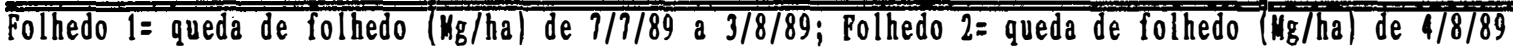
a $4 / 9 / 89$; Folhedo $3=$ queda de folhedo $(\mathrm{Mg} / \mathrm{ha}$ ) de $5 / 9 / 89$ a $7 / 10 / 89$; Folhedo $4=$ queda de folhedo $(\mathrm{Mg} / \mathrm{ha}$ ) de $8 / 10 / 89$ a $7 / 11 / 89$; Polhedo $5=$ queda de folhedo $(\mathrm{hg} / \mathrm{ha}$ ) de $8 / 11 / 89$ a $7 / 12 / 89$; Polhedo $6=$ queda de follhedo $\left(\mathrm{Hg}_{\mathrm{g}} / \mathrm{ha}\right)$ de $8 / 12 / 89$ a $\mathrm{S} / 1 / 90$

lim. inf. =linite inferior da média con intervalo de confiança (ic) de 95\%; lin. sup. =linite superior da média (ic=95\%); cr=coeficiente de variação; $x^{2} N=$ teste chi quadrado para distribuição normal; $x^{2}$ LN=teste chi quadrado para distribuição lognormal; No a/c= ajuste à distribuição normal pelo aétodo dos momentos (assimetria e curtose); $n^{\circ} 0,1=$ número de amostras necessárias para estimar a média con 10\% de variação; n $0,05=$ número de amostras necessárias para estimar a média com $5 x$ de variação.

\subsubsection{Valores médios das parcelas}

Não foram verificadas diferenças significativas entre as parcelas em nenhum dos períodos de produção de serapilheira (Figura 6) e não foi identificado um padrão definido de variação no espaço, apesar de existir certa proporcionalidade entre os períodos. O coeficiente de correlação entre o $4^{0}$ e $\circ 6^{0}$ período foi de 0,84 e entre o $3^{0}$ e $\circ 6^{0}$ período 0,79 , sendo em geral maior do que 0,5 e sempre significativo a $1 \%$, indicando que pontos que apresentaram registros elevados num período, continuaram 
apresentando registros elevados ao longo do tempo. Como não foi observada uma tendência definida de distribuição espacial dos valores na área como um todo, evidenciado pela diferença não significativa das médias das parcelas, pela elevada variância acumulada no primeiro nível de distância na análise de variância hierarquizada e ausência de estrutura definida dos semivariogramas, acredita-se que a dependência espacial seja de esciala pequena.

\subsubsection{Representação dos valores nos eixos direcionais}

No primeiro período de produção de serapilheira, não foi observada nenhuma tendência definida de variação dos valores em relação aos eixos direcionais (Figura 7). Os valores se distribuíram numa núvem uniforme em torno do valor médio e nenhum valor com desvio muito grande foi observado. o segundo períodos diferiu do primeiro apenas pela ocorrência de um valor anômalo, com elevado desvio positivo.

No terceiro período, o valor anômalo com elevado desvio positivo também ocorreu, e houve uma tendência de ocorrerem valores baixos serapilheira produzida no eixo y acima de $300 \mathrm{~m}$ e no eixo $\mathrm{z}$ em cotas inferiores a $5 \mathrm{~m}$ correspondendo à baixada. A ocorrência de composições florísticas diferentes em distintás posições do relevo foi relatada por SHIAVINI (1992) bem como alteraçñes dos atributos do solo (HAMMER et al., 1987), fatores provavelmente assuciados a estas mudanças. Aspectos relacionados a biologia ou fenologia das espécies predominantes podem estar associados a variações sazonais de prođução de serapilheira. Outra hipótese é a ocorrência de um evento climático extremo, o que parece ser mais provável, pelo fato da tendência não ter se mantido nos demais períodos. No quarto período esta tendência não se manteve, apenas um valor anômalo, com desvio positivo muito grande foi observado. No quinto e sexto períodos novamente apareceram valores com desvios positivos elevados sem que tenha havido uma tendência definida de variação.

A observação da distribuição dos valores não revelou nenhuma tendência bem definida em relação aos eixos x, y e $z$, com aparecimento de poucos valores anômalos com desvio positivo. 


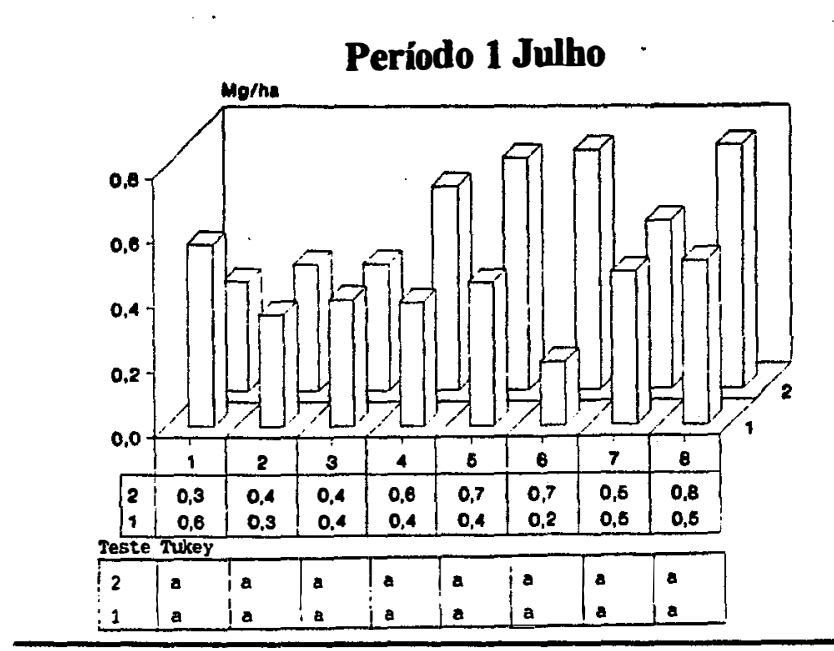

Período 3 Setembro

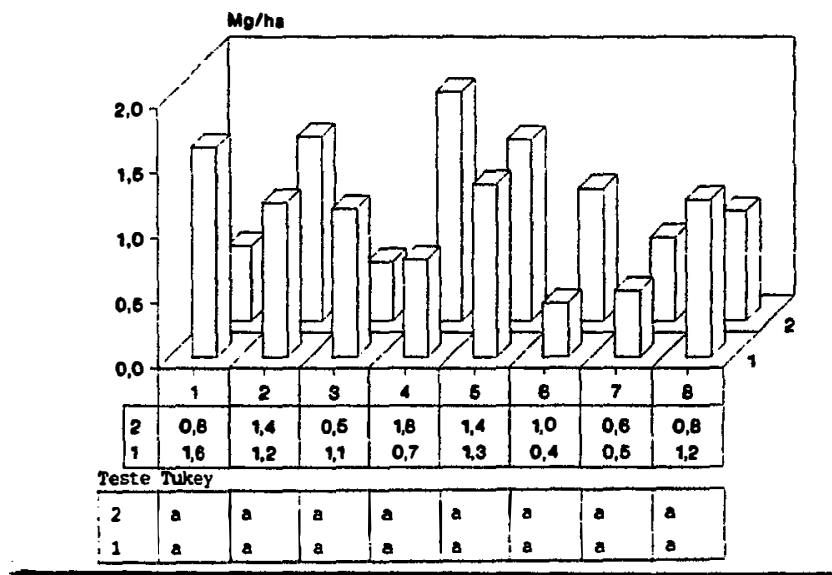

Período 5 Novembro

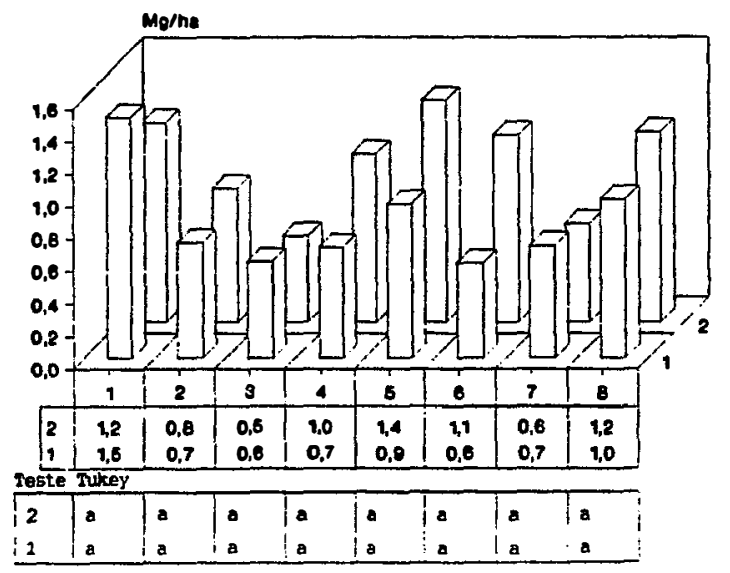

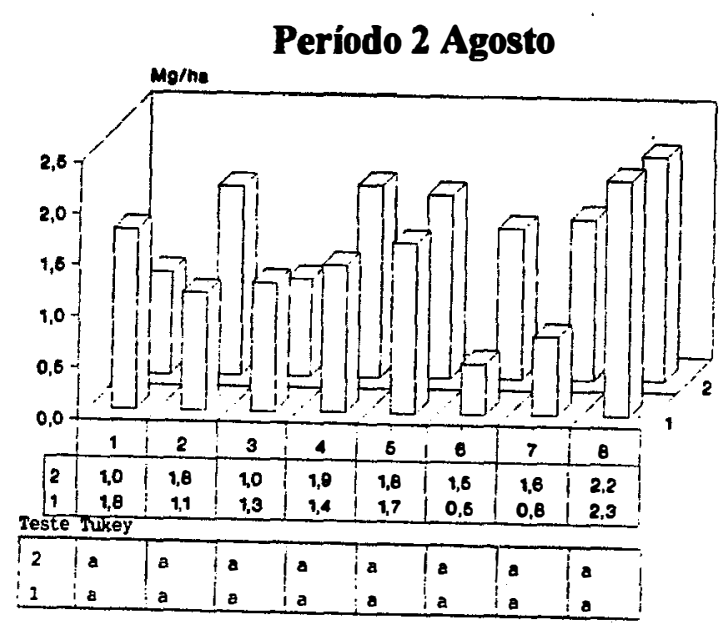

Período 4 Outubro

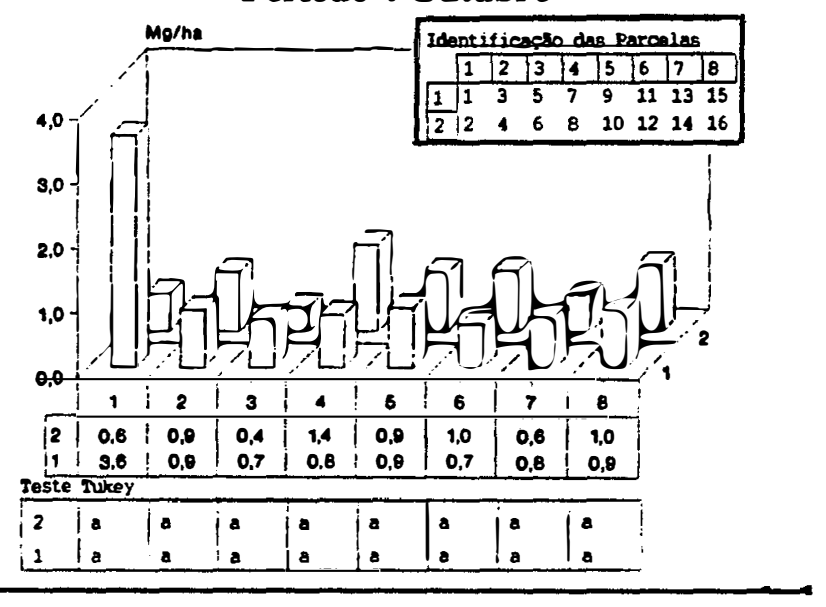

\section{Período 6 Dezembro}

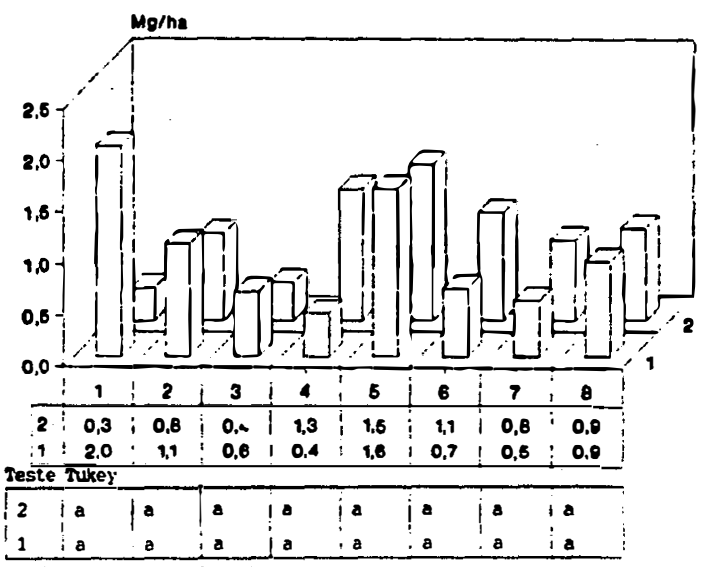

Figura 6 - Valores médios de serapilheira produzida das parcelas (barras) e diferenças significativas (Tukey 5\%) indicadas por letras distintas. 

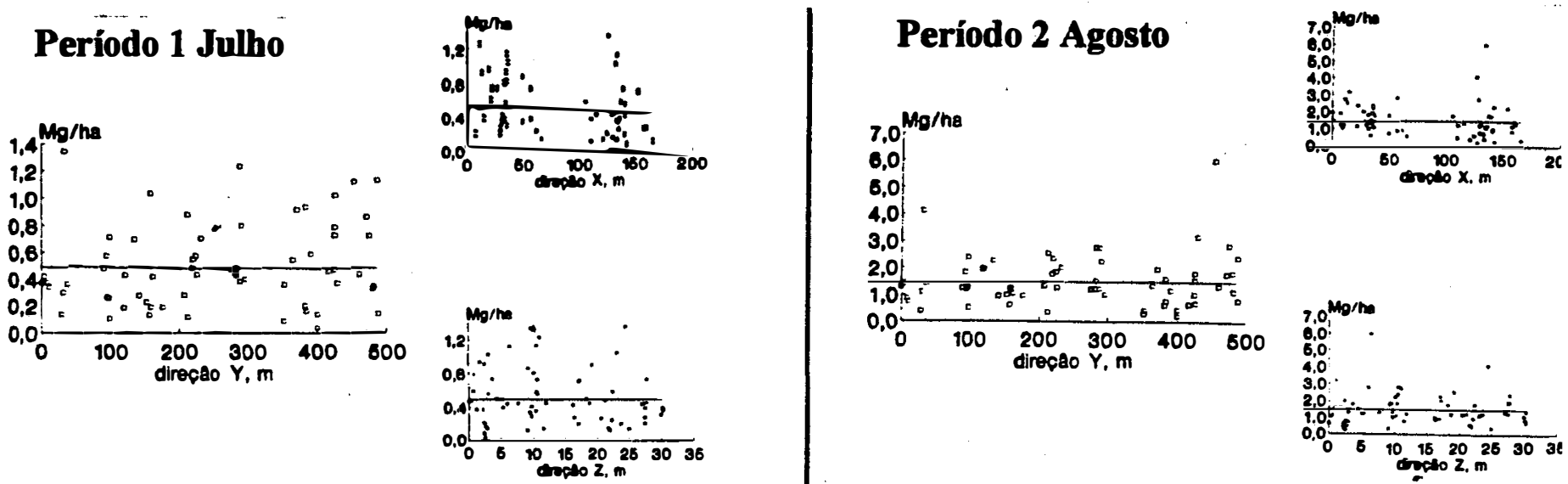

\section{Período 3 Setembro}
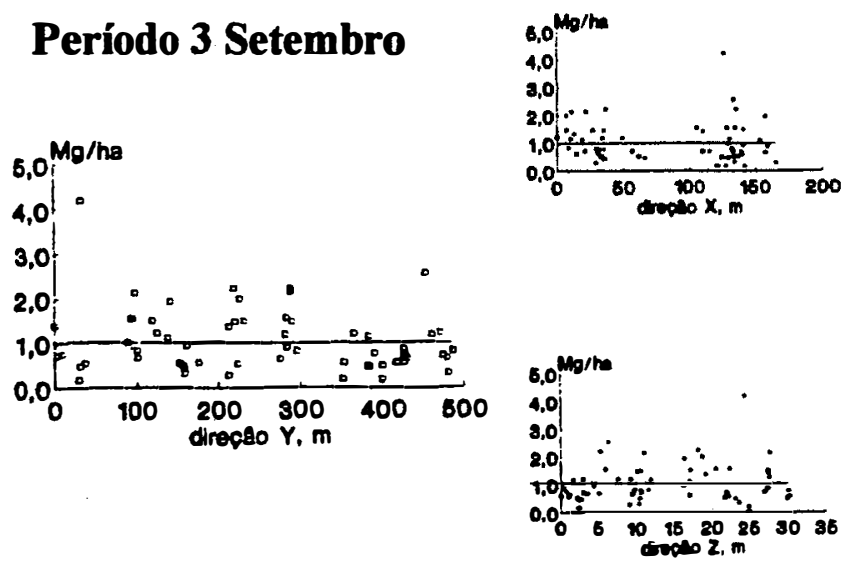

20263036
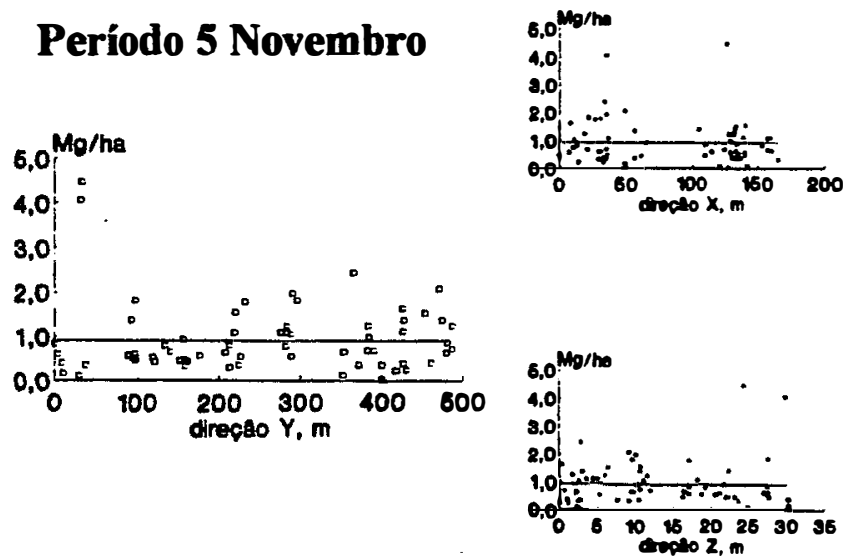
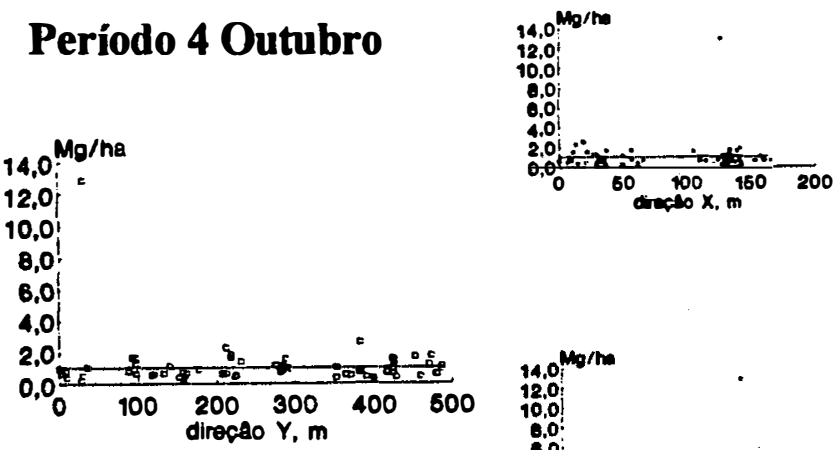

$14.00^{\mathrm{mo} / \mathrm{hm}}$

$12,0:$

(1).

2.0;

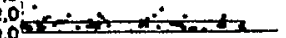

$0 \frac{10 \quad 16202530 \quad 36}{6}$

\section{Período 6 Dezembro}
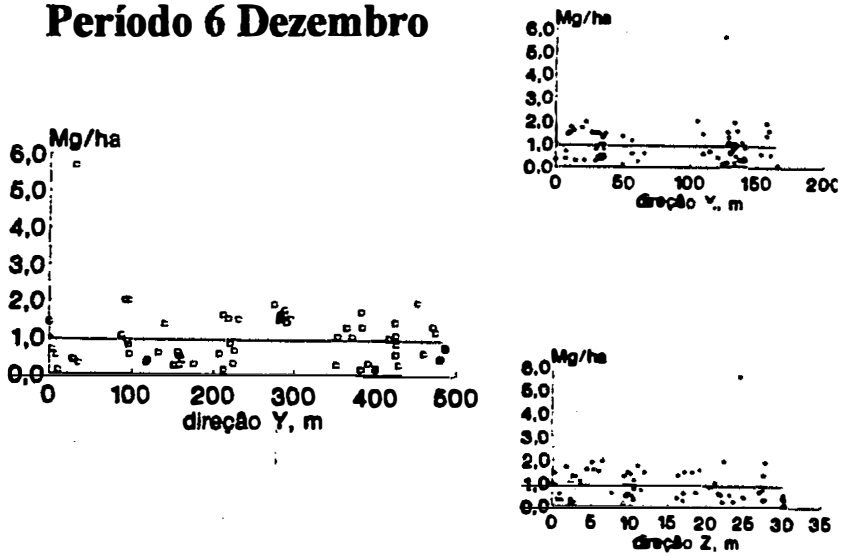

Figura 7 - Representação dos valores de serapilheira produzida (ponto) e da média (linha cheia) em relação aos eixos direcionais. 


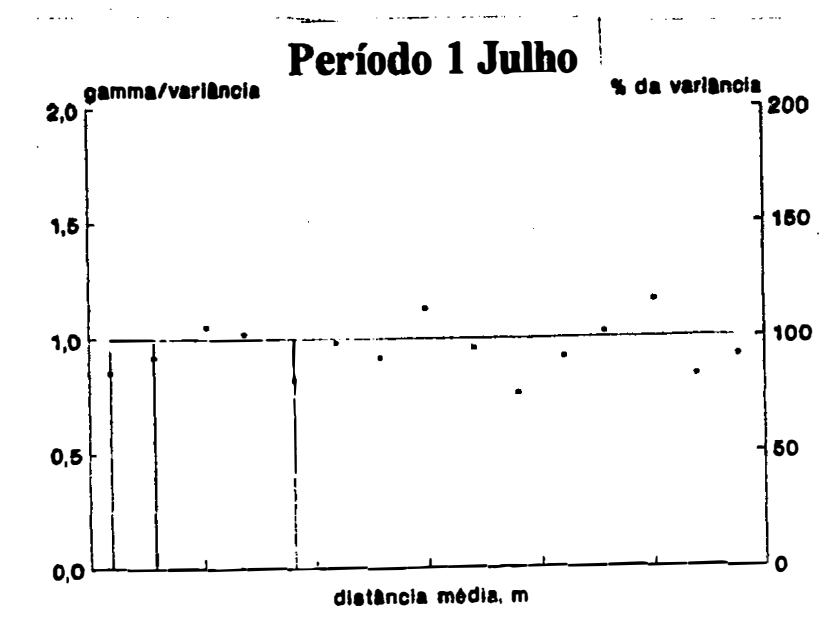

Período 3 Setembro

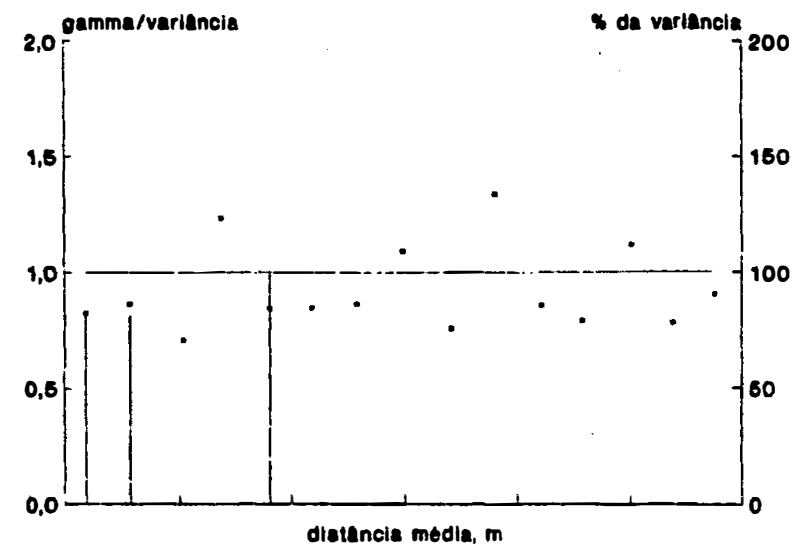

Período 5 Novembro

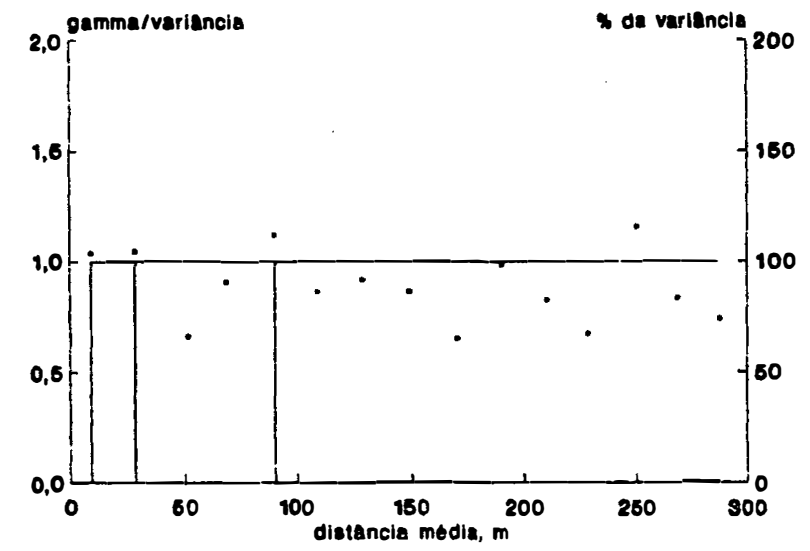

Periodo 2 Agosto

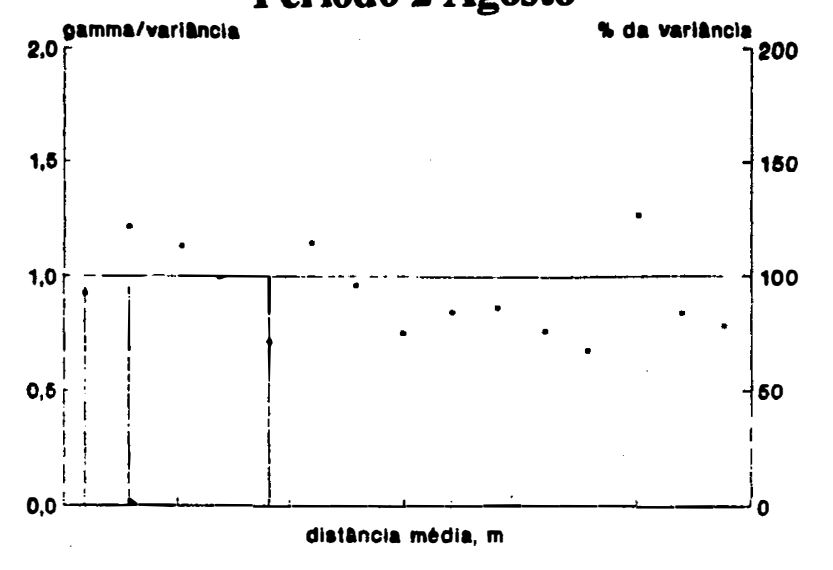

\section{Período 4 Outubro}

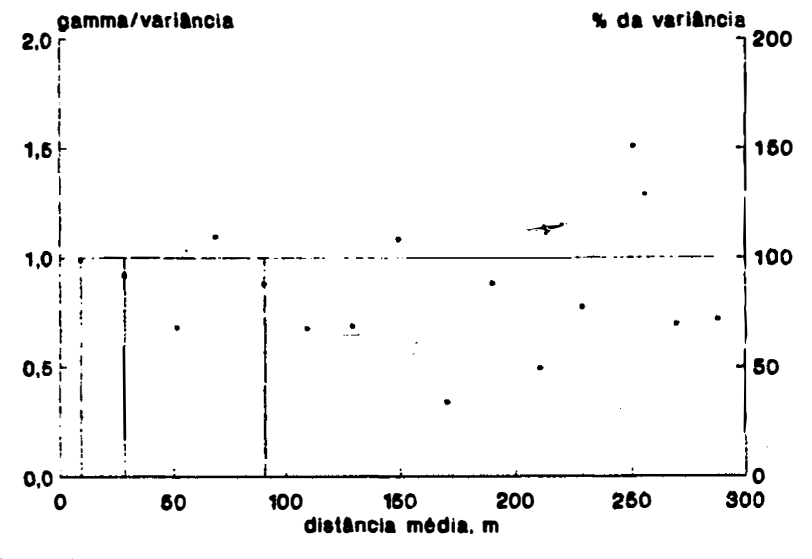

\section{Período 6 Dezembro}

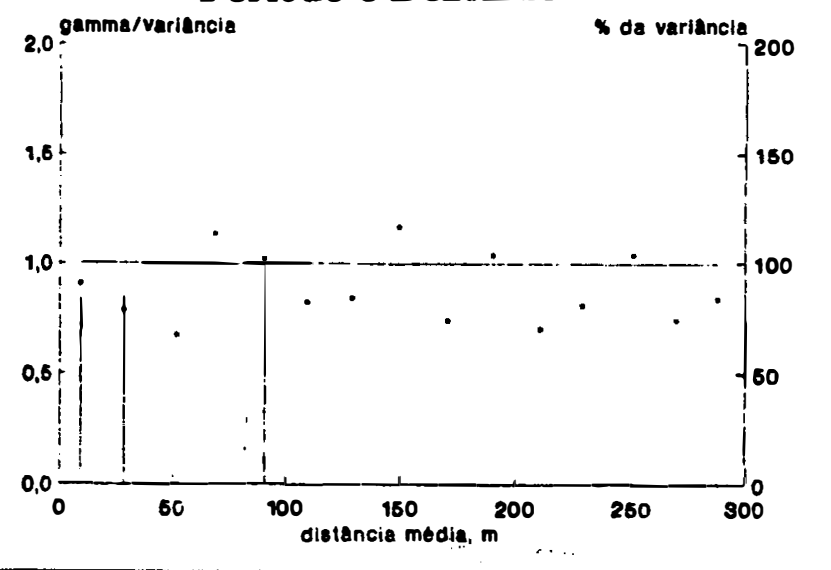

Figura 8 - Semivariância normalizada (pontos) e variância acumulada (linhas verticais) en função da distância da serapi lheira produzida. 


\subsubsection{Semivariograma e análise hierárquica de variância}

Os semivariogramas dos seis períodos de produção de serapilheira e a análise de variância hierárquica não indicaram dependência espacial da variação ou comportamento cíclico (Figura 8). A semivariância normalizada distribuiu-se casualmente em torno de 1 e no nível de $7 \mathrm{~m}$ a variância acumulada foi sempre muito alta.

\subsubsection{Análise global e delineamento recomendado}

Os valores de serapilheira produzida apresentaram elevado coeficiente de variação em todos os períodos, sem tendência definida de distribuição numa escala acima de $7 \mathrm{~m}$. A ausência de diferenças significativas entre parcelas e estrutura de variação dos semivariogramas, a variância em torno de $100 \%$ no nível de distância de $7 \mathrm{~m}$ e a observação dos valores em relação aos eixos, confirmam a afirmação anterior. Entretanto, foram observados elevados coeficientes de correlação entre os períodos de amostragem, indicando que pontos de amostragem que apresentaram um certo valor de produção de serapilheira tendem a apresentar sempre valores semelhantes ou proporcionais. Devido a isto, acredita-se exist ir dependência espacial entre os valores de serapilheira produzida em escala menor do que a escala mínima considerada neste estudo $(7 \mathrm{~m})$. Esta escala, provavelmente, deve ser de poucos metros, comparável a distância entre árvores. Uma determinada árvore provavelmente produz serapilheira de forma diferente de outra, sendo a maior parte da variância concentrada nesta escala. A deposição localizada de matéria orgânica também foi observada por HARVEY et al. (1985) e utilizada para explicar as variações do teor de matéria orgânica do solo após a derrubada da floresta.

Dessa forma, a determinação da produção de serapi lheira da área como um todo não precisa considerar a posição das observações. Os coletores devem ser distribuídos ao acaso na área. Como o coeficiente de variação foi muito elevado, deve-se procurar trabalhar com o maior número possível de coletores. A redistribuição periódica dos coletores, por exemplo, uma vez por semana no caso de registros mensais, pode reduzir o efeito da dependência espacial a curta distância. Essa redistribuição casual dentro 
da área não precisa ser a grande distância, bastando deslocar o coletor de poucos metros. Coletores portáteis e leves que podem ser montados no próprio local facilitam esse trabalho.

\subsection{Precipitação interna}

\subsubsection{Estatística descritiva}

$\mathrm{Na}$ Tabela 5 estão representados os valores médios e intervalos de confiança, o coeficiente de variação, o ajuste a distribuição normal e lognormal e o número de amostras necessárias para se obter uma variação na média de 10 e $5 \%$ para os dez eventos de precipitação interna registrados.

O volume da precipitação interna variou bastante nos diferentes eventos. o valor mínimo com média de $4,1 \mathrm{~mm}$ foi observado no segundo evento em $4 / 9 / 89$ e o máximo com média de $214,4 \mathrm{~mm}$ no último evento em $3 / 1 / 90$. O coeficiente de variação variou de 22 a $49 \%$ sendo seu valor médio de $35 \%$. O erro padrão da média foi de 5 a $12 \%$ com média de $8,7 \%$, sendo este, menor do que o observado por JACKSON (1971) numa floresta da Tanzânia. O erro padrão da média, est imado pela equação proposta por LLOYD \& MARQUES (1988) para 64 coletores em posição fixa é $8,3 \%$, valor muito próximo do observado, 8,7\%. O coeficiente de variação encontrado por DUIJSINGS et al . (1986) numa floresta homogênea em clima temperado foi de $15 \%$, um pouco menos da metade do encontrado neste estudo. Contudo o coeficiente de variação observado foi, na sua ordem de grandeza semelhante aos valores normalmente encontrados na literatura para florestas tropicais.

Apenas o segundo e os últimos dois eventos apresentaram ajuste a distribuição normal. Com relação à distribuição lognormal, os eventos de 4/10/89, 13/11/89 e 3/1/90 apresentaram ajuste significativo. O número de amostras necessárias para estimar a média com variação de $10 \%$ foi de 13

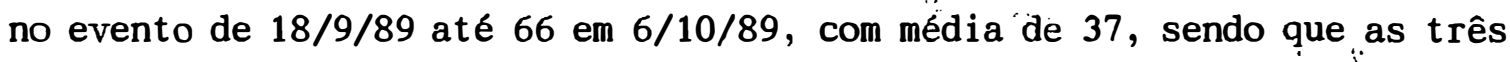
maiores precipitações apresentaram os menores números de coletores necessários, contrariando as observações de JACKSON (1971). Os valores encontrados para o número de coletores necessários foram maiores do que 
os recomendados por DUIJSINGS et al. (1986) para uma floresta homogênea de clima temperado.

\subsubsection{Valores médios das parcelas.}

Apenas em dois eventos foram observados diferenças significativas entre as médias das parcelas (Figura 9). No evento de 4/9/89 a parcela 6 apresentou o maior valor e sua vizinha, a parcela 8 , o menor. No evento seguinte, de 18/09/89, a mesma tendência se repete, isto $e$, o maior valor de precipitação ocorreu na parcela 6 e o menor na parcela 8 bem como a tendência geral de variação das outras parcelas nestes dois eventos foi semel hante. Nos out ros eventos não houve variação significativa das médias e não foi possível identificar uma tendência muito definida de variação. A correlação entre os diferentes eventos, na maior parte dos casos, foi pouco significativa. Em apenas 13 das 45 combinações possíveis entre os eventos o coeficiente de correlação foi acima de 0,5.

\subsubsection{Representação dos valores nos eixos direcionais}

No primeiro evento (Figura 10), em 28/8/89, observou-se que diversos valores se concentraram muito próximos da média. Os valores com desvio maior em relação à média distribuíram-se casualmente e os desvios negativos foram mais freqüentes. No evento de 4/9/89, 4/10/89, 15/12/89 e 3/1/89 nenhuma tendência definida de variação foi observada em relação aos eixos $x, y$ ou $z$. No evento de 18/9/89 a dispersão dos valores foi maior no eixo y com valores inferiores a $350 \mathrm{~m}$ ou nas cotas mais altas de z. Nos eventos de $13 / 11 / 89,22 / 11 / 89,28 / 11 / 89$ e 6/11/89 aparece um valor anômalo, com desvio positivo grande e repetiu-se em alguns casos a menor dispersão dos valores nas cotas baixas. Dessa forma, parece haver um controle sobre a variação da precipitação interna associado à posição no relevo, entretanto, as variações a curta distância também são expressivas é casuais, dificultando assim isolar causas especificas de variação. Uma provável distribuição distinta das espécies nas diferentes posições do relevo ou alterações na arquitetura do dossel causem estas variações. 
Tabela 5 - Valores médios e intervalos de confiança, coeficiente de variação, ajuste à distribuição da normal e lognormal e número de amostras necessárias para se obter uma variação na média de 10 e $5 \%$ para os dez eventos de precipitação interna registrados.

\begin{tabular}{|c|c|c|c|c|c|c|c|c|c|}
\hline $\begin{array}{l}\text { Evento } \\
\mathrm{d} / \mathrm{m} / \mathrm{a}\end{array}$ & média & $\underset{\mathrm{mm}}{\lim . \mathrm{inf} .}$ & $1 \mathrm{im.sup.}$ & $\begin{array}{l}\text { cv } \\
\%\end{array}$ & $\begin{array}{l}\mathrm{x}^{2} \\
\mathrm{~N}\end{array}$ & $\begin{array}{l}\mathrm{x}^{2} \\
\mathrm{LN}\end{array}$ & $\begin{array}{l}\text { Mo } \\
\text { a/c }\end{array}$ & $\begin{array}{l}\mathrm{n}^{\circ} \\
0,1\end{array}$ & $\begin{array}{l}n^{\circ} \\
0,05\end{array}$ \\
\hline $28 / 8 / 89$ & 25,5 & 23,2 & 27,8 & 37 & ns & ns & ns & 37 & 53 \\
\hline 4/9/89 & 4,1 & 3,7 & 4,5 & 39 & * & ns & * & 43 & 62 \\
\hline $18 / 9 / 89$ & 80,4 & 76,1 & 84,8 & 22 & ns & ns & ns & 13 & 19 \\
\hline $4 / 10 / 89$ & 31,1 & 28,5 & 33,7 & 34 & ns & * & ns & 33 & 47 \\
\hline $6 / 11 / 89$ & 36,9 & 32,5 & 41,3 & 49 & ns & ns & ns & 66 & 95 \\
\hline $13 / 11 / 89$ & 61,3 & 55,7 & 66,9 & 37 & ns & * & ns & 39 & 55 \\
\hline $22 / 11 / 89$ & 73,9 & 65,9 & 82,0 & 44 & ns & ns & ns & 55 & 79 \\
\hline $28 / 11 / 89$ & 39,8 & 36,4 & 43,2 & 35 & ns & ns & ns & 34 & 48 \\
\hline $15 / 12 / 89$ & 192,8 & 179,4 & 206,1 & 28 & * & ns & $*$ & 22 & 32 \\
\hline $3 / 1 / 90$ & 214,4 & 199,2 & 229,5 & 29 & $*$ & * & * & 23 & 33 \\
\hline
\end{tabular}

$\bar{d} / \mathrm{a} / \mathrm{a}=\mathrm{data}$ do evento dia/mês/ano

lim. inf.=linite inferior da nédia con intervalo de confiança (ic) de 95\%; li . sup.=linite superior da nédia (ic=95\%); cr=coeficiente de variação; $x^{2} N=$ teste chi quadrado para distribuiçăo norasl; $x^{2}$ LN=teste chi quadrado para distribuição lognornal; No a/c= ajuste à distribuição noral pelo aétodo dos monentos (assinetria e cortose); $n^{\circ} 0,1=$ número de amostras necessárias para estinar a aédia con 10\% de variação; $a^{0} 0,05=$ nínero de anostras necessárias para estinar a aédia con $5 \%$ de variação. 
4.2.4 Semivariograma e análise hierárquica de variância

Apenas os semivariogramas dos eventos de 4/9/89 e 18/9/89 apresentaram alguma estrutura na distribuição da variância (Figura 11). Entretanto, o ajuste de uma equação esférica aos dados apresentou coeficientes de determinação baixo, 0,33 para o evento de 4/9/89 e 0,26 para o de 18/9. Apesar de ter sido pouco significativo, o alcance no primeiro evento foi de $52 \mathrm{~m}$ e no segundo $91 \mathrm{~m}$, ambos com elevado efeito pepita. Os valores de variância acumulada da análise de variância hierárquica acompanharam a a tendência dos semivariogramas. Nos outros eventos a semivariância e a análise de variância hierárquica apresentaram valores flutuando em torno de 1 no primeiro caso e próximos a $100 \%$ no segundo mesmo nos níveis de distância pequenos.

\subsubsection{Análise global e del ineamento recomendado}

o número médio de registros de precipitação interna para estimar a média com $10 \%$ de variação foi de 37 . Este valor tendeu a ser menor com o aumento da intensidade da precipitação. A análise de variância das parcelas não indicou nenhuma tendência muito expressiva, entretanto, a observação dos valores em relação à posição nos eixos $x, y$ e $z$ mostrou que nas posições mais baixas a variação dos valores de precipitação interna foi menor. Os semivariogramas e a análise de variância hierarquizada indicaram pouca dependência espacial, mas nos dois eventos em que foi possível ajustar um modelo esférico, o alcance médio foi de $72 \mathrm{~m}$ e os coeficientes de correlação entre os eventos foram pouco significativos.

Assim, houve uma fraca associação entre os valores de precipitação interna e a posição no relevo verificada pela observação dos valores e por um alcance pouco significativo dos semivariogramas em distâncias maiores, com grande predomínio uma distribuição uniforme da variância na área. Dessa forma, para quant ificar a precipitação interna na área de estudo são necessários algo em torno de 40 coletores distribuídos casualmente na área sem necessidade de redistribuição periódica, registrando-se apenas sua posição no relevo. 


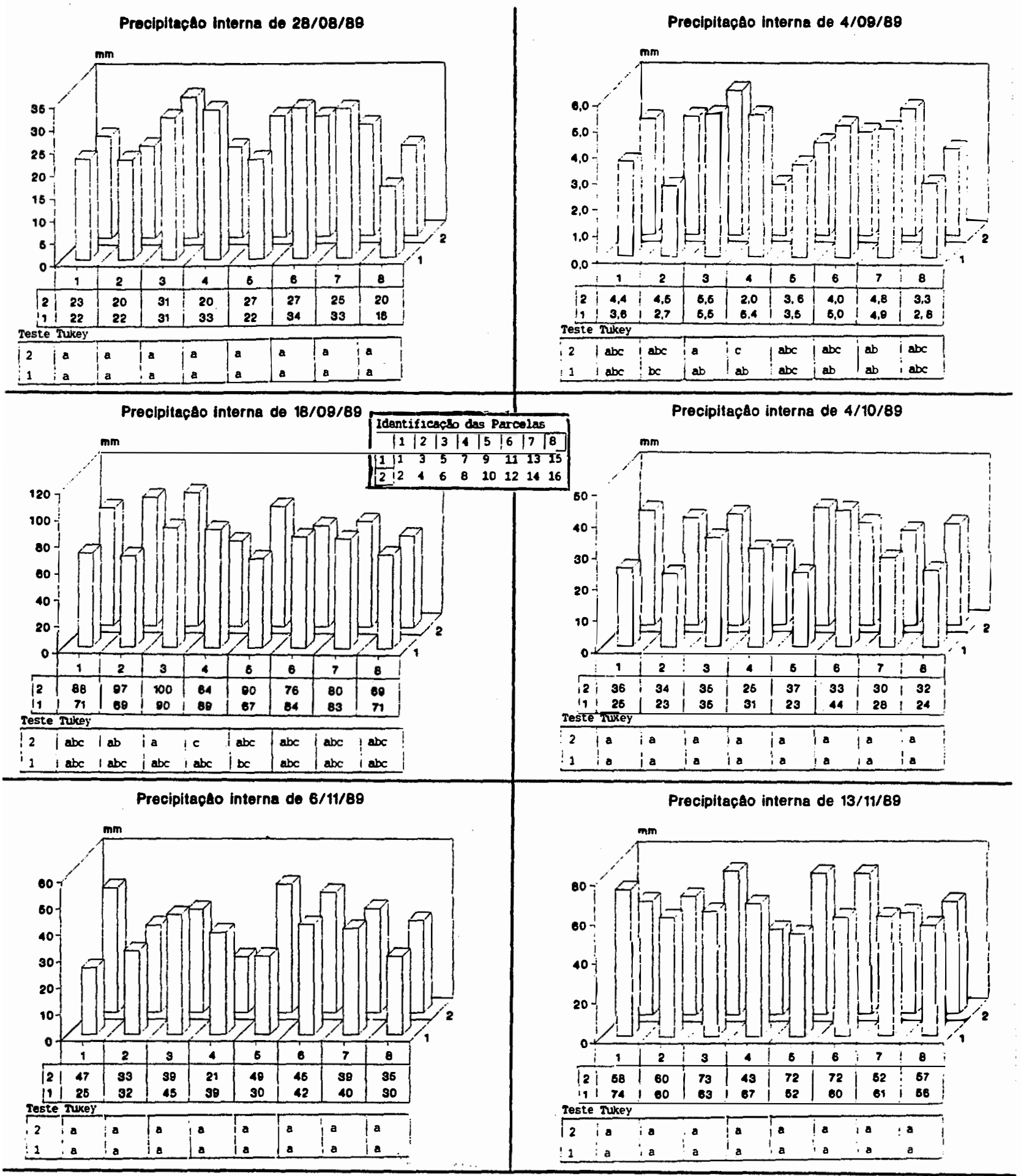

Figura 9 - Valores médios de precipitação interna (barras) e diferenças significativas (Tukey $5 \%$ ) indicadas por letras distintas. 


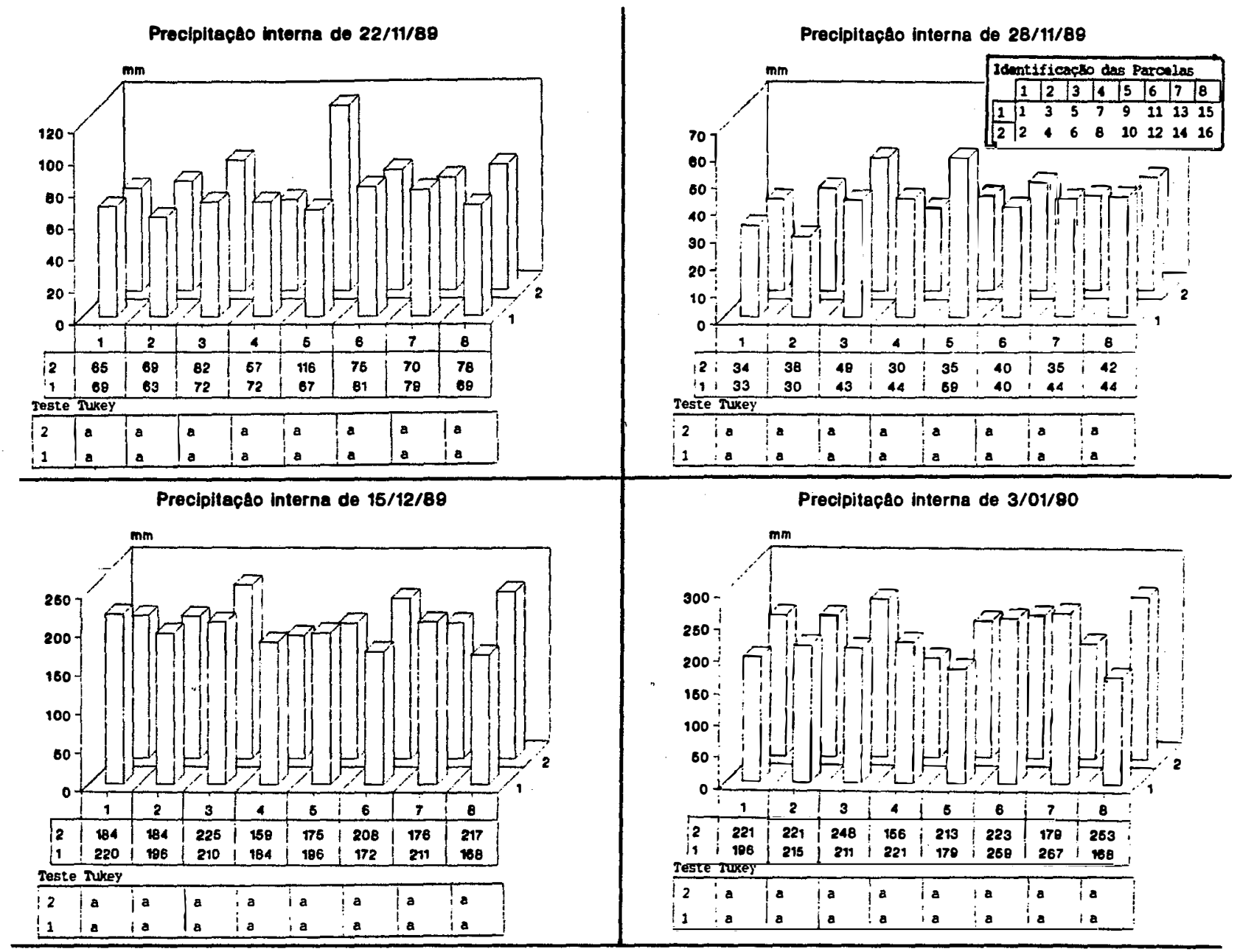

Figura 9 - cont inuação 

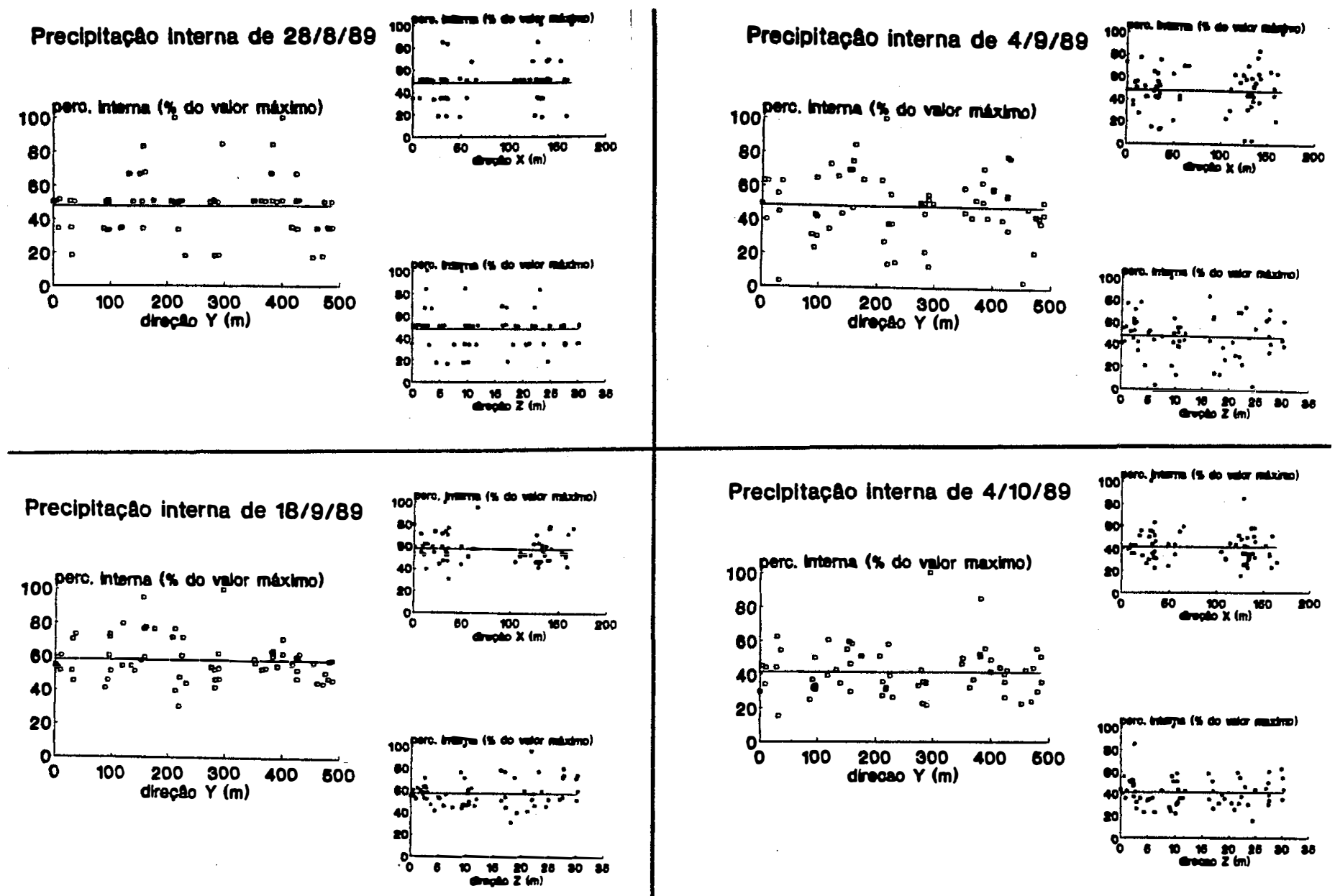

Preclpltacao interna de $4 / 10 / 89$
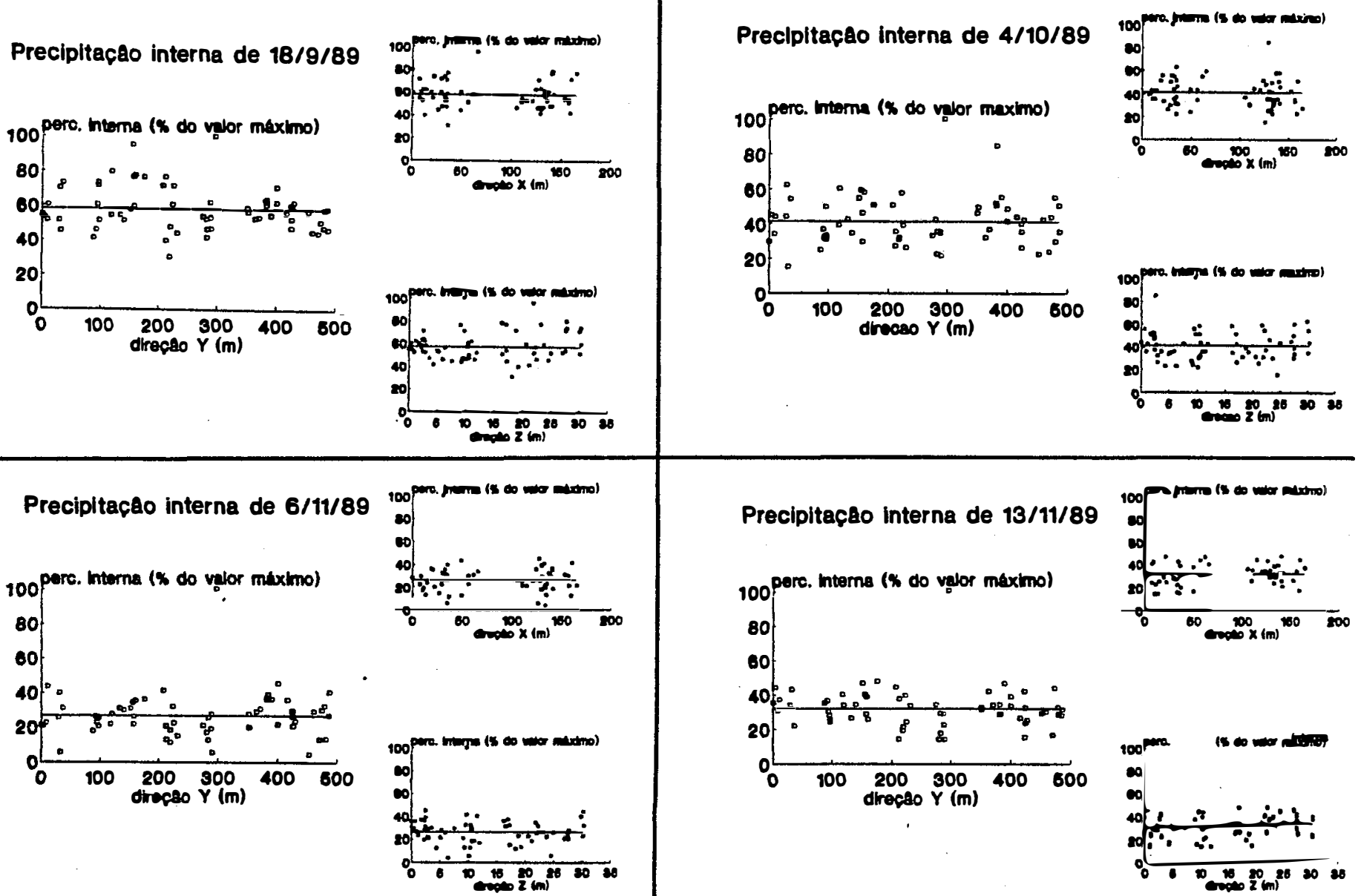

Precipitaço interna de $13 / 11 / 89$
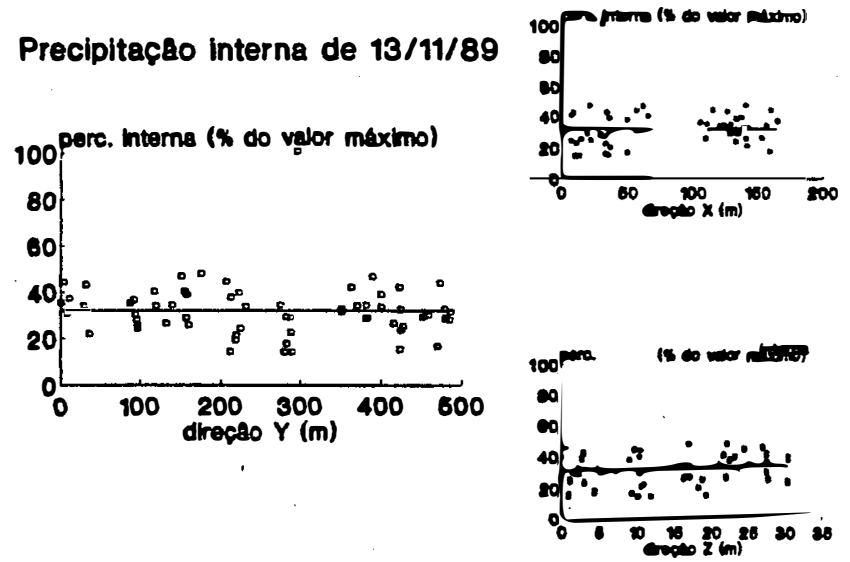

Figura 10 - Representação dos valores de precipitação interna (pontos) e da média (linha cheia) em relação aos eixos. 


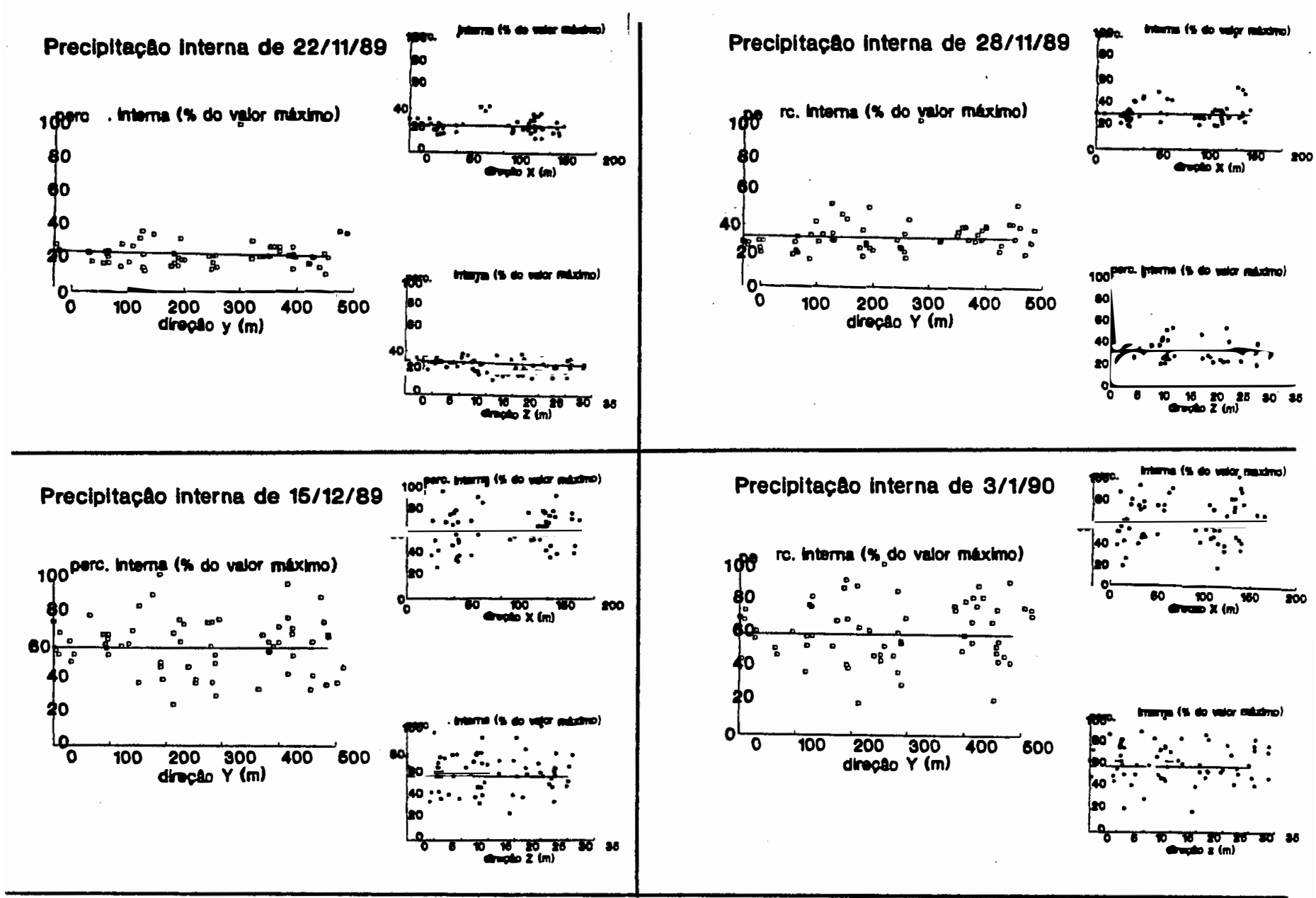

Figura 10 - continuação 


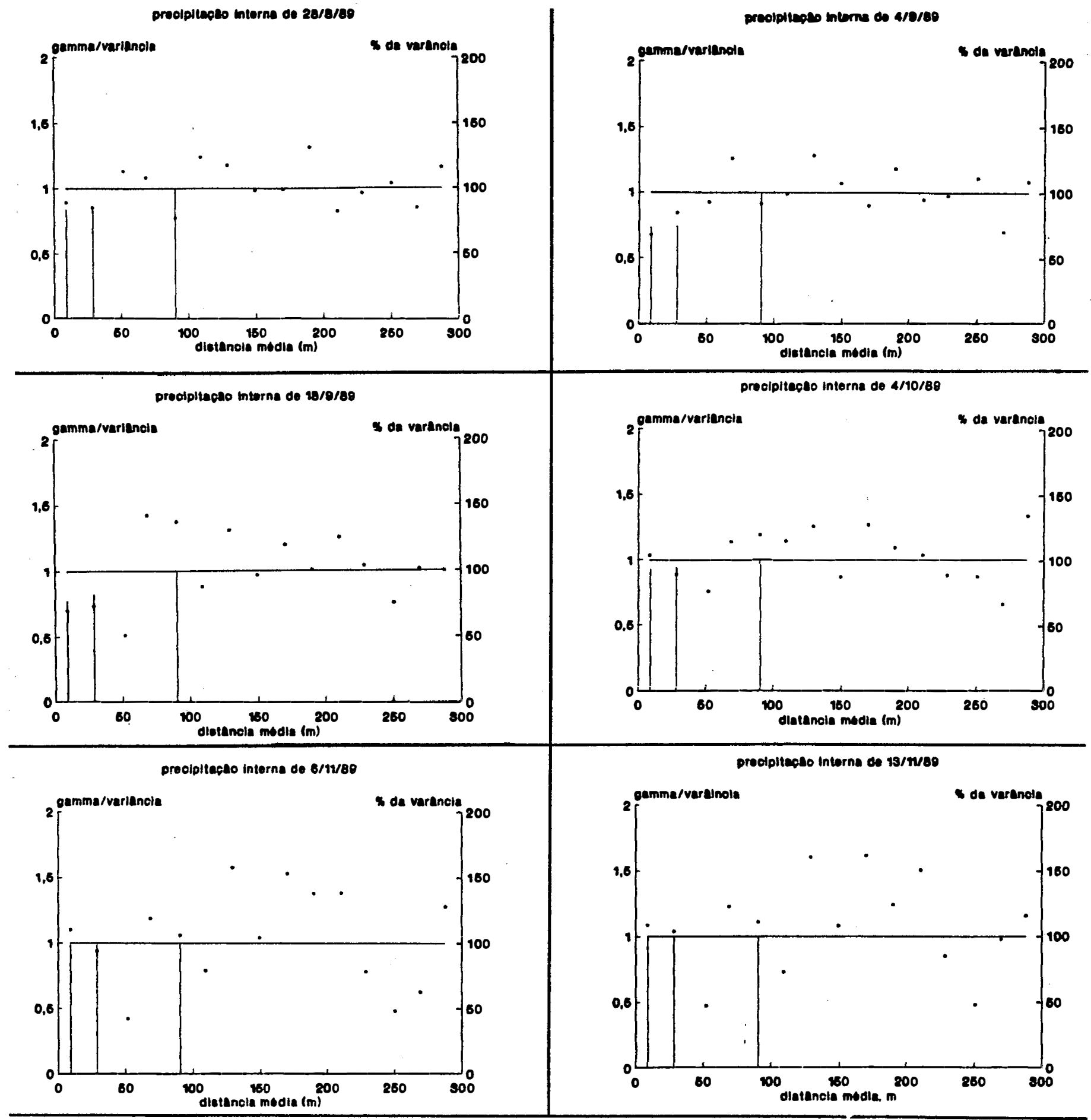

Figura 11 - Semivariância normalizada (pontos) e variância acumulada ( 1 inhas verticais) em função da distância da precipi tação interna. 


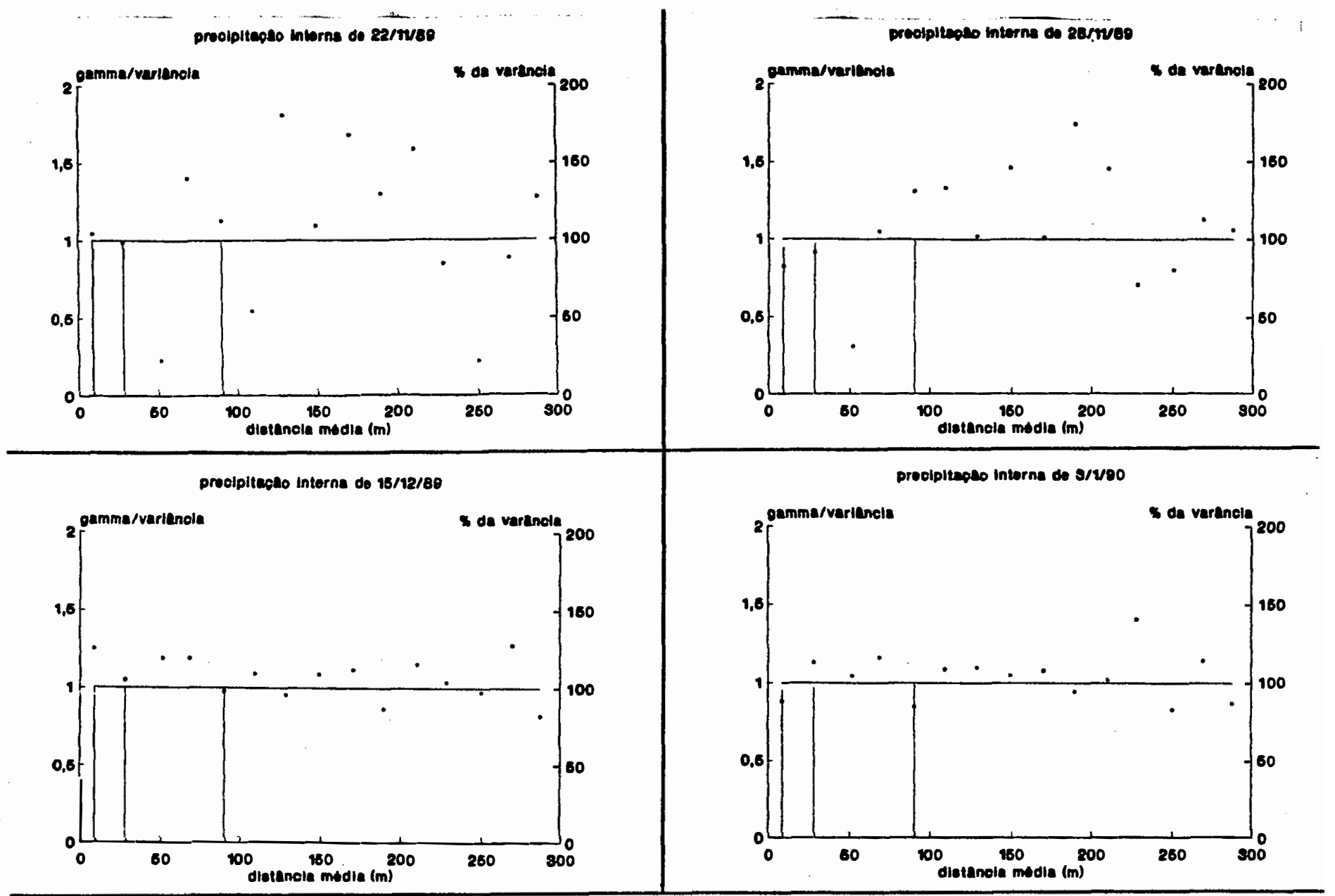

Figura 11 - cont inuação 


\subsection{Serapilheira acualada sobre o solo}

\subsubsection{Estatística descritiva}

Na Tabela 6 estão representados os valores médios e intervalos de confiança, o coeficiente de variação, o ajuste à distribuição normal e lognormal e o número de amostras necessárias para se obter uma variação na média de 10 e $5 \%$ da quantidade de serapilheira fina e grossa acumulada e dos teores e quantidades totais de $\mathrm{Ca}, \mathrm{Mg}, \mathrm{K}, \mathrm{N}, \mathrm{P}$ e $\mathrm{S}$ nessas duas frações.

A quantidade média de serapilheira grossa acumulada foi maior do que a da fração fina. Os coeficientes de variação para a quantidade de serapilheira acumulada foram altos, ficando acima de $67 \%$ para todas as frações e o melhor ajuste à distribuição de frequências foi lognormal. PAGANO (1985) determinou quantidades bem menores de serapi lheira acumulada com coeficiente de variação também menor numa mata mesófila semidecídua de Rio Claro (SP).

Os teores de todos os nutrientes avaliados foram semelhantes nas frações fina e grossa, não sendo necessário dessa forma analisá-los separadamente. Os coeficientes de variação dos teores dos elementos foram mais baixos do que os da quantidade total de serapilheira acumulada bem como da quantidade total dos elementos contidos nela. 0 ajuste se deu melhor à distribuição normal e o número de amostras necessárias para estimar a média com $10 \%$ de variação foi máximo para o teor de Ca na fração fina (67 amostras) e mínimo para o teor de $\mathrm{N}$ na fração grossa (6 amostras). As quantidades totais de nutrientes apresentaram coeficientes de variação muito elevados e se ajustaram melhor à distribuição lognormal.

ARP \& KRAUSE (1984) também observaram que o coeficiente de variação de teores de elementos foi mais baixo do que da sua quantidade total na serapilheira acumulada numa floresta mista do Canadá. Os coeficientes de variação observados para os teores de $\mathrm{Ca}, \mathrm{Mg}, \mathrm{K}, \mathrm{N}$ e $\mathrm{P}$ foram muito semelhantes aos observados neste trabalho. Os coeficientes de variação para a quantidade total dos elementos e quantidade de serapilheira acumulada no entanto foram mais baixos. Os autores também constataram que 
os teores dos elementos e sua quantidade total não apresentam ajuste à distribuição normal. BUNZL \& SCHIMMACK (1989) estudaram a variabilidade do coeficiente de distribuição que é a relação entre o teor do elemento adsorvido no material seco e em solução de vários lons inorgânicos na serapilheira acumulada numa floresta de Pinus no sul da Alemanha e observaram intervalos de confiança para a média semelhantes aos encontrados neste estudo. A variância da quantidade total de serapilheira acumulada, no entanto, foi bem menor. A distribuição de frequências do coeficiente de distribuição da maioria dos elementos estudados foi lognormal.

Assim, o número de amostras necessárias para determinar o teor dos elementos contidos na serapi heira acumulada com certa variação foi bem menor do que a necessidade de amostras para determinar a sua quantidade total ou a quantidade total dos elementos contidos nela.

\subsubsection{Valores nédios das parcelas.}

Os valores médios das parcelas da fração grossa e total de serapilheira acumulada não apresentaram diferenças significativas entre si (Figura 12). A fração fina apresentou diferenças significativas entre valores médios tendo sido o valor máximo observado na parcela 12 e o mínimo na parcela 4. Com exceção desses valores extremos, os valores intermediários se igualam entre si.

Os teores dos elementos $\mathrm{Ca}, \mathrm{Mg}, \mathrm{K}, \mathrm{N}$ e $\mathrm{S}$ não apresentaram diferenças significativas entre as parcelas na fração fina. Os teores de $\mathrm{Ca}, \mathrm{Mg}, \mathrm{K}$, $P$ e S na fração grossa e $P$ na fração fina, apresentaram diferenças significativas entre parcelas. Entretanto, não houve uma coincidência nessas diferenças, isto $e$, as parcelas que apresentaram os maiores teores de Ca não foram as mesmas que apresentaram os maiores teores de $\mathrm{Mg}$ e $\mathrm{K}$. As parcelas também não apresentaram diferenças significativas quanto aos teores totais dos elementos. 
Tabela 6 - Valores médios e intervalos de confiança, coeficiente de variação, ajuste à distribuição normal e lognormal e número de amostras necessárias para se obter uma variação na média de 10 e $5 \%$ da quantidade de serapilheira fina e grossa e dos teores e quantidades totais de $\mathrm{Ca}, \mathrm{Mg}$, $K, N, P$ e $S$ nessas duas frações.

\begin{tabular}{|c|c|c|c|c|c|c|c|c|c|}
\hline Parâmetro & média & lim.inf. & $1 \mathrm{im.sup.}$ & $\begin{array}{l}\text { cv } \\
\%\end{array}$ & $\begin{array}{l}\mathrm{x}^{2} \\
\mathrm{~N}\end{array}$ & $\begin{array}{l}x^{2} \\
L N\end{array}$ & $\begin{array}{l}\text { Mo } \\
\text { a/c }\end{array}$ & $\begin{array}{l}n^{\circ} \\
0,1\end{array}$ & $\begin{array}{l}\mathrm{n}^{\circ} \\
0,05\end{array}$ \\
\hline $\mathbf{F}$ & 5,9 & 4,8 & 7,1 & 81 & ns & $*$ & ns & 184 & 264 \\
\hline G & 9,0 & 7,5 & 10,5 & 69 & ns & ns & ns & 131 & 188 \\
\hline $\mathbf{T}$ & 15,0 & 12,5 & 17,4 & 67 & ns & $*$ & ns & 127 & 182 \\
\hline CaG & 2,48 & 2,35 & 2,61 & 21 & $*$ & $*$ & ns & 12 & 18 \\
\hline $\mathrm{CaF}$ & 1,25 & 1,10 & 1,40 & 49 & $*$ & ns & $*$ & 67 & 95 \\
\hline MgG & 0,25 & 0,23 & 0,26 & 21 & ns & ns & $*$ & 12 & 17 \\
\hline $\mathrm{MgF}$ & 0,16 & 0,15 & 0,17 & 35 & ns & ns & $*$ & 34 & 49 \\
\hline KG & 0,21 & 0,19 & 0,23 & 40 & ns & ns & ns & 45 & 65 \\
\hline $\mathbf{K F}$ & 0,12 & 0,11 & 0,13 & 34 & ns & ns & ns & 33 & 47 \\
\hline NG & 1,82 & 1,76 & 1,88 & 14 & ns & ns & ns & 6 & 8 \\
\hline NF & 1,24 & 1,14 & 1,35 & 36 & * & ns & ns & 35 & 51 \\
\hline PG & 0,07 & 0,06 & 0,07 & 26 & ns & ns & ns & 19 & 27 \\
\hline PF & 0,06 & 0,05 & 0,06 & 47 & ns & ns & $*$ & 62 & 89 \\
\hline SG & 0,98 & 0,94 & 1,03 & 20 & ns & ns & $*$ & 11 & 16 \\
\hline SF & 1,08 & 1,02 & 1,14 & 22 & * & ns & ns & 13 & 19 \\
\hline $\mathrm{CaT}$ & 309 & 249 & 368 & 79 & ns & * & ns & 173 & 249 \\
\hline MgT & 32 & 25 & 37 & 78 & ns & ns & ns & 170 & 244 \\
\hline KT & 27 & 18 & 37 & 142 & ns & * & ns & 560 & 803 \\
\hline NT & 241 & 198 & 283 & 71 & ns & ns & ns & 142 & 204 \\
\hline PT & 9,5 & 7,6 & 11,4 & 82 & ns & ns & ns & 186 & 267 \\
\hline ST & 15,2 & 12,8 & 17,5 & 62 & ns & ns & ns & 109 & 156 \\
\hline
\end{tabular}

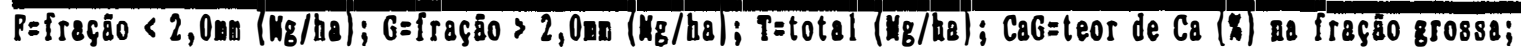

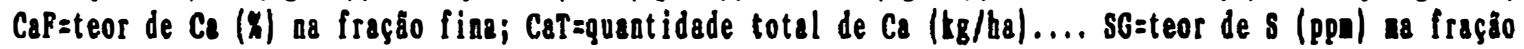
gros8a; SPateor de $S$ (PPa) as fração fina; $S T=q u a n t i d a d e$ total de $S(g /$ ha).

lin. inf.=linite inferior da aédia con intervalo de confianç (ic) de $95 \%$; lin. sup. =linite superior da aédia (ic=95X); cr=coeficiente de variação; $\mathbf{x}^{2} \mathrm{~N}=$ teste chi quadrado para distribuiçlo normal; $\mathbf{z}^{2}$ LH=teste chi quadsado para distribujção lognornal; No a/c= ajuste à distribuição normal pelo aétodo doš noantos (assiaetria e curtosel; $a^{\circ} 0,1=n$ beero de anostras aecessárias para estinar a nédia con los de variaçâo; $n^{\circ} 0,05=n$ anero de anostras necessárias para estiarar a aedia con $5 x$ de variação. 


\subsubsection{Representaçăo dos valores nos eixos direclonais.}

A quantidade total de serapilheira acumulada não apresentou uma tendência muito definida de variação em relação aos eixos direcionais (Figura 13). Observou-se apenas a ocorrência de valores anômalos com desvio positivo muito grande, nos valores de y em torno de $380 \mathrm{~m}$. Com relação aos teores de $\mathrm{Ca}$, Mg $\mathrm{K}$ observou-se o mesmo, isto é, pouca ou nenhuma tendência de distribuição definida na área, bem como na quantidade total de $S$ e no teor de $S$ na fração fina. O teor de $S$ na fração grossa apresentou valores mais elevados com valores de y até $120 \mathrm{~m}$, distribuindose uniformemente em torno da média acima desse valor. A quantidade total de $P$ não apresentou tendência definida de variação mas os teores de $P$ na fração fina e grossa apresentaram-se mais elevados na região de y acima de $350 \mathrm{~m}$ o que corresponde às cotas mais baixas de $\mathrm{z}$.

A observação dos valores indicou que a distribuição da maior parte dos valores não apresentou uma tendência facilmente ident ificável. Entretanto, os teores de alguns elementos, principalmente o $\mathrm{P}$ e o $\mathrm{S}$ ao contrário dos demais apresentaram tendências definidas de distribuição espacial, confirmada nos semivariogramas, e relacionada a intervalos de distância maiores, comparável à posição no relevo. A grande importância do $P$ na ciclagem de nutrientes em florestas, amplamente discutida por GOLLEY et al. (1978), justificam que especial atenção deva ser dispensada para este elemento.

A simples observação da distribuição espacial da quantidade total da serapilheira acumulada permitiu num remanescente de vegetação natural às margens do Rio Passa Cinco em Ipeúna (SP) a RODRIGUES (1991) explicar a ocorrência de determinados solos e espécies vegetais na área, auxiliando sobremaneira a compreensão das relações edáficas e floríst icas existentes. 


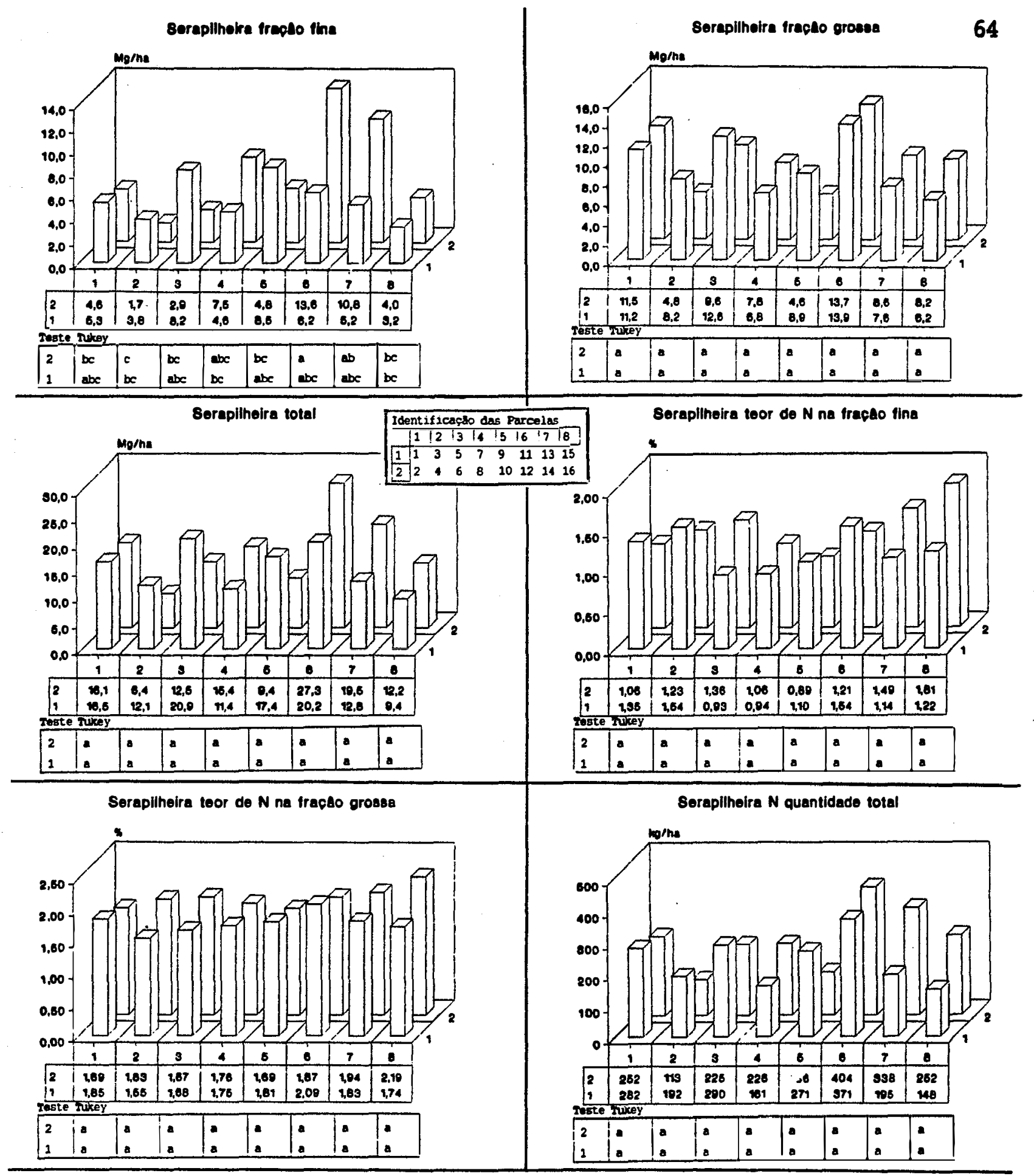

Figura 12 - Valores médios da quantidade de serapilheira acumulada, nutrientes contidos nela e seus teores (barras) e diferenças significativas (Tukey 5\%) indicadas por letras distintas. 

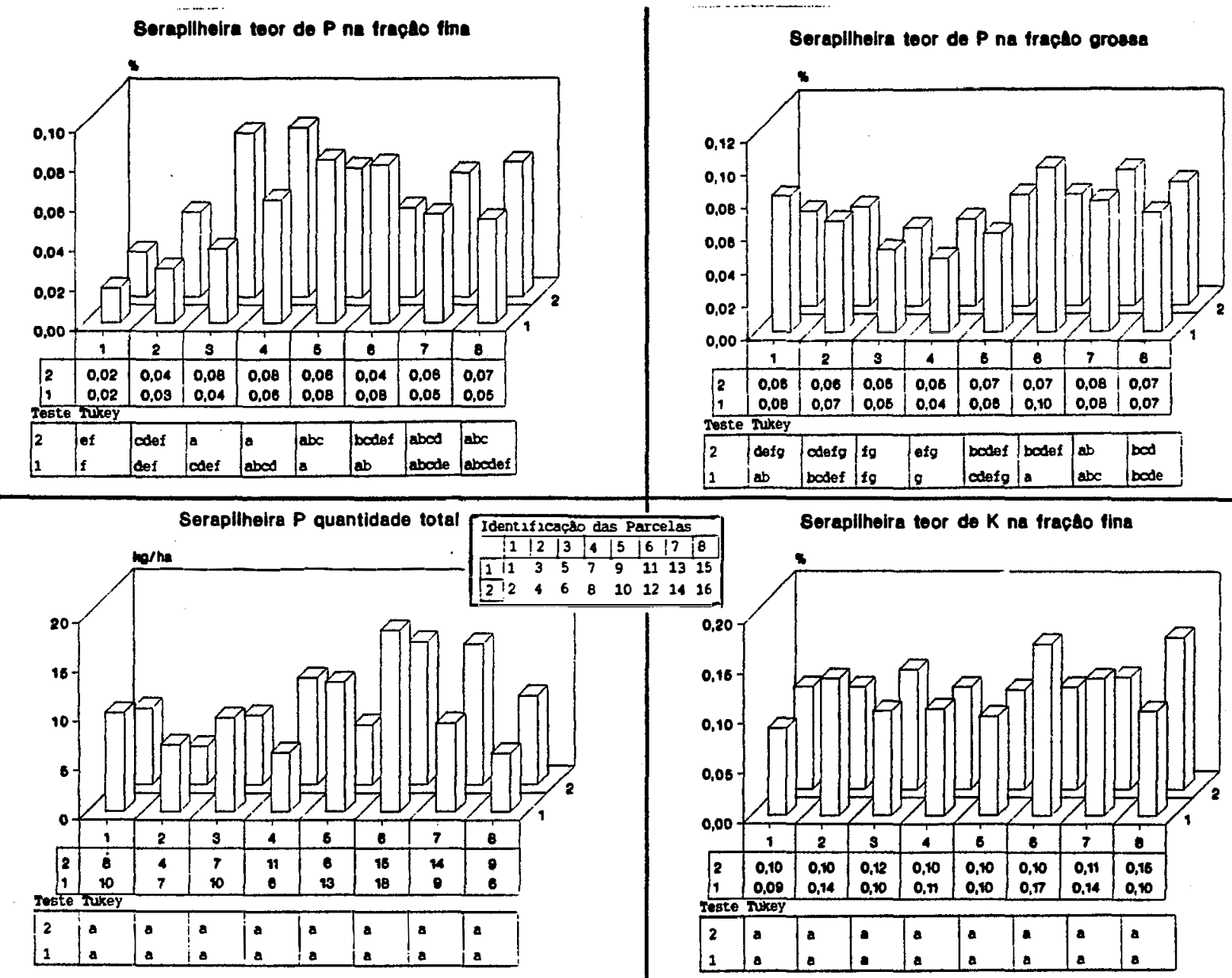

Serapilheira toor do $K$ na fracdo fina

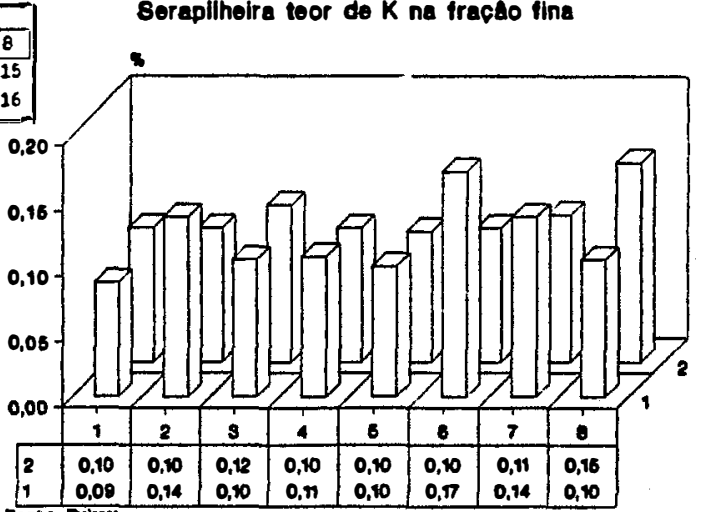
\begin{tabular}{r|r|}
1 & 0,00 \\
\hline Teste Tukey
\end{tabular}

\begin{tabular}{|c|c|c|c|c|c|c|c|c|}
\hline $\begin{array}{l}2 \\
1\end{array}$ & a & a & a & a & a & a & a & a \\
\hline
\end{tabular}
\begin{tabular}{|l|l|l|l|l|l|l|l|l|}
\hline 2 & $a$ & $a$ & $\bullet$ & $a$ & $a$ & $a$ & $a$ & $a$ \\
\hline & 0 & $a$ & $a$ & $a$ & $a$ & $a$ & $a$ & $a$ \\
\hline
\end{tabular}

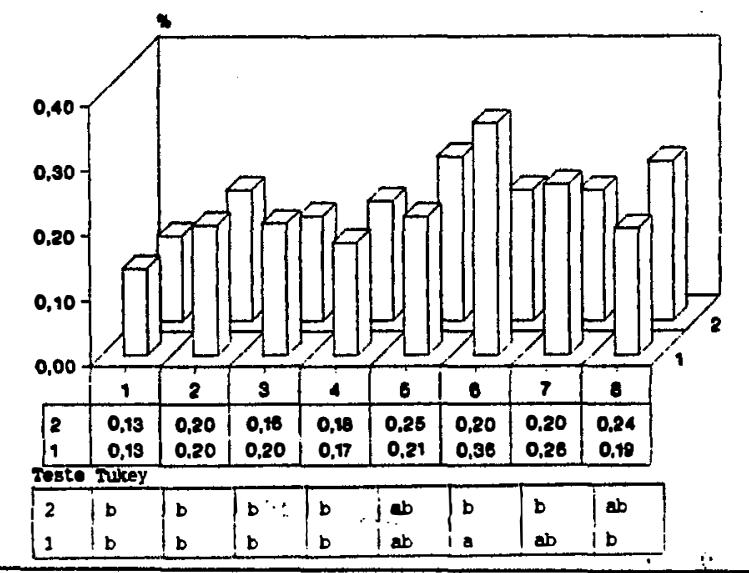

Serapilheira $K$ quantidade total

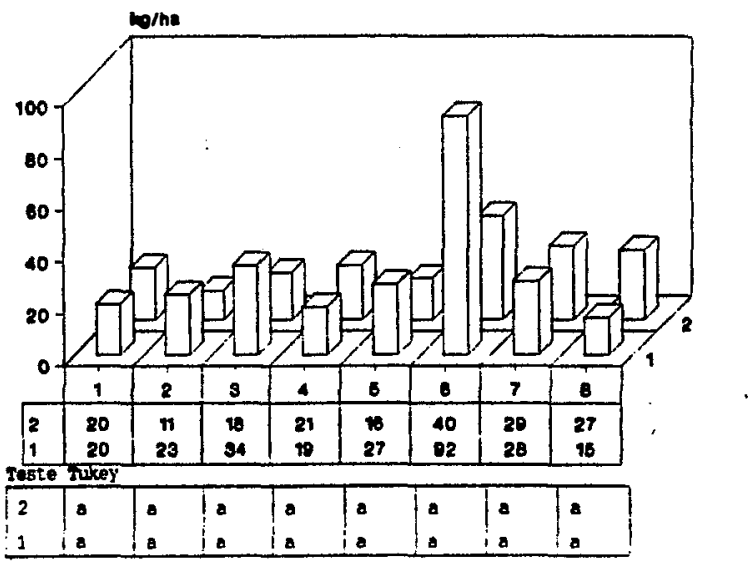

Figura 12 - cont inuação 

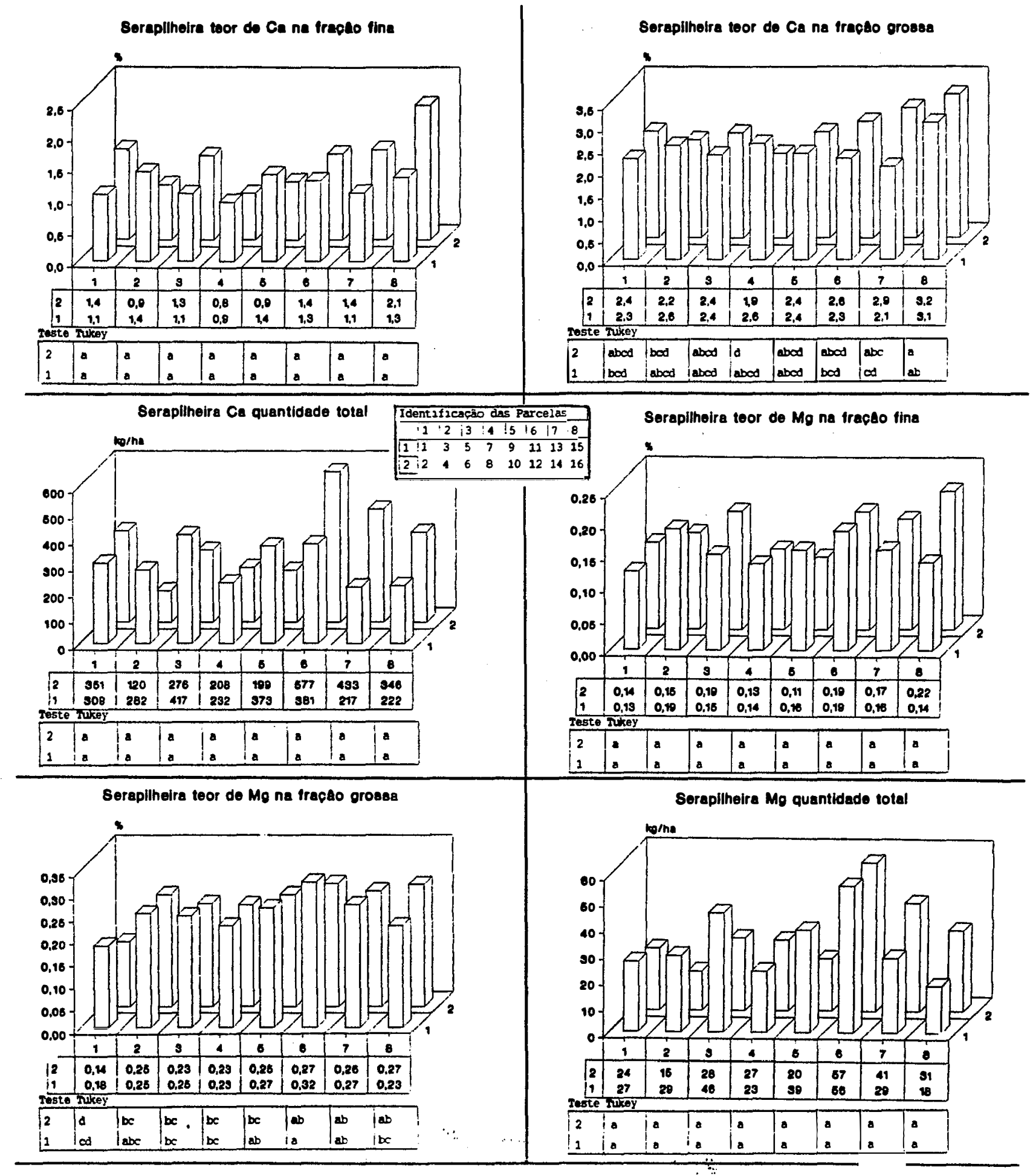

Figura 12 - cont inuação 

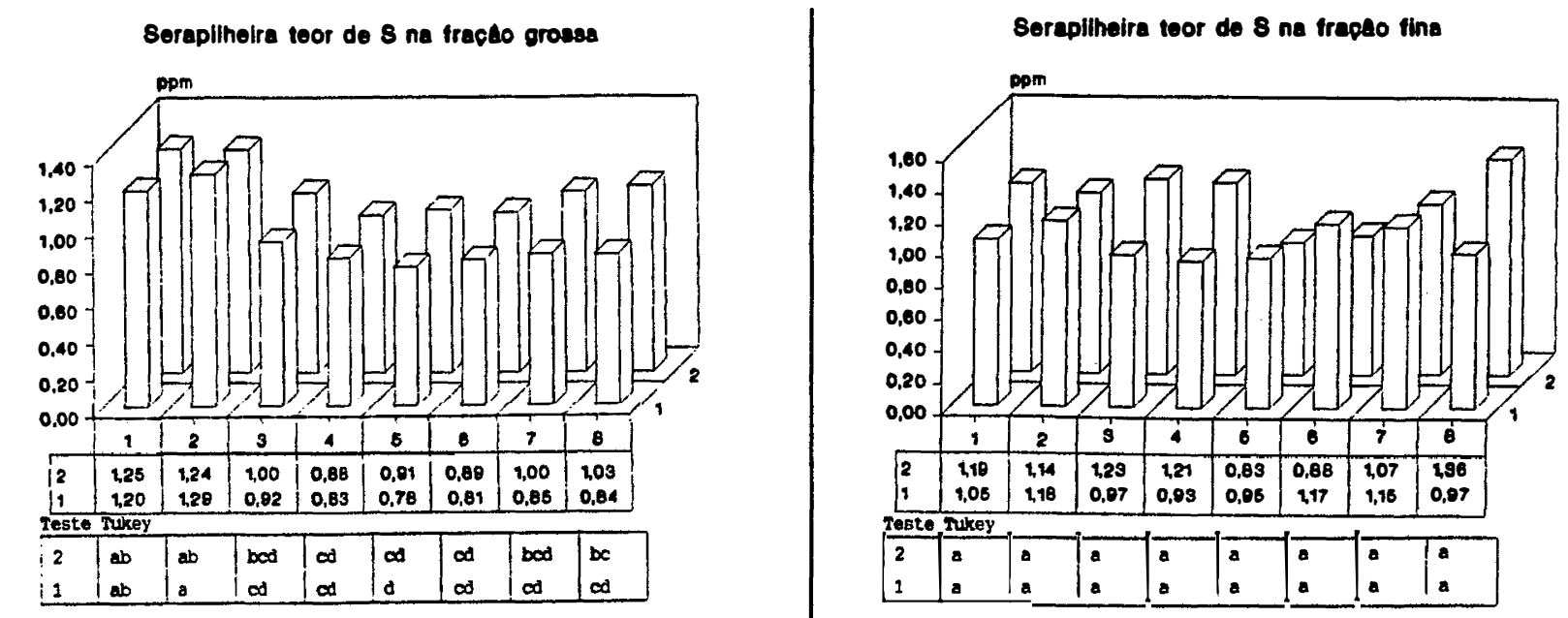

Serapilheira 8 quantidade total

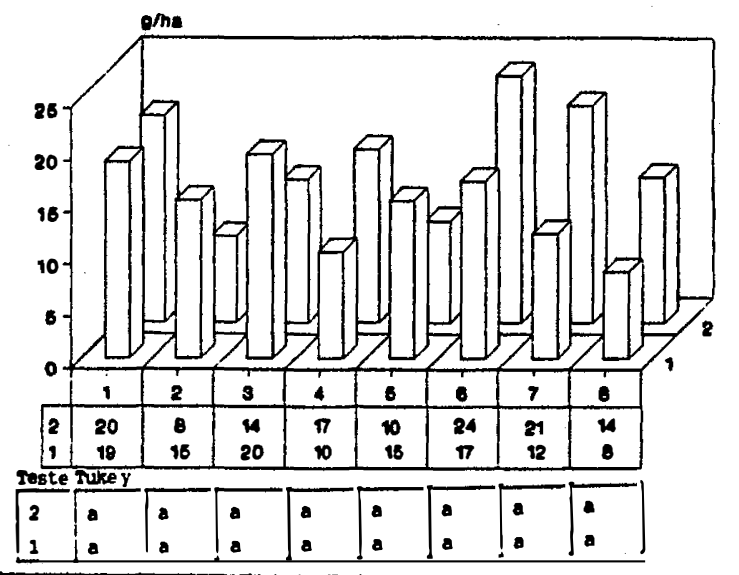

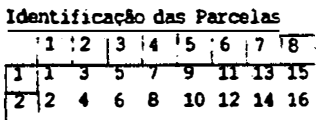

Figura 12 - cont inuação 


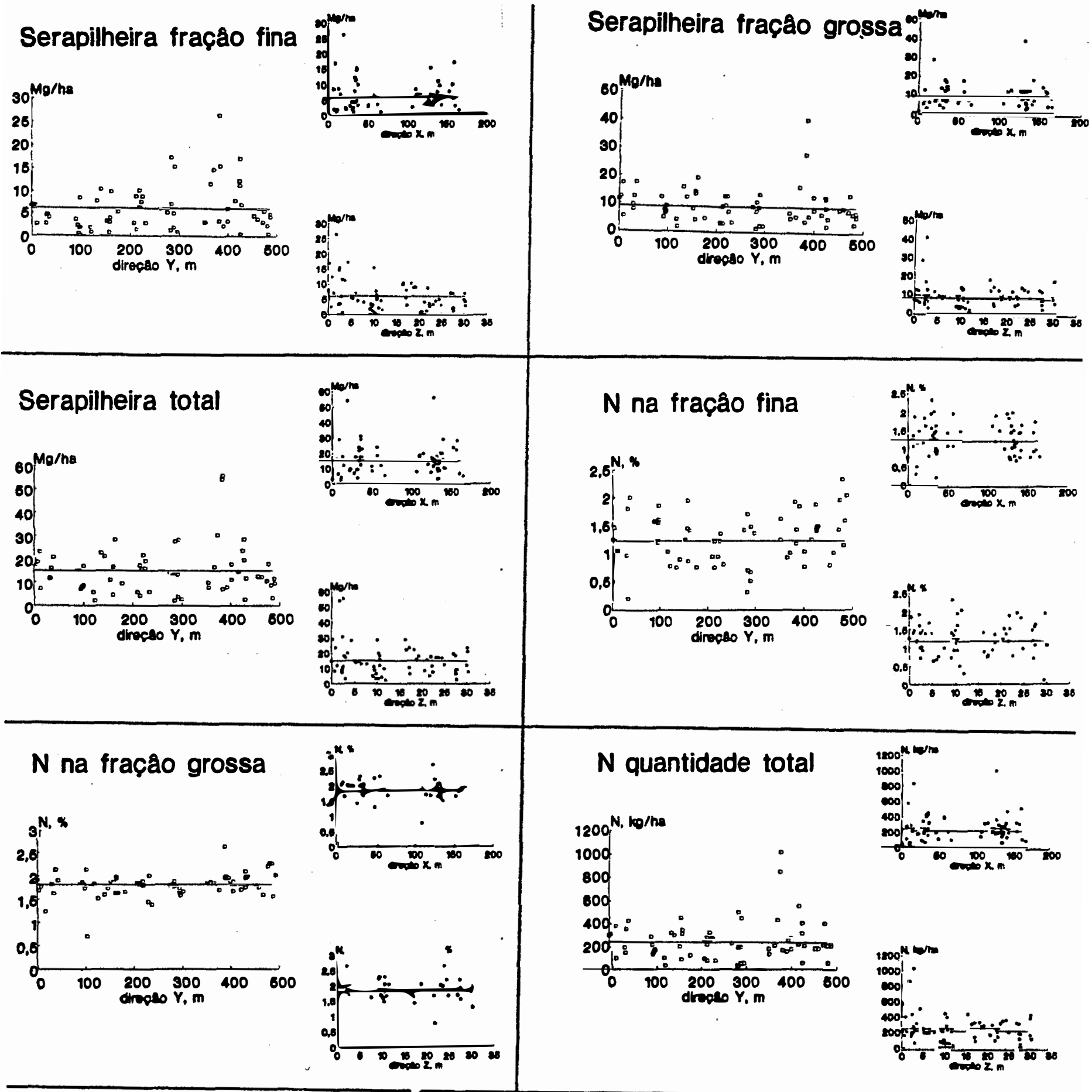

Figura 13 - Representação da quantidade de serapilheira acumulada, nutrientes contidos nela e seus teores (ponto) e da média (linha cheia) em relação aos eixos direcionais. 
P na fraçåo fina
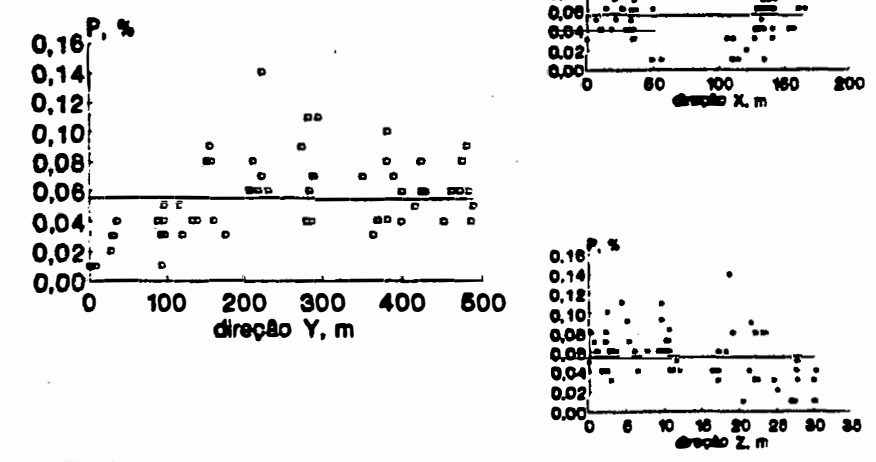

P quantidade total
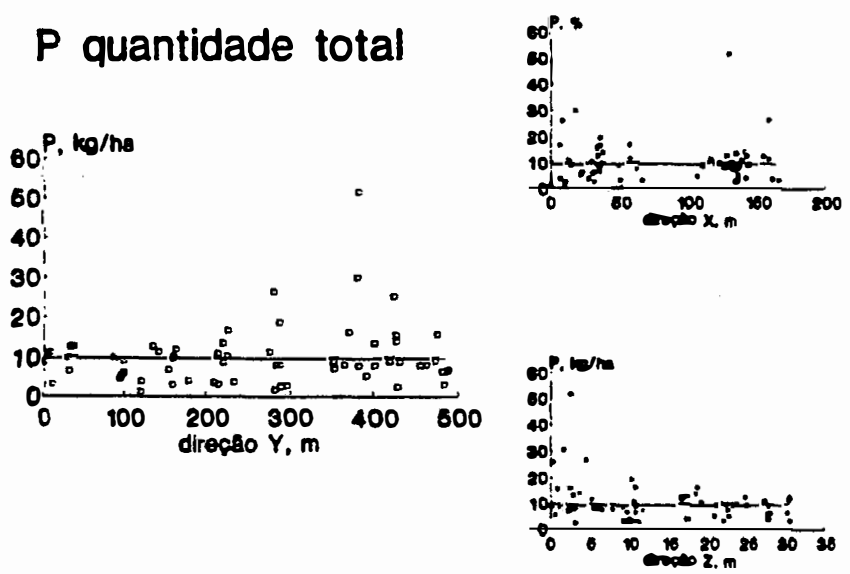

K na fraçâo grossa
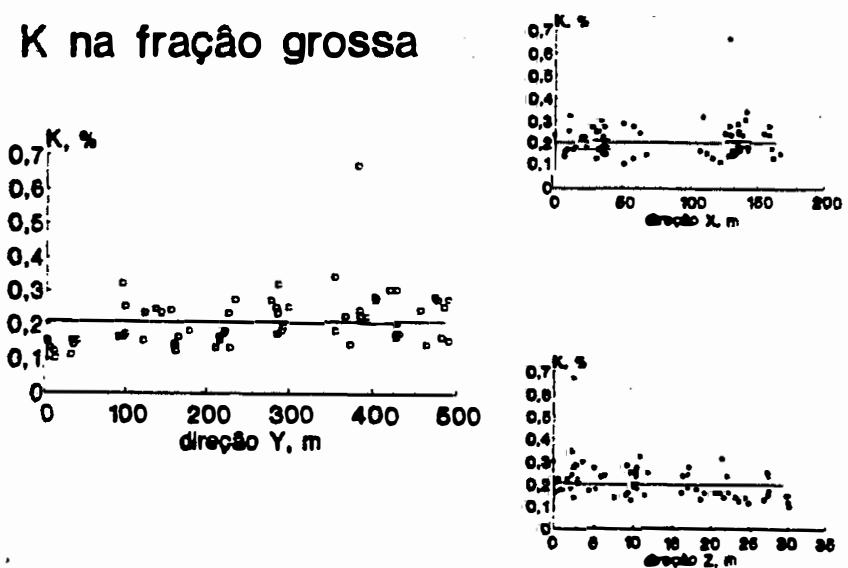

\section{P na fraçåo grossa}
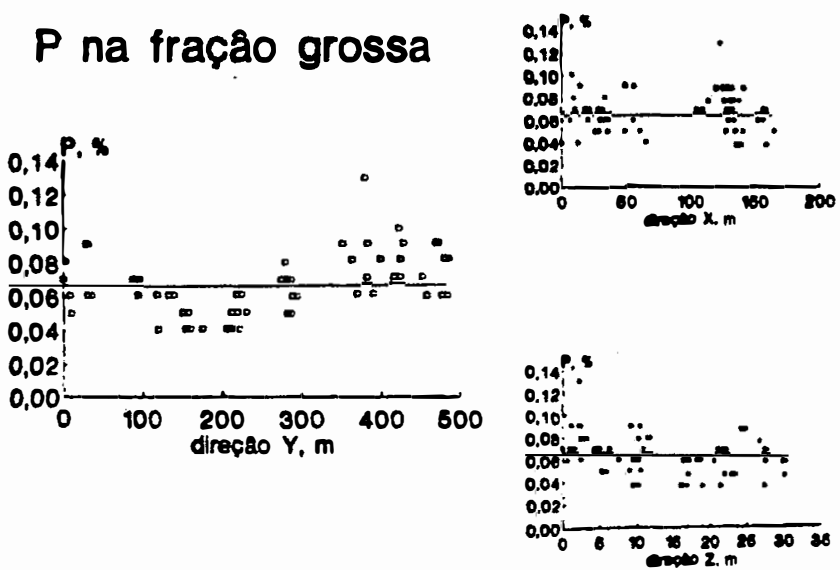

\section{$K$ na fraçâo fina}
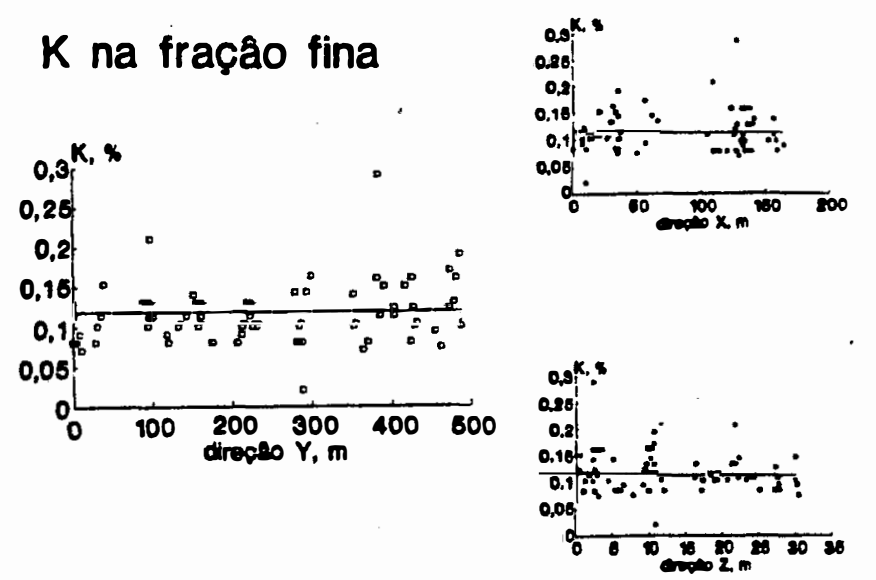

\section{$\mathrm{K}$ quantidade total}
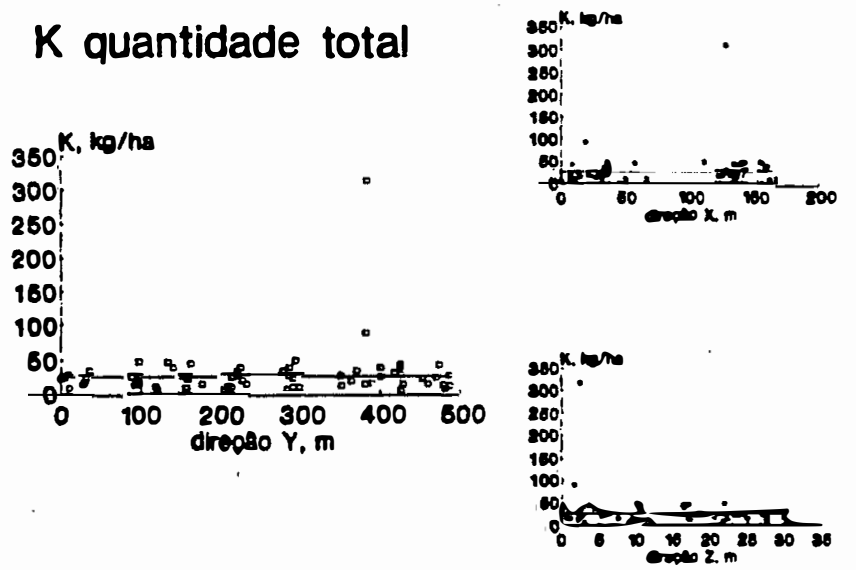

Figura 13 - cont i nuação 

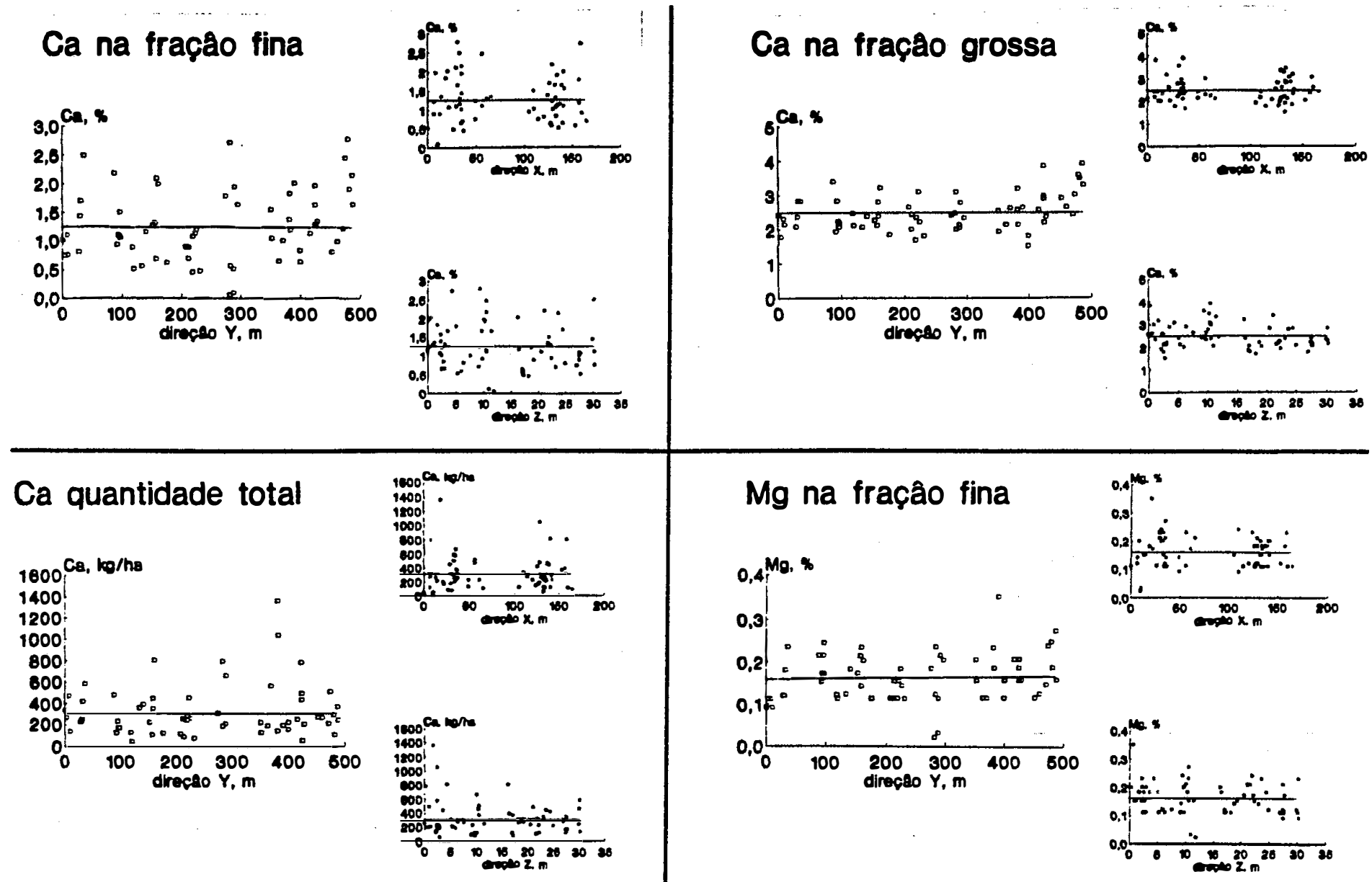

Mg na fraçåo grossa

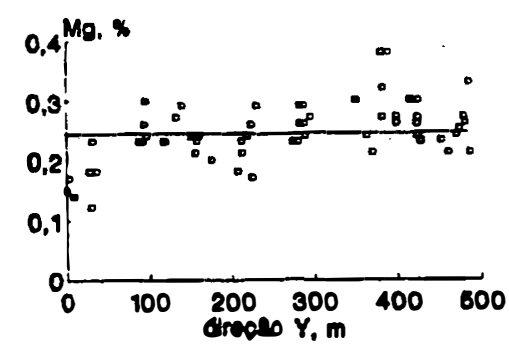

Mg quantidade total

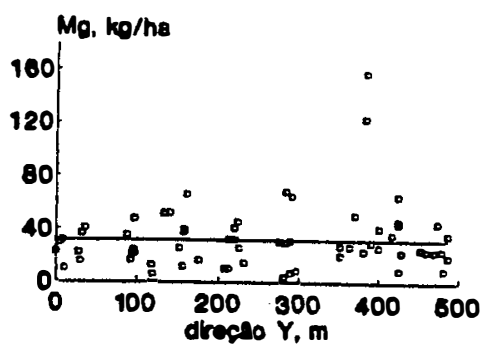

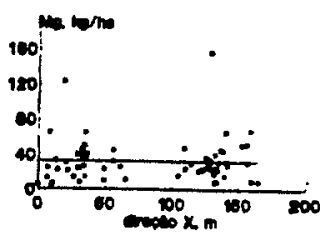

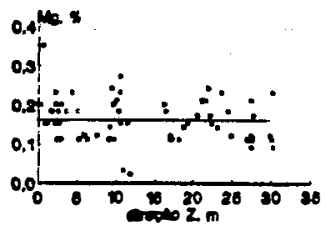

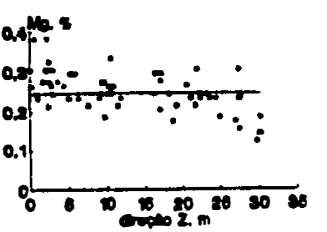

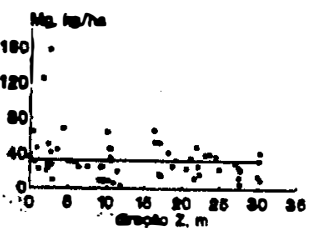

Figura 13 - cont inuação 


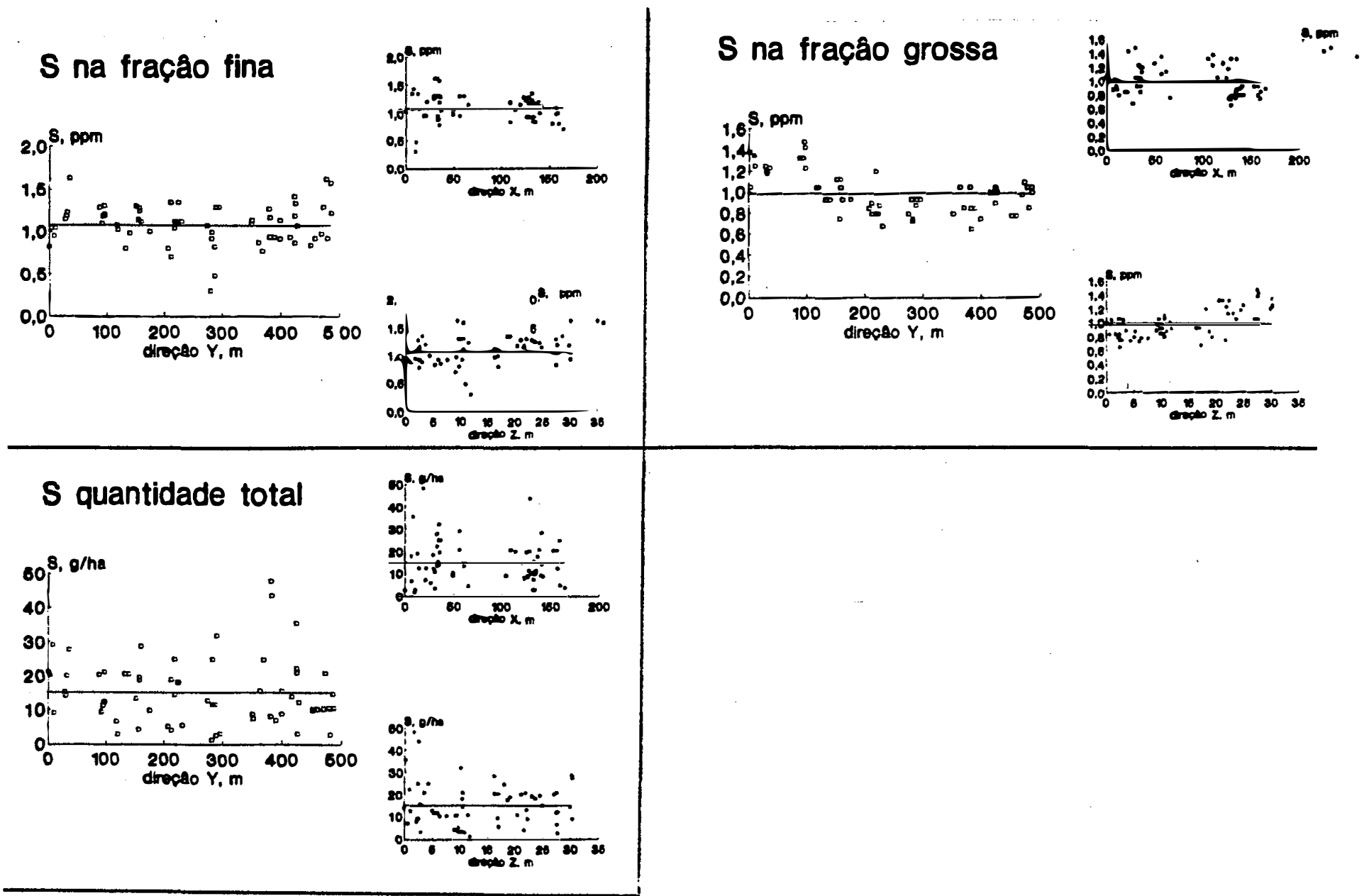

Figura 13 - cont inuação 


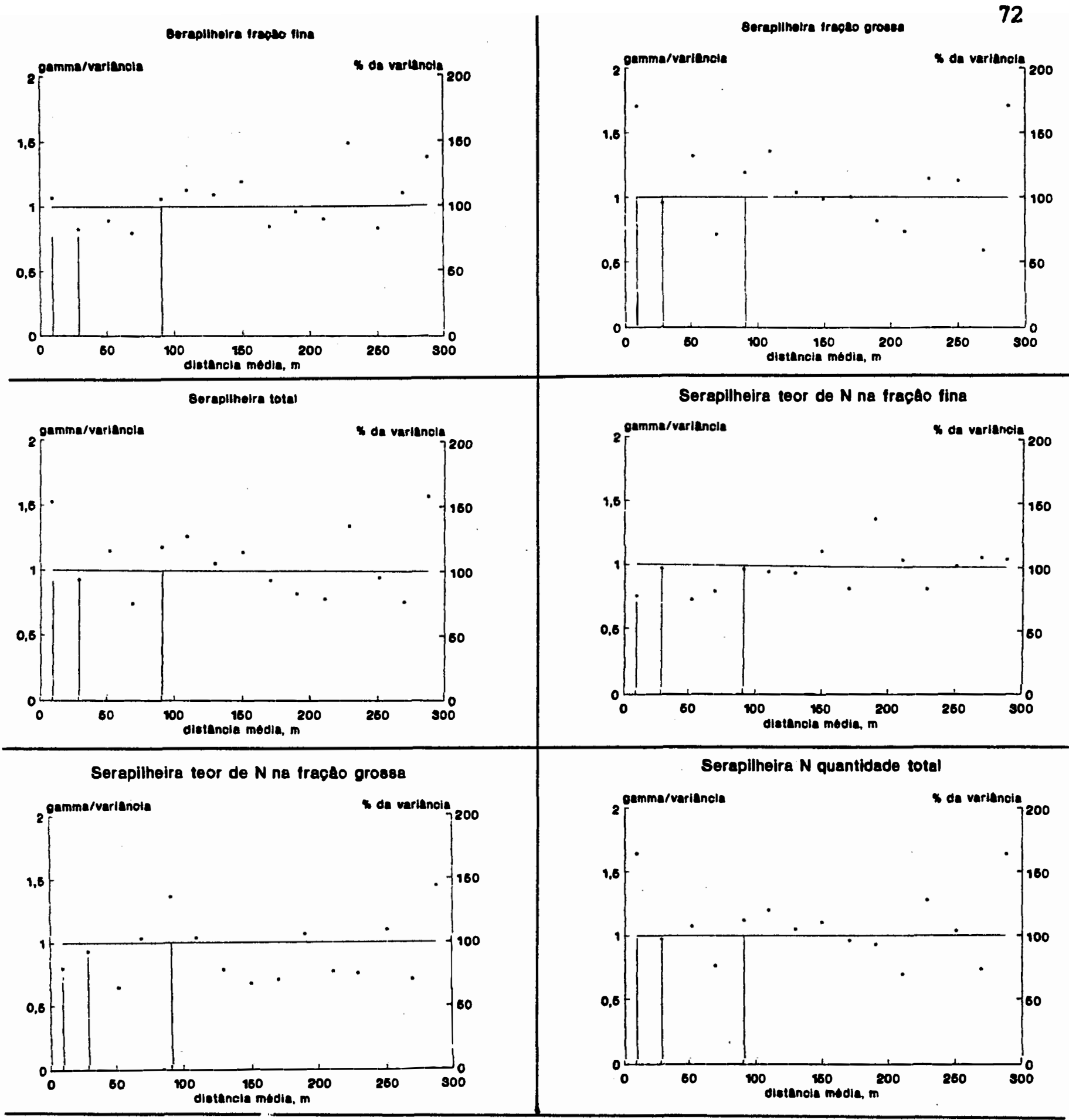

Figura 14 - Semivariância normalizada (pontos) e variância acumulada (linhas verticais) em funçảo da distância da quantidade de serapilheira acumulada, nutrientes contidos nela e seus teores 
Beraplihoira toor de P na trapto tine

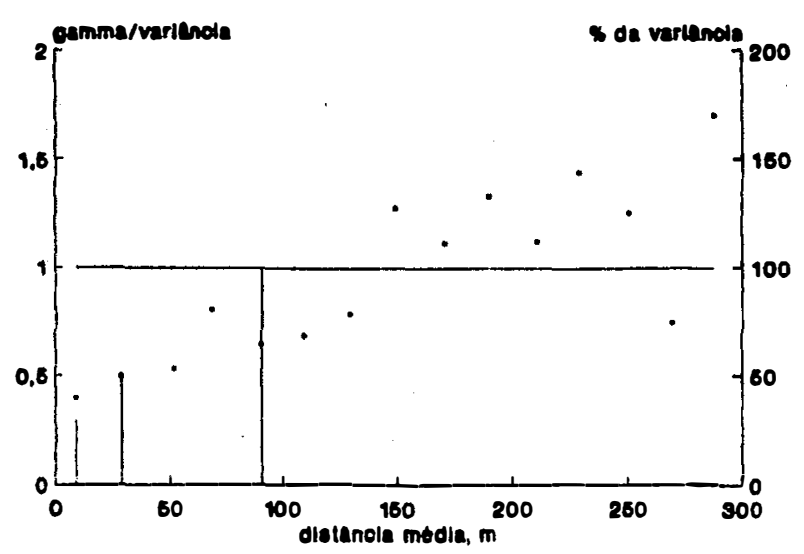

Serapilheira $P$ quantidade total

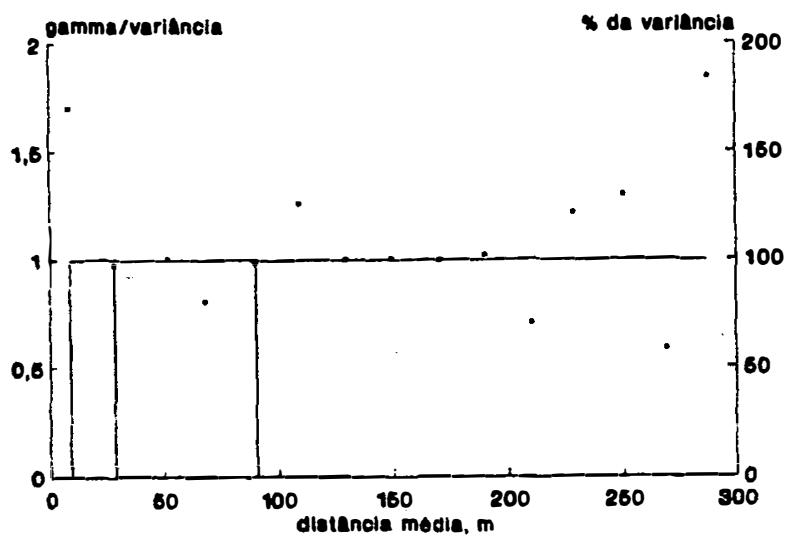

Serapilheira teor de K na fraço grossa

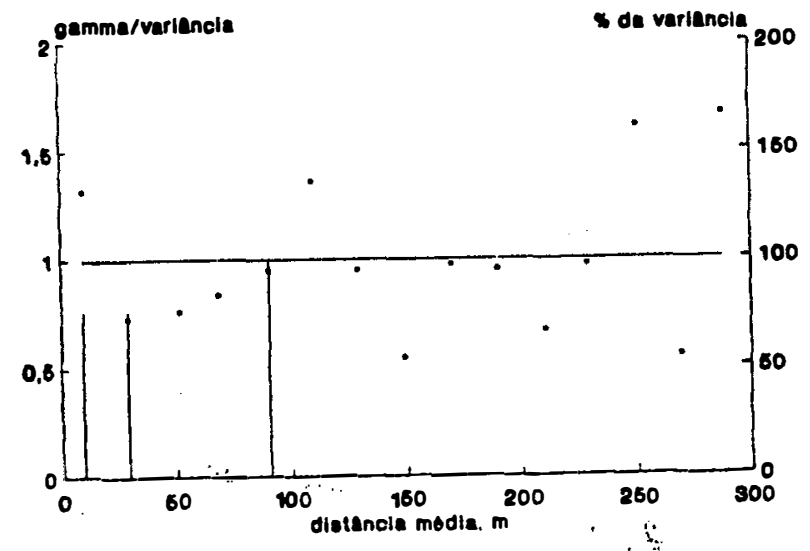

Serapilheira teor de P ne fracao groses

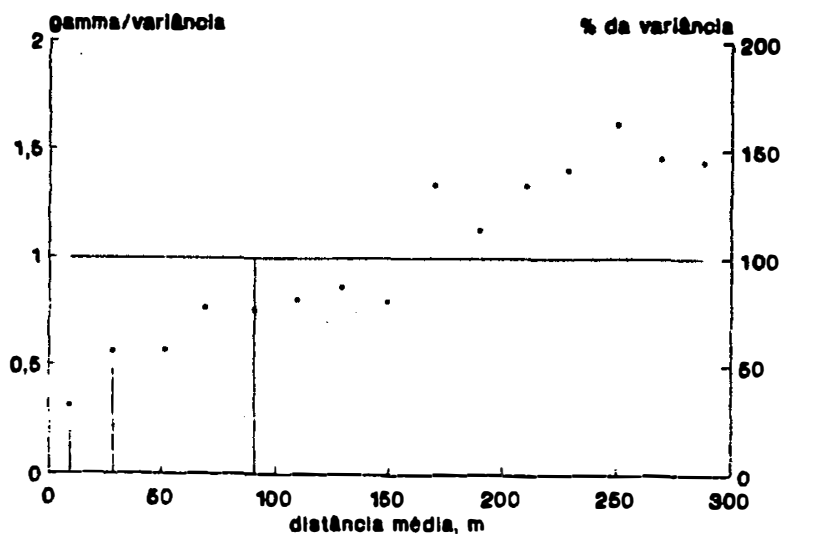

Serapilheira teor de $K$ na fracto fina

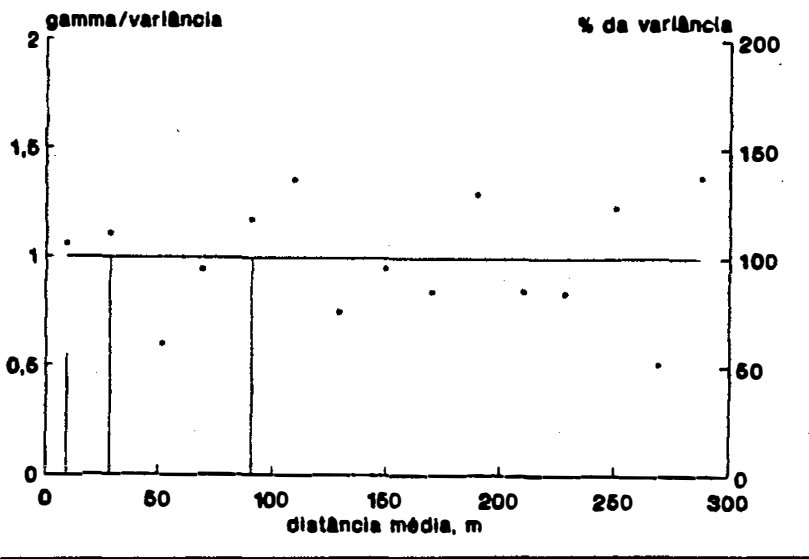

Serapilheira K quantidade total

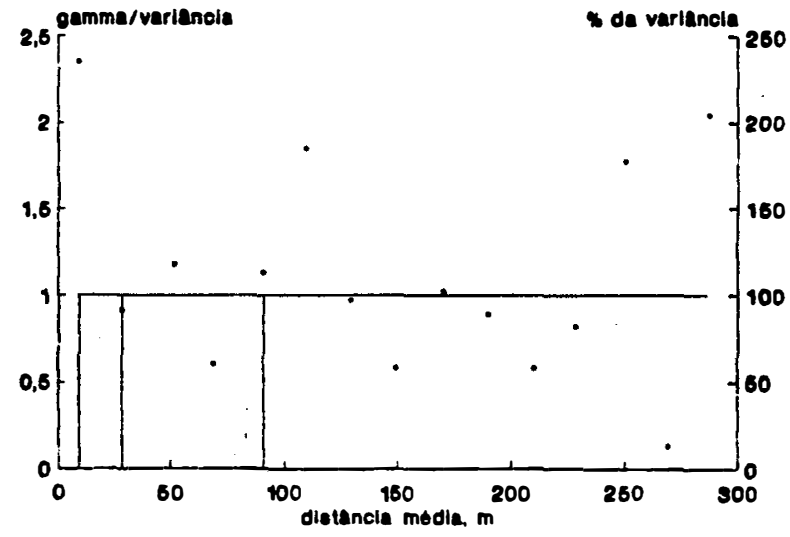

Figura 14 - cont inuação 


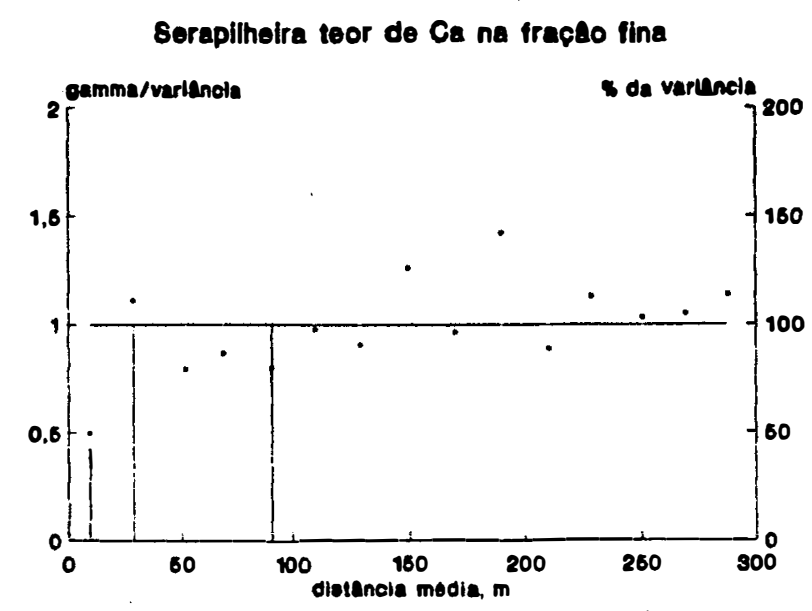

Serapilheira Ca quantidade total

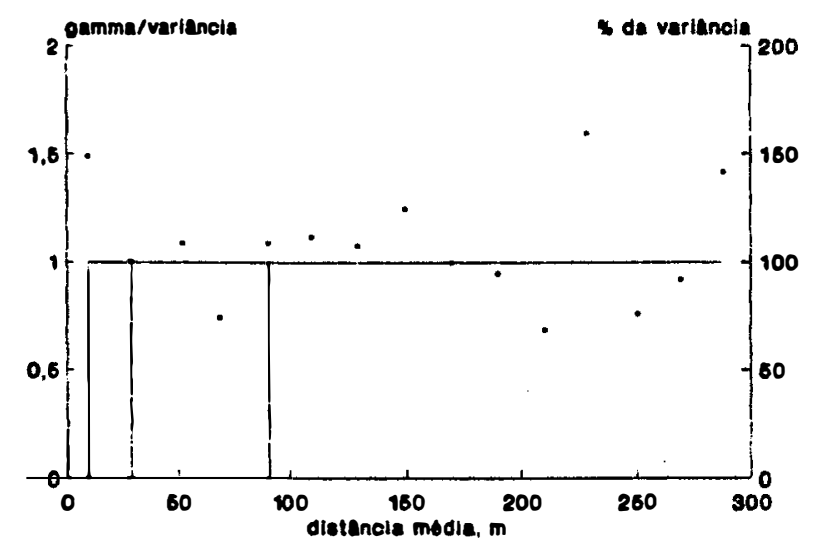

Serapilheira teor de Mg na fraça grossa

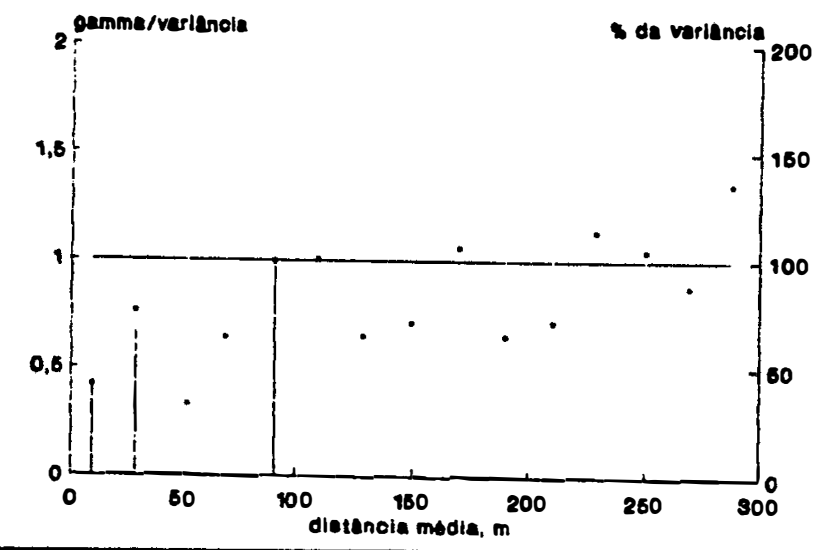

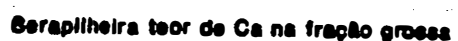

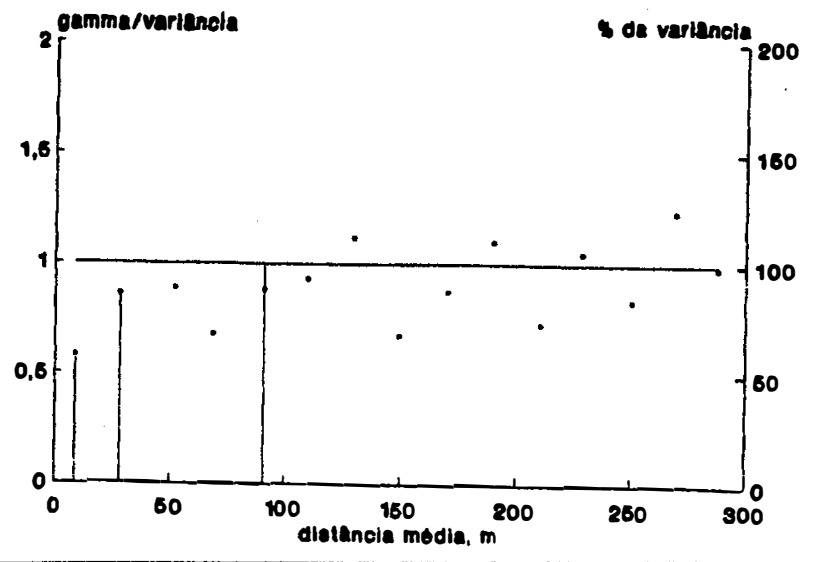

Serapilheira teor de Mg na fraceo fina

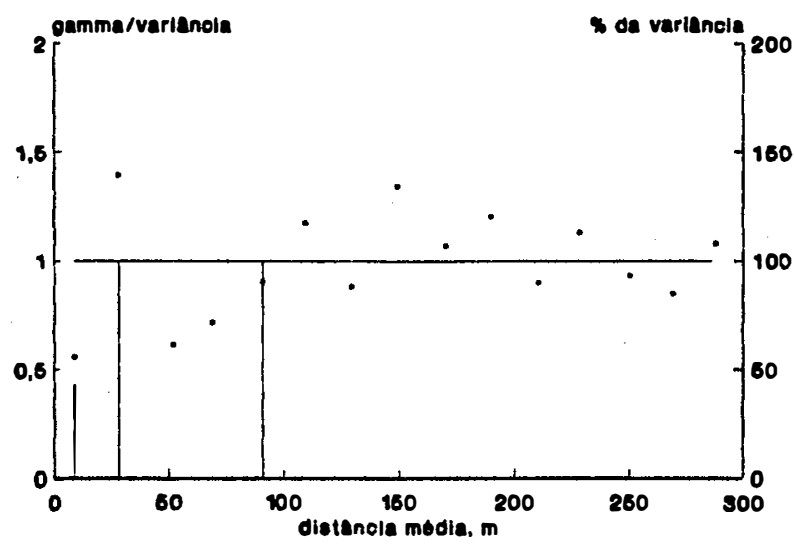

Serapilheira Mo quantidade total

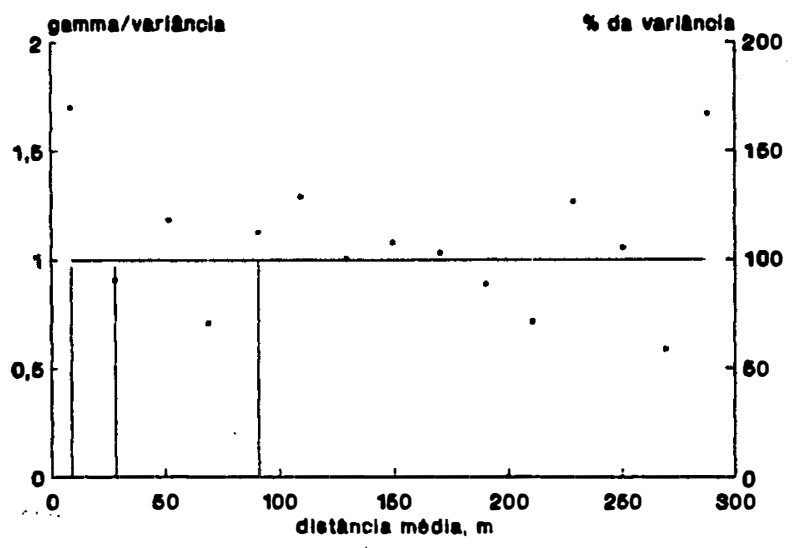

Figura 14 - cont inuação 


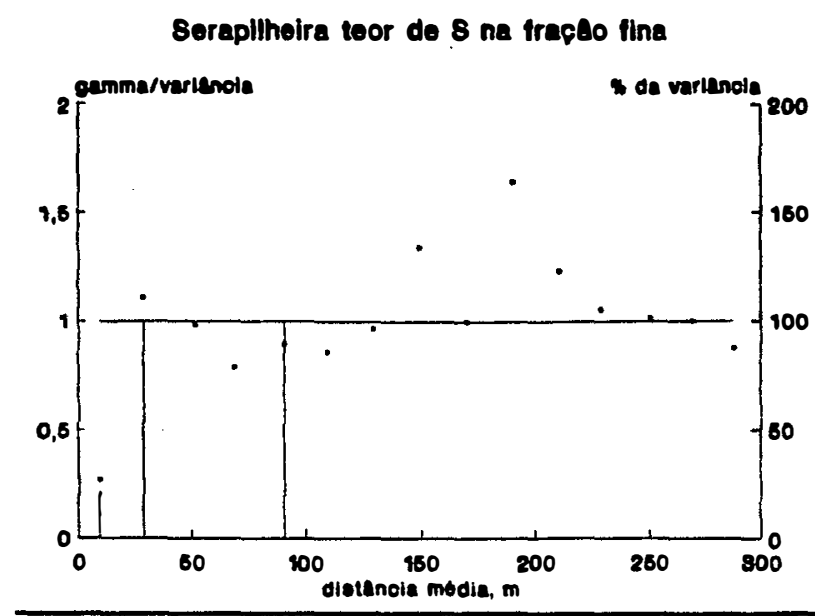

Serapilheira teor de $\mathbf{S}$ na fracto grossa

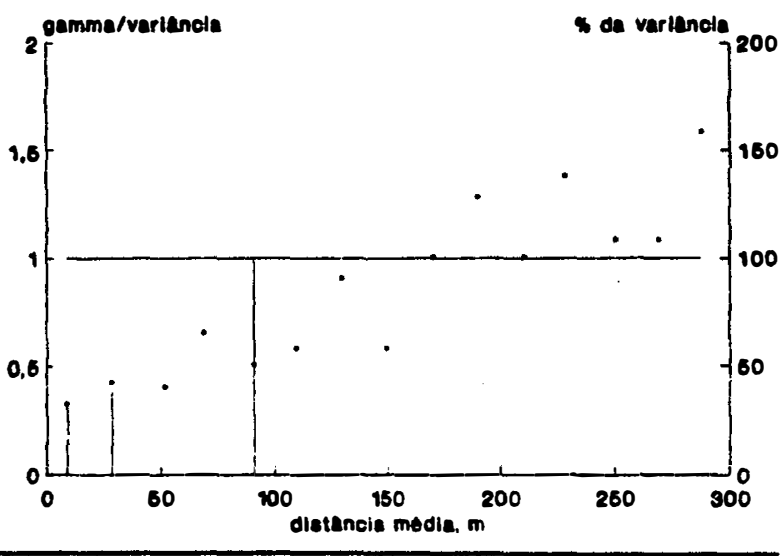

Serapilheira 8 quantidade total

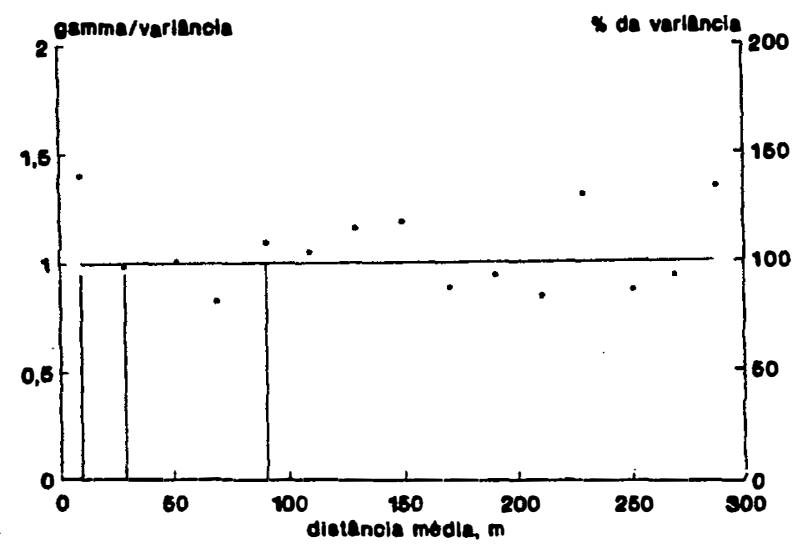

Figura 14 - cont inuação 


\subsubsection{Senivariograna e análise hierárquica de variância.}

A quantidade total de serapilheira acumulada e a quantidade total de elementos contidos nela não apresentaram semivariogramas com estrutura definida e a variância nos três niveis de distância $(7,25$ e $80 \mathrm{~m})$ foi sempre muito próxima de $100 \%$ (Figura 14).

Já com relação aos teores dos elementos, foram observada algumas tendências. $O$ teor de $P$ na fração grossa e fina apresentou semivariograma com estrutura esférica e alcance de $440 \mathrm{~m}$ para a fração grossa e $261 \mathrm{~m}$ para a fração fina com coeficiente de ajuste acima de 0,9. Os valores de variância acumulada na análise de variância hierárquica acompanharam as tendências dos semivariogramas. A forte dependência espacial verificada para os teores do $\mathrm{P}$ na serapilheira acumulada, associada à tendência bem definida de sua variação ao longo da encosta distinguem-no dos demais elementos. Os teores de outros elementos apresentaram alguma estrutura de variação nos semivariogramas, mas com ajustes aos modelos esférico, exponencial e gaussiano menos significativos. $O$ teor de $S$ na fração grossa apresentou comportamento semelhante ao do $\mathrm{P}$, diferindo deste por apresentar uma tendência mais linear dos valores de semivariância e do comportamento da distribuição de seus valores ao longo da encosta ter sido o inverso do $P$.

O teor de Ca e Mg nas frações fina e grossa apresentaram valores baixos de variância acumulada apenas no primeiro nível hierárquico de distância, acompanhados por valores igualmente baixos da semivariância, indicando uma dependência espacial a pequenas distâncias.

Ass im, o compor tamento em re lação à variabilidade espacial da quantidade de serapilheira acumulada, do teor dos elementos contidos nela e da quantidade total dos elementos foi bastante peculiar. A quantidade de serapilheira acumulada e a quantidade total dos elementos contidos nela não apresentaram dependência espacial da variância $e$ os valores distribuíram-se sem tendência definida na área. Os teores de alguns elementos, como o $\mathrm{N}$ e $\circ \mathrm{K}$ seguiram a mesma tendência. Já $\circ \mathrm{P}$ e $\circ \mathrm{S}$ apresentaram dependência espacial da variância em longas distâncias, comparável à posição no relevo e o $\mathrm{Ca}$ e $\mathrm{o} \mathrm{Mg}$ em pequenas distâncias, 
comparáveis a distância entre árvores.

\subsubsection{Análise global e delineamento reconendado}

A quantidade total de serapilheira acumulada apresentou elevado coeficiente de variação. A quantidade de amostras necessárias para estimar sua média com $10 \%$ de variação com probabilidade de $95 \%$ foi de 127 amostras. No entanto, os valores distribuíram-se sem tendência definida na área, não tendo sido verificada diferença significativa entre parcelas ou dependência espacial nos semivariogramas e análise de variância hierarquizada. 0 mesmo comportamento foi observado para a quant idade total dos elementos contidos na serapilheira acumulada.

O teor dos elementos na serapi lheira acumulada apresentou coeficientes de variação mais baixos e distribuição normal na maior parte dos casos. O número de amostra necessárias para estimar a média com $10 \%$ de variação e 95\% de probabilidade variou de 6 a 67 com valor médio de 29 amostras. Os semivariogramas, a análise de variância hierárquica e a observação dos valores em relação aos eixos indicaram um comportamento distinto para elementos diferentes, isto é, nenhuma dependência espacial para o $\mathbf{N}$ e $K$, dependência espacial a longa distância para o S e P e a curta distância para o Ca e Mg.

Dessa forma, a amostragem para a determinação da quantidade de serapilheira acumulada deve ser distinta da amostragem para a avaliação dos teores dos elementos contidos nela. A amostragem para a determinação da quantidade não precisa ser referenciada, podendo ser feita de forma casual, sendo necessário um número elevado de determinações. Algumas amostras, de localização conhecida, devem ser analisadas quanto aos teores dos elementos sem a necessidade de separação das frações. A amostragem para a determinação dos teores pode ser feita na forma de transeções curtas, com pequeno intervalo de distância entre os pontos, distribuidas nas diferentes posições do relevo como topo, ombro, meia encosta, baixada ou associadas à mudanças de solo, permitindo a análise da variância tanto em pequenas como grandes distâncias. 


\subsection{Atributos quínicos do solo mineral}

\subsubsection{Estatística descritiva}

Na Tabela 7 estão representados os valores médios e intervalos de confiança, o coeficiente de variação, o ajuste à distribuição normal e lognormal e o número de amostras necessárias para se obter uma variação na média de 10 e $5 \%$ dos atributos químicos das amostras de terra nas profundidades de 0 a $5 \mathrm{~cm}, 5$ a $25 \mathrm{~cm}$ e 60 a $80 \mathrm{~cm}$.

Os valores médios dos atributos químicos do solo, de uma maneira geral, indicaram haver uma grande diferença entre as profundidades de 0 a $5 \mathrm{~cm} e$ 5 a $25 \mathrm{~cm}$, diferença esta maior do que entre as profundidades de 5 a $25 \mathrm{~cm}$ e $60 \mathrm{a} 80 \mathrm{~cm}$. Teores elevados na camada superficial do solo mineral, imediatamente abaixo da serapilheira acumulada, foram observados principalmente para a matéria orgânica, fósforo disponível, cálcio e magnésio trocável e capacidade de troca de cátions. Da mesma forma EWEL et al. (1981) verificaram uma grande diferença nos teores de $N, P, K, S$ e C em relação a camada de $0-3 \mathrm{~cm}$ e $3-8 \mathrm{~cm}$ de profundidade do solo e diferenças menores para o $\mathrm{Ca}$ e $\mathrm{Mg}$ numa floresta tropical úmida da Costa Rica, HAMMER et al. (1987) também observaram grande diferença nos teores de $\mathrm{C}, \mathrm{Ca}, \mathrm{Mg} \mathrm{e} \mathrm{K}$ do horizonte superficial para o subsuperficial em florestas homogêneas no Tenessee, VUONO (1985) encontrou grandes diferenças no teor de nutrientes no solo em profundidade numa floresta em São Paulo e RODRIGUES (1991) observou um gradiente elevado dos atributos químicos do solo em profundidade numa floresta às margens do Rio Passa Cinco em Ipeúna (SP). O elevado gradiente dos teores dos nutrientes em profundidade nas florestas tropicais, verificando-se uma grande concentração imediatamente abaixo da serapilheira acumulada, pode ser explicado pela pouca influência do solo mineral no ciclo biológico dos nutrientes que se constitui no principal mecanismo de sua transferência para as plantas (NYE; 1961; JORDAN \& KLINE, 1972; JORDAN, 1982; VITOUSER \& SANFORD, 1986). Os nutrientes que chegañ à superfície pela precipitação interna ou produção de serapilheira são absorvidos pelas raízes imediatamente abaixo da camada de serapilheira acumulada, como foi 
demonstrado por STARK \& JORDAN, (1978) num estudo com elementos marcados numa floresta tropical úmida na Venezuela. Neste estudo, menos de $0,1 \%$ dos elementos $\mathrm{P}$ e $\mathrm{Ca}$ marcados conseguiram ultrapassar alguns centímetros abaixo da superfície do solo mineral, sendo, a maior parte, rapidamente absorvida pelas plantas no contato do solo com a serapilheira acumulada, região de sua maior concentração. Desta forma, o estudo da serapilheira acumulada e sua interação com o solo imediatamente abaixo, numa camada de poucos centímetros, limite este nem sempre facilmente identificável (FEDERER, 1982), parece ser essencial em qualquer estudo preocupado com a compreensão da dinâmica de nutrientes em florestas tropicais. Estes resultados reforçaram a necessidade de subdividir o horizonte mineral superficial do solo em camadas de apenas alguns centímetros na coleta de amostras em florestas. A coleta de amostras na profundidade de $0-20 \mathrm{~cm}$ ou do primeiro horizonte pedológico, como é usual em áreas cultivadas, não é sensível para ident ificar e quant ificar a grande concentração da maioria dos elementos logo abaixo da camada de serapilheira acumulada. Por outro lado, BUNZL \& SCHIRMMACK (1989) não encontraram correlação entre o teor de diversos íons inorgânicos na serapilheira acumulada e na camada superficial do solo mineral em floresta de pouca diversidade de espécies no sul da Alemanha.

Os valores médios indicaram solos de reação próxima à neutralidade, saturação por bases elevada e capacidade de troca de cátions média na camada de 60 a $80 \mathrm{~cm}$. 0 teor de fósforo, com exceção da camada de $0-5 \mathrm{~cm}$, apresentou-se muito baixo. o coeficiente de variação apresentou relativa uniformidade em profundidade para o valor pH, $\mathrm{K}, \mathrm{Ca}, \mathrm{Mg}$ trocável e, diminuição em profundidade para o teor de matéria orgânica, P disponível, capacidade de troca de cátions e saturação por alumínio. Apenas no caso da saturação por bases houve um aumento desse valor em profundidade indicando que aparentemente este parâmetro foi homogeneizado pela influência da dinâmica superficial. A influência do tipo de vegetaçáo sobre o teor de elementos no solo foi verificado por MESSENGER et al. (1978) que estudaram o efeito de algumas espécies de Pinus sobre o toor de alumínio e acidez do solo em áreas com diferentes épocas de 
implantação, em relação a áreas com vegetação nativa. Neste caso, houve um aumento significativo do teor de alumínio no solo superficial até $10 \mathrm{~cm}$ de profundidade com a introdução das espécies de Pinus, variável de acordo com a espécie e a época de introdução. Este aumento foi atribuído ao elevado teor de alumínio das acículas que estariam sendo depositadas sobre o solo. Assim, pode se esperar que dependendo das espécies existentes e do seu comportamento em relação à absorção e deposição de elementos via ciclagem biológica possa haver alterações dos teores nas camadas superficiais do solo mineral, logo abaixo da serapilheira acumulada, na forma de aumento ou diminuição da variabilidade em relação às camadas mais profundas, menos dependentes da dinâmica superficial e mais relacionadas aos processos pedogenéticos.

O número de amostras necessárias para estimar a média com uma variação de $10 \%$ variou de 2 para o valor do $\mathrm{pH}$ e $\mathrm{V}$ a $0-5 \mathrm{~cm}$ até 812 no $\mathrm{P}$ a $0-5 \mathrm{~cm}$. Considerando todos os atributos avaliados o número médio de amostras necessárias para estimar a média com uma variação de $10 \%$ foi de 226 para a profundidade de $0-5 \mathrm{~cm}, 84$ para $5-25 \mathrm{~cm}$ e 88 para $60-80 \mathrm{~cm}$ indicando a necessidade de coletar um maior número de amostras nas camadas superficiais do que nas subsuperficiais. A coleta de um grande número de amostras, principalmente nas camadas superficiais, e uma posterior seleção dos atributos a serem analisados, procedendo-se análise de maior número de amostras daqueles atributos de maior coeficiente de variação como fósforo e alumínio e menor daqueles de menor coeficiente de variaçăo como o $\mathrm{pH}$ pode garantir uma alta precisão na quantificação dos atributos do solo com redução substancial dos custos em relação à análise sistemática de todas as amostras. McNABB et al. (1986) estudaram seis florestas no Oregon e verificaram que a necessidade de amostras para estimar a média com $10 \%$ de variação foi de 17 a 47 amostras com média de 30 amostras, muito próximo dos valores encontrados para matéria orgânica, neste trabalho. COURTIN et al. (1983) trabalhando com florestas recém plantadas próximo à Vancouver,. também observaram coeficientes de variação muito baixos para o valor $\mathrm{pH}$ do solo e muito altos para o teor de $\mathrm{P}$ e, o número de amostras necessárias para estimar a média com $10 \%$ de variação com $95 \%$ 
de probabilidade para o teor de carbono variou bastante, no entanto, de uma forma geral foi menor do que os observados na camada superficial deste estudo, o mesmo ocorrendo para o teor de P e Ca no solo. RIHA et al. (1986) também observaram baixos coeficientes de variação para o pH em florestas homogêneas de 50 anos plantadas sobre solos cultivados, em Dryden (EUA) sendo que os coeficientes de variação para o teor de matéria orgânica do solo foram maiores do que os observados neste estudo.

A maior parte dos atributos químicos nas profundidades de 5 a 25 e 60 a $80 \mathrm{~cm}$ apresentaram ajuste à distribuição normal, com exceção do teor de fósforo disponível e do cálcio e alumínio trocáveis que, no primeiro caso não apresentou ajuste à distribuição normal e lognormal e no segundo e terceiro casos apenas à distribuição lognormal. Na camada superficial de $0-5 \mathrm{~cm}$, apenas $\mathrm{o} \mathrm{pH}$ apresentou ajuste à função normal, ressaltando o comportamento distinto dos atributos químicos nesta camada em relação às camadas mais profundas e, conseqüentemente a necessidade de amostrá-la e proceder a análise dos dados de forma diferenciada das demais.

\subsubsection{Valores ádios das parcelas}

Na Figura 15 foram representados os valores médios das 16 parcelas localizadas na área e seus respectivos quadros de análise de variância para os valores de $\mathrm{pH}$, teores de Ca, Mg e $\mathrm{K}$ trocáveis, $\mathrm{P}$ disponível, capacidade de troca de cátions, saturação por bases e saturação por alumínio.

A média do valor $\mathrm{pH}$ decresceu em profundidade e foram detectadas diferenças significativas entre as parcelas em todas as profundidades sendo que a parcela dois sempre apresentou o valor mais elevado do pH. De uma maneira geral a diminuição no valor do $\mathrm{pH}$ foi proporcional, isto é, a diferença entre os valores médios manteve-se entre as parcelas nas três profundidades, apesar de, na maior parte dos casos, não terem sido observadas diferenças significativas. Foram encontrados valores com diferenças significativas em parcelas vizinhas, como nas parcelas 9 e 11 . A parcela 11 e parte da parcela 9 situam-se numa área de convergência de dois córregos que atravessam a mata. Nesta área ocorrem depósitos 
Tabela 7 - Valores médios e intervalos de confiança, coeficiente de variação, ajuste à distribuição da normal e lognormal e numero de amostras necessárias para se obter uma variação na média de 10 e $5 \%$ dos atributos químicos das amostras de terra nas profundidades de 0 a $5 \mathrm{~cm}, 5$ a $25 \mathrm{~cm}$ e 60 a $80 \mathrm{~cm}$.

\begin{tabular}{|c|c|c|c|c|c|c|c|c|c|}
\hline $\begin{array}{l}\text { Parâmetro } \\
\text { profundidade }\end{array}$ & média & $\lim _{\text {inf. }}$ & $\begin{array}{l}1 \mathrm{im} . \\
\text { sup. }\end{array}$ & cv & $\mathrm{x}_{\mathrm{N}}^{2}$ & $\overrightarrow{\mathrm{LN}}$ & $\begin{array}{l}M o \\
a / c\end{array}$ & $\begin{array}{l}\mathrm{n}^{\circ} \\
0,1\end{array}$ & $\begin{array}{l}n^{\circ} \\
0,05\end{array}$ \\
\hline pH $0-5 \mathrm{~cm}$ & 6,8 & 6,7 & 6,9 & 8 & ns & $*$ & $*$ & 2 & 3 \\
\hline $\mathrm{pH} 5-25 \mathrm{~cm}$ & 6,4 & 6,2 & 6,5 & 10 & ns & $*$ & $*$ & 3 & 4 \\
\hline $\mathrm{pH} 60-80 \mathrm{~cm}$ & 5,9 & 5,8 & 6,1 & 11 & ns & $*$ & ns & 3 & 4 \\
\hline MO $0-5 \mathrm{~cm}$ & 5,8 & 5,2 & 6,5 & 45 & ns & ns & ns & 57 & 81 \\
\hline MO $5-25 \mathrm{~cm}$ & 2,2 & 2,1 & 2,3 & 23 & ns & $*$ & $*$ & 15 & 22 \\
\hline MO 60-80 cm & 1,2 & 1,1 & 1,2 & 22 & ns & ns & $*$ & 14 & 20 \\
\hline P $0-5 \mathrm{~cm}$ & 11 & 6 & 16 & 171 & ns & ns & ns & 812 & 1164 \\
\hline P $5-25 \mathrm{~cm}$ & 3,3 & 2,7 & 3,9 & 75 & ns & ns & ns & 157 & 226 \\
\hline P $60-80 \mathrm{~cm}$ & 1,0 & 0,67 & 1,27 & 126 & ns & ns & ns & 444 & 636 \\
\hline $\mathrm{K} 0-5 \mathrm{~cm}$ & 0,37 & 0,31 & 0,44 & 70 & ns & ns & ns & 135 & 194 \\
\hline K $5-25 \mathrm{~cm}$ & 0,27 & 0,22 & 0,31 & 69 & ns & $*$ & ns & 131 & 188 \\
\hline K 60-80cm & 0,23 & 0,19 & 0,26 & 58 & * & ns & $*$ & 92 & 133 \\
\hline $\mathrm{Ca} 0-5 \mathrm{~cm}$ & 13,0 & 10,8 & 15,2 & 69 & ns & ns & ns & 131 & 188 \\
\hline $\mathrm{Ca} 5-25 \mathrm{~cm}$ & 4,2 & 3,6 & 4,7 & 53 & ns & $*$ & ns & 78 & 112 \\
\hline $\mathrm{Ca} \quad 60-80 \mathrm{~cm}$ & 1,9 & 1,7 & 2,2 & 57 & ns & $*$ & ns & 92 & 132 \\
\hline $\mathrm{Mg} 0-5 \mathrm{~cm}$ & 2,2 & 1,9 & 2,4 & 44 & ns & ns & ns & 54 & 77 \\
\hline$M g \quad 5-25 \mathrm{~cm}$ & 1,0 & 0,9 & 1,1 & 43 & $*$ & ns & ns & 51 & 74 \\
\hline $\mathrm{Mg} \quad 60-80 \mathrm{~cm}$ & 1,1 & 0,9 & 1,2 & 50 & $*$ & ns & $*$ & 71 & 102 \\
\hline T $0-5 \mathrm{~cm}$ & 16,8 & 14,4 & 19,2 & 58 & ns & ns & ns & 93 & 133 \\
\hline T $5-25 \mathrm{~cm}$ & 7,0 & 6,4 & 7,6 & 34 & ns & ns & ns & 32 & 46 \\
\hline T $60-80 \mathrm{~cm}$ & 5,2 & 4,8 & 5,6 & 32 & ns & ns & $*$ & 28 & 40 \\
\hline $\mathrm{V} 0-5 \mathrm{~cm}$ & 89 & 87 & 91 & 9 & ns & ns & ns & 2 & 3 \\
\hline V $5-25 \mathrm{~cm}$ & 75 & 72 & 79 & 19 & ns & ns & ns & 10 & 14 \\
\hline V $60-80 \mathrm{~cm}$ & 60 & 56 & 64 & 28 & ns & ns & * & 22 & 31 \\
\hline m $0-5 \mathrm{~cm}$ & 3 & 2 & 4 & 165 & ns & ns & ns & 755 & 1083 \\
\hline m $5-25 \mathrm{~cm}$ & 6 & 4 & 7 & 100 & ns & $*$ & ns & 279 & 399 \\
\hline m $60-80 \mathrm{~cm}$ & 16 & 12 & 20 & 10 & ns & $*$ & ns & 277 & 397 \\
\hline
\end{tabular}

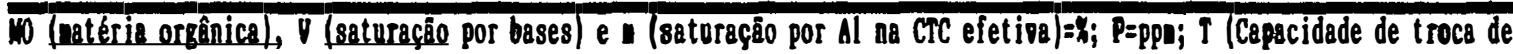

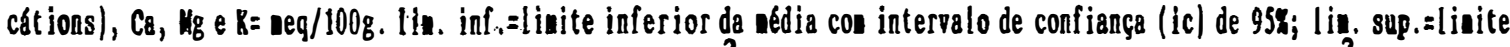
superior da ádia (ic=95x); cv=coeficiente de variaçẫo; $\tau^{2}$ H=teste chi quadrado para distribuição nornal; $\Sigma^{2}$ LN=teste chi quadrado para distribuiçấo lognornal; Mo a/c= ajuste a distribuiçâo nornal pelo aétodo dos nonentos (assinetria e curtose); $a^{\circ} 0,1=n$ ánero de anostras necessárias para estinar a nédia con $10 \%$ de pariação; $a^{\circ} 0,05=$ núnero de anostras necessárias para estinar a nédia con $5 \%$ de variação. 
aluvionares, não mapeados por LEPSCH \& VALADARES (1976) e que são bastante distintos das unidades Pindorama e Concreção ident ificadas no mapeamento da Estação, a primeira constituída por podzólico vermelho amarelo, Tb, eutrófico, abrupto, A moderado, textura arenosa/média, fase relevo ondulado e a segunda por podzblico vermelho amarelo, Ta, distrófico, abrupto, A moderado, textura arenosa/média, fase relevo ondulado. Neste depósitos, numa área pequena, foi aberta uma clareira na mata e feita a implantação de uma pastagem abandonada há 12 anos sobre a qual a mata está em regeneração.

O teor de matéria orgânica diminuiu muito da camada de 0 a 5 para a camada de 5 a $25 \mathrm{~cm}$ de profundidade em toda as parcelas. Apesar de não terem sido observadas diferenças significativas na profundidade de 0 a $5 \mathrm{~cm}$, observou-se uma tendência nesta e na profundidade de $5-25 \mathrm{~cm}$ de os valores serem menores nas parcelas da meia encosta, também confirmada pela observação dos valores em relação aos eixos direcionais. Na profundidade de 60 a $80 \mathrm{~cm}$, apesar da amplitude dos valores médios ter apenas de 1,5\% na parcela 10 até $0,7 \%$ na parcela 11, foram identificadas diferenças significativas, indicando uma diminuição do teor de matéria orgânica das parcelas da parte alta para parte a baixa, tendência esta inversa daquela das camadas superficiais.

A capacidade de troca de cátions nas profundidades de 0 a 5 e 5 a $25 \mathrm{~cm}$ seguiu tendências muito semelhantes às da matéria orgânica, isto é, diminuição em profundidade e um padrão de variação muito semelhante apesar de não terem sido observadas diferenças significativas entre as parcelas. Novamente, no entorno da parcela 11 foram observados valores significativamente menores de CTC na profundidade de 60 a $80 \mathrm{~cm}$, reforçando que esta parcela apresentou-se anômala em relação aos atributos químicos do solo devido à sua origem distinta dos demais solos mapeados na área.

Os teores de cálcio e magnésio trocável foram bem mais elevados na camada de 0 a $5 \mathrm{~cm}$ do que nas demais, não ocorrendo entretanto diferenças significativas entre as parcelas nem tendo sido possível detectar um padrão definido de variação nesta camada. Na camada de 5 a $25 \mathrm{~cm}$ apesar de ter se mantida uma tendência muito semelhante de variação em relação à 
camada superior, na meia encosta e na parcela 11, os valores médios foram menores. Esta tendência manteve-se na profundidade de 60 a $80 \mathrm{~cm}$, provavelmente, pelo fato do Ca trocável estar em sua maior parte ligado à matéria orgânica. A forte ligação do Ca à matéria orgânica do solo de florestas, sendo este o seu principal depósito e, consequientemente a sua dinâmica estar muito ligada à produção e acúmulo de serapilheira e matéria orgânica no solo foi detalhadamente discutida por LIKENS et al. (1977).

o teor de fósforo disponível não apresentou diferenças significativas entre as parcelas nas camadas de 0 a 5 e 60 a $80 \mathrm{~cm}$ de profundidade entretanto, na camada de 0 a $5 \mathrm{~cm}$, a parcela 11 apresentou um valor médio muito superior ao valor das demais parcelas. Os valores médios do teor de $P$ foram menores em profundidade e mantiveram-se significativamente superiores na profundidade de 5 a $25 \mathrm{~cm}$ na parcela 11 . Na profundidade de 60 a $80 \mathrm{~cm}$ os valores foram muito baixos, o teor mais elevado na parcela 11 desapareceu e não foi observada tendência definida de variação. Como a parcela 11 se situa sobre solos aluvionares, o maior acúmulo de $P$ na camada superficial se deve, provavelmente, às frequientes inundações dessa área e a conseqüente deposição superficial de material orgânico, que é um grande acumulador desse elemento nas florestas tropicais (GOLLEY et al., 1978). A pouca mobilidade do $P$, mesmo considerando que os sedimentos são predominantemente arenosos, justifica sua permanência na camada superficial.

o teor de potássio apresentou um comportamento semelhante ao do fósforo, isto é, não foram observadas diferenças significativas na camada de 0 a $5 \mathrm{~cm}$, mas o valor da parcela 11 foi o maior. Na profundidade de 60 a $80 \mathrm{~cm}$ observaram-se diferenças significativas entre as parcelas $e$, novamente, a vizinhança da parcela 11 apresentou valores significativamente inferiores.

A saturação por bases apresentou valores muito elevados na camada de 0 a $5 \mathrm{~cm}$ que decresceram em profundidade, mas, apesar de terem ocorrido diferenças significativas na camada de 0 a $5 \mathrm{~cm}$, a diferença entre o maior valor, que ocorreu na parcela 16 (95\%) e o menor da parcela 10 (81\%), foi pequena. A vegetação parece ter tido um efeito de homogeneização desse 
atributo, provavelmente relacionado à biociclagem de alguns elementos, como apontado por MESSENGER et al. (1978). Na profundidade de 5 a $25 \mathrm{~cm}$ as diferenças entre as parcelas aumentam, ficando novamente os valores significativamente mais baixos no entorno da parcela 11. Na profundidade de 60 a $80 \mathrm{~cm}$ a parcela 11 ainda apresentou valores baixos o que também foi observado em outras parcelas.

Houve diferenças significativas entre as parcelas em todas as profundidades em relação à saturação por alumínio, sendo que, na profundidade de 0 a 5 e 5 a $25 \mathrm{~cm}$ os valores elevados concentraram-se nas parcelas a direita e da parte baixa e na profundidade de 60 a $80 \mathrm{~cm} \mathrm{a}$ parcela 11 apresentou o maior valor de saturação por alumínio que, de uma maneira geral, foi crescente em profundidade.

A análise de variância de uma forma geral, mostrou que a variação dos atributos químicos do solo foi distinto na camada de $0-5 \mathrm{~cm}$ em relação às camadas de maior profundidade sendo que, em profundidade houve uma variação associada principalmente à posição no relevo como topo, meia encosta e baixada. Já, na camada de $0-5 \mathrm{~cm}$ as diferenças significativas observadas não seguiram um padrão regional de grande amplitude, uma vez que foram observados valores máximos e mínimos em parcelas vizinhas, sem ter sido evidente a relação com a posição no relevo. Neste caso, a variação parece ser controlada por condições locais, com escala semelhante a das parcelas ou menor. HAMMER et al. (1987) também observou uma forte associação da posição no relevo com os atributos do solo usando anál ise de variância em florestas de uma única espécie no Tenessee. Pela comparação das médias das parcelas não foi possível ident ificar exatamente - limite das unidades Concreção e Pindorama descritas por LEPSCH \& VALADARES (1976) e representadas na Figura 1.

\subsubsection{Representação dos valores nos eixos direcionais}

Na Figura 16 estão representados os valores observädos' e médios de $\mathrm{pH}$, teores de $\mathrm{Ca}$, $\mathrm{Mg}$ e $\mathrm{K}$ trocáveis, $\mathrm{P}$ disponível, capacidade de troca de cátions, saturação por bases e saturação por alumínio em relação a sua posição nas coordenadas $x, y$ e $z$. 


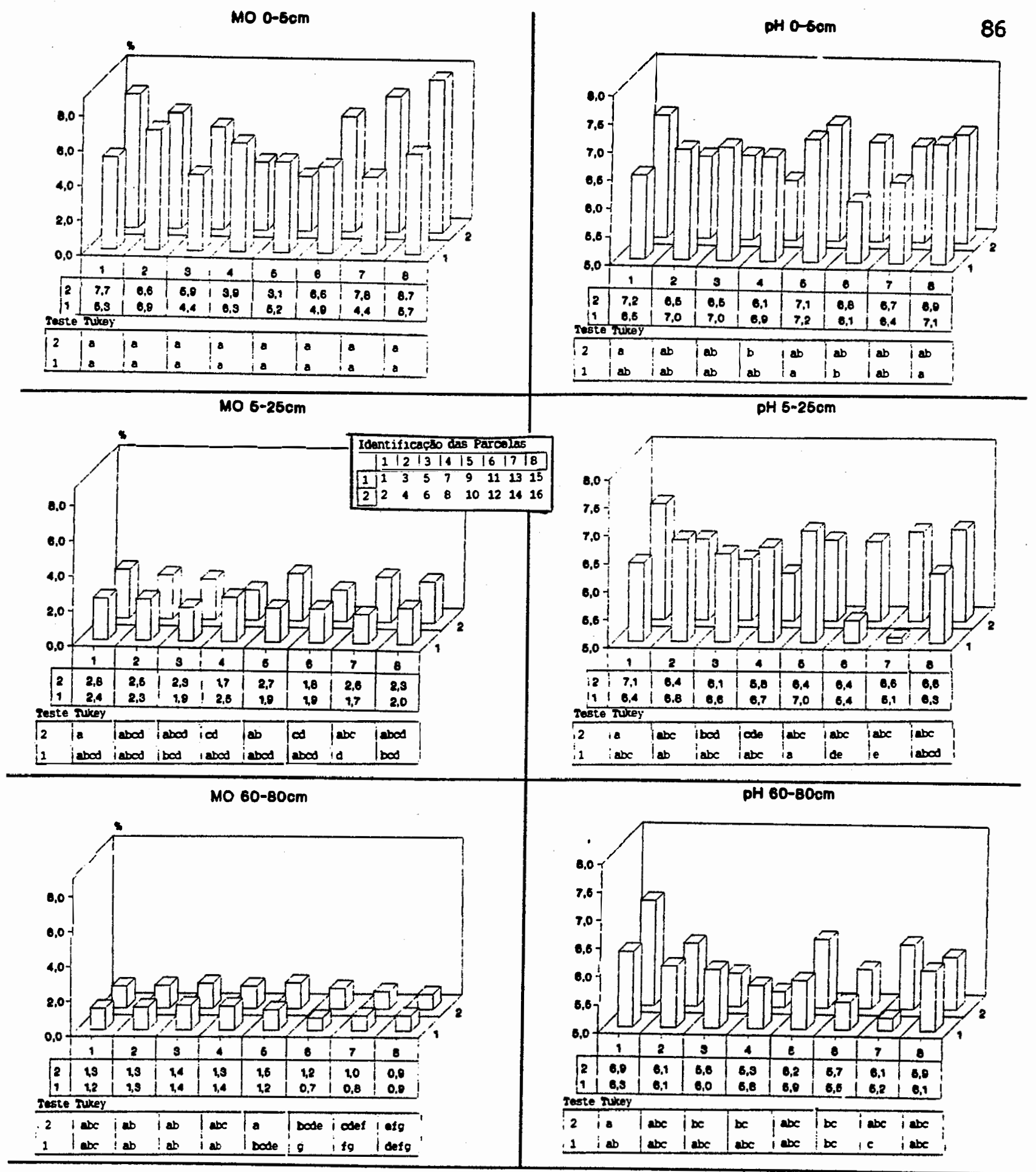

Figura 15 - Valores médios dos atributos químicos do solo nas três profundidades (barras) e diferenças significativas (Tukey 5\%) indicadas por letras distintas. 


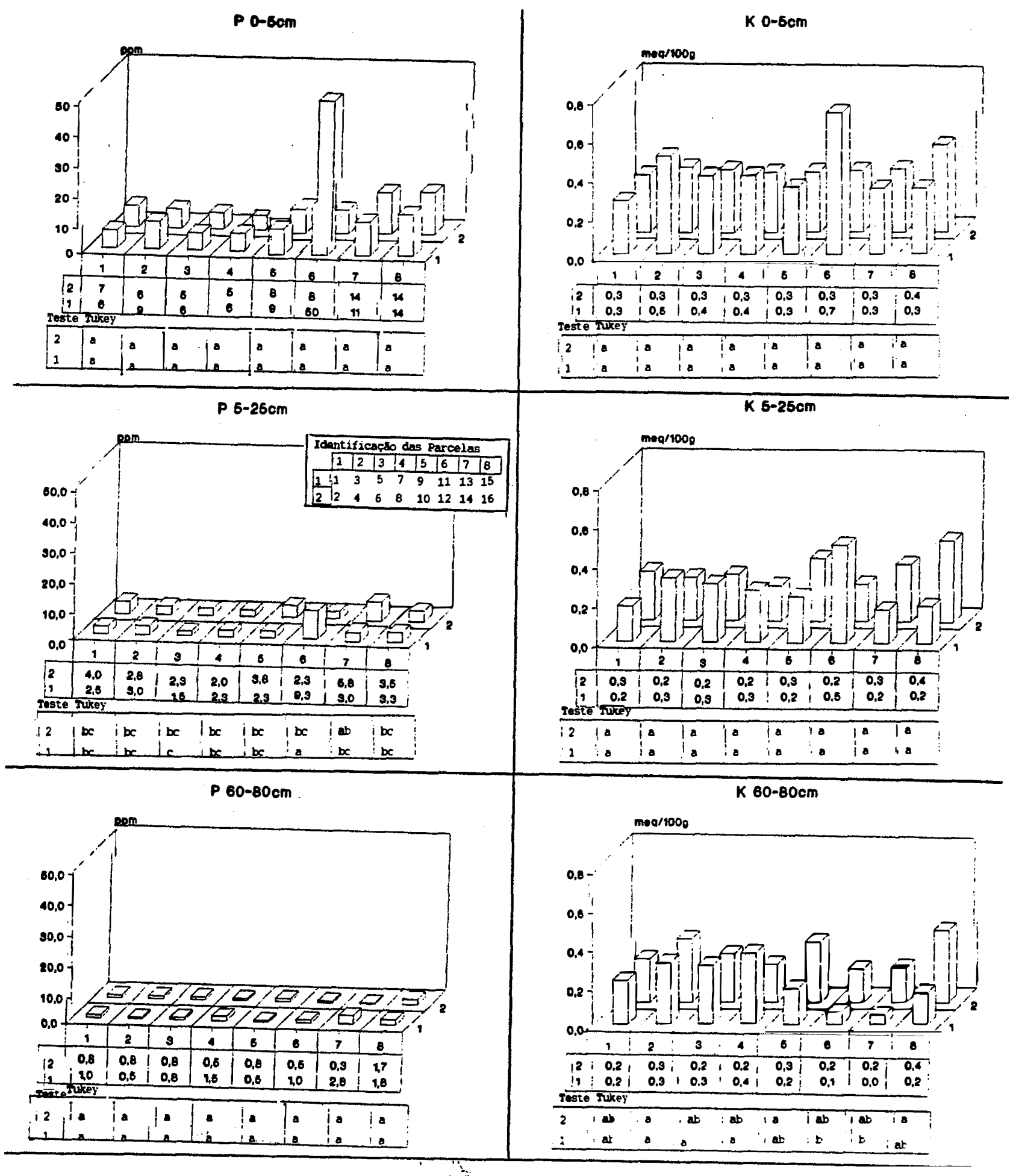

Figura 15 - cont inuação 


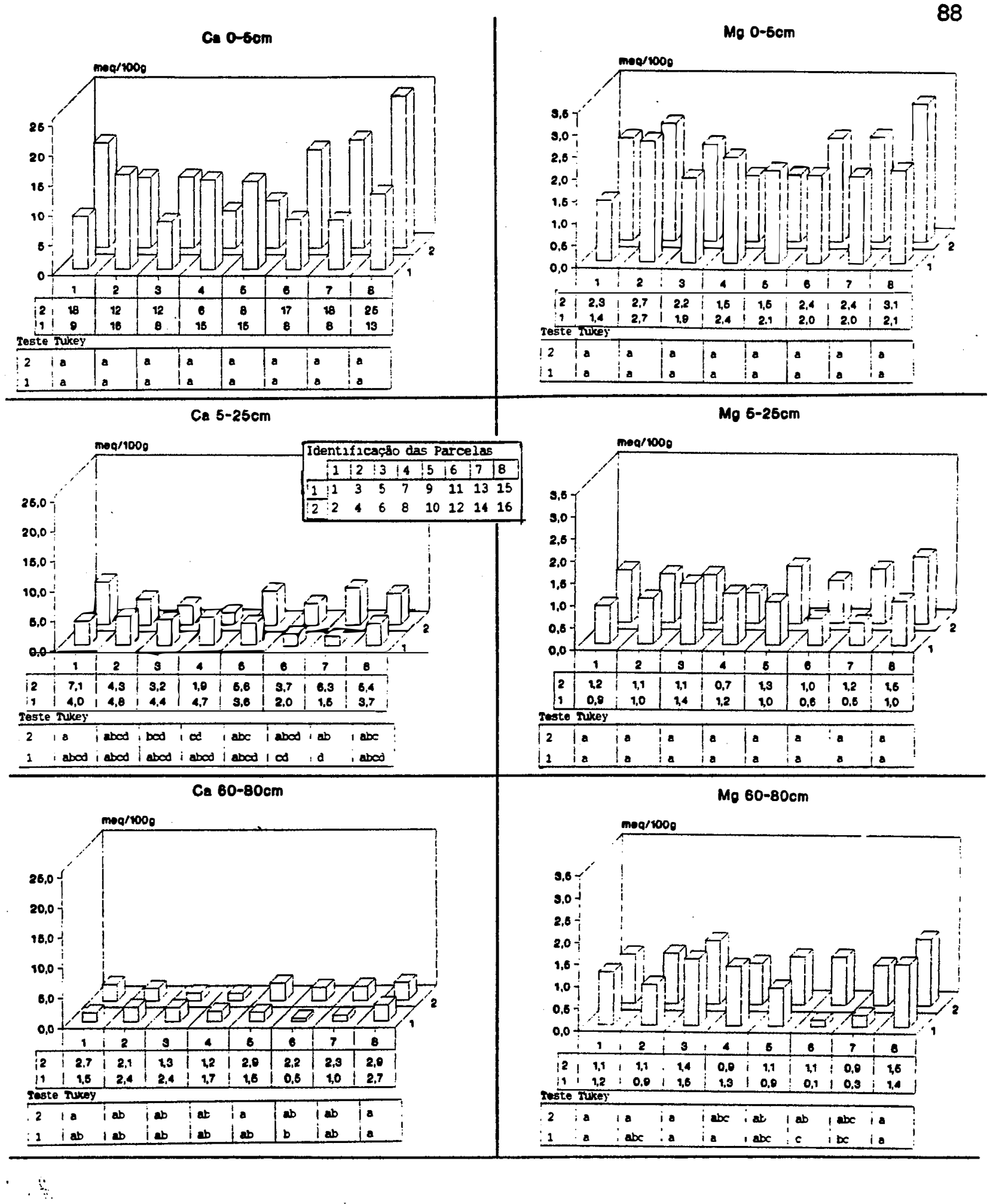

Figura 15 - cont inuação 


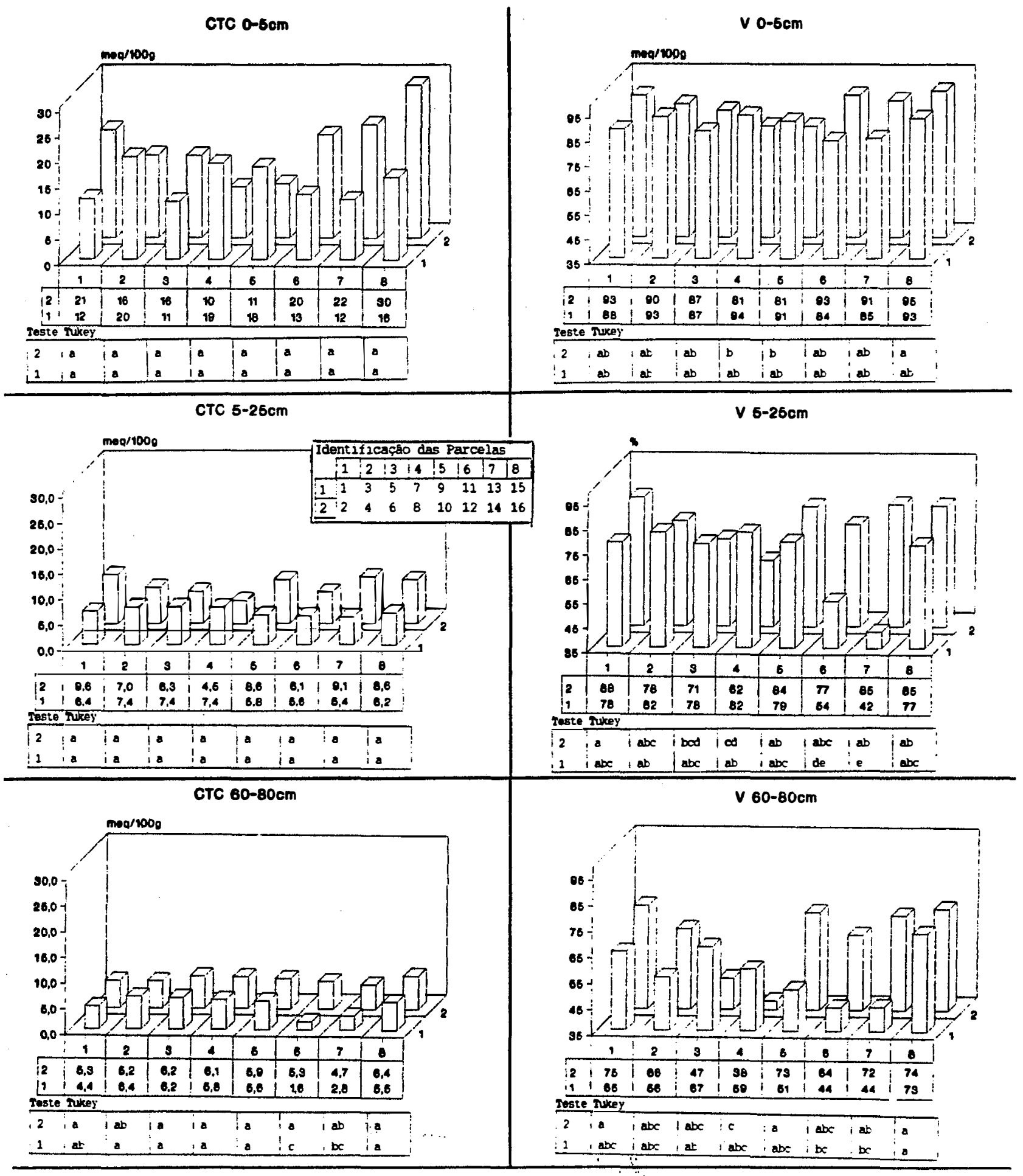

Figura 15 - cont inuação 


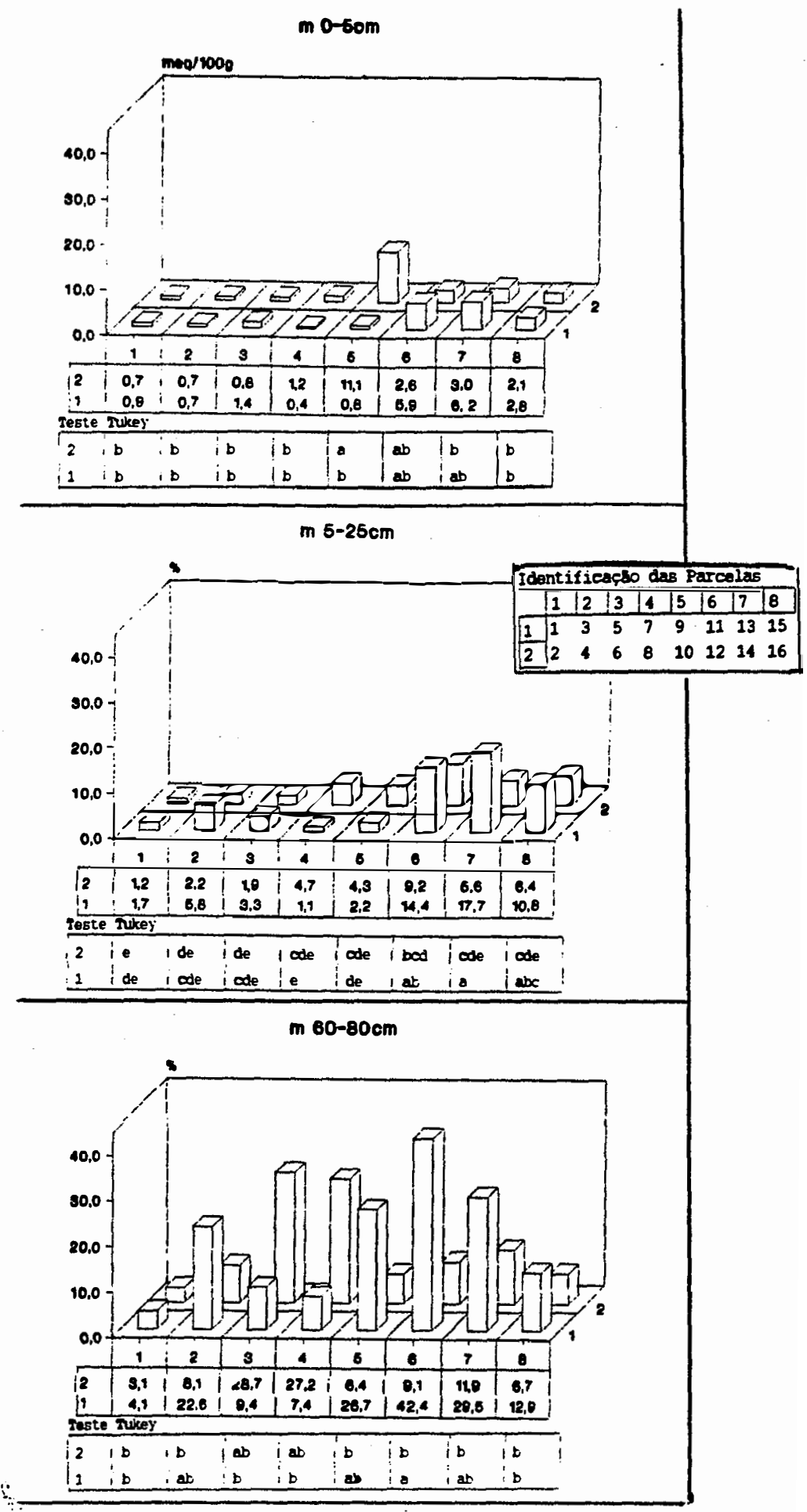

Figura 15 - cont i nuação 


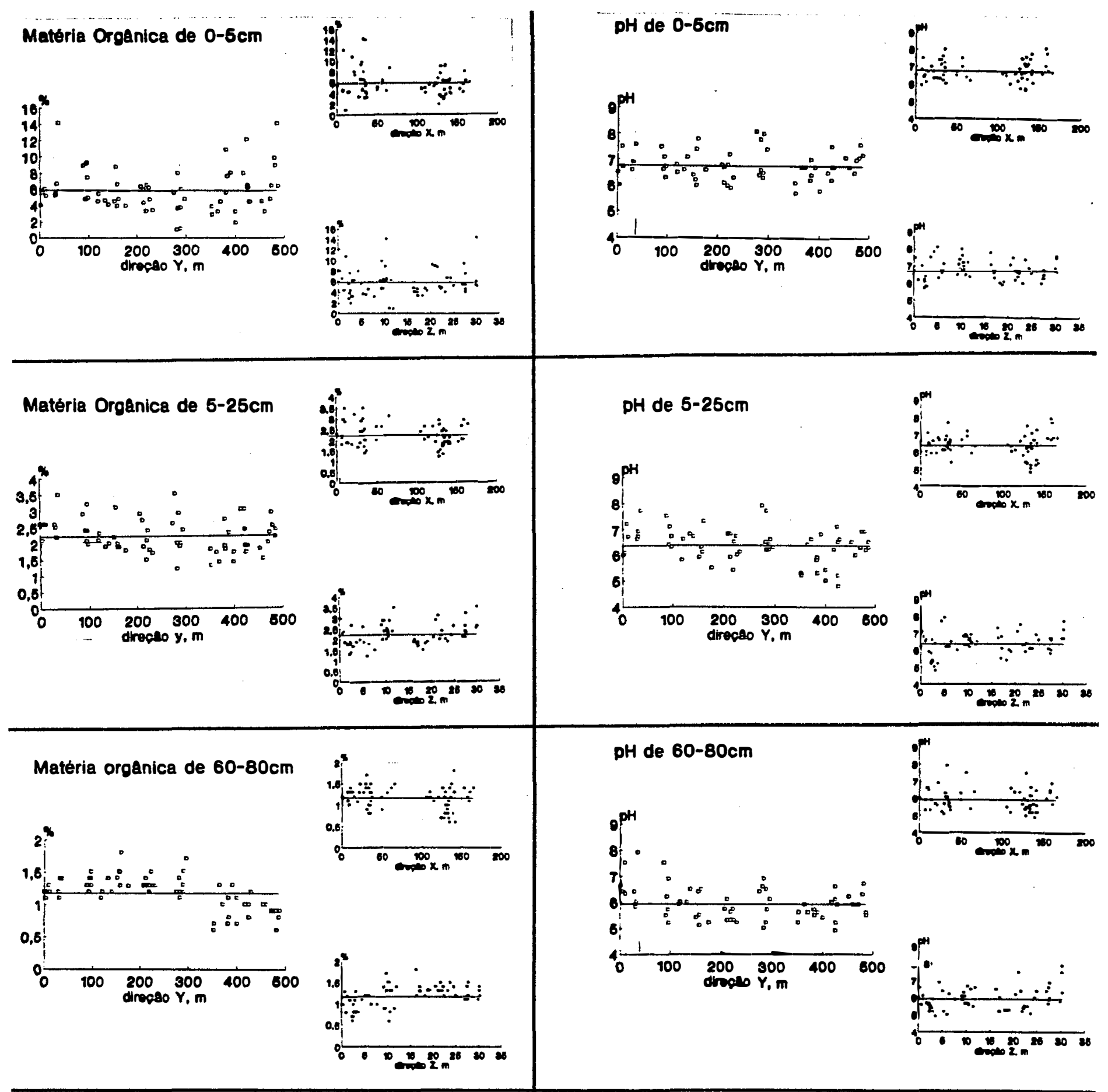

Figura 16 - Representạ̧ão dos atributos químicos do solo nas três profundidades (ponto) e da média (linha cheia) em relação aos eixos direcionais. 


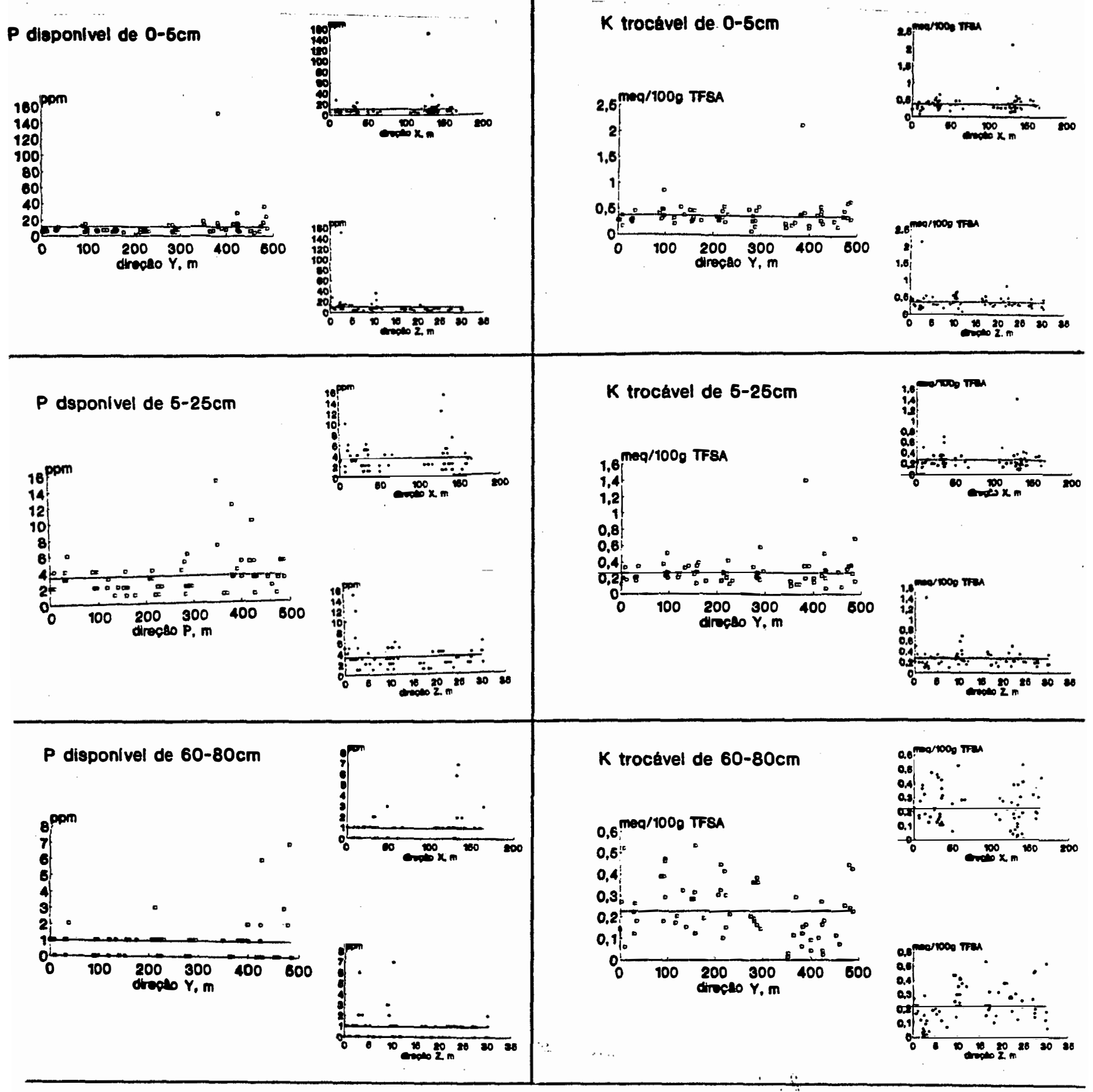

Figura 16 - cont inuação 


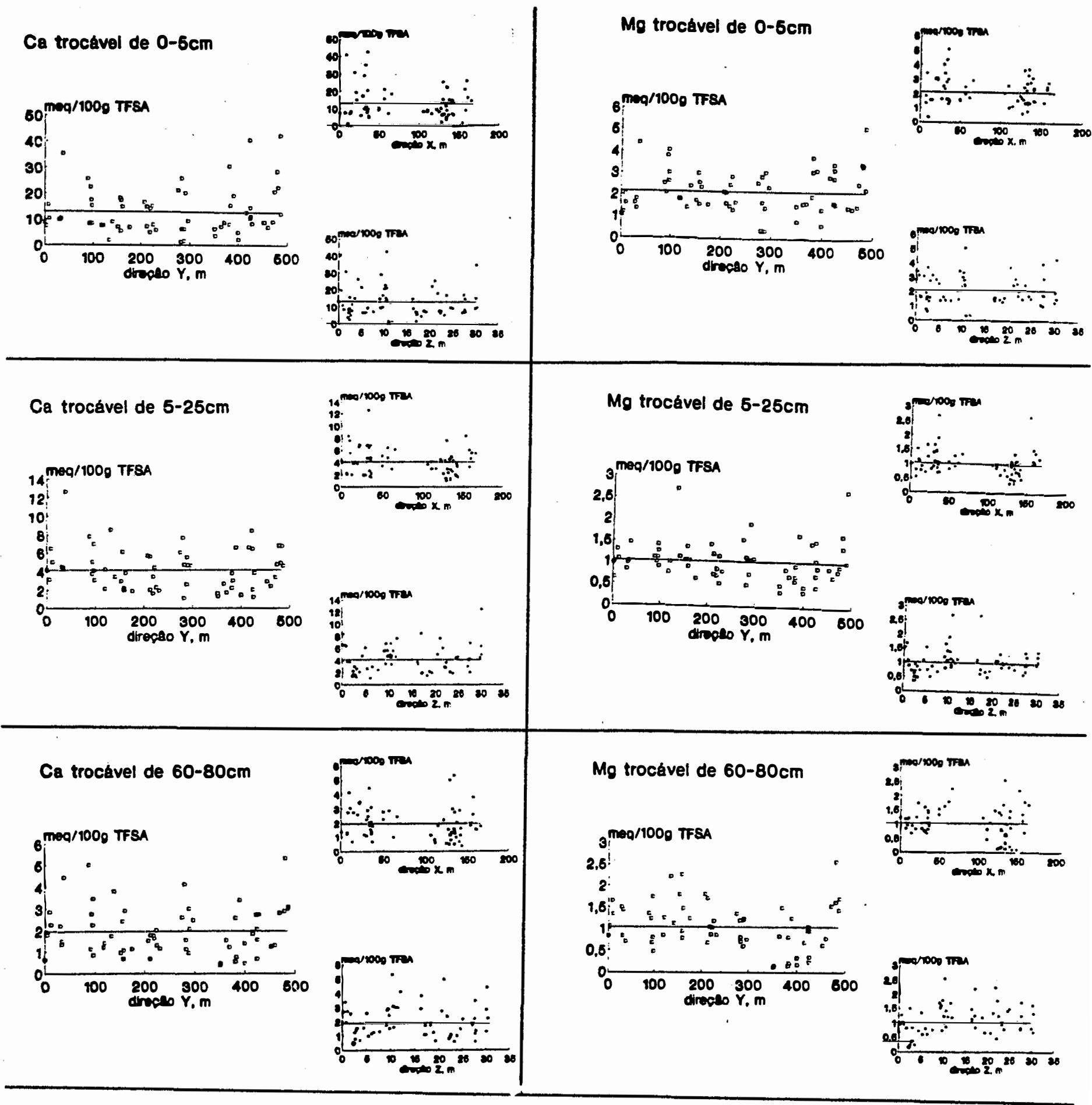

Figura 16 - cont inuação 


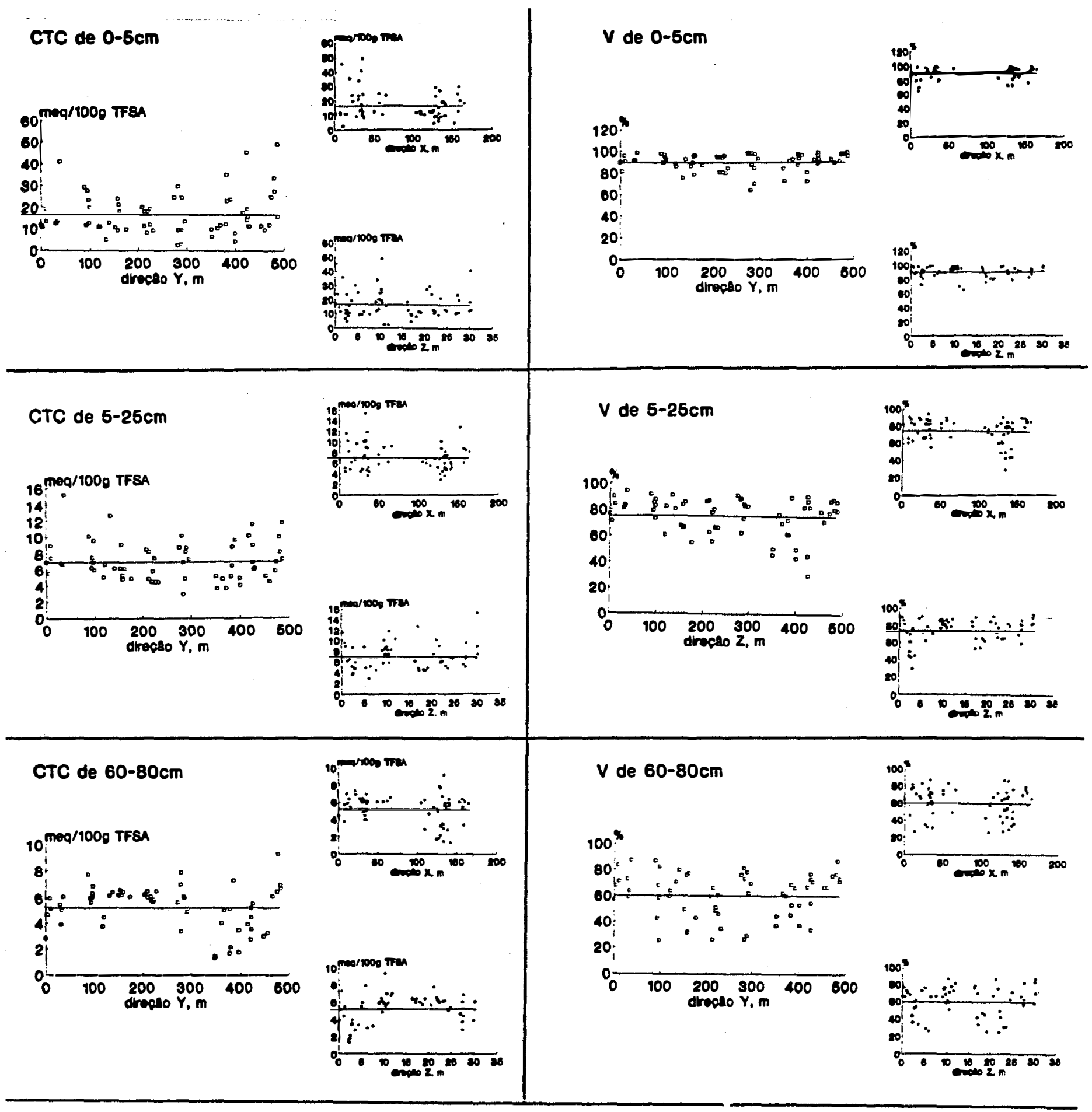

Figura 16 - cont inuação 

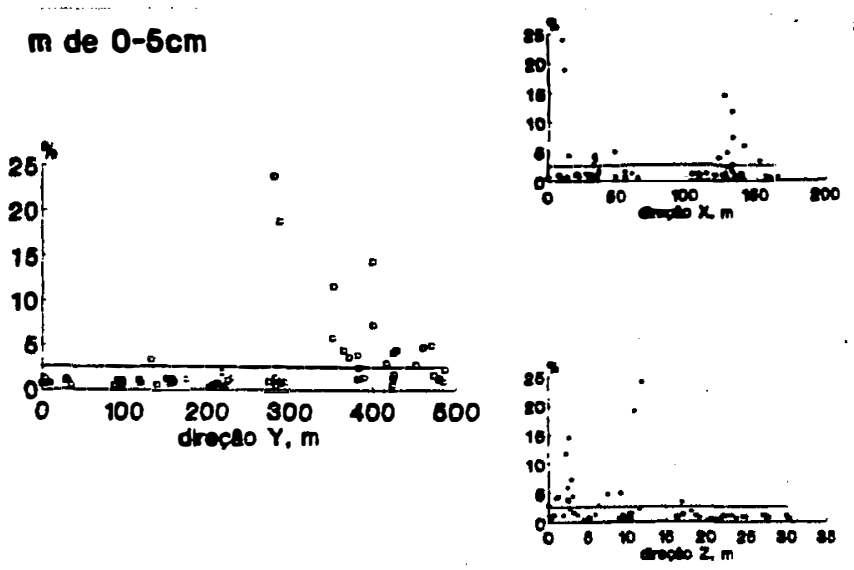

$m$ de $5-25 \mathrm{~cm}$
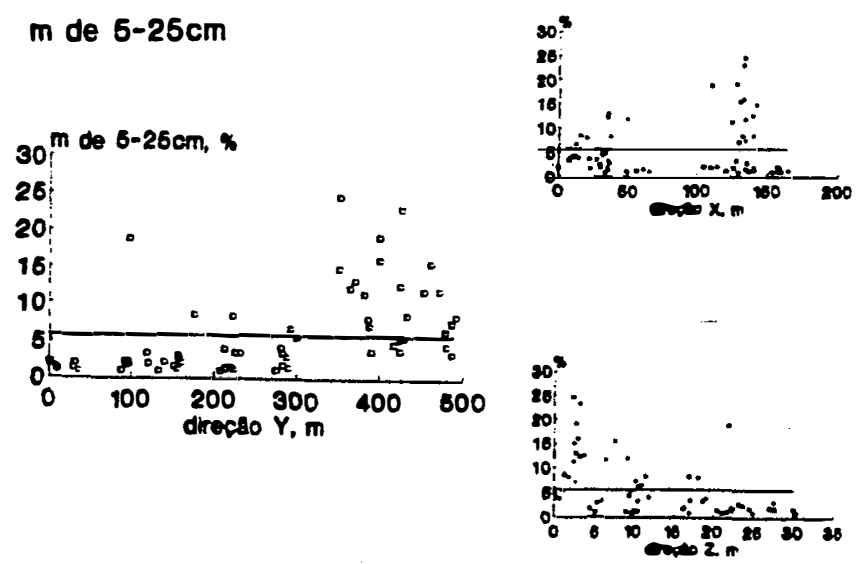

$m$ de 60-80cm
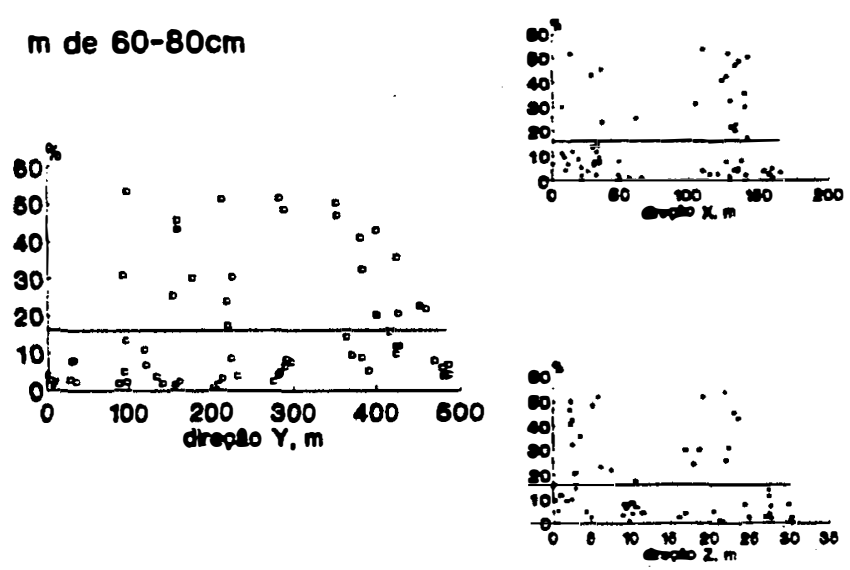

Figura 16 - cont inuação 


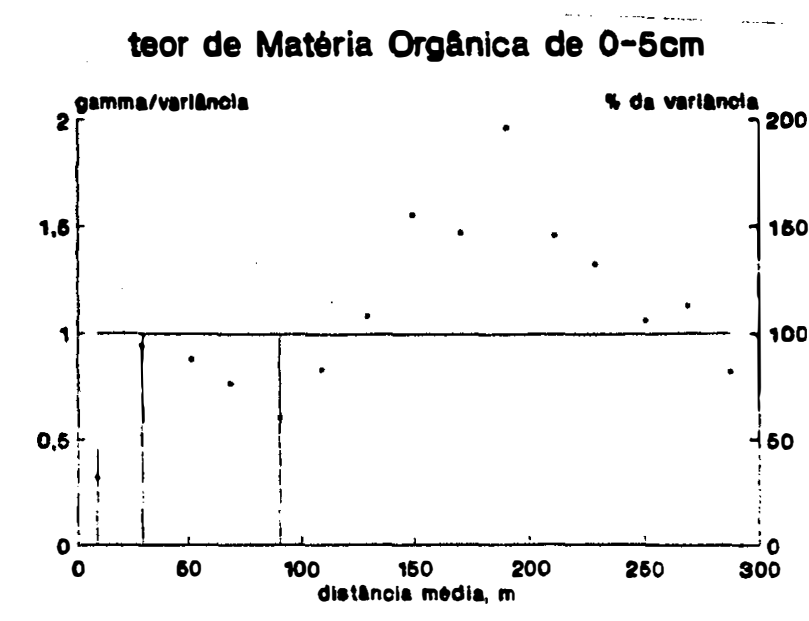

DH de $0-5 \mathrm{~cm}$

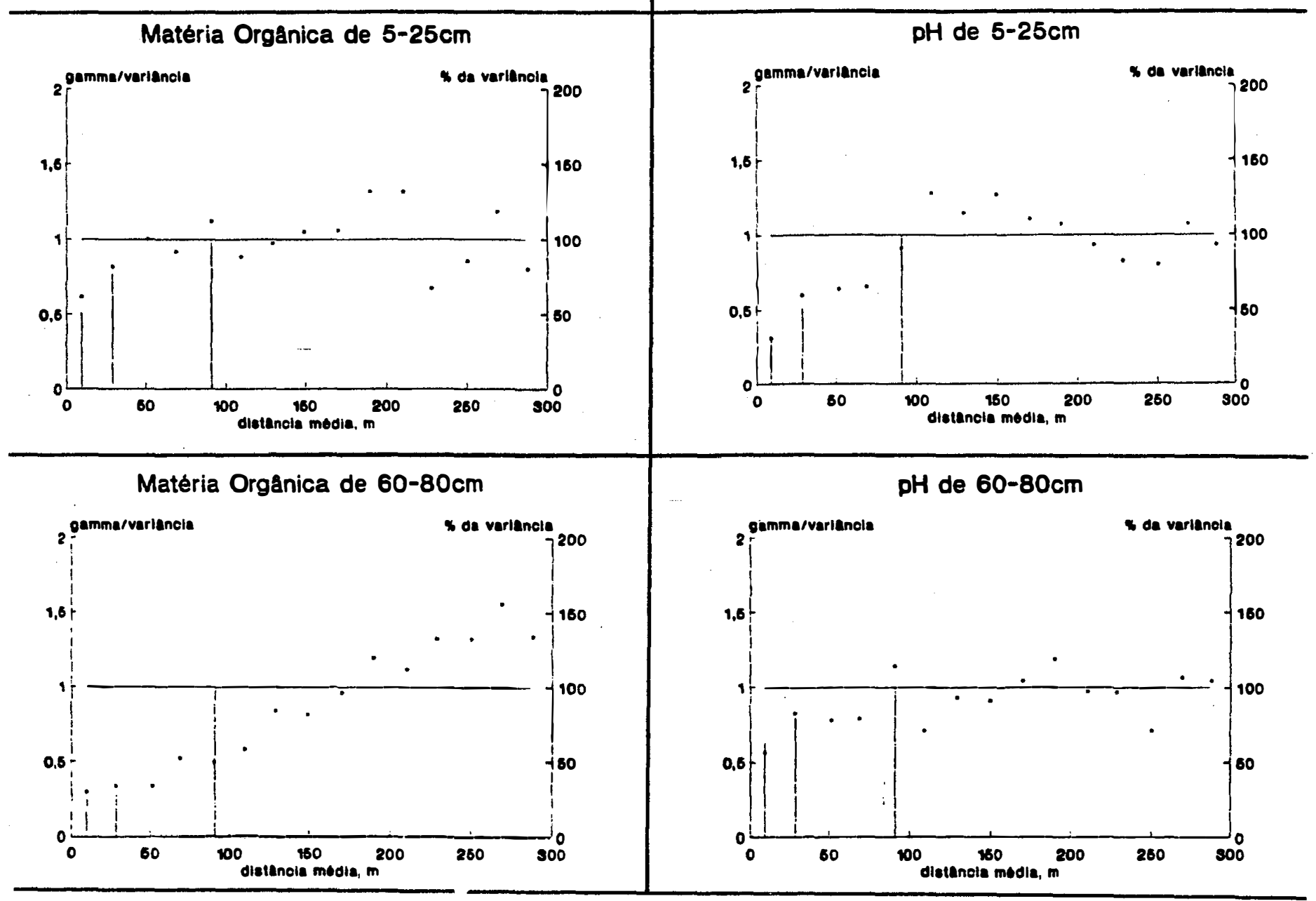

Figura 17 - Semivariância normalizada (pontos) e variância acumulada ( 1 inhas verticàis) em função da distância dos atributos químicos do solo nas três profundidades 
teor de $\mathrm{P}$ disponivel de $0-5 \mathrm{~cm}$

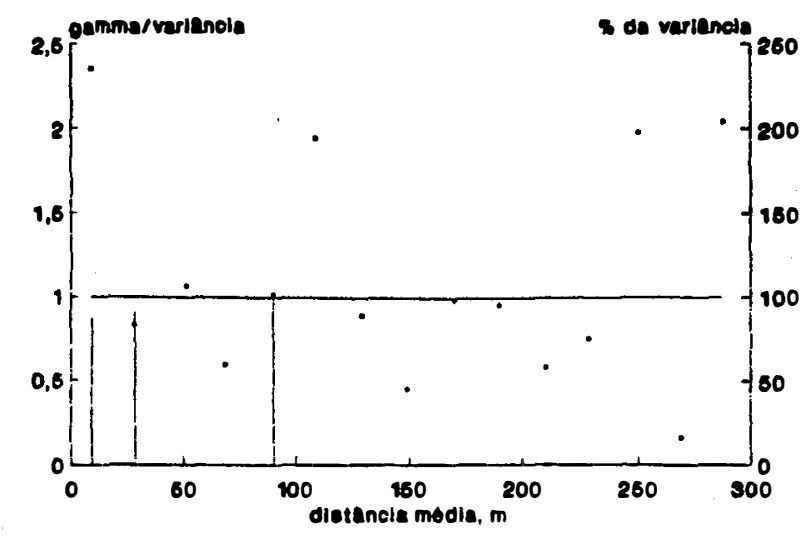

$P$ disponivel de $5-25 \mathrm{~cm}$

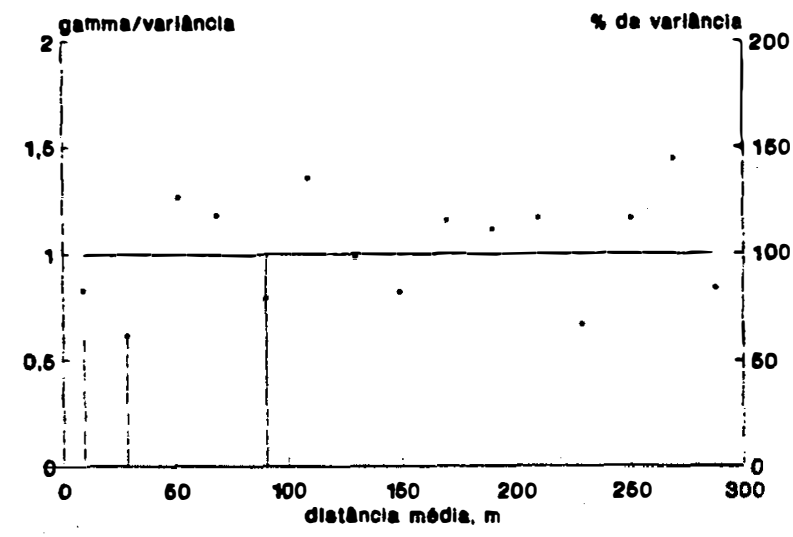

$P$ disponivel de $60-80 \mathrm{~cm}$

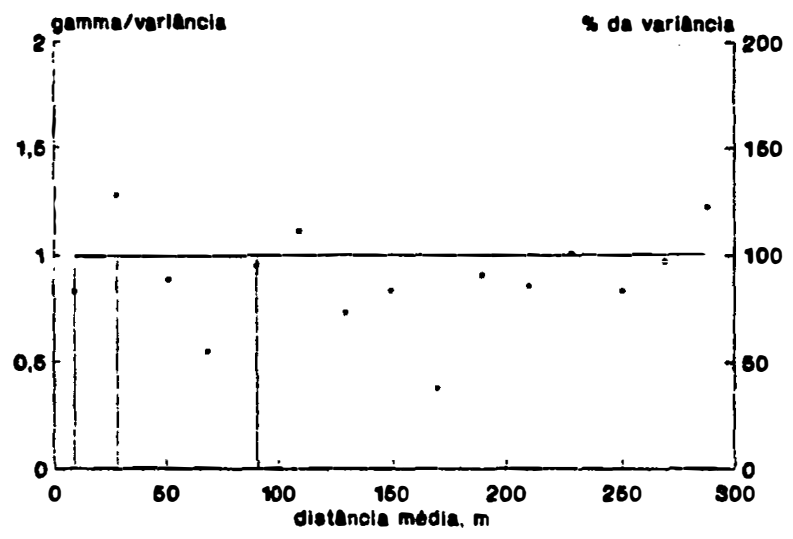

teor de $\mathrm{K}$ trocável de $0-5 \mathrm{~cm}$

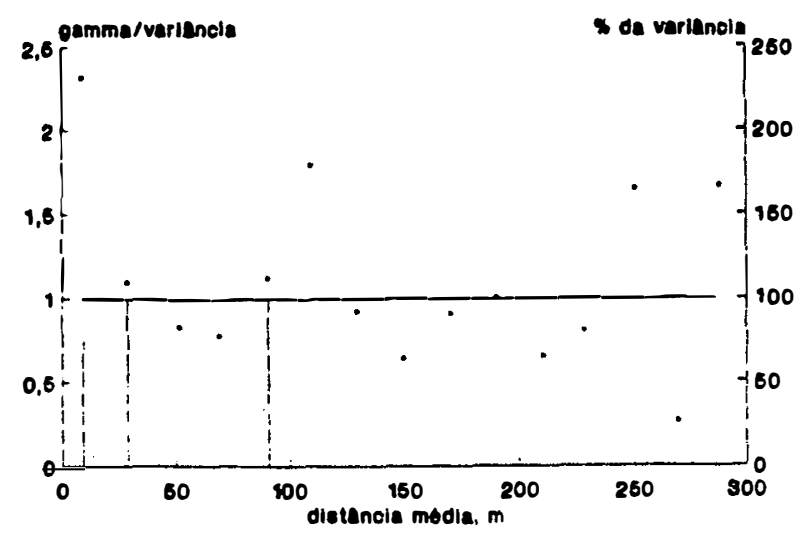

$K$ trocável de $5-25 \mathrm{~cm}$
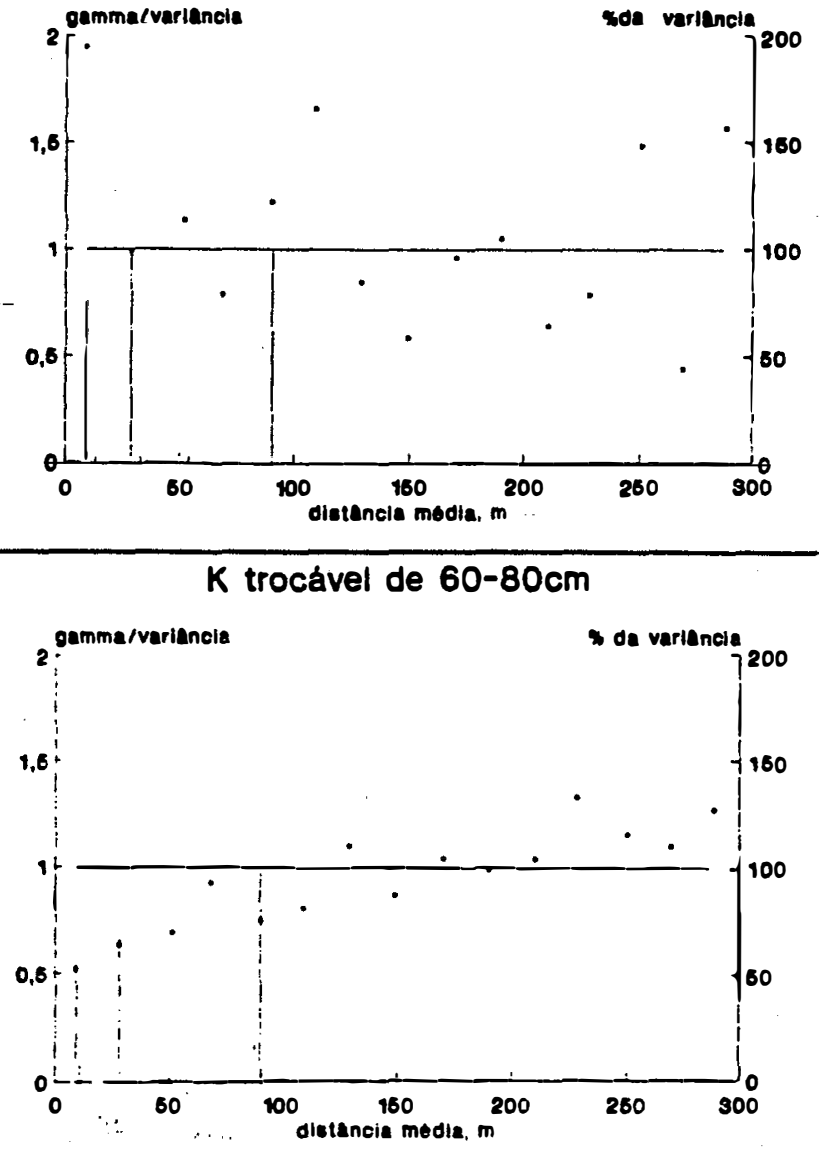

Figura 17 - cont inuação 


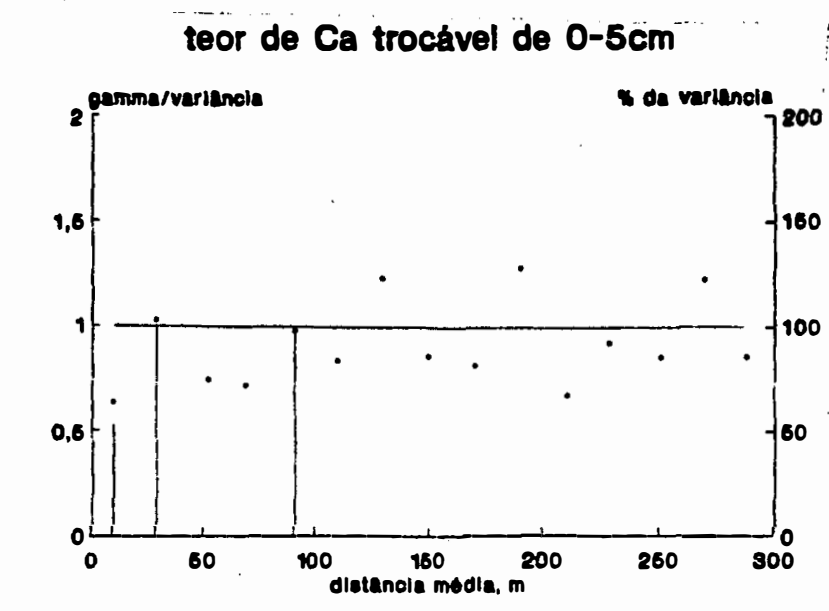

Ca trocável de $5-25 \mathrm{~cm}$
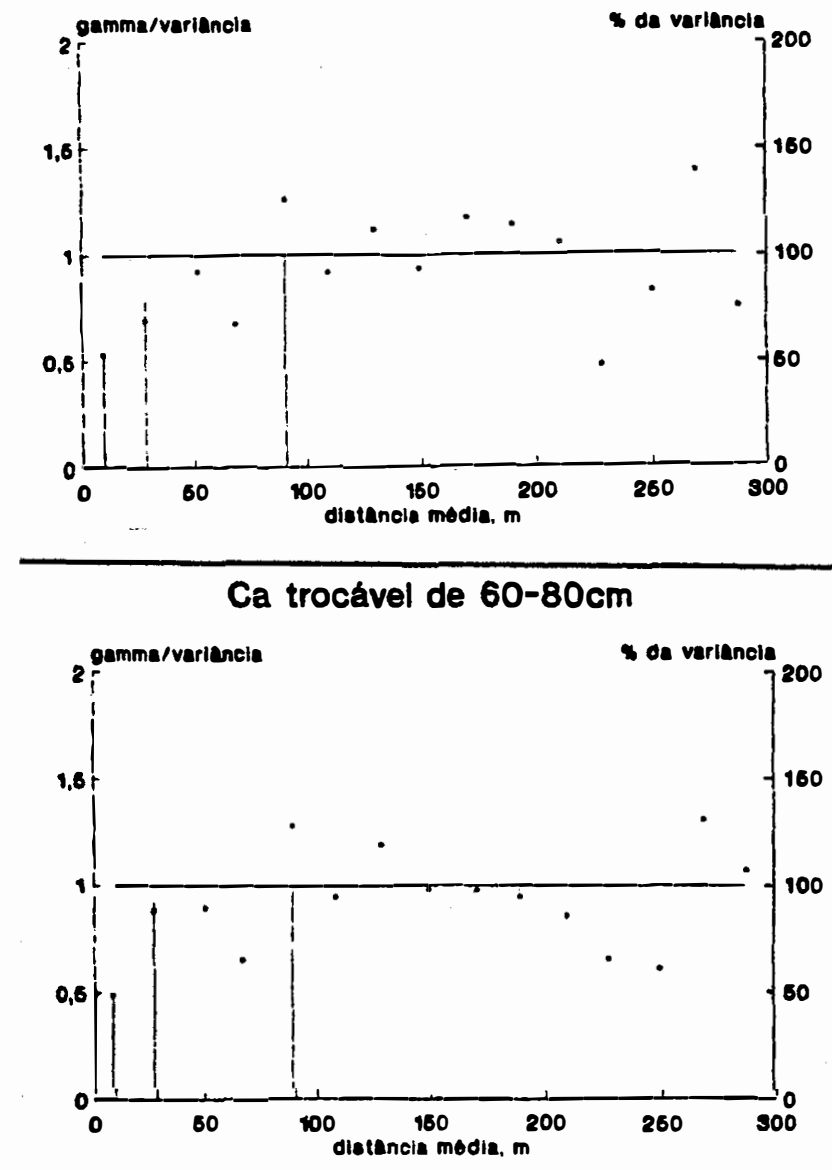

teor de Mg trocável de $0-5 \mathrm{~cm}$

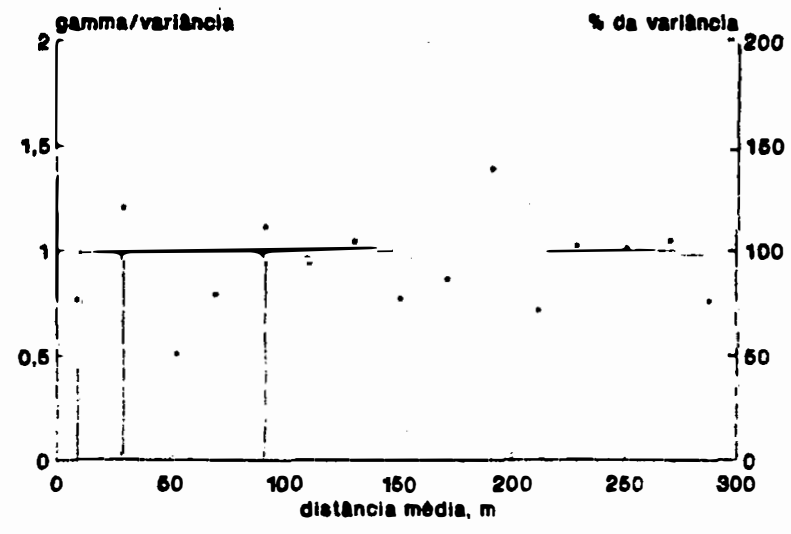

Mg trocável de $5-25 \mathrm{~cm}$

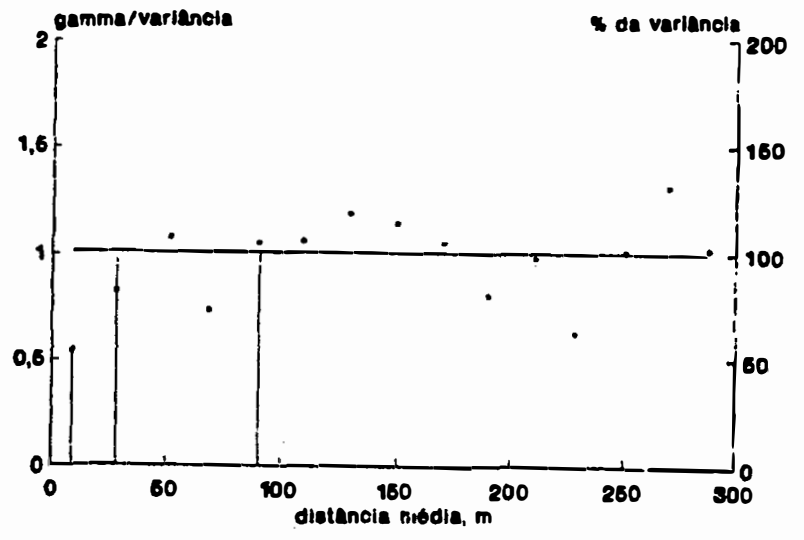

$\mathrm{Mg}$ trocável de $60-80 \mathrm{~cm}$

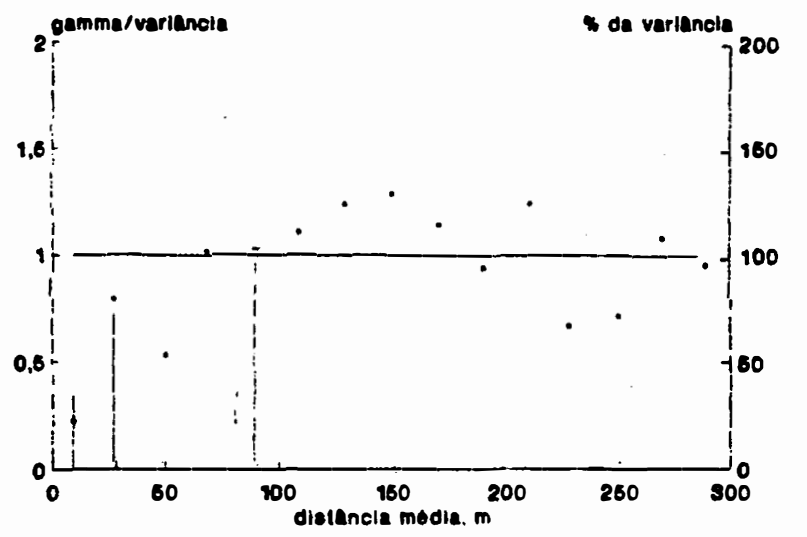

Figura 17 - cont inuação 


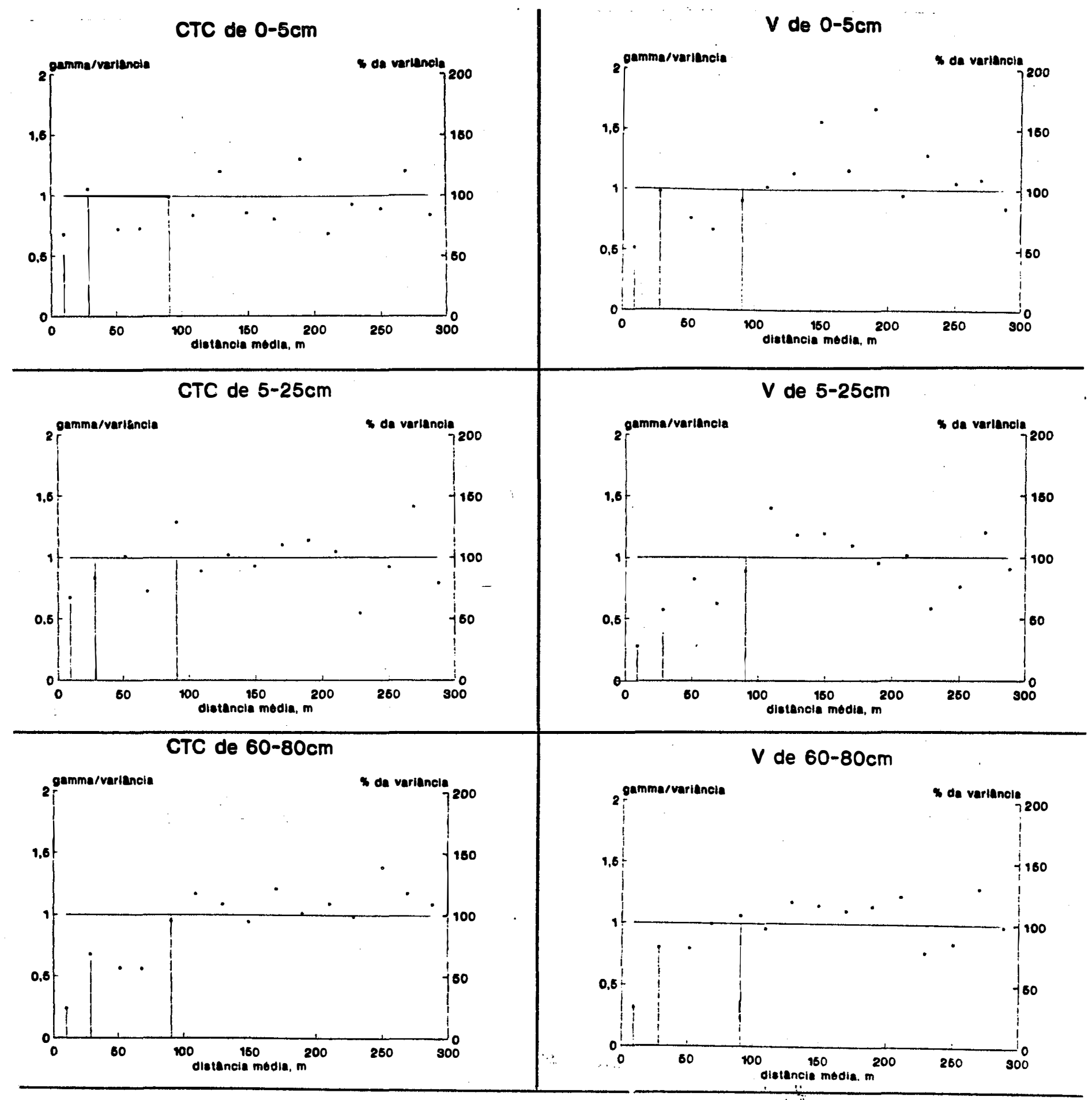

Figura 17 - cont inuação 


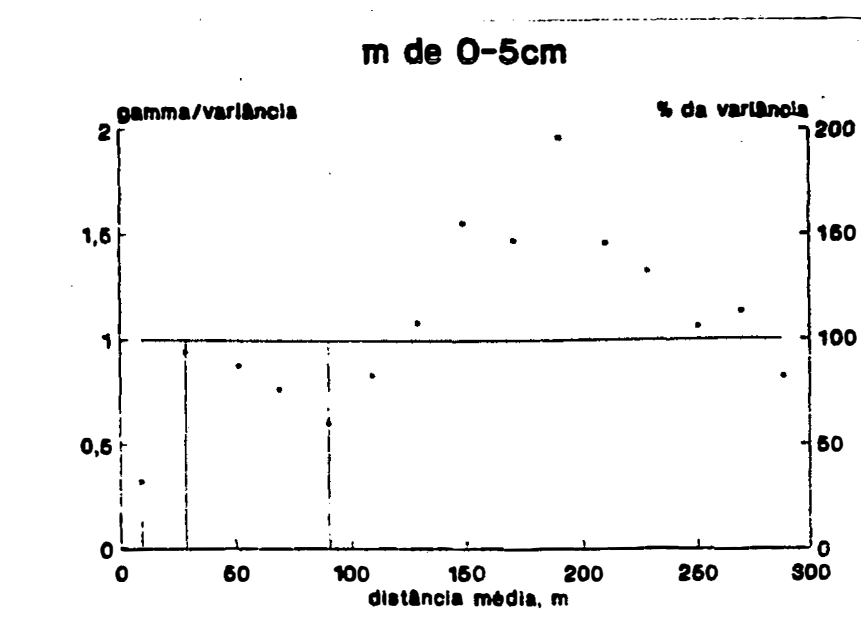

$m$ de $5-25 \mathrm{~cm}$

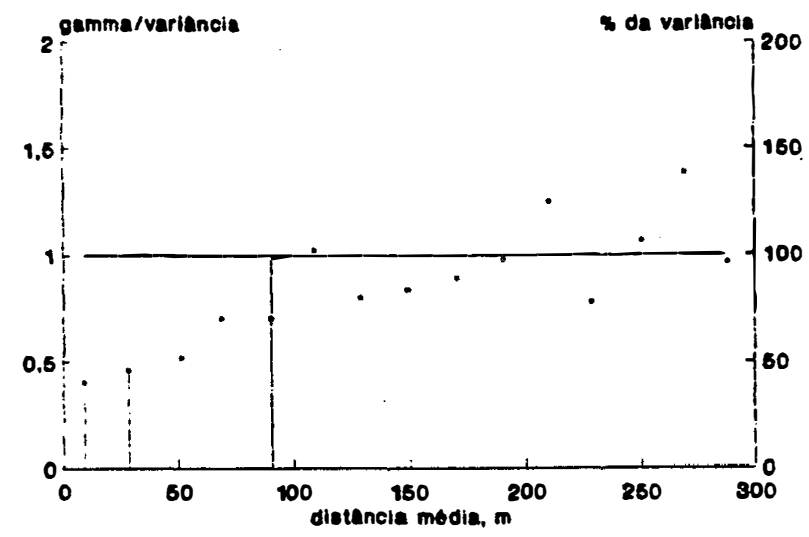

$m$ de $60-80 \mathrm{~cm}$

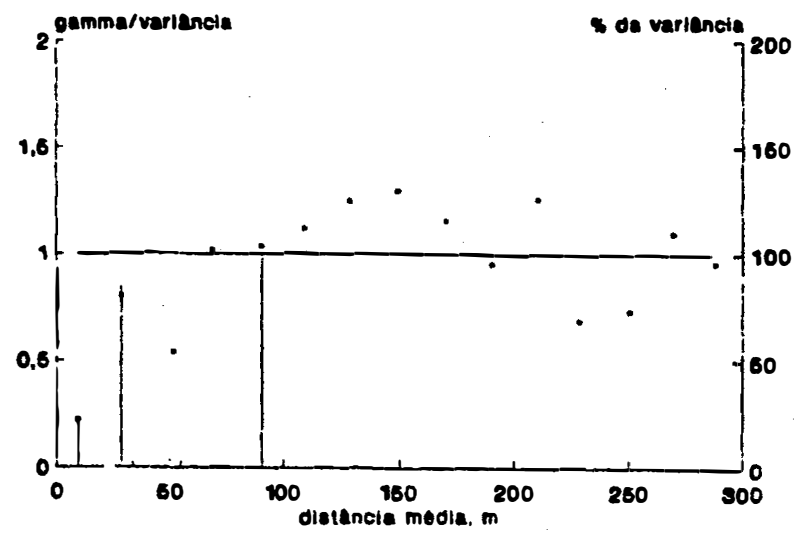

Figura 17 - cont inuação 
No caso do valor do $\mathrm{pH}$, os desvios em relação à média foram pequenos e em relação ao eixo y na camada de 0 a $5 \mathrm{~cm}$ não foi observada tendência definida de variação tendo os valores se distribuído uniformemente próximos ao valor médio ao longo de todo o eixo. Nas profundidades de 5 a 25 e 60 a $80 \mathrm{~cm}$ os valores do $\mathrm{pH}$ foram mais elevados nos valores baixos de $y$, correspondente ao topo, e mais baixos com valores de y entre 350 e $400 \mathrm{~m}$, correspondente ao terço inferior da encosta (Figura 2). Esta tendência foi mais evidente no eixo $z$ sendo que nas cotas mais baixas os valores do $\mathrm{pH}$ foram menores $\mathrm{e}$ nas mais elevadas observaram-se, freqüentemente, valores de $\mathrm{pH}$ acima da média. A distribuição dos solos na área verificada por LEPSCH \& VALADARES (1976) com a ocorrência da unidade Pindorama constituída de solos eutróficos no topo e a unidade Concreção de solos distróficos no terço inferior da encosta confirma esta tendência. Da mesma forma que para a saturação por bases verificou-se para o pH uma tendência de maior homogeneização na camada de $0-5 \mathrm{~cm}$ de profundidade em relação às demais, isto $e$, não foi verificado um padrão definido de variação em relação à posição no relevo e o coeficiente de variação foi mais baixo do que nas camadas mais profundas.

o teor de matéria orgânica apresentou tendências bea definidas de variação sendo que na profundidade de 0 a $5 \mathrm{~cm}$ ocorreu grande dispersão dos valores ou grande amplitude de variação de 0 a 100 e 350 a $500 \mathrm{~m}$ no eixo $y$ e de 0 a $50 \mathrm{~m}$ no eixo $x$. Na camada de 5 a $25 \mathrm{~cm}$ evidenciou-se uma tendência de os teores de matéria orgânica serem mais baixos nas cotas inferiores o que ficou mais evidente na profundidade de 60 a $80 \mathrm{~cm}$, indicando que a distribuição dos teores de matéria orgânica do solo na camada superficial de $0-5 \mathrm{~cm}$ obedeceram a um padrão diferente de variação do que os das camadas mais profundas. As diferenças em relação à posição no relevo ficaram bem evidentes apenas na camada de $60-80 \mathrm{~cm}$. Assim, na profundidade de 0 a $5 \mathrm{~cm}$ a variação do teor de matéria orgânica deve estar associada aos processos de dinâmica superficial e de escala espacial pequena, como produção e acúmulo de serapi lheira e precipitação interna, que apresentaram comportamento semelhante. Nas camadas mais profundas, a variação deve estar relacionada a processos que ocorrem numa escala 
espacial maior como os processos pedogenéticos ou de formação do relevo. HAMER et al. (1987) também observou a associação dos atributos do solo com a posição no relevo em florestas nos EUA.

A capacidade de troca de cátions seguiu aproximadamente a mesma tendência dos teores de matéria orgânica. Ficou evidente uma tendência de valores com desvios negativos elevados na profundidade de 60 a $80 \mathrm{~cm}$ no eixo y de 350 a $450 \mathrm{~m}$, correspondente às cotas mais baixas. Observou-se também, como no caso da matéria orgânica, uma dispersão maior dos valores no eixo $x$ de 0 a $50 \mathrm{~m}$ na camada de 0 a $5 \mathrm{~cm}$, sugerindo que a contribuição da matéria orgânica na capacidade de troca de cátions nestes solos seja muito grande.

o teor de potássio trocável não apresentou tendência definida de variação nas profundidades de 0 a 5 e 5 a $25 \mathrm{~cm}$. A presença de um valor anômalo, com desvio positivo muito grande foi observada nas duas profundidades. Na profundidade de 60 a $80 \mathrm{~cm}$ ocorreu uma região de valores com desvio negativo entre os 350 e $450 \mathrm{~m}$, correspondente ao terço final das encostas.

o fósforo também apresentou um valor anômalo com desvio positivo muito grande na profundidade de 0 a $5 \mathrm{~cm}$. Nas profundidades de 5 a $25 \mathrm{~cm}$ e, principalmente de 60 a $80 \mathrm{~cm}$ os valores mais elevados de fósforo disponível concentraram-se acima de $350 \mathrm{~m}$ no eixo y e nas cotas mais baixas. Em relação ao eixo $x$, nenhuma tendência definida de variação ficou evidenciada.

O teor de cálcio trocável apresentou uma forte tendência de valores com desvio negativo em todas as profundidades no eixo $x$ de 120 a $150 \mathrm{~m}$ e o teor de magnésio trocável não apresentou tendências muito definidas de variação na camada de 0 a $5 \mathrm{~cm}$. O desvio negativo no eixo $x$ de 120 a $150 \mathrm{~m}$ e no eixo y de 350 a $450 \mathrm{~m}$ ficou evidente nas profundidades de 5 a 25 e 60 a $80 \mathrm{~cm}$.

A saturação por bases apresentou desvios pequenos na camada de 0 a $5 \mathrm{~cm}$ sem tendência definida de variação. Na camada de 5 a $25 \mathrm{~cm}$ os desvios negativos no eixo $\mathrm{y}$ de 350 a $450 \mathrm{~m}$ e $\mathrm{x}$ de 120 a $150 \mathrm{~m}$ foram bem evidentes, indicando a presença dos depósitos aluvionares. Além disso, na direção y até aproximadamente $150 \mathrm{~m}$ os valores são mais elevados, coincidindo com a 
distribuição dos solos na área identificada no mapeamento, isto é, solos eutróficos no topo e distróficos no final das encostas. Na camada de 60 a $80 \mathrm{~cm}$, apesar de exist irem alguns valores com elevada saturação por bases no eixo y em torno de $300 \mathrm{~m}$, área já influenciada pelos depósitos aluvionares, observam-se valores mais baixos de saturação por bases entre os 200 e $400 \mathrm{~m}$ no eixo y, correspondendo às cotas mais baixas de z. Esta faixa delimita de forma clara as unidades Pindorama com alta saturação por bases no horizonte $B$ e Concreção com baixa saturação por bases no horizonte B. Aparentemente a camada de $0-5 \mathrm{~cm}$ de profundidade, em relação à saturação por bases, não foi sensível aos processos que diferenciaram seu valor nas camadas mais profundas como material de origem, processos pedogenéticos e tempo de formação do solo distintos. Seu valor parece estar mais diretamente relacionado à biociclagem dos nutrientes, como sugerido por MESSENGER et al. (1978), que neste caso levou a sua homogeneização. O comportamento distinto, em maior ou menor grau, de vários elementos na camada de $0-5 \mathrm{~cm}$ de profundidade em relação às demais, em praticamente todos os procedimentos estatísticos realizados, reforçam esta idéia.

Valores anômalos de saturação por alumínio, com desvio positivo foram observados na camada de 0 a $5 \mathrm{~cm}$. Na camada de 5 a $25 \mathrm{~cm}$ observou-se uma tendência dos valores de saturação por alumínio aumentarem com o aumento dos valores do eixo y, e diminúr rem com o aumento da cota. Na camada de 60 a $80 \mathrm{~cm}$ a dispersão dos valores foi grande não tendo sido observada forte tendência de variação em nenhum eixo.

De uma maneira geral, as tendências de distribuição dos valores dos atributos químicos estudados ao longo dos eixos foi diferente para a camada superficial do solo mineral de $0-5 \mathrm{~cm}$ em relação às camadas de 5-25 e $60-80 \mathrm{~cm}$. Nestas duas últimas, principalmente na camada de $60-80 \mathrm{~cm}$, as diferentes tendências observadas parecem acompanhar a posição no relevo, ou seja topo, meia encosta e baixada. Na camada superficial, normalmente a dispersão dos valores foi maîor e as relações com a posição no relevo pouco evidentes. Provavelmente, a maior relação dessa camada com os processos da dinâmica superficial diminua sua relação com os processos 
pedogenéticos, mais relacionados com o relevo, e provavelmente responsáveis pelas variações nas camadas subsuperficiais.

A anomalia no entorno da parce la 11, localizada no eixo entre 312 e 375m ficou mais evidente pela observação dos valores do que na comparação das médias das parcelas. Valores anômalos de alguns atributos químicos do solo em determinados pontos de amostragem também foram observados por vUONO (1985) numa floresta de São Paulo e por RODRIGUES (1991) numa amostragem sistemática de atributos químicos e granulométricos do solo numa floresta às margens do Rio Passa Cinco em Ipeúna (SP) que neste caso estavam associados a características de microrelevo. Foram observadas tendências diferentes em várias profundidades nesta região para quase todos os atributos observados. Na comparação das médias apareceram diferenças significativas apenas para alguns atributos em algumas profundidades. Além disso, ficou evidente que a região de influência dos solos aluvionares é maior do que a parcela, estendendo-se no eixo y até 400 ou $450 \mathrm{~m}$, fato não constatado pela comparação das médias das parcelas.

\subsubsection{Semivariograma e análise hierárquica de variância}

Na Figura 17 são representados os semivariogramas e os resultados da análise de variância em níveis hierárquicos dos valores de $\mathrm{pH}$, teores de Ca, Mg e $\mathrm{K}$ trocáveis, $\mathrm{P}$ disponível, capacidade de troca de cátions, saturação por bases e saturação por alumínio.

Os semivariogramas do valor $\mathrm{pH}$ apresentaram estrutura de variação bem definida nas profundidades de $0-5$ e $5-25 \mathrm{~cm}$ sendo que o efeito pepita foi de 0,11 e $o$ alcance $43 \mathrm{~m}$ na profundidade de $0-5 \mathrm{~cm}$ e 0,27 e $122 \mathrm{~m}$ na profundidade de $5-25 \mathrm{~cm}$ calculados por ajuste de uma equação esférica. Na profundidade de $60-80 \mathrm{~cm}$ o modelo esférico não foi significativo a $10 \%$ de probabilidade de F, entretanto, verificou-se um claro aumento do alcance em profundidade. A variância acumu lada pela análi se hierárquica acompanhou a tendência dos semivariogramas e os dois métodos foram eficientes para detectar a relação da variância com a distância entre os pontos de amostragem. BRINGMARK (1989) observou estruturas de variação bem definidas do $\mathrm{pH}$ do solo em relação à distância em florestas de coníferas no sul da 
Suécia, porém em intervalos de distância menores, de apenas alguns centímetros. RIHA et al. (1986) estudaram floreștas homogêneas plantadas sobre solos cultivados nos anos 40 em Dryden (EUA) e observaram que grupamentos de árvores de diferentes espécies alteraram o valor do $\mathrm{pH} e$ o teor de carbono do solo.

O semivariograma do teor de matéria orgânica na profundidade de 0 a $5 \mathrm{~cm}$ apresentou grande flutuação em torno de 1, evidenciando a presença de variações cíclicas indicando que os fatores que causaram a sua variação repetiram-se em intervalos de distância pequenos. 0 coeficiente de determinação de ajuste do modelo esférico foi de 0,18. Na profundidade de 5 a $25 \mathrm{~cm}$ o efeito pepita foi de 0,49 , mostrando que o componente casual foi bastante elevado e o alcance foi de $62 \mathrm{~m}$. Na profundidade de 60 a $80 \mathrm{~cm}$ o semivariograma apresentou estrutura linear nos limi tes da área estudada, indicando forte tendência de variação regional, com amplitude maior do que a área em estudo. A variância acumulada na análise de variância em níveis hierárquicos também foi distinta nas três profundidades. Na camada de 0 a $5 \mathrm{~cm}$-apenas na distância de $7 \mathrm{~m}$ o valor foi baixo, acompanhando a tendência do semivariograma, e nas distâncias de 25 e $80 \mathrm{~m}$ o valor acumulado foi 1. Na profundidade de 5 a $25 \mathrm{~cm}$, os valores acompanharam o semivariograma e na profundidade de 60 a $80 \mathrm{~m}$ os valores acumulados de variância foram bastante baixos. Este comportamento indicou que o padrão de variação da matéria orgânica foi distinto para cada profundidade, isto é, variação cíclica na camada de 0 a $5 \mathrm{~cm}$, dependência espacial com patamar definido e alto efeito pepita de 5 a $25 \mathrm{~cm}$ e forte tendência regional de 60 a $80 \mathrm{~cm}$, indicando de que o teor de matéria orgânica tem a sua variação controlada por processos distintos dependendo da profundidade no perfil do solo. Novamente ficou evidente o aumento do alcance em profundidade.

Os semivariogramas da capacidade de troca de cátions apresentaram estrutura bem definida na profundidade de 60 a $80 \mathrm{~cm}$ com alcance de $170 \mathrm{~m}$ e efeito pepita 0,26 sendo que a variância acumulada acompanhou a

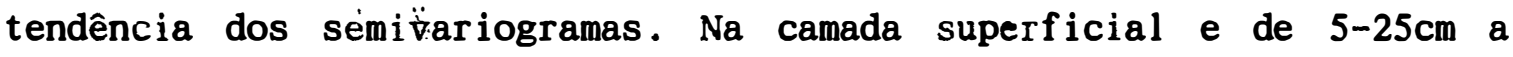
estrutura do semivariograma não foi muito evidente. A variância acumulada pela análise hierárquica de variância foi baixa apenas no nível de $7 \mathrm{~m}$ na 
camada superficial e na camada de $5-25 \mathrm{~cm}$, indicando dependência espacial com distâncias pequenas, associadas provavelmente à influência de uma árvore ou conjunto de árvores.

Os semivariogramas do teor de fósforo disponível não apresentaram estrutura em nenhuma camada e os valores de variância acumulada foram baixos apenas na camada de 5 a $25 \mathrm{~cm}$ nos níveis de 7 e $25 \mathrm{~m}$, indicando pouca ou nenhuma dependência espacial.

No caso do teor de potássio trocável, os semivariogramas das camadas de 0 a 5 e 5 a $25 \mathrm{~cm}$ não apresentaram estrutura definida. Na camada de 60 a $80 \mathrm{~cm}$ o ajuste de um modelo esférico foi significativo a $10 \%$ pelo teste $\mathrm{F}$ e apresentou coeficiente de determinação de 0,74 tendo o alcance sido de $149 \mathrm{~m}$ e o efeito pepita 0,29 . A variância acumulada na profundidade de 60 a $80 \mathrm{~cm}$ nos níveis de 7 e $25 \mathrm{~m}$ acompanhou as tendências do semivariograma. Nas camadas superficiais, apareceram valores de variância acumulada, em torno de 0,7 apenas no nível de $7 \mathrm{~m}$, convergindo para a indicação de pouca dependência espacial nestas profundidades considerando distâncias maiores.

Os semivariogramas do teor de cálcio trocável não apresentaram valores significativos a $5 \%$ de $\mathrm{F}$ no ajuste de um modelo esférico. Entretanto, o primeiro valor de variância, correspondente a $7 \mathrm{~m}$, foi baixo tanto no semivariograma como na análise de variância hierárquica. A menor variância nas distâncias pequenas provavelmente está condicionada às alterações da cobertura vegetal.

A dependência espacial não ficou evidente no semivariograma do teor de magnésio trocável e na variância acumulada na profundidade de 0 a $5 \mathrm{~cm}$ e 5 a $25 \mathrm{~cm}$, apesar do valor de variância baixo no nível de $7 \mathrm{~m}$. No semivariograma da camada de 60 a $80 \mathrm{~cm}$ a estrutura ficou mais evidente, com alcance de $99 \mathrm{~m}$ e efeito pepita de 0,28 . A variância acumulada seguiu a mesma tendência dos semivariogramas.

A estrutura do semivariograma do valor de saturação por bases na camada de 0 a $5 \mathrm{~cm}$ indicou uma certa tendência de variação cíclica, observada pela flutuação dos valores em torno de 1. A variância acumulada foi baixa apenas no nível de $7 \mathrm{~m}$. Na profundidade de 5 a $25 \mathrm{~cm}$ e 60 a $80 \mathrm{~cm}$ verificouse estrutura de variação com ajuste ao modelo esférico significativo a $5 \%$ 
de $F$ com efeito pepita de 0,07 e alcance de $110 \mathrm{~m}$ na camada de 5 a $25 \mathrm{~cm}$ e 0,26 e $90 \mathrm{~m}$ na camada de 60 a $80 \mathrm{~cm}$. A variância acumulada seguiu a mesma tendência dos semivariogramas.

A saturação por alumínio comportou-se de maneira semelhante à saturação por bases na camada de 0 a $5 \mathrm{~cm}$, isto é, flutuação dos valores de semivariância indicando variações cíclicas. O efeito pepita foi de 0,39; 0,38 e 0,21 e o alcance 190, 279 e 104m nas camadas de 0 a 5,5 a 25 e 60 a $80 \mathrm{~cm}$ respect ivamente. A variância acumulada seguiu a mesma tendência dos semivariogramas. TRAGMAR et al. (1987) observaram estruturas de variação com alcance de poucos metros numa área recém desmatada na Indonésia. A variação a curta distância mostrou-se maior do que a variação média entre as diferentes feições presentes na área.

\subsubsection{Análise global e delineanento recomendado}

o comportamento dos atributos químicos do solo mineral variou muito na área em relação à profundidade, fato verificado em todas as análises de dados realizadas. Dessa forma, o delineamento experimental para a amostragem e análise de dados para diferentes profundidades do solo não pode ser o mesma. As amostras superficiais, normalmente não apresentaram dependência espacial considerando longas distâncias, entretanto, a variância acumulada no primeiro nível hierárquico de distância geralmente foi baixa. Isto indicou que provavelmente haja uma dependência espacial entre diferentes árvores ou grupamentos de árvores e os atributos químicos do solo superficial. O coeficiente de variação também se alterou em profundidade, aumentando na maioria dos casos, porém, em relação à saturação por bases e $\mathrm{pH}$ verificaram-se valores menores nas camadas superficiais. Se considerarmos a saturação por bases um indice integrador do comportamento principalmente do $\mathrm{Ca}$ e do $\mathrm{Mg}$ do solo em relação à CTC verificamos que existem diferenças naturais na área, isto é, solos eutróficos nas cotas mais altas e distróficos no final das encostas, identificados no levantamento pedológico da área (LEPSCH \& VALADARES, 1976). Entretanto, a dinâmica superficial desses elementos, representada por sua ciclagem biológica parece ter homogeneizado este índice na camada 
de $0-5 \mathrm{~cm}$ de profundidade. Provavelmente a característica peculiar do $\mathrm{Ca}$ e $\mathrm{Mg}$ de terem uma velocidade de ciclagem lenta através do ciclo biológico se comparado por exemplo ao $\mathrm{K}$ ou $\mathrm{P}$ estejam associados a este comportamento (GOLLEY et al., 1978).

As amostras das camadas mais profundas, de uma maneira geral, apresentaram dependência espacial em intervalos de distância bem maiores, indicando que houve um controle sobre a variabilidade não mais condicionado pela dinâmica superficial, mas pela litologia, posição no relevo ou processos pedogenéticos, tendo sido o coeficiente de variação geralmente menor do que nas amostras superficiais. O trabalho de TIESSEN \& SANTOS (1989) demonstra a associação entre a litologia e os processos pedogenéticos com atributos do solo em área de caatinga recém desmatada em Pernambuco.

Dessa forma, na coleta de amostras superficiais é importante verificar a localização dos pontos de amostragem em relação às mudanças da cober tura vegetal da área bem como das fenofases da época de amostragem. A amostragem em várias transeções curtas, espacialmente localizadās na área, com intervalo entre coletas de poucos metros é uma estratégia recomendável, podendo-se assim verificar tanto a dependência espacial numa escala pequena, associada à dinâmica superficial bem como o comportamento numa escala maior, pela comparação das diferentes transeções. A amostragem das camadas subsuperficiais também deve ser espacialmente referenciadas, mas tomadas em transeções ou malhas com distância entre coletas maiores e cobrindo toda a área de estudo. A coleta de amostras compostas não possibilita o estudo da relação dos atributos químicos do solo com a dinâmica superficial no caso de amostras superficiais e com a posição no relevo ou litologia no caso de amostras subsuperficiais. A observação dos valores em relação aos eixos direcionais mostrou-se muito eficiente na identificação de áreas anômalas, devendo, por isso, todas as amostras serem referenciadas espacialmente.

O número de amostras necessárias para estimar a média variou bastante, tendo sido menor para o valor pH e teor de MO e muito elevado para o teor de $P$. A análise de um número maior de amostras dos elementos de maiores 
coeficientes de variação pode ser interessante com o objetivo de reduzir os custos sem comprometer a precisão dos resultados. 0 teor de $\mathbf{P}$ disponível no solo apresentou elevados coeficientes de variação, ajuste não'significativo à distribuição normal ou lognormal, semivariogramas sem estrutura de variação e variância quase total no primeiro nível hierárquico de distância sendo dessa forma o de maior dificuldade de estudo. Observação semelhante com relação a grande variabilidade do $P$ foi feita por GOLDIN \& LAVKULICH (1988) num estudo em diferentes formações florestais do Canadá e Estados Unidos da América e por HARVEY et al. (1985) em floresta tropical na Nigéria.

LEPSCH \& VALADARES (1976) mapearam duas séries de solos distintas na área de estudo que são as unidades Pindorama (podzólico vermelho amarelo, Tb, eutrófico, abrupto, A moderado, textura arenosa/média, fase relevo ondulado) e Concreção (podzólico vermelho amarelo, Ta, distrófico, abrupto, A moderado, textura arenosa/média, fase relevo ondulado), que aparecem representados na Figura 1. Estas duas séries diferenciam-se principalmente pela saturação por bases da camada subsuperficial. Esta diferença ficou evidente na observação dos valores em relação aos eixos direcionais e não aparece representada de forma clara na comparação das médias das parcelas. Na observação dos valores em relação aos eixos direcionais e na comparação das médias o depósito aluvionar, que não foi delimitado no mapa de solos, ficou bastante evidente. Assim, a descrição dos solos por amostragens sistemáticas e o levantamento pedológico clássico mostraram-se complementares, sendo que o levantamento de solos permitiu a identificação e a compreensão da distribuição espacial das principais classes de solos existentes, e a amostragem sistemática a identificação de áreas com comportamento anômalo, possivelmente não detectadas no levantamento pedológico pela natural dificuldade de sua execução em áreas com cobertura florestal.

\subsection{Granulometria do solo}

\subsubsection{Estatística descritiva}

$\mathrm{Na}$ Tabela 8 são representados os valores médios e intervalos de 
confiança, o coeficiente de variação, o ajuste à distribuição normal e lognormal e o número de amostras necessárias pára se obter uma variação na média de 10 e 5\% da granulometria das amostras de terra coletadas nas profundidades de $0-5,5-25$ e $60-80 \mathrm{~cm}$.

Os valores médios da profundidade de $0-5 \mathrm{~cm}$ e $5-25 \mathrm{~cm}$ não diferiram muito, indicando que a subdivisão da camada superficial não é muito importante para os dados granulométricos. A profundidade de $60-80 \mathrm{~cm}$, no entanto, diferiu bastante das superficiais.

Os menores coeficientes de variação foram observados na fração areia e o ajuste a distribuição normal e lognormal não ocorreu na maior parte dos casos. Apenas o teor de argila de 5-25cm e a relação argila $60-80 / 5-25 \mathrm{~cm}$ apresentaram ajuste significativo à distribuição normal e o teor de argi la de $0-5 \mathrm{~cm}$ ajustou-se à distribuição lognormal. O número de amostras para representar a média com variância de $10 \%$ variou de 2 para areia de $5-25 \mathrm{~cm}$ até 81 para a relação textural sendo que na maior parte dos casos este número ficou abaixo de 50 .

O valor da relação argi la $60-80 / 5-25 \mathrm{~cm}$ foi bastante elevado, indicando que houve um grande aumento do teor de argila em profundidade. A relação areia fina/média apresentou a mesma média para as profundidades de 5-25 e $60-80 \mathrm{~cm}$.

\subsubsection{Valores médios das parcelas}

Nas profundidades de 0-5 e 5-25cm, praticamente não ocorreram diferenças significativas entre as médias das parcelas (Figura 18). Na profundidade de $60-80 \mathrm{~cm}$ foi verificado um valor anômalo, com desvio positivo muito elevado na parcela 16 na relação areia fina/média. 0 teor de areia na profundidade de $60-80 \mathrm{~cm}$ foi maior na parcela 11 e menor na parcela seis e o de silte e argila menores nas parcelas 11 e 13 e mais elevados na 16 e seis. A região do entorno da parcela 11, novamente mostrou-se distinta das demais.

A relação textural, isto é, teor de argi la da camada de 60-80/5-25, foi mínima nas parcelas 11 e 13 (entre 0,5 e 0,6) e máxima na parcela 8, com valor de 4,3 sendo este parâmetro muito útil para a distinção das parcelas 
Tabela 8 - Valores médios e intervalos de confiança, coeficiente de variação, ajuste à distribuição normal e lognormal e número de amostras necessárias para se obter uma variação na média de 10 e $5 \%$ da granulometria das amostras de terra coletadas nas profundidades de 0-5, $5-25$ e $60-80 \mathrm{~cm}$.

\begin{tabular}{lllllllllll} 
Parâmetro & média & lim. & lim. & cv & x & $\mathrm{x}^{2}$ & Mo & $\mathrm{n}^{\circ}$ & $\mathrm{n}^{\circ}$ \\
profundidade & & inf. & sup. & & & $\mathrm{N}$ & $\mathrm{LN}$ & $\mathrm{a} / \mathrm{c}$ & 0,1 & 0,05 \\
\hline Are 0-5 & 75,4 & 73,3 & 77,5 & 11 & ns & ns & ns & 37 & 53 \\
Are 5-25 & 77,3 & 75,8 & 78,8 & 8 & ns & ns & ns & 2 & 3 \\
Are 60-80 & 70,2 & 67,8 & 72,6 & 14 & ns & ns & ns & 5 & 7 \\
Arg 0-5 & 6,9 & 6,3 & 7,4 & 34 & ns & $*$ & ns & 33 & 47 \\
Arg 5-25 & 8,6 & 7,8 & 9,4 & 36 & $*$ & $*$ & ns & 37 & 53 \\
Arg 60-80 & 18,9 & 16,8 & 21,0 & 46 & ns & ns & ns & 58 & 83 \\
Si 1 60-80 & 10,9 & 9,7 & 12,0 & 42 & ns & ns & ns & 50 & 72 \\
R f/m 5-25 & 2,4 & 2,1 & 2,6 & 39 & ns & ns & ns & 41 & 59 \\
R f/m 60-80 & 2,4 & 2,1 & 2,7 & 53 & ns & $*$ & ns & 79 & 114 \\
GF 60-80 & 62,4 & 58,9 & 65,9 & 22 & ns & ns & ns & 14 & 20 \\
R 5-25/60-80 & 2,4 & 2,1 & 2,8 & 54 & ns & ns & $*$ & 81 & 115
\end{tabular}

aresteor de areia; Argateor de argila; sil=teor de silte; $R$ f/n=relaçáo areia fina/areia aédia; GF=grau de floculaçâo e $R=$ relação tertoral

lin. inf.=liaite inferior da nédia con intervalo de confiança (ic) de 95\%; lin. sup.=linite superior da nédia (ic=95\%); cv=coeficiente de variação; $x^{2} N=$ teste chi quadrado para distribuição noraal; $x^{2}$ Ln=teste chi quadrado para distribuição lognoraal; ho a/c= ajuste l distribuiçåo nornal pelo nétodo dos nonentos (assinetria e curtose); $\pi^{\circ} 0,1=$ núnero de anostras necessárias para estinar a aédia con 10\% de variação; $a^{\bullet} 0,05=$ número de anostras necessárias para estinar a nédia con $5 \%$ de variação. 
quanto aos seu atributos granulométricos.

\subsubsection{Representação dos valores nos eixos direcionais}

A maior dispersão dos valores em relação ao eixo $z$ foi observada com valores inferiores a $15 \mathrm{~m}$, o que corresponde a $y>350$ (Figura 19). Alguns valores anômalos foram observados, como no teor de silte a $60-80 \mathrm{~cm}$, e relação areia fina/média nas profundidades de $5-25$ e $60-80 \mathrm{~cm}$. Na profundidade de $60-80 \mathrm{~cm}$ observou-se uma região concentrada no eixo $z$ de 2 a $7 \mathrm{~m}$ com forte tendência de desvio positivo em relação à média. Nessa região, a relação textural assume valores muito baixos. Em relação ao eixo $z$, os valores do teor de argila a $60-80 \mathrm{~cm}$ apareceram divididos em duas regiōes distintas, a primeira com valores de $z$ menores do que $15 \mathrm{~m}$, com valores predominantemente abaixo da média e, a segunda com valores de $z$ maior do que $15 \mathrm{~m}$ com valores acima da média.

\subsubsection{Senivariograma e análise hierárquica de variância}

Os semivariogramas que apresentaram estrutura e variação definida foram areia $60-80 \mathrm{~cm}$, argi la $60-80 \mathrm{~cm}$ grau de floculação de $60-80 \mathrm{~cm}$, relação areia fina/média de $60-80 \mathrm{~cm}$ e relação textural (argila 5-25/60-80cm) (Figura 20). O alcance do modelo esférico ajustado foi de $296 \mathrm{~m}$ para o teor de areia de $20-80 \mathrm{~cm}$ em torno de $130 \mathrm{~m}$ para os demais.

A variância acumulada no primeiro nível hierárquico, em geral foi menor do que nos dados químicos, mesmo nos casos em que o semivariograma não apresentou estrutura de variação definida. Provavelmente exista alguma relação entre a dinâmica superficial, promovida pela inversão de solo devido a queda de árvores ou a ação da mesofauna como termitas e minhocas considerando intervalos de distância pequenos. Os estudos de SCHAETZL (1986) e SCHAETZL \& LANSING (1990), descrevem este processo e confirmam sua importância na dinâmica de florestas de clima temperado.

\subsubsection{Análise global e delineamento recomendado}

Da mesma forma que para os atributos químicos, as relações espaciais em pequenos intervalos de distância parecem ser importantes para os atributos 
granulométricos da camada superficial. Provavelmente a dinâmica superficial, neste caso representada pela inversão de camadas motivada pela queda de árvores ou ação da mesofauna, tiveram influência sobre o comportamento dos atributos granulométricos. Entretanto, como foi verificado um comportamento semelhante entre a camada de $0-5$ e $5-25 \mathrm{~cm}$, esta influência deve ter ocorrido em profundidade maior do que para os atributos químicos. Nas camadas subsuperficiais as relações espaciais entre os valores e a distância ocorreram em intervalos maiores, provavelmente mais inf luenciados pelos processos pedogenét icos em si, como ocorreu para os atributos químicos.

Dessa forma, o delineamento experimental para a amostragem e análise dos dados pode ser igual nos dois casos, isto é, atribuir maior peso às relações espaciais de curta distância nas amostras superficiais e a longa distância nas subsuperficiais. A coleta em transeções dispostas na área como descrito para os atributos químicos é recomendável. Entretanto, a subdivisão da camada superficial não é necessária e o número de amostras analisadas pode ser menor. 

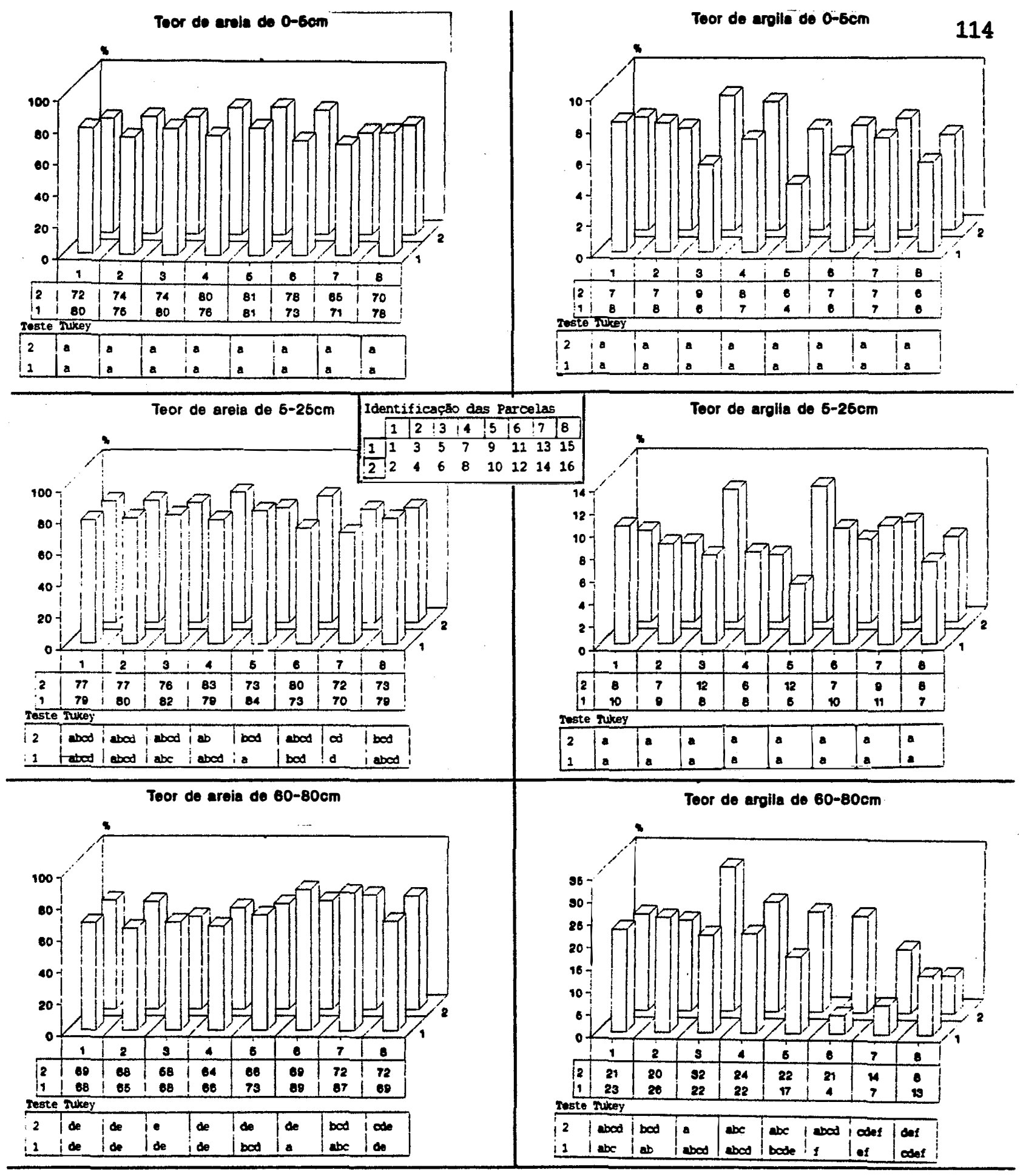

$\because$ Figura 18 - Valores médios dos atributos granulométricos do solo naś três profundidades (barras) e diferenças significativas (Tukey 5\%) indicadas por letras distintas. 


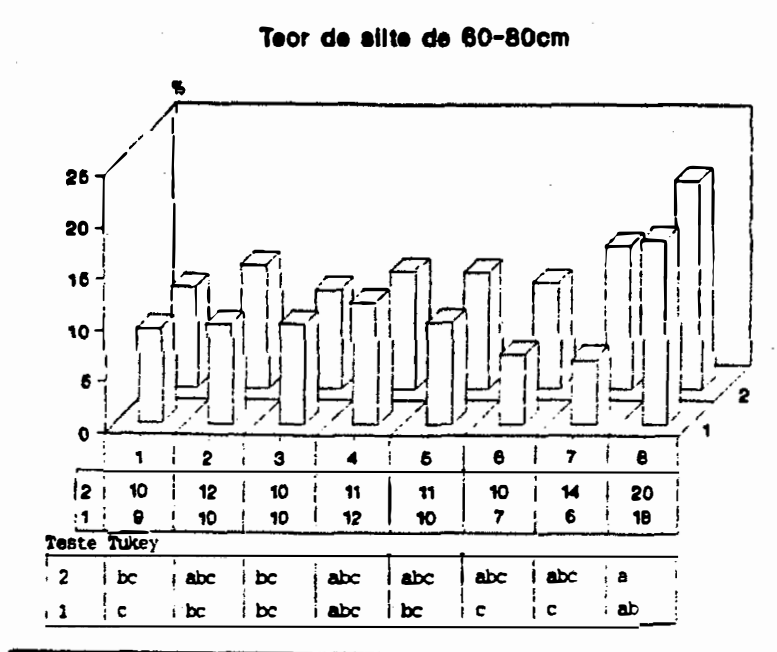

Relacto areia fina/mbdia de $6-26 \mathrm{~cm}$

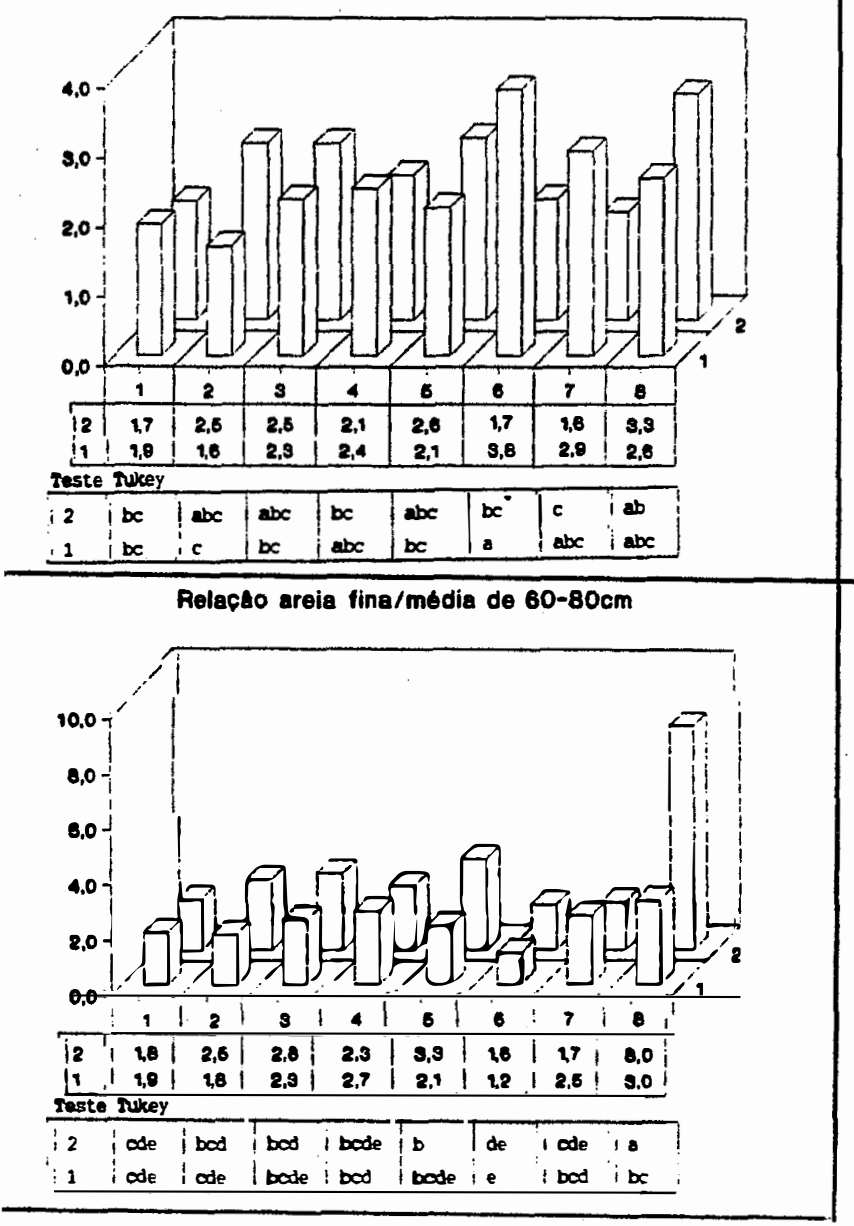

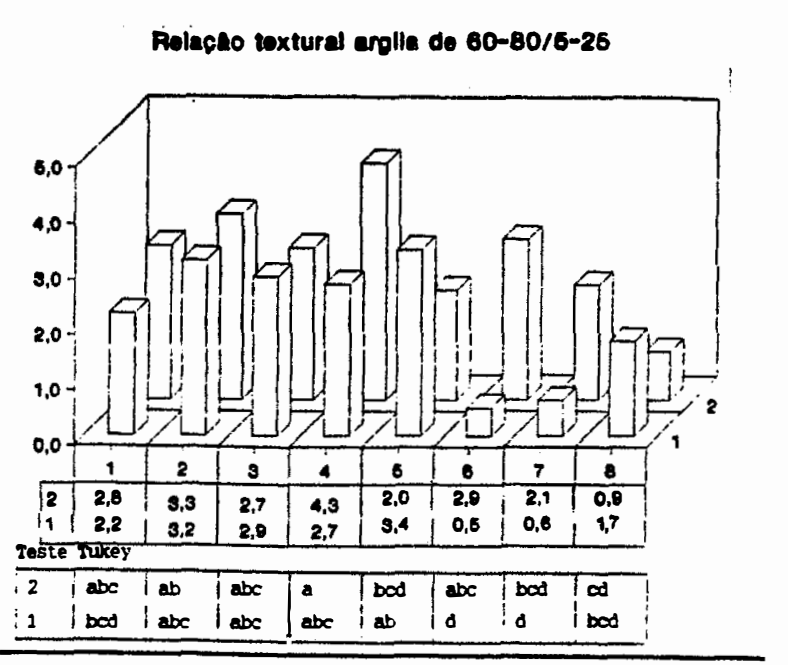

Grau de floculaça de 60-80cm

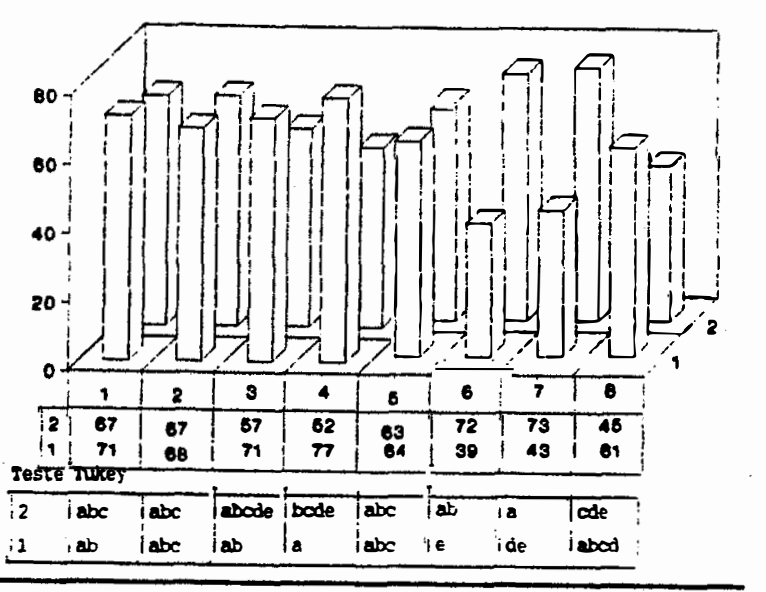

Figura 18 - cont inuação 
Teor de arele de $0-5 \mathrm{~cm}$

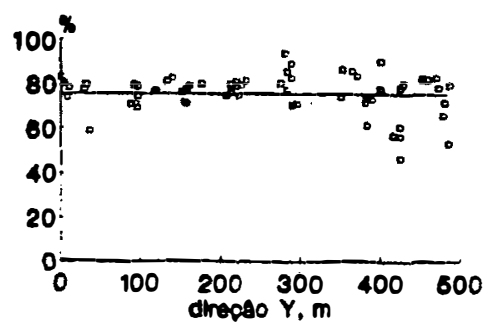

Teor de areia de $5-25 \mathrm{~cm}$

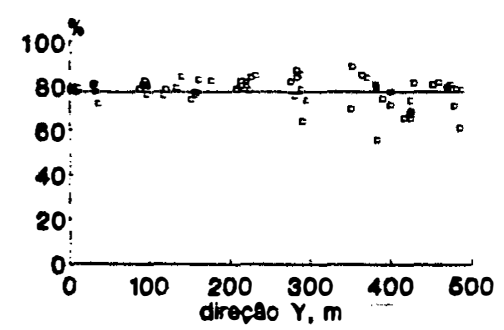

Teor de areia de $60-80 \mathrm{~cm}$

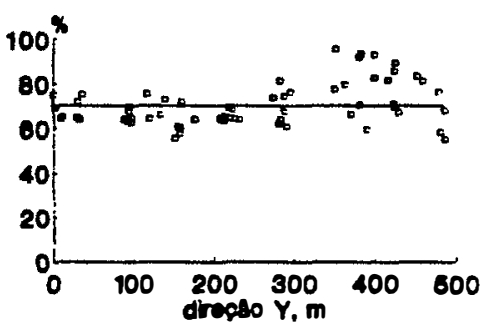

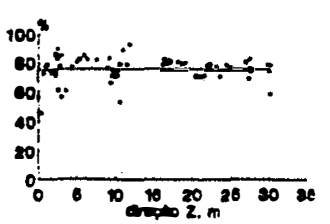
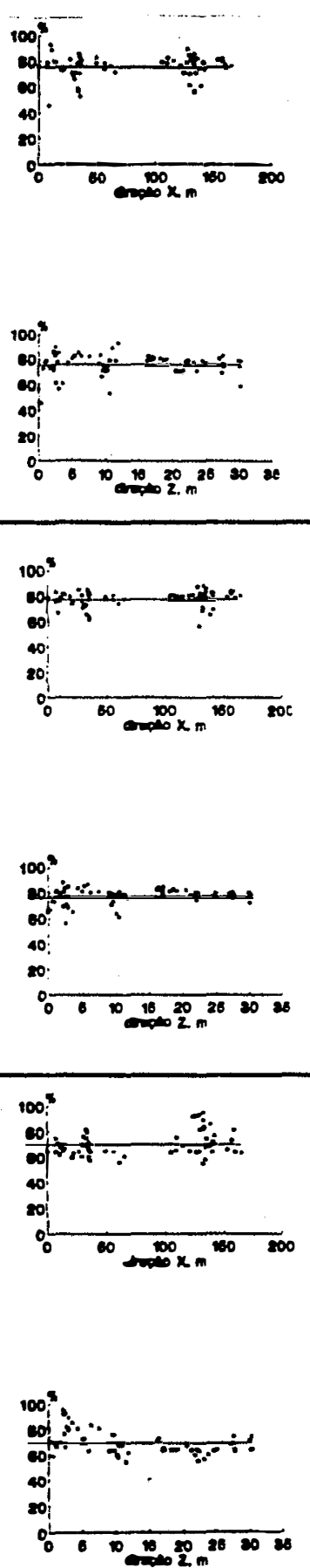

Teor de argila de $0-6 \mathrm{~cm}$
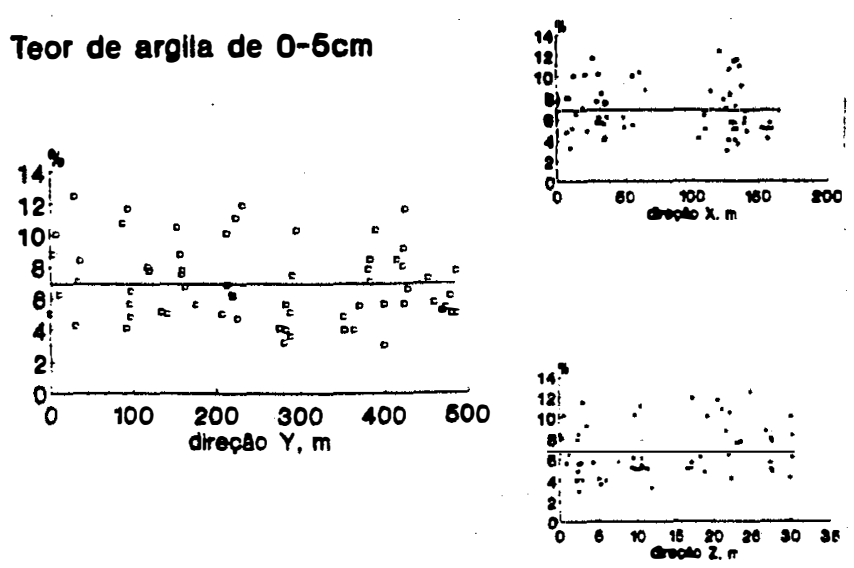

Teor de argila de $5-25 \mathrm{~cm}$
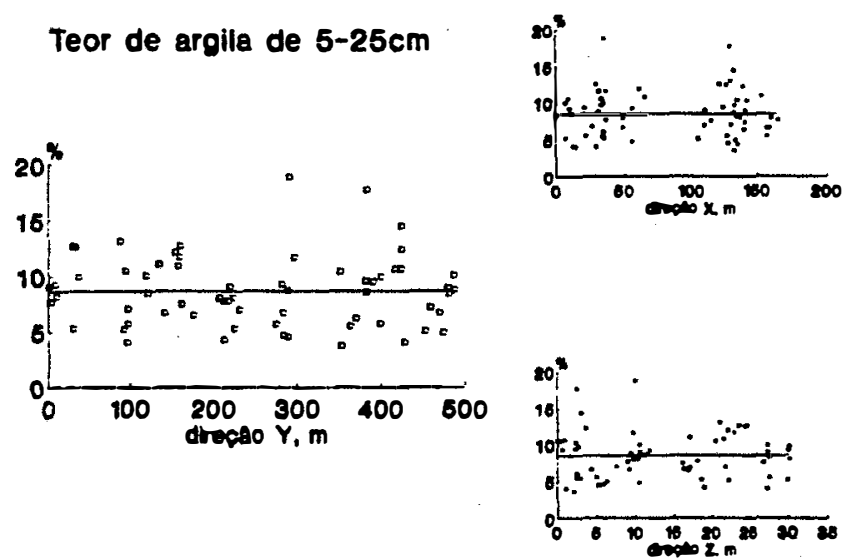

Teor de argila de $60-80 \mathrm{~cm}$
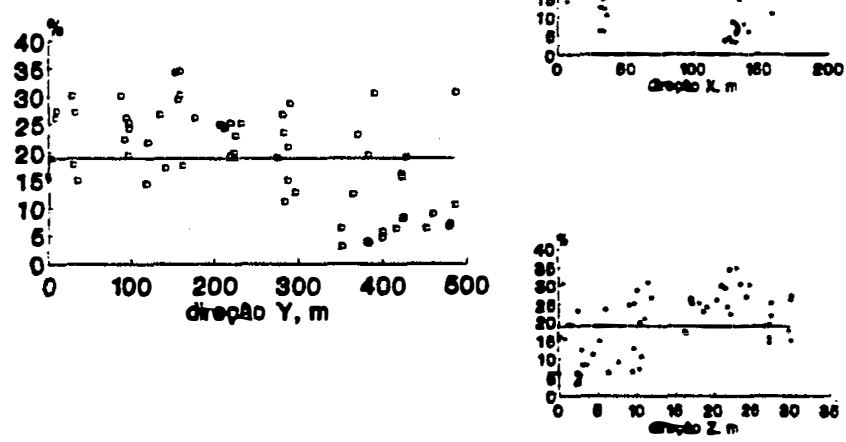

Figura 19 - Representação dos atributos granulométricos do solo nas três profundidades (ponto) e da média ( 1 inha cheia) em relação aos eixos direcionais. 
Teor de sllte de $60-80 \mathrm{~cm}$
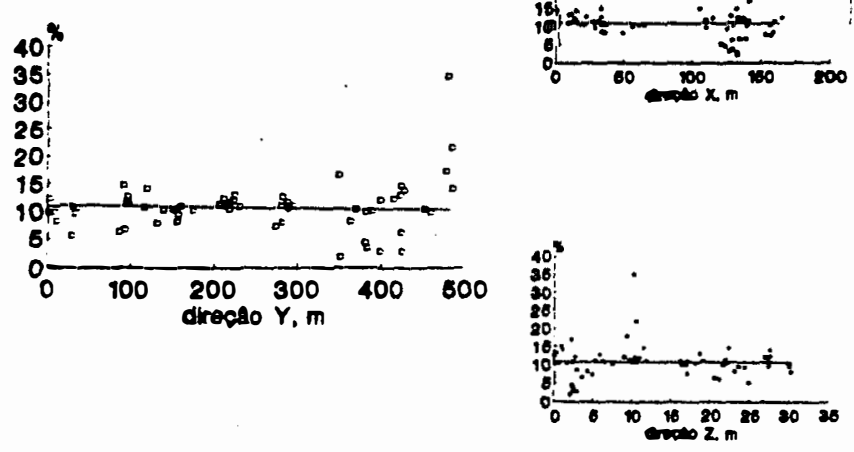

Relacto textural arolla de 60-80/6-26

117
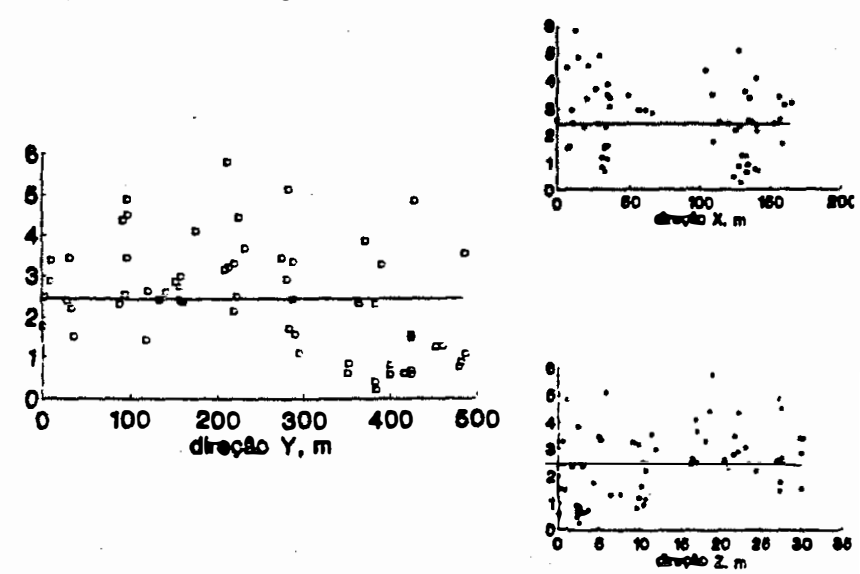

Relaçao areia fina/média de $5-25 \mathrm{~cm}$

8
6
4
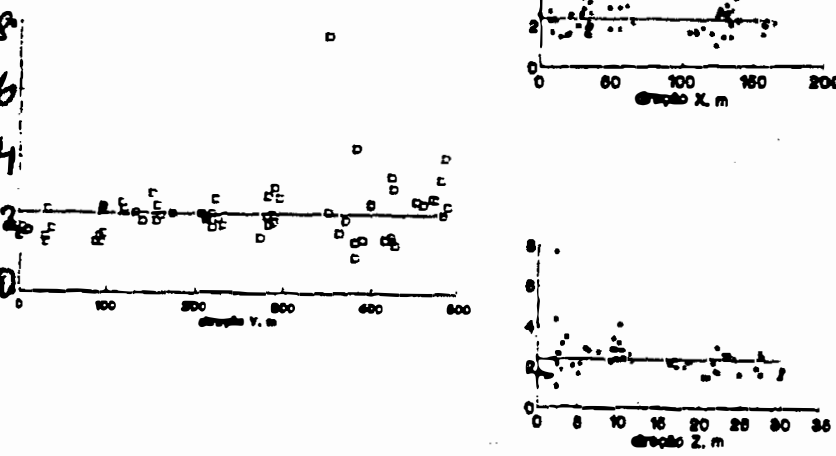

Grau de floculaçlo de $60-80 \mathrm{~cm}$

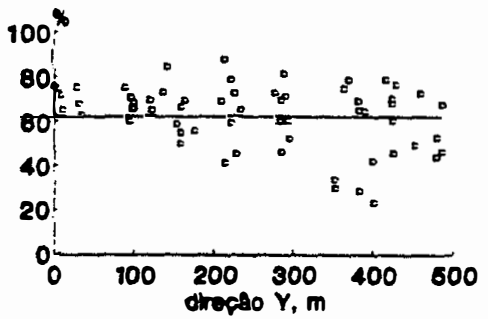

Relaçâo areia fina/média de $60-80 \mathrm{~cm}$

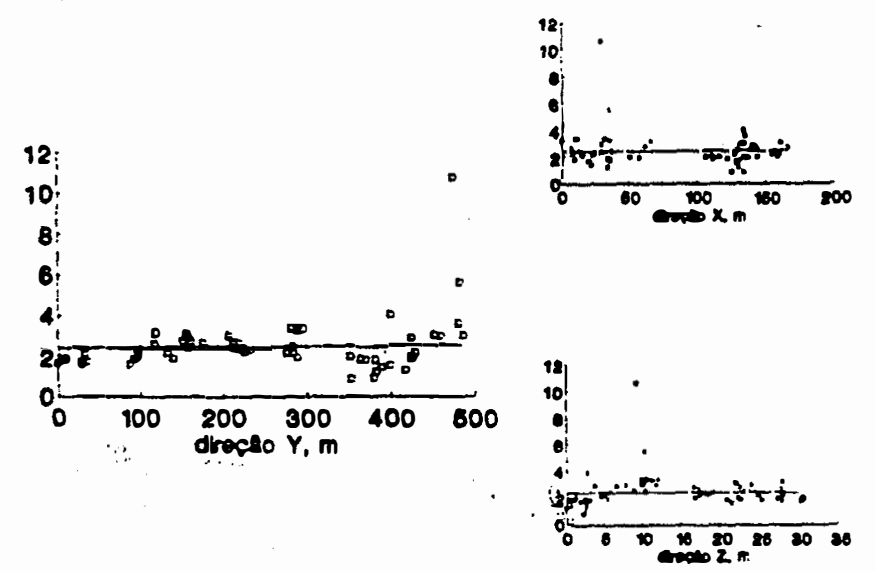

Figura 19 - cont inuação 
teor de areia de $0-5 \mathrm{~cm}$

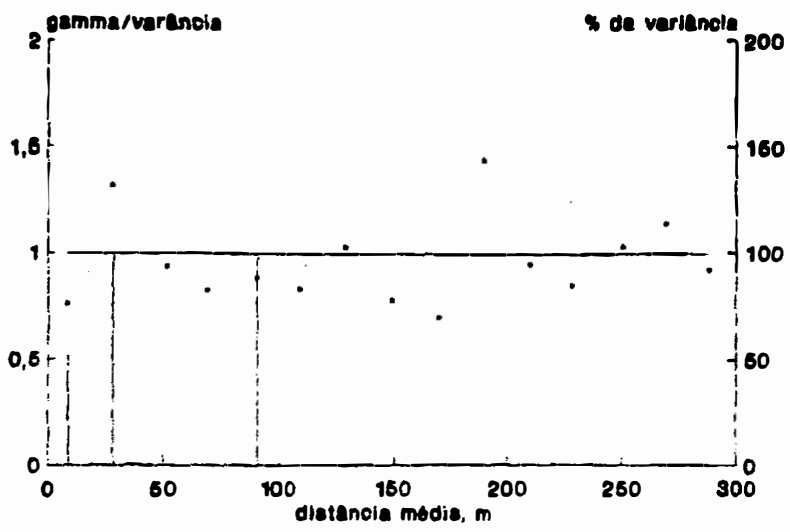

teor de areia de $5-25 \mathrm{~cm}$

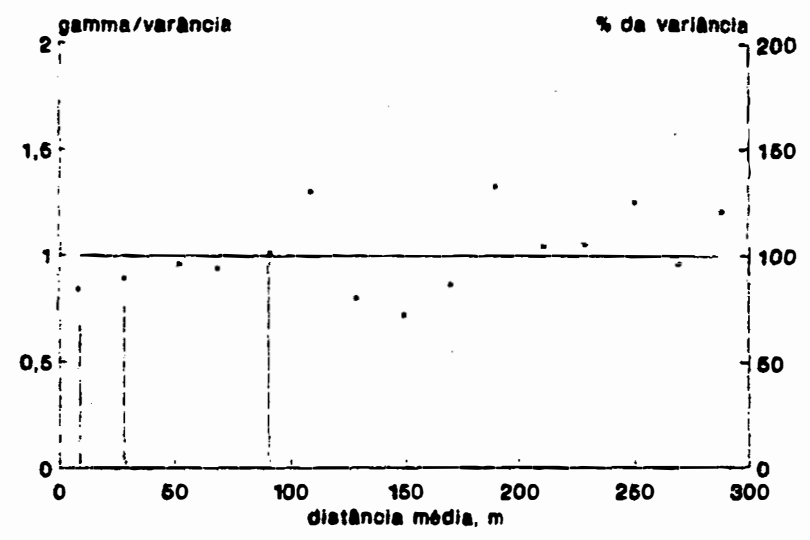

teor de areia de $60-80 \mathrm{~cm}$

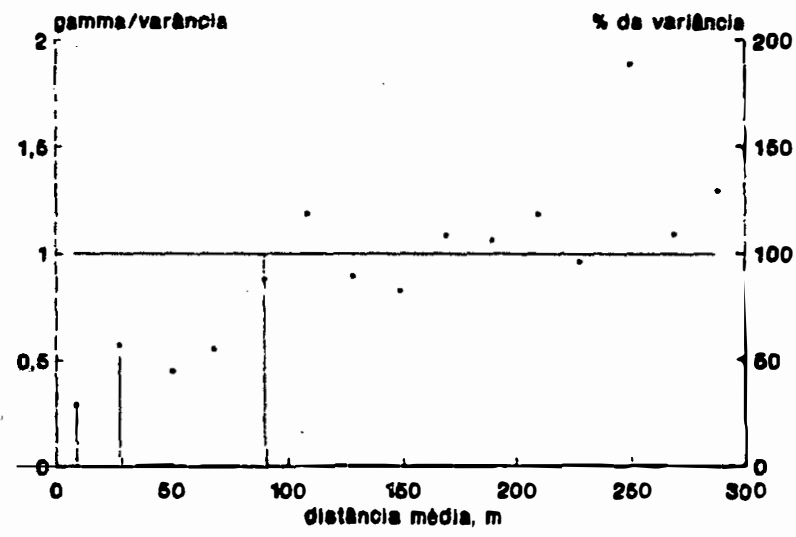

teor de argila de $0-5 \mathrm{~cm}$

118

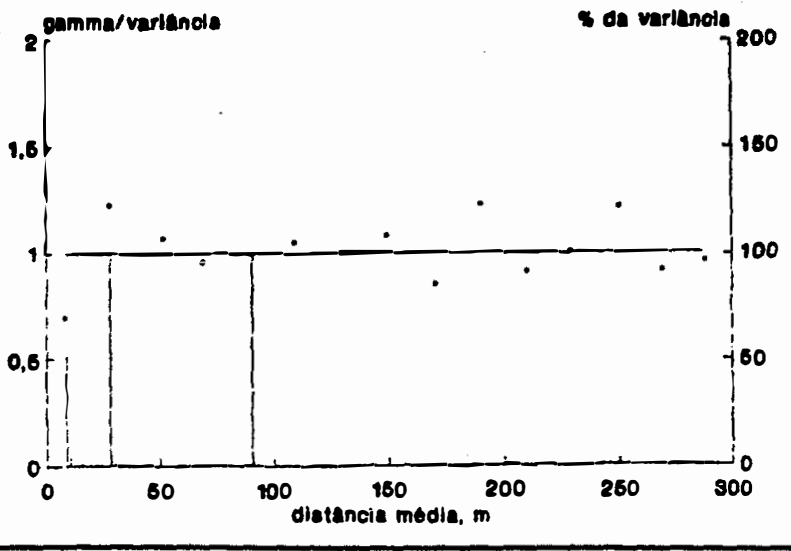

teor de argila de $5-25 \mathrm{~cm}$

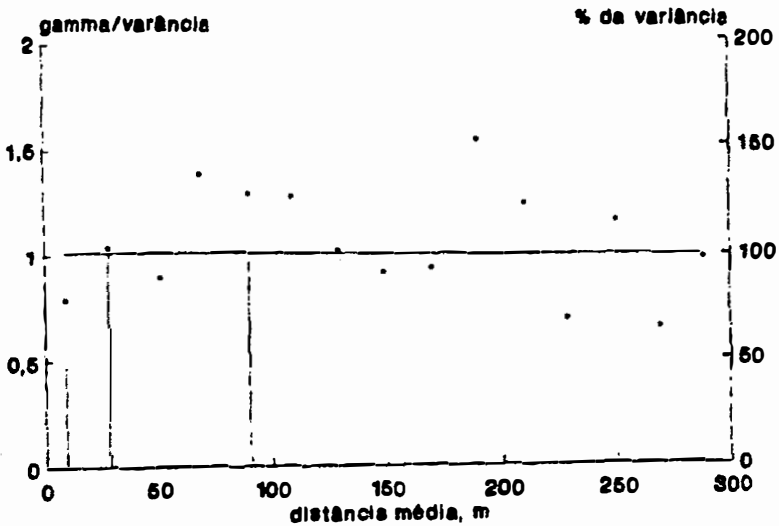

teor de argila de $60-80 \mathrm{~cm}$

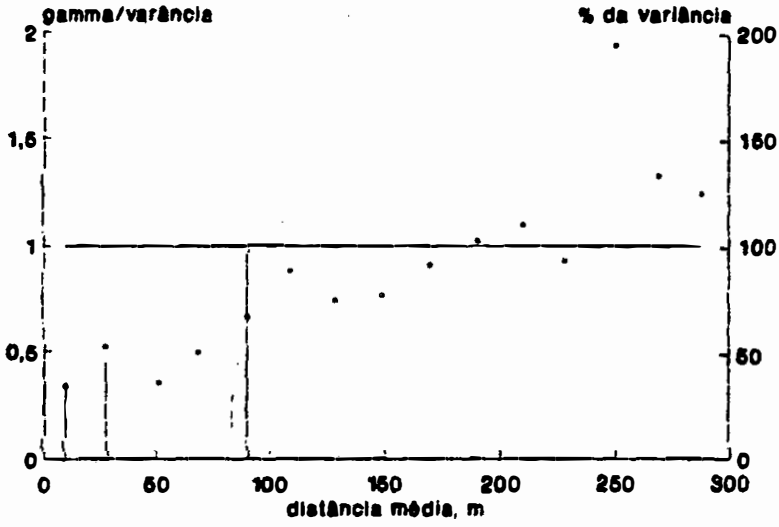

Figura 20 - Semivariância normalizada (pontos) e variância acumulada (linhas verticais) em função da distância dos atributos granulométricos do solo nas três profundidades estudadas. 
teor de silte de $0-5 \mathrm{~cm}$

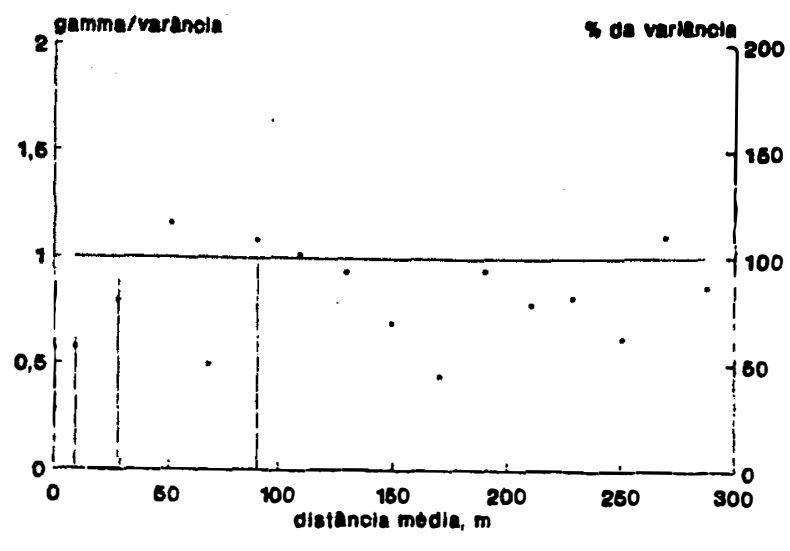

Relaça areia fina/média de $5-25 \mathrm{~cm}$

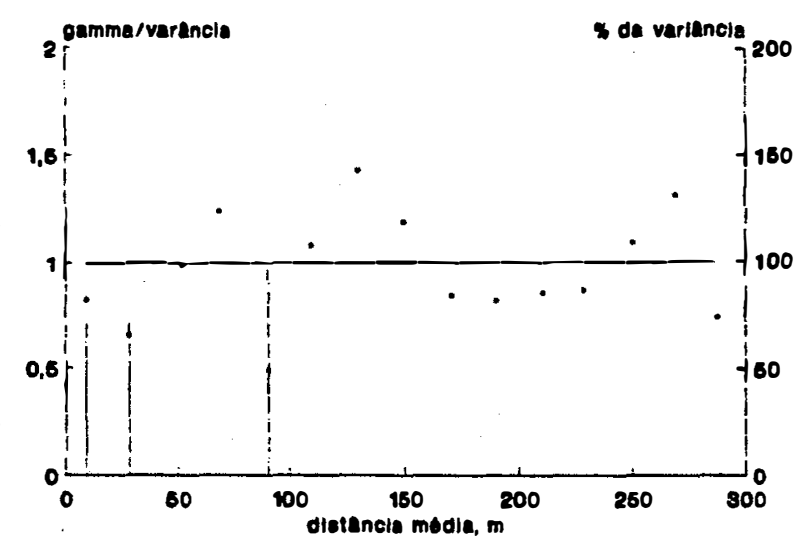

Relaçao areia fina/média de $60-80 \mathrm{~cm}$

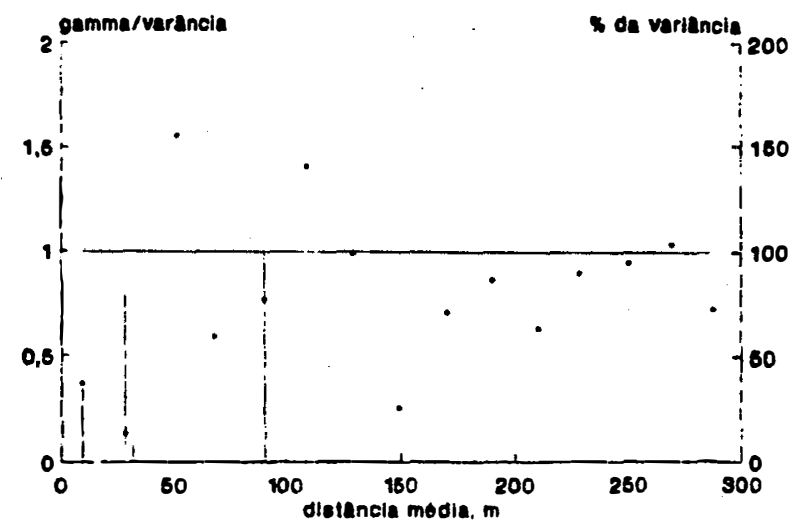

Relaça textural argila $5-25 / 60-80 \mathrm{~cm}$

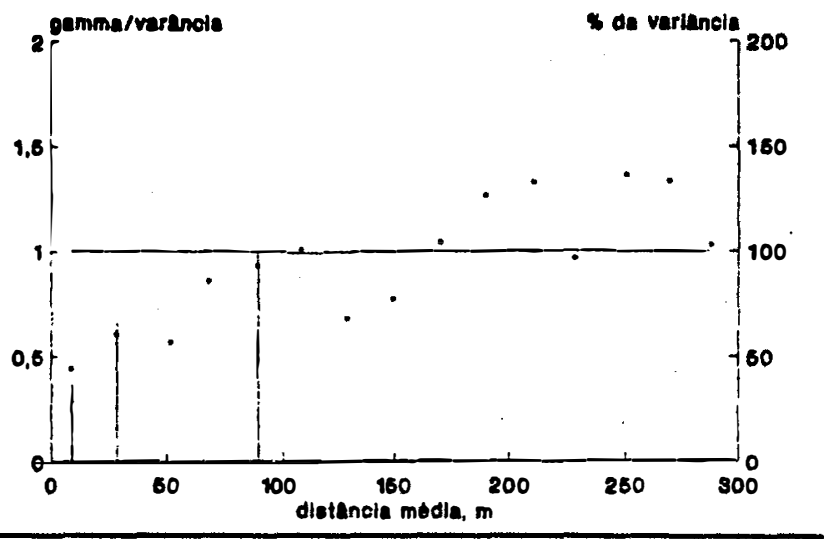

grau de floculaçáo de $60-80 \mathrm{~cm}$

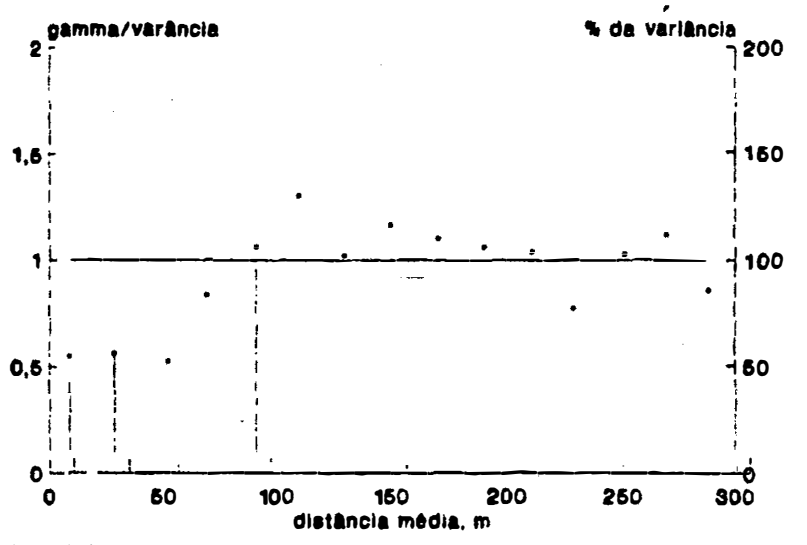

Figura 20 - cont inuação 


\section{CONCLUSÕES}

O delineamento experimental adotado e as análises feitas levaram a resultados que permitem chegar as seguintes conclusões gerais:

a) A variabilidade dos diferentes atributos edafo-bio-climáticos analisados no remanescente florestal diferiu de forma substancial em vários aspectos, justificando-se assim que sejam adotados delineamentos experimentais para a amostragem e análise de dados distintos para cada caso.

b) No caso da adoção de um único delineamento para todos os atributos, como, por exemplo, estações fixas distribuídas na área nas quais são registrados todos as variáveis, provavelmente, verificar-se-a três situações simultaneamente: 1) estimativa correta de alguns atributos, dentro do limite de precisão desejado; 2) estimativa acima do limite de precisão necessário para o estudo, significando custo excessivo e gasto supérfluo de tempo e 3 ) estimativa abaixo do limite de precisão necessário, fazendo com que a comparação ou correlação com os outros atributos leve a resultados imprecisos ou enganosos.

c) A imprecisão na estimativa de um atributo pode ter duas origens distintas: '1) a não consideração da variabilidade sistemática, principalmente espacial, que foi detectada em vários casos e com comportamento diferenciado e 2) a subestimação da variabilidade casual.

Podemos ainda apresentar algumas conclusões especificas com relação ao delineamento experimental para amostragem e análise de dados dos diferentes atributos analisados, referente a área de estudo.

d) A determinação da produção de serapi lheira não precisa considerar a posição das observações e deve-se procurar trabalhar com o maior número possível de coletores. A redistribuição periódica dos coletores pode reduzir o efeito da dependência espacial a curta distância. 
e) Para quant ificar a precipitação interna são necessários 40 coletores distribuídos casualmente na área sem necessidade de redistribuição perí́dica com o registro da sua posição no relevo.

f) A amostragem para a determinação da quantidade de serapilheira acumulada sobre o solo deve ser distinta da amostragem para a avaliação dos teores dos elementos contidos nela. Para a determinação da quantidade de serapilheira as amostras não precisam ser referenciadas espacialmente, sendo necessário um número elevado de determinações. Algumas amostras, de localização conhecida, tomadas na forma de transeções curtas, com pequeno intervalo de distância entre os pontos, distribuídas nas diferentes posições do relevo como topo, ombro, meia encosta, baixada ou associadas à mudanças de solo devem ser analisadas quanto aos teores dos elementos.

g) Para a coleta de amostras superficiais do solo é importante verificar a localização dos pontos de amostragem em relação às mudanças da cobertura vegetal. A amostragem em várias transeções curtas, espacialmente localizadas na área, com intervalo entre amostragens de poucos metros uma estratégia recomendável. As amostragens das camadas subsuperficiais também devem ser espacialmente referenciadas, mas tomadas em transeções ou malhas com distância entre amostragens maiores e cobrindo toda a área de estudo. A análise de um número maior de amostras dos elementos de maiores coeficientes de variação pode reduzir os custos analíticos sem prejudicar a precisão. A descrição dos solos por amostragens sistemáticas e o levantamento pedológico clássico mostraram-se técnicas complementares. 


\section{REFERANCIAS BIBLIOGRAFICAS}

ANDERSON, J.M. \& INGRAM, J.S.I. Tropical soil biology and fertility: a handbook of methods. CAB International, Wallingford, 1989. 171p.

ARAÚJO, G.M. de Comparação da estrutura e do teor de nutrientes nos solos e nas folhas de espécies arbóreas de duas matas mesófilas semidecíduas no triângu lo mineiro. Campinas, 1992. 159p. (Doutorado - Instituto de Biologia/UNICAMP)

ARNOLD, R.W. \& WILDING, L.P. The need to quant ify spatial variability. In: MAUSBACH, M.J. \& WILDING, L.P. (Ed.) Spatial variabilities of soils and landforms. SSSA Special publication number 28. pág. 1-8, 1991.

ARP, P.A. Forest floor variability and factor analysis: a case study. Canadian Journal of Soil Science, Ottawa, 64(ago): 457-461, 1984.

ARP, P.A \& KRAUSE, H.H. The forest floor: lateral variability as revealed by systematic sampling. Canadian Journal of Soil Science, ot tawa, 64(ago):423-437, 1984

BAATH, E. \& SöDERSTRöM, B. Seasonal and spatial variation in fungal biomass in a forest soil, soil Biol. Biochem., Oxford, 14:353-358, 1982 .

BACHHUBER, H.; BUNZL, K. \& SCHIMMACK, W. Spatial variability of the distribution coeff icients of ${ }^{137} \mathrm{Cs},{ }^{65} \mathrm{Zn},{ }^{85} \mathrm{Sr},{ }^{57} \mathrm{Co},{ }^{109} \mathrm{Cd},{ }^{141} \mathrm{Ce},{ }^{103} \mathrm{Ru}$, ${ }^{951} \mathrm{Tc}$, and ${ }^{131} \mathrm{I}$ in a cultivated soil. Nuclear Technology, München, 
72: 359-371, 1985 .

BACHHUBER, H.; BUNZL, K. \& SCHIMMACK, W. Spatial variability of fallout $-{ }^{137} \mathrm{Cs}$ in the soil of a cultivated field. Environmental. Monitoring and Assessment, London, 8:93-101, 1987.

BERNACCI, L.C. Estudo florístico e fitossociológico de uma floresta no município de Campinas, com ênfase nos componentes herbáceo e arbustivo. Campinas, 1992. 147p. (Mestrado - Instituto de Biologia/UNICAMP).

BERTONI, J.E. de A. Composição florística e estrutura fitossociológica de uma floresta do interior do Estado de São Paulo: reserva estadual de Porto Ferreira. Campinas, 1984. 196 p. (Mestrado Instituto de Biologia/UNICAMP)

BONELL, M.; CASSELLS, D.S.; GILMOUR, D.A. Spatial variations in soil hydraulic properties under tropical rainforest in northeastern Australia. In: PROCEEDINGS OF THE PRE-CONFERENCE OF THE INTERNATIONAL CONFERENCE ON INFILTRATION DEVELOPMENT AND APPLICATION. Hawai i, p. 153-165, 1987.

BöTCHER, J. \& STREBEL, O. Spatial variability of groundwater solute concentrations at the water table under arable land and coniferous forest. Part 1: Methods for quantifying spatial variability (geostatistics, time series analysis, Fourier transform smoothing. Z. Pf lanzenernaehr. Bodenk., Weinheim, 151:185-190, 1988 (a).

BöTCHER, J. \& STREBEL, 0. Spatial variability of groundwater solute concentrations at the water table under arable land and coniferous forest. Part 2: Field data for arable land and statistical analysis. Z. Pf lanzenernaehr. Bodenk., Weinheim, 151:191-195, 1988 (b). 
BöTCHER, J. \& STREBEL, 0. Spatial variability of groundwater solute concentrations at the water table under arable land and coniferous forest. Part 3: Field data for a coniferous forest and statistical analysis. Z. Pflanzenernaehr. Bodenk., Weinheim, 151:197-203, 1988 (c).

BREEMEN van, N. Tropenbos: nutrient and moisture cycling - report of a working group. IN PROCEEDINGS OF SECOND INTERNATIONAL TRPENBOS SEMINAR, Amsterdam, p.109-121, 1987.

BRINGMARK, E. Spatial variation in soil $\mathrm{pH}$ of beech forest in relation to buffering proprieties and soil depth. OIKOS, Copenhagen, 54:165$177,1989$.

BUNZL, K. \& SCHIMMACK, W. Associations between the fluctuations of the distribution coefficients of $\mathrm{Cs}, \mathrm{Zn}, \mathrm{Sr}, \mathrm{Co}, \mathrm{Cd}, \mathrm{Ce}, \mathrm{Ru}, \mathrm{Tc}$ and I in the upper horizons of a podzol forest soil. Chemosphere, Oxford 18(11-12): 2109-2120, 1989.

BUNZL, K. \& SCHIMMACK, W. Distribution coefficients of radionuclides in the soil: Analysis of the field variability. Radiochimica Acta, Wien, 44-45:355-360, 1988.

CAMARGO, O.A.; MONIZ, A.C. JORGE, J.A. \& VALADARES, J.M.A.S. Métodos de análise química, mineralogica e física de solos do Instituto Agronômico do Estado de São Paulo. Ból. Tec., 106. Campinas, 94p. 1986.

CAVASSAN, 0.; CESAR, O.; MARTINS, F.R. Fitossociologia da vegetação arbórea da reserva estadual de Bauru, Estado de São Paulo. Revta.

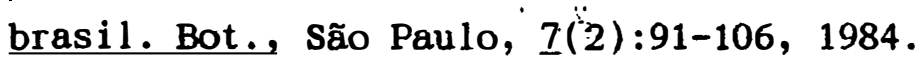


COURTIN, B.C.; FELLER, M.C.; KLINKA, K. Lateral variability in some properties of disturbed forest soils in southwestern British Columbia. Canadian Journal Soil Science, Ot tawa, 63: 529-539, 1983.

CRITCHFIELD, H.J. General climatology. Englewood Cliffs, PrenticeHall. 1960. 486 p.

DAHIYA, I.S., ANLAUF, R., KERSEBAUM, K.C. \& RICHTER, J. Spatial variability of some nutrient of an Alfisol from loess II. Geostatistical analysis. Z. Pflanzenernähr. Bodenk., Weinheim, 148:268-277, 1985 .

DAHIYA, I.S., KERSEBAUM, K.C. \& RICHTER, J. Spatial variability of some nutrient of an Alfisol from loess I. classical statistical analysis. Z. Pflanzenernähr. Bodenk., Weinheim 147:695-703, 1984.

DAVIS, J.C. Statistics and data analysis in Geology. John Wiley \& Sons, New York. 550 p. 1973.

DUIJSINGS, J.J.H.M.; VERSTRATEN, J.M.; BOUTEN, W. Spatial variability in nutrient deposition under an Oak/Beech canopy. $\underline{Z}$. Pflanzenernaehr. Bodenk., We inheim, 149: 718-727, 1986.

EMBRAPA/SNLCS Manual de métodos de análise de solo. Rio de Janeiro. 115p. 1979.

EMBRAPA/SNLCS Critérios para distinção de classes de solos e de fases de unidades de mapeamento; normas em uso pelo SNLCS. Rio de Janeiro, 67p. 1988 .

EWEL, J.; BERISH, C.; BROWN, B., PRICE, N. \& RAICH, J. Slash and burn impacts on a Costa Rican wet forest site. Ecology, Brooklyn, $\underline{63}(3): 816-829,1981$. 
FEDERER, C.A. Subjectivity in the separation of organic horizons of the forest floor. Soil Sci. Soc. Am. J., Madison, 46():1090-1093, 1982 .

FISHER, R.A. Statistical methods for research workers, Edinburgh, F.A.E. Crew, 1950. 356 p.

GARRIDO, M.A. \& POGGIANI, F. Avaliação da quantidade e conteúdo de nutrientes do folhedo de alguns povoamentos puros $e$ misto de espécies indígenas. Silvicultura, são Paulo, 15/16:1-22, 1982.

GILBERT, N. Statistics. W.B. Saunders Company, Philadelphia. 364 p. 1976.

GOLDIN, A. \& LAVKULICH, L.M. Historical land clearing in the Fraser Lowland of British Columbia and Washington State: II. Effects on soil variability. Soil Sci. Soc. Am. J., Madison, 52:473-477, 1988.

GOLLEY, F.B.; MCGINNIS, J.T.; CLEMENTS, R.G.; CHILD, G.I. \& DUEVER, M.J. Ciclagem de minerais em um ecossistema de floresta tropical úmida. EDUSP. São Paulo, 256 p., 1978.

GROHMANN, F. \& CATANI, R.A. O empobrecimento causado pela erosão e pela cultura algodoeira no solo do arenito Bauru. Campinas, Bragantia, Campinas, $\underline{9}: 126-132,1949$

HAMMER, R.D.; O'BRIEN, R.G.; LEWIS, R.J. Temporal and spatial soil variability on three forested landtypes on the Mid-Cumberland Plateau. Soil Sci. Soc. Am. J.. Madison, 51:1310-1326, 1987.

HARVEY, I.M., JUO, A.S.R. \& WILD, A. Soil organic C, N, S and P af ter forest clearance in Nigeria: mineralization rates and spatial variability. Journal of Soil Science, London, 36:585-591, 1985. 
HASE, H.; FöLSTER, H. \& LINDHEIM, M. On the accuracy of estimating aboveground tree biomass in an evergreen forest near Manaus, Brazil. A simulation study. BIOTROPICA, Durham, 17(3):191-195, 1985 .

HOCKMAN, J.; BURGER, J.A. \& SMITH, D.M. Spatial and temporal variability of foliar nutrient levels in faser fir christmas trees. Forest Science, Washington, 35(2):632-639, 1989.

JACKSON, I.J. Problems of throughfall and interception assessment under tropical forest. Journal of Hydrology, Amsterdam, 12:234-254, 1971

JORDAN, C.F. The nutrient balance of an Amazonian rain forest. Ecology, Brooklyn, 63(3):647-654, 1982.

JORDAN, C.F. \& KLINE, J.R Mineral cycling: some basic concepts and their application in tropical rain forest. Ann. Rev. Ecol. Syst., California, $\underline{3}(): 33-49,1972$.

KRIGE, D.G. A statistical approach to some basic mine valuation problems on the Witwaterrand. J. Chem. Metal1. and Min. Soc. South Africa, 52(6): 119-139, 1951 .

LANDIM, P.M.B., Introdução à geoestatística. Publicação didática 3, Laboratório de Geomatemática. UNESP/IG. Apostila. 114 p., 1988.

LEPSCH, I.F. \& VALADARES, J.M.A.S. Levantamento pedológico detalhado da estação experimental de Pindorama, SP. Bragantia, Campinas, $\underline{35}(2): 13-40,1976$.

LIKENS, G.E.; BORMANN, F.H.; PRICE, R.S.; EATON, J.S. \& JHONSON, N.M. Bio-geo-chemistry of a forested ecosystem. Springer Verlag, New 
York, 148 p., 1977.

LLOYD, C.R. \& MARQUES F., A.O. Spatial variability of throughfall and stemflow measurements in Amazonian rainforest. Agric. For. Meteorol. Elsevier, 42:63:73, 1988.

MALAVOLTA, E.; VITTI, G.C.; OLIVEIRA, S.A.de Avaliação do estado nutricional das plantas. Princípios e aplicações. POTAFOS, Piracicaba, 201 p. 1989.

MARTINS, F.R. O método de quadrantes e a fitossociologia de uma floresta residual do interior do Estado de São Paulo: parque estadual de Vassununga. São Paulo, 1979. 239p. (Doutorado Instituto de Biociências/USP).

MATHERON, G. Principles of geostatistics. Economic Geology, 58: 12461266, 1963.

MATTHES, L.A.F.; LEITÃo FILHO, H.de F.; MARTINS, F.R. Bosque dos Jequitibás (Campinas, SP): composição florística e estrutura fitossociológica do estrato arbóreo. In: Anais do V Congresso da SBPC, p. 55-76, 1988 .

MCNABB, D.H., CROMACK Jr, K., FREDRICKSEN, R.L. Variability of nitrogen and carbon surface soils of six forest types in the Oregon Cascades. Soil Sci. Soc. Am. J., Madison, 50: 1037-1041, 1986.

MEAD, R. \& CURNOW, R.M. Statistical methods in agriculture and experimental biology. New York, Chapman and Hall, 1983. 163p.

MEGURO, M.; VINUEZA, G.N. \& DELITTI, W.B.C. Ciclagem de nutrientes minerais na mata mesófila secundária - São Paulo -. I - Produção e conteúdo de nutrientes minerais no folhedo. Bol. Botânica, Univ. S. 
Paulo, São Paulo, 7:11-31, 1979.

MESSENGER, A.S.; KLINE, J.R. \& WILDEROTTER, D. Aluminum biocycling as a factor in soil change. Plant and soil, The Hague, 49()703-709, 1978.

NYE. P.H. Organic matter and nutrient cycles under moist tropical forest. Plant and Soil, The Hague, 13(4):333-346, 1961.

OLIVEIRA-FILHO, A.T.; RATTER, J.A.; SHEPHERD, G.J. Floristic composition and community structure of a central brazilian gallery forest. Flora, Jena, 184:103-117, 1990.

PAGANO, S.N. Estudo florístico, fitossociológico e de ciclagem de nutrientes em mata mesófila semidecídua, no município de Rio Claro, SP. Rio Claro, 1985. 201p. (Livre Docência - Instituto de Biociências/UNESP)

PERRIER, E.R. \& WILDING, L.P. An evaluation of computational methods for field uniformity studies. Advances in Agronomy, New York, 39: 265-312, 1986.

POHLMAN, A.A. \& MCCOLL, J.G. Soluble organics from forest litter and their role in metal dissolution. Soil Sci. Soc. Am, J., Madison, 52: 265-271, 1988.

RIHA, S.J.; SENESAC,G.; PALLANT,E. Effects of forest vegetation on spatial variability of surface mineral soil $\mathrm{pH}$, soluble aluminum and carbon. Water, Air and Soil Pollution,_Ithaca, 31:929-940, 1986.

RIZZINI, C.T. Tratado de fitogeografia do Brasil. HUCITEC/EDUSP, São Paulo, 327 pág., 1976. 
RODRIGUES, R.R. Análise de um remanescente de vegetação natural às margens do Rio Passa Cinco, Ipeúna, SP. Campinas, 1991. 325p. (Doutorado - Instituto de Biologia/UNICAMP).

SCHAETZL, R.J. \& LANSING, E. Effects of treethrow microtopography on the characteristics and genesis of spodosols, Michigan, USA. Catena, Cremlingen, 17-111-126, 1990.

SCHAIK van, C.P. \& MIRMANTO, E. Spatial variation in the structure and literfall of a Sumatran rain forest. BIOTROPICA, Durham, 17(3):196$205,1985$.

SCHIAVINI, I. Estrutura das comunidades arbóreas de mata de galeria da estação ecológica do Panga (Uber lândia, MG). Campinas, 1992. 139p. (Doutorado - Instituto de Biologia/UNICAMP).

SCHIMMACK, W.; BUNZL, K. \& BACHHUBER, H. Variability of the sorption of $\mathrm{Cs}, \mathrm{Zn}, \mathrm{Sr}, \mathrm{Co}, \mathrm{Cd}, \mathrm{Ce}, \mathrm{Ru}, \mathrm{Tc}$ and $\mathrm{I}$ at trace concentrations by a forest soil along a transect. Environment international, 13:427436,1979 .

SHAETZL, R.J. Complete soil profile inversion by tree uprooting. Physical Geography, Michigan, I(2):181-189, 1986.

SILVA, A.P. Variabilidade espacial de prâmetros físicos do solo. Piracicaba, 1988. 98 p. (Doutorado - Escola Superior de Agricultura "Luiz de Queiroz",/USP).

SNEDECOR, G.W. Statistical methods. Ames, Iowa State University Press, 1946. $485 \mathrm{p}$.

STARK, N.M. \& JORDAN, C.F. Nutrient retention by the root mat of an amazonian rain forest. Ecology, Brooklyn, 59(3):434-437, 1978. 
TIESSEN, H. \& SANTOS, C.D. Variability of C, N and P content of a tropical semiarid soil as affected by scil genesis, erosion and land clearing. Plant and Soil, The Hague, 119:337-341, 1989.

TRAGMAR, B.B.; YOST, R.S.; WADE, M.K.; UEHARA, G. \& SUDJADI, M. Spatial variation of soil properties and rice yield on recently cleared land. Soil Sci. Soc. Am. J., Madison, 51:668-674, 1987.

UPCHURCH, Dan R. \& EDMONDS, W.J Statistical procedures for specific objectives: In: MAUSBACH, M.J. \& WILDING, L.P. (Ed.) Spatial. variabilities of soils and landforms. SSSA Special publication number 28. pág. 49-71, 1991.

VIEIRA, S.R.; HATFIELD, J.L.; NIELSEN, D.R. \& BIGGAR, 'J.W. Geostatistical theory and application to variability of some agronomical properties. Hilgardia, Davis, $\underline{51(3): 2-75,1983 .}$

VITOUSEK, P.M. \& SANFORD Jr., R.L. Nutrient cycling in moist tropical forest. Ann. Rev. Ecol. Syst.,17():137-167, 1986.

VITTI, G.C. Avaliação e interpretação do enxof re no solo e na planta. FUNEP, Jaboticabal. 37 p. 1989.

VUONO, Y.S. de Fitossociologia do estrato arbóreo da floresta da reserva biológica do Instituto de Botânica (São Paulo, SP). São Paulo, 1985. 213p. (Doutorado - Instituto de Biociências/USP)

WEBSTER, R. Qunatitative spatial analysis of soil in the field. Advances in Soil Science, Springer Verlag New York, $\underline{3}(): 1-70,1985$

WILSON, G.V. \& LUXMOORE, R.J. Infiltration, macroporosity, and mesoporosity distributions on two forested watersheds. Soil Sci. Soc. Am. J., Madison, 52():329-335, 1988. 
WOPEREIS, M.C.; GASCUEL-ODOUX, C.; BOURRIE, G. \& SOIGNET, G. Spatial variability of heavy metals in soil on a one-hectare scale. Soil Science, Baltimore, $\underline{146}(2): 113-118,1988$. 